\title{
OPTIMIZATION OF RESOURCE ALLOCATION TO THE GENETIC TYPE IN REPRODUCTIVE RABBIT DOES
}

\author{
Alberto Arnau-Bonachera \\ $\mathrm{PhD}$ thesis \\ Manuscript submitted to fulfil the requirements necessary to achieve the \\ degree of doctor at Universitat Politècnica de València
}

Supervisor

Dr. Juan José Pascual Amorós

June 2017 


\title{
THESIS COMMITTEE
}

\author{
President \\ Dr. Nicolas Charles Friggens \\ Institute National de la Recherche Agronomique, France
}

\author{
Secretary \\ Dr. Maria Mocé Cervera \\ Universidad CEU Cardenal Herrera
}

Vocal

Dr. Nuria Nicodemus Martin

Universidad Politécnica de Madrid

THESIS EVALUATORS

Evaluator one

Dr. Laurence Fortun Lamothe

Institute National de la Recherche Agronomique, France

\section{Evaluator two}

Dr. Laurence Puillet

Institute National de la Recherche Agronomique, France

\author{
Evaluator three \\ Dr. Gerolamo Xiccato \\ Università degli studi di Padova
}


'Whatever you do may seem insignificant, but it is very important that you do it.'

Mahatma Gandhi. 



\section{Agradecimientos}

Cuando estamos a punto de alcanzar un objetivo muy deseado, muchas veces tenemos la tendencia a creer que la mayor parte del mérito se debe a nuestras propias capacidades. De hecho, no somos conscientes de la influencia de los demás hasta que no reflexionamos profundamente sobre ello. Después de hacerlo, me he dado cuenta de que, a lo largo de mi vida, he tenido la suerte de conocer y poder contar con grandes personas. Vosotros me habéis hecho querer ser mejor cada día, no solo en lo profesional sino también en lo personal. A veces con una idea, a veces con una conversación, a veces con un comportamiento. Después de los casi cinco años que ha durado esta fase de mi vida, puedo decir que no soy la misma persona que cuando empecé. Como muchas veces has dicho Juanjo, entré siendo un chavalín y salgo siendo un hombre, casado y todo. También, creo que puedo decir que este cambio se debe en su mayor parte a las personas que me habéis acompañado durante este periodo. A todos vosotros gracias.

Gracias papá por enseñarme que, cuando tenemos que enfrentarnos a un esfuerzo considerable, más vale romperse la cabeza pensando que la espalda trabajando. Gracias mamá por apoyarme y respetar siempre mis decisiones (y por los tuppers que me hicieron sobrevivir durante mucho tiempo). A mis Marías os doy las gracias por entenderme y aceptarme, con mis virtudes y mis defectos (tomándolos con humor), y por hacerme querer ser siempre mejor persona. A mi familia (la de toda la vida y la nueva) y a mis amigos, tanto los que vivís lejos como los que vivís cerquita, porque siempre puedo contar con vosotros.

Gracias a todas las personas del departamento de ciencia animal, sin vuestra ayuda no habría sido posible terminar este trabajo. Eugenio y Luis, con vosotros he compartido mucho y gracias a vuestras 'sutiles técnicas' para conseguir almuerzos, me integrasteis como uno más desde el primer día. Además, os doy las gracias porque junto con Javi y con Juan Carlos hacéis posible la realización de las experiencias que se nos ocurren. Davi, Mariola, Ana, Marina, Maricarmen y Pablo, vosotros habéis sido mis compañeros y amigos durante estos años. Ha sido una experiencia extraordinaria en la que todos hemos aprendido de todos. Concha, Enrique y Carlos, vosotros siempre habéis estado disponibles para escucharme y ayudarme siempre que os lo he pedido. Vuestra experiencia y vuestros consejos han sido fundamentales para enfrentarme a los nuevos retos de este año. Tampoco quiero olvidarme de mis compañeros de la universidad Cardenal Herrera CEU. Juanma, David y Laura, ha sido un placer colaborar con vosotros y espero que sigamos haciéndolo en el futuro. Carlos, Mariola, Lorena y especialmente Olga, vosotros me habéis ayudado a empezar esta nueva fase como profesor universitario. Por último y en especial, me gustaría darte las gracias Juanjo por ser mi supervisor, mi mentor, mi amigo. Gracias por todo, especialmente por creer siempre en mí, incluso cuando yo no lo he hecho. 



\section{List of contents}

\begin{tabular}{lc}
\hline Abstract & $-1-$ \\
Resumen & $-3-$ \\
Resum & $-5-$ \\
\hline General introduction & $-7-$ \\
The background of animal nutrition and breeding briefly & $-9-$ \\
Defining the theoretical framework & $-12-$ \\
The rabbit female & $-16-$ \\
$\quad$ Nutrition and resource allocation & $-16-$ \\
Genetics and resource allocation & $-18-$ \\
Hypothesis and objectives & $-21-$ \\
\hline
\end{tabular}

Paper I: Accounting for (co)variance structure of longitudinal data from traits associated to productive performance in reproductive rabbit females: Model fitting and performance

Abstract

Introduction

Materials and methods

Animals and experimental procedure

Traits and data

Statistical analysis

Results and discussion

Structures considering residual variation exclusively: Group $1 \quad-46-$

Structures including variation between animals: Group 2

Structures including variation between lactations

from a given animal: Group 3
Conclusions

Acknowledgments

References

Paper II: Homeorhetic control and homeostatic regulation from a mixed-model view:

Reinterpreting nutrient partitioning using the rabbit female as a model

Abstract

Introduction

Materials and methods

Animals and experimental procedure $\quad-62$ -

Traits -63-

Statistical analysis 
Results

Evolution of traits over the reproductive cycle

Relations among traits

Discussion

(Co)Variation between animals and the homeorhetic control

Covariation within animals and homeostatic regulation

Body condition under this framework

Conclusions

Acknowledgments -76-

References

Paper III: Long-term implications of fitting feed energy source to the genetic type in reproductive rabbit females $I$. Resource acquisition and allocation

Abstract

Introduction

Materials and methods

Animals

Diets

Experimental procedure

Traits

Statistical analysis

Results -88-

Acquisition and allocation of resources

Blood plasma parameters

Discussion

General pattern of acquisition and allocation of resources

Acquisition and allocation patterns of genetic types -96-

Primiparous females

Conclusions

Acknowledgments $\quad-100$ -

References -100 -

Paper IV: Long-term implications of fitting feed energy source to the genetic type in reproductive rabbit females III. Fitness and productivity -105-

Abstract 107 -

Introduction

Materials and methods

Animals $\quad-110-$

Diets $\quad-110$

Experimental procedure $\quad-110-$ 
Statistical analysis

Results

$-112-$

Discussion

-116 -

Energy source

$-116-$

Genetic type

-117 -

Genetic type x energy source and the genetic background

Conclusions

$-121-$

Acknowledgments

-121-

References

-121 -

\begin{tabular}{lc}
\hline General discussion & $-125-$ \\
Statistical approach & $-127-$ \\
The role of the animal and the effect of energy source & $-127-$ \\
Optimizing resource allocation to the genetic type & $-129-$ \\
References & $-132-$ \\
\hline Conclusions & $-135-$ \\
\hline Perspectives & $-139-$ \\
\hline Short curriculum vitae & $-143-$ \\
\hline Supplementary material & $-145-$ \\
\hline
\end{tabular}




\section{List of Tables}

Table

Short description

Page

1.1 Means and number of records for the monitored traits

-39 -

1.2 (Co)variances structures

$-42-$

1.3 Fitting information using Akaike information criteria (AIC)

$-47-$

1.4 Decomposition of variance for the structures from group 2

$-52-$

2.1 Means and number of records for the monitored traits

2.1 Phenotypic variance and repeatability of traits conditioning acquisition and partition of energy at different states of the reproductive rabbit-female cycle

$-67-$

2.2 Within-trait correlations for the traits conditioning acquisition and partition of energy of the reproductive rabbit female

2.3 Permanent and residual correlations among traits

$-69-$

3.1 Ingredients and chemical composition of experimental diets

$-85-$

3.2 LSmeans and standard errors of the main effects on feed intake, perirenal fat thickness, milk yield and litter weight

3.3 Effect of genetic type, energy source and time control on plasma concentration of glucose, $\beta$-OH-butyrate, non-esterified fatty acids and leptin

4.1 Effect of genetic type and energy source on female traits

4.2 Effect of genetic type and energy source on litter traits 


\section{List of Figures}

Figure

Short description

Page

0.1 Possible reaction norms of two animals in arbitrary phenotypic and environmental units

0.2 Schematic view of genetically driven trajectories (targeted trajectory) homeorhetic control and homeostatic regulation

0.3 Schematic view of the effect of energy source on milk yield and body condition under the resource allocation framework

0.4 Relative priorities between current and future litters of females differently selected for litter size at weaning during

0.5 References related with energy requirements in function of the number of cycles evaluated in the experiment

$-22-$

1.1 Estimated evolution of phenotypic variance over time with different structures for feed intake, body weight and milk yield

1.2 Estimated phenotypic correlations with different structures for feed intake, body weight and milk yield

$-50-$

2.1 Individual trajectories of rabbit females across the reproductive cycle for each one of the evaluated traits

2.2 Estimated permanent value for each rabbit female and trait

2.3 Schematic view of the relation between nutrient partitioning and information provided by the estimated residuals with mixed models

2.4 Studentized residuals for two different traits from two rabbit females

3.1 Evolution of feed intake over the reproductive cycle and across reproductive cycles depending on genetic type and energy source

3.2 Evolution within a reproductive cycle of perirenal fat thickness depending on genetic type and energy source

$-92-$

3.3 Evolution of milk yield over the reproductive cycle and across reproductive cycles depending on genetic type and energy source

$-92-$

3.4 Plasma glucose and non-esterified fatty acids concentration throughout time depending on genetic type

3.5 Plasma $\beta$-OH-butyrate concentration throughout time depending on genetic type and energy source

3.6 Inner-average temperature per month of the farm and number of females that had their first parturition in the corresponding month

$-98-$

4.1 Percentage of adult weight at insemination for the subsequent RC depending on the genetic type

4.2 Cumulated survival rate (\%) at parturition in each reproductive cycle depending on genetic type

4.3 Conception rate depending on genetic type and energy source

4.4 Offspring survival rate during lactation in each reproductive cycle depending on genetic type and energy source

4.5 Live history traits for each genetic type depending on energy source 
5.1 Relative priorities between current and future litter of females selected for different criteria 


\section{Abstract}

During the last 50 years, there has been an overall improvement of efficiency in all domestic species thanks to an improvement in productivity traits. However, during the last years, disorders associated to a loss of functionality of animals (such as poor fertility, health and longevity of reproductive females) with high productivity standards have been observed. In this scenario, interactions between genetics and nutrition are becoming relevant. The main hypothesis of the present thesis is that nutritional strategies adapted to the genetic type could help to modulate productivity and functionality of females in the long term. To evaluate this hypothesis, 203 rabbit females were used which gave birth a total of 758 litters. These females belonged to 3 genetic types that differed greatly on their breeding goals: $\mathrm{H}$, maternal line characterized by hyper-prolificacy; LP, maternal line characterized by functional hyperlongevity; R, paternal line characterized by growth rate. Females were fed during 5 consecutive reproductive cycles with 2 iso-energetic and iso-protein diets differing in energy source: Animal fat enhancing milk yield (84 g of ether extract per $\mathrm{kg}$ of DM and $105 \mathrm{~g}$ of starch per $\mathrm{kg}$ of DM); Cereal starch promoting body reserves recovery (21 g of ether extract per $\mathrm{kg}$ of $\mathrm{DM}$ and $237 \mathrm{~g}$ of starch per $\mathrm{kg}$ of DM). This experiment generated a set of longitudinal data with particular structures of (co)variances among data which had to be taken into account. Several models differing in the way data structure is modelled were evaluated. We found that none of the tested models was the best in terms of goodness of fit to the data for all traits, but it seems that models in which (co)variance structure was modelled in blocks of (co)variances for each reproductive cycle could be the most recommendable because they presented an overall suitable statistic performance (in terms of parsimony and fitting) and biological interpretation. These models provided useful information to understand acquisition and allocation of individual animals. In this sense, it seems that we can modulate allocation between energy addressed to milk or to body reserves by changing energy source of diet, but altering normal homeostasis of animals. Respect to the strategies of genetic types, results of the present experiment seem to indicate that $\mathrm{R}$ females were characterized by greater adult weight and by a high dependence on the body reserves to cope with the reproductive requirements of the current reproductive cycle. They gave birth little but heavier kits, although it seems they could be more immature. When $\mathrm{R}$ females were fed with a diet promoting milk yield, they invested more on the current litter, whereas when fed with a diet promoting body reserves recovery, it seems that they invested more in recovering for future reproduction. On the contrary, females from the maternal lines were smaller and had numerous but lighter kits, but each genetic type used different strategies. H females were also high dependent on body reserves, but storing body reserves during lactation to cope with future reproduction. This strategy makes them more sensible to 
the energy source of the diet, triggering problems to ensure future reproduction when fed with a diet promoting body reserves recovery (low conception rate or higher mortality of females). LP females were characterized by an acquisition capacity better fitted to changing requirements, safeguarding body reserves. This strategy seems to be more generalist, allowing them to ensure high performance of the current litter without neglecting future reproduction and with less sensitivity to the diet. Therefore, to properly balance between productivity and functionality, results reported in the presented thesis suggest that apart from requirements, the way each genetic type acquire and allocate energy over its life trajectory should be considered when formulating diets for reproductive rabbit females. 


\section{Resumen}

En los últimos 50 años, gran parte de la investigación en genética y nutrición ha estado dirigida a aumentar la productividad de los animales de granja. Esto ha llevado a una mejora general de la productividad y en consecuencia de la eficiencia en todas las especies domésticas. Sin embargo, durante los últimos años se han observado trastornos asociados a una pérdida de funcionalidad en animales con altos estándares de productividad (como baja fertilidad, salud o longevidad de las hembras reproductivas). En este escenario, las interacciones entre la genética y la nutrición son cada vez más relevantes. La principal hipótesis de la presente tesis es que estrategias nutricionales adaptadas al tipo genético podrían ayudar a modular entre productividad y funcionalidad de las hembras. Para evaluar esta hipótesis, se utilizaron 203 conejas que dieron lugar a un total de 758 lactaciones. Estas conejas pertenecían a 3 tipos genéticos que diferían ampliamente en sus objetivos de selección: $H$, línea materna caracterizada por hiper-prolificidad; LP, línea materna caracterizada por hiper-longevidad funcional; R, línea paterna caracterizada por la velocidad de crecimiento. Las conejas fueron alimentadas durante 5 ciclos reproductivos consecutivos con 2 dietas iso-energéticas $e$ iso-proteicas que diferían en la fuente de energía: Grasa animal para fomentar la producción de la leche (84 g de extracto etéreo por kg MS y $105 \mathrm{~g}$ de almidón por kg MS); Almidón de cereal para promover la recuperación de las reservas del corporales ( $21 \mathrm{~g}$ de extracto etéreo por $\mathrm{kg}$ MS y $237 \mathrm{~g}$ de almidón por kg MS). El experimento generó una base de datos con datos longitudinales con unas estructuras particulares de (co)varianzas entre los datos y que debían tenerse en cuenta. En este sentido, se evaluaron varios modelos que diferían en la forma en que se modelan la estructura de datos. Se encontró que ninguno de los modelos probados fue el mejor en términos de bondad de ajuste para todos los caracteres. Sin embargo, parece que los modelos en los que la estructura (co) varianza se modeló en bloques de (co)varianzas para cada ciclo reproductivo podrían ser los más recomendables, ya que presentaron un ajuste estadístico adecuado (en términos de parsimonia y ajuste) y una buena interpretación biológica. Estos modelos proporcionaron información útil para comprender la adquisición y asignación de animales individuales. Respecto al efecto de la fuente de energía de la dieta, parece que podemos modular la asignación entre la energía dirigida a la producción de leche o la ganancia de reservas corporales cambiando la fuente de energía de la dieta, pero alterando la homeostasis normal de los animales. Respecto a las estrategias de los tipos genéticos, los resultados del presente experimento parecen indicar que las hembras $\mathrm{R}$ se caracterizaron por un mayor peso adulto y por una alta dependencia de las reservas corporales para hacer frente a las necesidades reproductivas del ciclo reproductivo actual. Estas hembras parieron menos gazapos, pero más pesados, aunque parece que podrían ser más inmaduros. Cuando las hembras $\mathrm{R}$ fueron alimentadas con una dieta que promovía la producción de la leche, 
invirtieron más en la camada actual, mientras que cuando se les alimentó con una dieta que promovía la recuperación de las reservas corporales, invirtieron más en la recuperación para su futura reproducción. Por el contrario, las hembras de las líneas maternas fueron más pequeñas y tuvieron más gazapos, pero más ligeros. No obstante, cada tipo genético utilizó una estrategia diferente. Las hembras $\mathrm{H}$ también fueron muy dependientes de las reservas corporales, pero almacenando reseras corporales durante la lactación para hacer frente a la futura reproducción. Esta estrategia les hace sensibles a la fuente de energía de la dieta, desencadenando problemas para asegurar la reproducción futura cuando fueron alimentadas con una dieta que promueve la recuperación de las reservas corporales (baja tasa de concepción o mayor mortalidad de las hembras). Las hembras LP se caracterizaron por una capacidad de adquisición mejor adaptada a las necesidades cambiantes. Esta estrategia parece ser más generalista, lo que les permite asegurar un alto rendimiento de la camada actual sin descuidar la reproducción futura, salvaguardando las reservas corporales, y con menos sensibilidad a la dieta. Por lo tanto, para balancear adecuadamente productividad y la funcionalidad, los resultados de la presente tesis sugieren que aparte de las necesidades, la forma en la que cada tipo genético adquiere y utiliza los recursos también debería ser considerado al formular dietas para las hembras reproductoras de conejo. 


\section{Resum}

En els últims 50 anys, gran part de la investigació en genètica i nutrició ha estat dirigida a augmentar la productivitat dels animals de granja. Açò, ha aportat una millora general de la productivitat $i$, en conseqüència, de l'eficiència en totes les espècies domèstiques. No obstant això, al llarg dels últims anys s'han observat trastorns associats a una pèrdua de funcionalitat en animals amb estàndards elevats de productivitat (com baixa fertilitat, salut o longevitat de les femelles reproductives). En este context, les interaccions entre la genètica i la nutrició són cada vegada més rellevants. La hipòtesi principal de la tesi proposa que les estratègies nutricionals adaptades al tipus genètic permeten modular la productivitat i funcionalitat de les femelles. Per avaluar esta hipòtesi es van utilitzar 203 conilles que proporcionaren un total de 758 lactacions. Estes conilles pertanyien a tres tipus genètics que diferien àmpliament en els seus objectius de selecció: $\mathrm{H}$, línia materna caracteritzada per hiperprolificitat; LP, línia materna caracteritzada per hiperlongevitat funcional; R, línia paterna caracteritzada per velocitat de creixement. A les conilles se'ls va subministrar 2 dietes isoenergètiques i isoproteiques durant cinc cicles reproductius consecutius, els quals diferien en la font d'energia: Greix animal per fomentar la producció de llet (84 g d'extracte eteri per kg MS i 105 g de midó per kg MS); Midó de cereal per promoure la recuperació de les reserves del corporals (21 g d'extracte eteri per kg MS i $237 \mathrm{~g}$ de midó per kg MS). L'experiment va generar una base de dades amb dades longitudinals amb unes estructures particulars de covariàncies entre les dades que havien de tindre's en compte. En este sentit, es van avaluar diversos models que diferien en la forma en què modelitzaven l'estructura de les dades. Es va trobar que cap dels models provats va ser millor en termes de bondat d'ajust per a tots els caràcters. No obstant això, pareix que els models en què l'estructura covariància es va modelar en blocs de covariàncies per a cada cicle reproductiu podrien ser els més recomanables, ja que presenten un ajust estadístic adequat (en termes de parsimònia i ajust) i una bona interpretació biològica. Estos models van proporcionar informació útil per a comprendre l'adquisició i assignació d'animals individuals. Respecte a la font d'energia de la dieta, pareix que podem modular l'assignació entre l'energia dirigida a la producció de llet o el guany de reserves corporals si canvia la font d'energia de la dieta, tanmateix l'homeòstasi normal dels animals es veu alterada. Des del punt de vista de les estratègies segons el tipus genètics, els resultats del present experiment pareixen indicar que les femelles $\mathrm{R}$ es van caracteritzar per tindre major pes adult i per una dependència elevada de les reserves corporals per a fer front a les necessitats reproductives del cicle reproductiu actual. Estes femelles van parir menys catxaps, però més pesats, encara que és probable que siguen més immadurs. Quan les femelles $\mathrm{R}$ van ser alimentades amb una dieta que promovia la producció de la llet, van invertir més en la ventrada actual, mentres que quan se'ls va alimentar amb una dieta que promovia la recuperació de les reserves corporals, van 
invertir més en la recuperació per al següent cicle reproductiu. Contràriament, les femelles de les línies maternes van ser més menudes i van tindre més catxaps, però més lleugers. No obstant això, cada tipus genètic va utilitzar una estratègia diferent. Les femelles $\mathrm{H}$ també van ser molt dependents de les reserves corporals, però emmagatzemaren reserves corporals durant la lactació per a fer front a pròxima reproducció. Esta estratègia les fa més sensibles a la font d'energia de la dieta, i conseqüentment, desencadena problemes per assegurar la reproducció propera quan es nodrixen amb una dieta que promou la recuperació de les reserves corporals (baixa taxa de concepció o major mortalitat de les femelles). Les femelles LP es van caracteritzar per una capacitat d'adquisició de recursos millor adaptada a les necessitats canviants. Esta estratègia pareix més generalista, la qual cosa les permet assegurar un rendiment alt de la ventrada actual sense descuidar la reproducció futura, salvaguardant les reserves corporals, i amb menys sensibilitat a la dieta. Per tant, per balancejar adequadament productivitat i la funcionalitat, els resultats d'aquesta tesi suggerixen que, a banda de les necessitats, la manera en què cada tipus genètic adquirix $\mathrm{i}$ utilitza els recursos també hauria de ser considerat al formular dietes per a les femelles reproductores de conill. 
GENERAL INTRODUCTION 



\section{The background of animal nutrition and breeding briefly}

Traditionally, the emphasis of nutrition has focus on formulating diets to meet minimum requirements at the lowest cost. Research in nutrition and development of chemistry and technology have helped to better definition of requirements of the animals and the nutritional value of foodstuffs for each one of the immediate principles of foods, such as water, carbohydrates, lipids, proteins, vitamins and minerals (McDonald et al., 2011). Firstly, as determining immediate principles is very complex and hard, most information about food composition was based in the Proximate analyse (Henneberg and Stohmann, 1859). However, during the last 50 years, new analytical techniques have been developed, which have improved the information about food composition, getting closer to the immediate principles and their fractions. For example, we have moved from the initial fibre or protein concepts of the Proximate analyse to the Van Soest fractions of fibre (Van Soest et al., 1991) or amino acid profiles for protein. Secondly, as there are losses associated to the digestion and metabolism processes, not all these acquired components from food are completely available for the animal. Consequently, different fractions from each component have been studied in detail in order to describe their availability for animals. For example, gross energy is decomposed to digestible energy, this to metabolizable energy and the latter to net energy, which is the amount of ingested energy that is directly available to the animal for maintenance and production proposes. Thirdly, as efficiency to synthetize milk is not the same than the efficiency to develop foetuses, it is also possible to define for each function the amount of each component of food that is finally available for the animal to cover their minimum requirements. In other words, it is possible to define the amount of digestible energy that it is required to produce $1 \mathrm{MJ}$ of milk, foetus, growth or body reserves accretion.

Concurrently, there has also been a huge improvement on genetics. The goal of selection is to identify the best animals on the current population for a given trait to use them as parents for the next generation. Part of the superiority of parents for this trait will be inherited by the offspring and accumulated over generations. To perform this selection, animals are ranked according to their breeding value for the given trait, which generally presents high economic interest. Important efforts on genetics have been addressed to improve the methods to rank animals. From the individual selection, based on observed phenotypes or family index which also uses information of the relatives, to the generalization of the use of best linear unbiased prediction (BLUP), which is based on linear mixed models, or the more recent use of molecular techniques (Falconer and Mackay, 1996; Khalil and AlSaef, 2008).

In this way, despite nutrition and genetics have generally been studied separately, they have evolved together towards improving productivity of animals, considering that 
increasing productivity of animals dilutes the cost of maintenance and improves efficiency. This strategy has been applied for a long time, leading to a generalized phenotypic improvement in productivity and efficiency in all the domestic species in the last 50 years (Hill, 2008). To give some examples, Havenstein et al. (2003) reported that broilers from the genetic type existing in 1959 and fed with diets of that time weighted $1430 \mathrm{~g}$ at 84 days of live, whereas modern animals fed with modern diets weighted $5520 \mathrm{~g}$ at that age. The consequence of the heavier body weight of modern strategies was a reduction in the feed conversion ratio from 3.84 to 2.72 . Similarly, Jones et al. (2001) reported that the $57 \%$ of laying hens existing in 1950 produce one egg in a day at the age of $50 \%$ of production, which average weight was $34 \mathrm{~g}$, whereas the $73 \%$ of the females existing in 1993 produce one egg, which average weight was $49 \mathrm{~g}$. These changes reduced feed conversion ratio from 3.13 to 2.35 for egg production. In dairy cattle (Council on Dairy Cattle Breeding, 2016), on average cows yielded $5906 \mathrm{~kg}$ of milk per year in 1957 and $12862 \mathrm{~kg}$ per year in 2014. In pigs existing in 1930 daily gain was $500 \mathrm{~g}$ per day with a backfat of $45 \mathrm{~mm}$, whereas in 1990 daily gain was $840 \mathrm{~g}$ per day and the backfat was $24 \mathrm{~mm}$, these changes leading to a reduction of 0.7 in the feed conversion ratio of growing pigs (Merks, 2000). Finally, there has been a reduction of 1.0 point in the global feed conversion ratio of meat rabbits from 1984 to 2012 thanks to improvements in conception rate of females, litter size and reduction of mortality in kits (Braine and Coutelet, 2012).

However, the sustainability of this strategy is starting to be challenged due to problems associated with a loss of functionality of animals with high productivity standards. Functionality usually refers to traits related with fertility, health or longevity (Strandberg et al., 1996), so functional traits could be defined as traits related with the ability of the animal to reproduce and survive succesfully in a given environment. These traits do not neccesary have a direct economic interest. However, sometimes they are negatively correlated with productive traits. Conequently, long term selection exclusively for productive criteria can be accompanied by undesired side effects on functional traits (Rauw et al., 1998; Hocking, 2014). To give some examples, the relation between selection for growth rate and pulmonary arterial hypertension in broilers (ascites syndrome) has been largely recognize (Wideman et al., 2013). Pavlidis et al. (2007) reported that 10 generations of divergent selection for ascites incidence resulted in approximately $163 \mathrm{~g}$ heavier chickens of susceptible animals respect to resistant animals. Blasco et al. (1993) reviewed the genetics of prenatal survival of pigs and rabbits and reported that generally there were a negative genetic correlation between ovulation rate and piglet survival before birth. Negative consequences of selection for milk output in dairy cattle have also been reviewed, affecting mainly to health, fertility and consequently longevity (Veerkamp et al., 2009). 
Apart from the negative side effects associated with selection for productivity and due to genetic correlations existing between functional and productive traits, Friggens et al. (2013) stated that selection was acting reducing the 'room to manoeuvre' of selected animals to cope with different environments. It means that selected animals could prioritize production under any environmental condition, even if doing it has negative consequences (Friggens and Van der Waaij, 2009). Consequently, if this statement is true, genetic by environment interactions $(\mathrm{GxE})$ must exist, which means that the response of an animal to a given environment will depend not only on the environment, but also on its genotype. Similarly, Kolmodin et al. (2003) argued that, in a selection context where GxE exists, animals more sensitive to the environment would be more easily selected. Consequently, selection would act favouring specialized animals in the context of selection (Savietto et al., 2015). An intuitive view of this idea, which was proposed by Kolmodin et al. (2003), is represented in Figure 0.1. In this figure, the interaction between the phenotype and the environment of two animals is represented by reaction norms. The magnitude of this interaction is given by the slopes of the reaction norms. We can observe in the figure that the slope of the animal represented by the solid line is higher than the slope of the animal represented by the dashed line, which means that the former animal is more sensitive to the environment. In the bad environment, the animal represented by the solid line performs worse than the animal represented by the dashed line, not being selected in that environment. As research and technology progress, the quality of the environment would improve. Consequently, despite the animal represented by the solid line is more sensitive to the environment, the phenotype of that animal would be better in the 'good' environment, and that animal would be selected. Under these 'good' environmental conditions of selection, generation over generation the mean phenotype would improve but, as these phenomena will be repeated, mean sensitivity to environment would be also accumulated. Evidences of these kind of interactions have been reported for reproductive sows (Knap and $\mathrm{Su}, 2008$ ), growing pigs (Fix et al., 2010) and broilers (Havenstein et al., 2003).

If high standards of production could be linked to problems of functionality, it seems that strategies addressed to improve productivity exclusively will not be sustainable in the long term. Therefore, one of the main challenges for animal science is to develop sustainable strategies for the long term. In this sense, we should start thinking of alternatives keeping on improving efficiency without affecting negatively to functionality of animals. To cope with that situation, breeding goals are changing. The relative weight of productivity traits in the selection indexes is becoming lower and the number and the relevance of functional traits are becoming higher, and is expected to increase for the next years (Neeteson-van Nieuwenhoven et al., 2013; VanRaden and Cole 2014). 


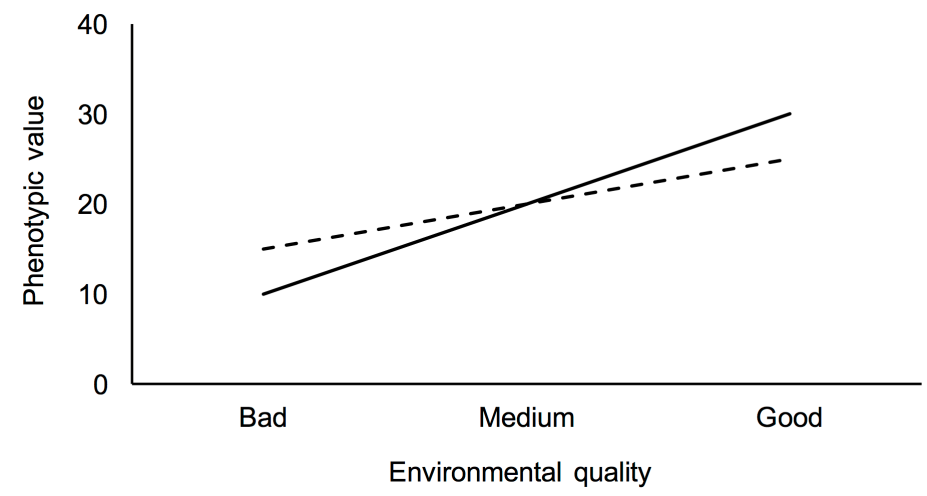

Figure 0.1 Possible reaction norms of two animals in arbitrary phenotypic and environmental units (adapted from Kolmodin et al., 2003)

On the other hand, nutritionists are improving the environment providing better diets adapted to the requirements of selected animals (Ingvartsen, 2006). But, does better mean better for all the individuals? Moreover, what does better mean? When coping with GxE interactions we have to deal with these questions, but they have not always an easy answer. For example, if we are talking about milk yield of females, under the interpretation presented above at Figure 0.1, the female represented by the solid line in the environment we classify as good would be better because that female yielded more milk (which theoretically is good for the farmer in short term). However, this comment only refers to one particular trait, milk yield, and ignores the rest. If that female produce more milk because that diet promotes her mobilization of body reserves, the risk of not getting pregnant or being culled could be increased (Roche et al., 2009; Pascual, 2010). This situation is not good from the female's point of view. Moreover, despite the higher production of milk, the feed efficiency of that female could be lower in the long term than that for the female represented by the dashed line because the longer non-productive periods (Puillet et al., 2016), which is not good for the farmer in long term. Consequently, to properly evaluate GxE interactions using more than the single-trait interpretation from reaction norms would be recommended (Friggens and Van der Waaij, 2009) and traits involving productivity and functionality should be considered.

\section{Defining the theoretical framework}

For some time now, concepts and ideas from ecology have been incorporated to animal science. Perhaps, one of the most important is the concept of fitness. From a practical point of view, fitness could be defined as the number of progeny produced over a lifetime which survive to breed' (Beilharz, 1998). However, as recording in that way would be very time consuming, the total number of young weaned over longish period of time would be a good approximated measure of fitness (Beilharz et al., 1993). According to survival of the 
fittest of Darwin's theory, fitness can be used as a measure of how much an animal is fitted to its environment. From a given animal, the higher is the number of surviving offspring reaching to breed, the higher is its fitness and the fitter is this animal to its environment. Assuming that fitted animals in a given environment must be functional in that environment, the study of fitness and its components could be an interesting way to evaluate functionality of animals. However, it requires the evaluation of animals during a longish period of their life trajectory and consequently long-term experiments.

Another important incorporation from ecology is the resource acquisition and allocation theory (Van Noordwijk and De Jong, 1986; Beilharz et al., 1993), whose adaptation to farm animal production is collected in detail in Rauw (2009). It states that fitness is the product of several components $(\mathrm{A}, \mathrm{B}, \mathrm{C}, \ldots)$ such as the mean litter size, survival of the offspring at different periods before breed, number of reproductive events or fertility... The relation of these components with fitness is multiplicative.

$$
\text { Fitness }=\mathrm{A} \times \mathrm{B} \times \mathrm{C} \times \ldots
$$

Each one of the components of fitness $(\mathrm{A}, \mathrm{B}, \mathrm{C} \ldots)$ uses resources $(\mathrm{a}, \mathrm{b}, \mathrm{c}, \ldots)$, where ' $\mathrm{a}$ ' denotes the amount of resources allocated to the component ' $\mathrm{A}$ ' of fitness and so on. Under this theory, we consider that resources consumed by one function are not available for others (e.g. resources addressed to yield milk are not available to fetus development). Consequently, the components of resources are additively related.

$$
\text { Resources }=\mathrm{a}+\mathrm{b}+\mathrm{c}+\ldots
$$

The use of these two equations provide a simple framework with important consequences. If resources are not limited, every component of fitness could be improved by increasing the amount of resources addressed to it, without affecting the amount of resources addressed to other fitness components. On the other hand, when resources become limited, there is an optimum of resources addressed to each function that maximizes fitness (Beilharz et al., 1993). Friggens and Van der Waaij (2009) proved that this maximum would be reached for intermediate values for the different fitness components. It means that most of resources are not addressed to one single function. When a limiting situation is reached, if more resources are addressed to one function, aiming to maximize one unique fitness component, this fitness component will trade off with another one (Stearns, 1992; Roff and Fairbairn, 2007), not increasing or even reducing the global fitness. Thus, genetic correlations among fitness components are expected to exist. However, according to the model proposed by Van Noordwijk and De Jong (1986), their sign and magnitude will depend on the capacity of animals to acquire resources in the environment they are living and the coefficients of partition of resources (mean and variation between animals; Roff and 
Fairbairn, 2007). For example, if resources are limited, selection for litter size (one of the components of fitness) could decrease fitness because in that situation increasing the amount of resources addressed to litter size would decrease the amount or resources addressed to other functions. On the contrary, if resources are not limited, litter size could be improved by selection without affecting or even improving fitness. Thus, according to this framework, functionality does not necessary trade off with productivity. In fact, under ad libitum circumstances, we would not expect any resource constrain, as theoretically animals could increase their intake to acquire more resources. However, environmental factors (such as the energy content of the diet or the temperature of the farm) jointly with intrinsic factors of the animal (such as the capacity of the digestive tract, rate of eating, faecal output, heat dissipation, ATP degradation...; Poppi et al., 1994), could constrain the acquisition capacity of animals limiting, at some point of their life trajectory, the amount or resources an animal is able to acquire.

At this point, the relevance of understanding the way animals acquire and use resources has also been recognized by nutritionists for understanding properly energy balance of animals (especially for reproductive females, Friggens and Newbold, 2007; Friggens et al., 2013). In this topic, rather than allocation of resources framework is more common the use of nutrient partitioning framework. Both frameworks are related because they recognize a central role of the animal and its genetics in the use of resources. However, in the resource allocation framework presented above, time and the life trajectories of females are not necessary included in the process of allocation. On the contrary, nutrient partitioning distinguishes two different process where time is an explicit driver of partitioning: the homeorhetic control and the homeostatic regulation (Friggens et al., 2013). Homeorhesis, defined as 'all the orchestrated changes in the animal necessary to support a physiological state' (Bauman and Currie, 1980), is related with the evolution of the priorities of the animal through its life trajectory (growth, balance of body reserves, ensure survival of the unborn, ensuring survival of the new born, ensuring survival of the suckling offspring, ageing; Martin and Sauvant, 2010). These priorities determine trajectories of the life functions throughout the lifetime of females which are genetically driven. Consequently, the genetically driven trajectory for a given function, such as lactation or body reserves storing, is the trajectory over time that will be achieve by the animal under non-limiting conditions as a consequence of the homeorhetic control. Likewise, homeostasis, defined as 'the maintenance of equilibrium within a physiological state' (Bauman and Currie, 1980), is related to the ability of an animal to respond to environmental perturbations adjusting nutrient partitioning to attempt to maintain the targeted trajectory (Friggens et al., 2013). These ideas are schematized in Figure 0.2, where it is represented an effective trajectory for a given live 
function (such as milk yield) and how homeorhetic control and homeostatic regulation act to attempt to achieve the targeted trajectory.

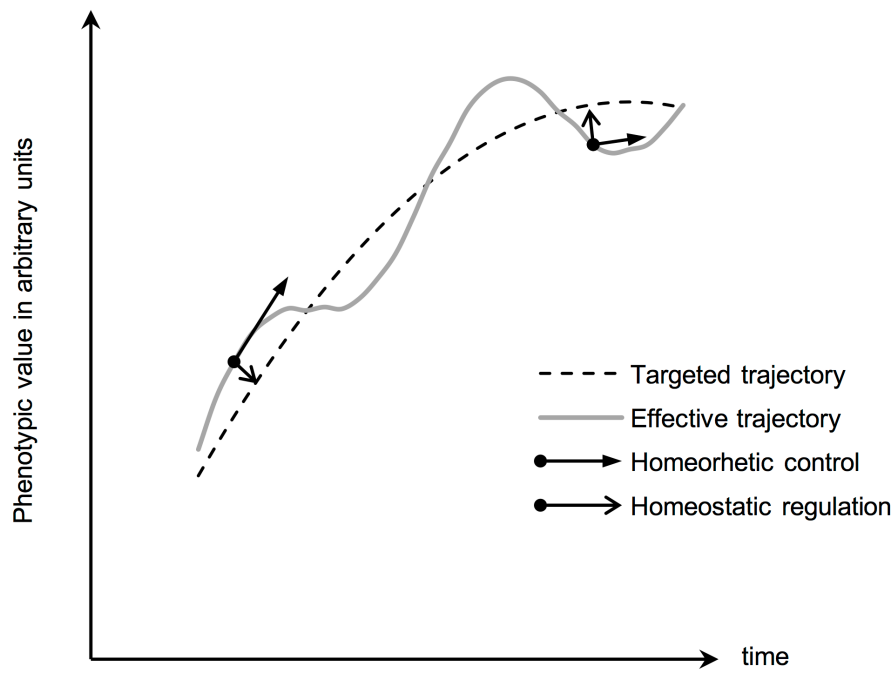

Figure 0.2 Schematic view of genetically driven trajectories (targeted trajectory) homeorhetic control and homeostatic regulation.

However, it seems that there are limits to the capacity of some animals to maintain homeostasis when they are raised under some environmental conditions (Friggens et al., 2013). In that situation, if the effective trajectory (such as the trajectory of body reserves) is far from the targeted one, some functions of the female (such as the onset of oestrus cycling postpartum) could be compromised (Friggens, 2003). In fact, Ingvartsen (2006) proposed that homeorhetic and homeostatic mechanisms could be insufficient for some cows to function optimally, these cows suffering from physiological imbalances and increasing their risk of suffering functional disorders. Nevertheless, he proposed that specific feeding and management strategies could help to prevent this situation in those females. This idea suggests that we can lessen or exacerbate the risk of functional disorders of different females depending on the feeding or management strategy used.

Therefore, the concepts and ideas exposed above highlight the relevance of understanding properly the way animals acquire and use resources. To simplify and to be clearer, I will refer to the framework described in this section as resource allocation. In such framework, time and the role that the animal plays are key points to understand resource allocation. Likewise, the feeding system could be a possible strategy modulating homeorhetic and homeostatic mechanisms. In this scenario, the dynamics of traits (effective trajectories) involved in acquisition and allocation (or partitioning) of resources and the 
relations among these traits will determine the way animals will respond to environmental perturbations, their productivity and finally their fitness.

\section{The rabbit female}

Despite rabbits are many times used as model to investigate some topics, their breeding also presents zootechnical interest, mainly in the Mediterranean countries. Consequently, their study has also practical application. In fact, from all the domesticated species, the rabbit could be one of the best options to investigate the way animals acquire and use energy: (i) as they are small, they are easily handled by people and it is possible to breed the large number of animals required to perform experiments in small farms; (ii) as a consequence of their fast-reproductive rhythm, rabbit females can lactate and gestate, even simultaneously, several litters per year. This fact reduces the time of experimentation that is required for the evaluation of a longish period of the lifetime of animals; (iii) acquisition and allocation of resources can be challenging for females as their reproductive effort is considerably high due to the fast reproductive rhythm, the large number of offspring per litter and the high energetic cost of milk (Maertens et al., 2006). Moreover, as we will see in the following sections, due to particularities of its nutrition and genetic backgrounds, the rabbit present suitable reasons to adapt nutrition to the genetic type.

\section{Nutrition and resource allocation}

Traditionally, voluntary feed intake of rabbit females has been considered to be physically limited in primiparous females and regulated by a chemostatic mechanism in adult females. Although it depends on different intrinsic and extrinsic factors, we could generalize that this chemostatic mechanism would act for from $10.5 \mathrm{MJ}$ of digestible energy (DE) per kg of dry matter (DM; Xiccato and Trocino, 2010). In this way, adult reproductive rabbit females can ingest around 1.1-1.3 $\mathrm{MJ}$ of DE per $\mathrm{kg}$ of DM and $\mathrm{kg}$ of metabolic weight (Xiccato and Trocino, 2010). Considering that females can lactate the current litter whereas gestate the next one, this energy intake usually is not enough to cover their high energy requirements during part of the reproductive cycle and females use their body reserves to cope with that situation (Xiccato, 1996; Fortun-Lamothe et al., 1999). This situation is even worse for primiparous females (Xiccato, 1996). In addition, poor body condition has been related with reproductive (Cardinali et al., 2008) or even health (Sánchez et al., 2012) disorders which increase the risk of culling of females (Theilgaard et al., 2006; Rosell and de la Fuente, 2009). Consequently, mobilization of body reserves was considered also as a disorder of the females and several nutritional strategies were addressed to increase energy intake and to avoid body reserves mobilization (reviewed by FortunLamothe, 2006; Castellini et al., 2010; Pascual, 2010). Regarding to nutritional strategies 
addressed to reproductive females, the efforts have been mainly addressed towards highenergy diets and/or the main energy source of the diet (Pascual et al., 2003).

There is large variation among the results of the studies performed with high-energy diets. Thus, following comments will refer to the main findings and conclusions reached in the revision of this issue performed by Pascual et al. (2003). Despite dry matter intake of high-energy diets is greatly controversial, it seems that high-energy diets tend to increase the energy intake of females during lactation, especially when females were fed with a diet enriched in animal fat (Xiccato et al., 1995; Lebas and Fortun-Lamothe, 1996). However, this extra-energy intake was differently distributed depending on the main energy source of the diet (Pascual et al., 2002). Likewise, animal-fat enriched diets tend to increase milk yield (between 5 and 24\%), cereal-starch enriched diets tend to decrease it slightly (both comparisons respect to moderate-energy diets Fortun-Lamothe and Lebas, 1996). Moreover, milk from females fed with animal fat was also associated to an increase in the fat content (on av. $+12 \%$ ) and a variation in the profile of fatty acids. Thus, milk-energy output of females was greatly increased by using diets enriched in animal fat. On the other hand, when females were fed with cereal-starch enriched diets, the extra-energy intake was mainly addressed towards body reserves (Fortun-Lamothe and Lebas, 1996).

Pascual et al. (1999) reported a correlation between milk and dietary fatty acid profile. In this sense, they reported that milk from females fed with fat enriched diets presented higher proportion of long-chain fatty acids and lower proportion of medium-chain fatty acids, whereas they did not found differences in short-chain fatty acids. In fact, Pascual et al. (2003) argued that long-chain fatty acids of rabbit milk must come from diet whereas short-chain (less than ten atoms long) come from lipogenesis de novo. Therefore, to explain the relevant role that energy source of diet plays on acquisition and allocation of energy it could be proposed the following mechanism; as digestion and metabolization of fat do not promote insulin release, it does not incorporate any glucose to blood plasma. Low levels of insulin limit the activation of adipocytes and prevent fatty acids to enter in the fat tissues from the plasma (Frayn, 1998). The extra fat in plasma stream of animal-fat enriched diets (mainly long-chain fatty acids) would be excreted in lactating females mainly through the mammary gland, promoting milk fat output. On the contrary, the digestion and metabolization of starch-enriched diets lead to increase plasma glucose levels promoting insulin release. Consequently, high levels of insulin activate adipocytes and finally glucose from the digestion of starch is incorporated to the fat tissues via lipogenesis de novo, as well as the uptake of fatty acids existing in blood plasma.

However, despite the relevant role of energy source of the diet on acquisition and allocation of energy, none the studied strategies prevented completely mobilization of 
females. In fact, Xiccato (1996) reported that almost no primiparous female was able to avoid negative energy balance during the whole reproductive cycle. Moreover, as indicated for fat enrich diets, when animals are able to obtain extra-energy, it is addressed towards milk rather than body reserves accretion. Therefore, do we really understand how and why body reserves are used by the animal? In this sense, Friggens (2003) proposed that body reserves are also genetically driven. In this sense, the trajectories over the reproductive cycle are defined by the genetics of the animal and shaped by the evolutionary strategy of the specie. It indicates that the animal plays a central role on the use of body reserves and means that not all mobilization is a malfunction of the animal. Supporting this statement, Pascual et al. (2002) reported that females with greater body reserves at parturition presented higher mobilization during lactation and yielded more milk. They also reported that females with higher mobilization at the end of lactation increased their body reserves during weaning to parturition interval due to a higher intake during this period (Pascual et al., 2003). It suggests some regulation of body reserves on energy intake (Kennedy, 1953) and implies that energy intake must be regulated by more than the single chemostatic mechanism (Forbes, 2007). Therefore, understanding the role of the animal in the trajectories of the traits involved in acquisition and allocation of resources and the relation among these traits could help to explain many situations and to develop suitable strategies. In this sense, the theoretic framework described previously could be a useful tool and energy source of the diet a good treatment to evaluate the modulation of allocation (Figure 0.3).
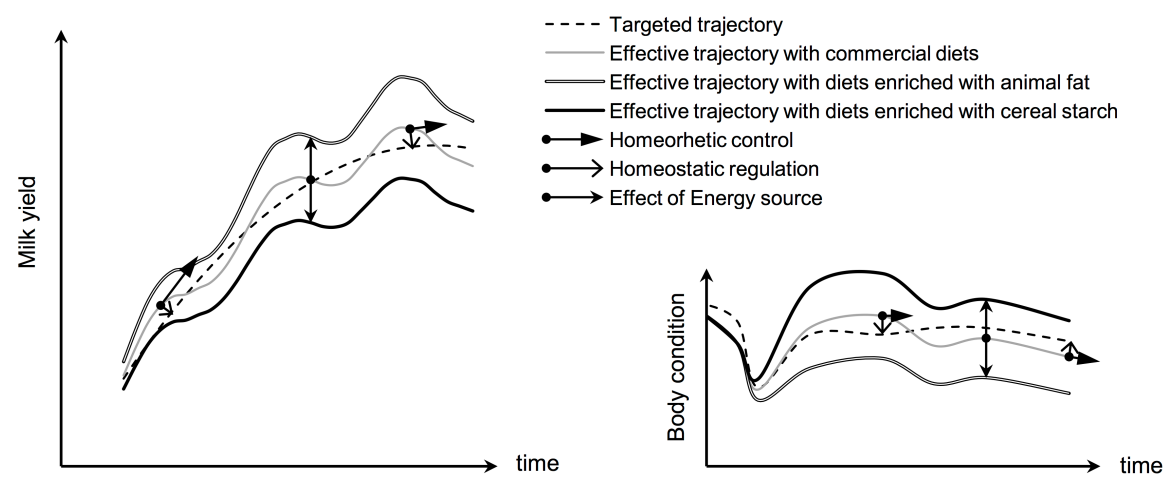

Figure 0.3 Schematic view of the effect of energy source on milk yield and body condition under the resource allocation framework.

\section{Genetics and resource allocation}

In most of the breeding schemes of rabbit production, there are three genetic types involved in two different crosses. This three-way crossbreeding scheme aims to take advantage from the heterosis and complementary between traits of the different genetic 
types that take part in the crosses (Baselga, 2004). The aim of the first cross is to obtain a crossbreed female with high heterosis and low inbreeding from two genetic types with maternal aptitudes. The second cross will produce the final meat rabbits. In this second cross the crossbreed female is inseminated (or mated) with males from a genetic type characterized by great feed conversion ratio during the growing period (paternal line). Thus, genetic programs aiming to develop this scheme require a minimum of one paternal line and two maternal lines. The goal of paternal lines is to improve feed conversion ratio. However, as it is difficult and expensive to obtain, animals from these lines are usually selected by postweaning daily gain (Estany et al., 1992) or weight at slaughter time (Lukefahr et al., 1996), because they are negatively and favourable correlated with feed conversion ratio (Piles et al., 2004). On the other hand, despite several alternatives have been tested (uterine capacity, Santacreu et al., 2005; ovulation rate, Ibañez et al., 2006; environmental variance of litter size, Blascto et al., 2017), maternal lines are mainly selected for litter size at birth or at weaning (reviewed by Khalil and Al-Saef, 2008). In this sense, the number of traits used during selection is considerable lower than that performed in other species with higher economic revenues as pigs (Neeteson-van Nieuwenhoven et al., 2013) or cows (VanRaden and Cole 2014). However, by selecting properly the base population of a genetic line, it is possible to extend the breeding goals of that line. To do it, Baselga (2004), who reviewed the existing alternatives to found lines, proposed defining realistically the desired specialization of the line and applying, in very large populations (such as commercial farms), very high intensities of selection for the traits related with the specialization interest. This hyper-selection strategy at foundation, among others, has been successfully applied in the genetic program of the Institute for Animal Science and Technology of the Universitat Politècnica de València (Spain) to hyper-prolificacy (Line H; Cifre et al., 1998) and to functional hyper-longevity (Line LP; Sánchez et al., 2008). Therefore, there are in our institute a wide range of genetic types differing in the base population, the intensity and the criteria used during the selection process (EL Nagar, 2015; Mínguez et al., 2015).

Respect to the way animals acquire and allocate resources, it is important to distinguish between individual variation and differences between genetic types. Regarding to individual variation, little is known about individual variation of genetically driven trajectories or allocation strategies, nor about the way animals respond to perturbations adjusting nutrient partitioning. However, the way some of the existing genetic types acquire and allocate resources has been evaluated in several experiments (Pascual et al., 2013). Cifre et al. (1994) reported that hyper-prolific females ( $\mathrm{H}$ females) were characterized by a higher ovulation rate compared to other maternal lines more selected for litter size. Savietto et al. (2015) showed that, in a specialized maternal line, twenty generations of selection for litter size at weaning was not accompanied by an increase of acquisition capacity of the females 
in several environmental conditions. However, to increase the number of weaned kits, selection altered the way animals allocated resources over the reproductive cycle, increasing the energy addressed to produce viable kits at birth, increasing milk yield during early lactation and decreasing during late lactation, without any negative effect on body reserves and fertility. To explain this situation, they hypothesized that selection for litter size at weaning, in a context were big litters in a short interval are demanded, was favouring an extended priority around parturition to the current litter to ensure large viable kits, but rapid change of the female's priorities between the current and the future litter at middle lactation safeguarding body reserves to ensure next litter viability (Figure 0.4). However during a heat challenge, Savietto, (2014) concluded that, despite highly selected animals were more robust for short term challenges, these animals would result exhausted if the environmental challenge persists. In this sense, Ferrian et al. (2012) suggested that selection for litter size at weaning could diminish the immune system's response and adaptation capacity of these animals.

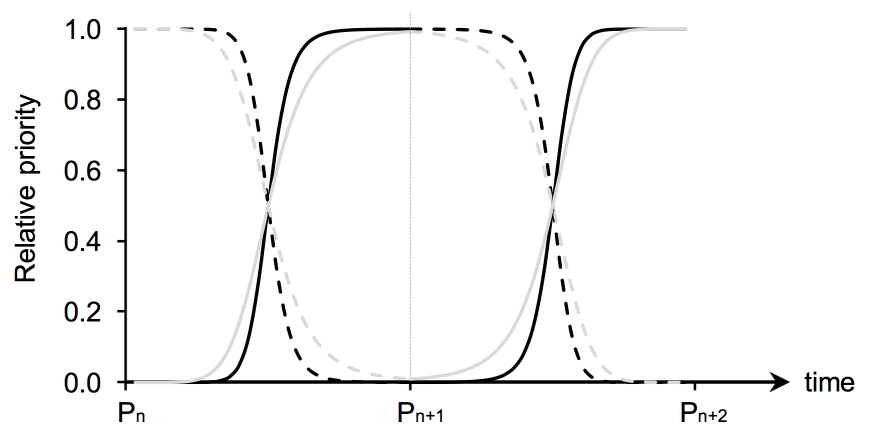

Figure 0.4 Relative priorities between current (litter being nurse; dotted line) and future (litter being gestate; solid line) litters of females selected for litter size at weaning during 36 generations (black line) and during 16 generations (gray line).

Adapted from Savietto et al. (2015)

On the other hand, founding a maternal line (LP) selecting females for functional hyper-longevity under commercial farm conditions (more than 25 reproductive cycles with an average litter size of 8.9 born alive; Sánchez et al., 2008) resulted in unexpected positive side effects. Likewise LP animals perform almost as well as other specialized maternal lines under normal conditions (Theilgaard et al., 2007; Savietto et al., 2013), they were able to better confront productive (Theilgaard et al., 2009), immunological (Ferrian et al., 2013) or environmental challenges (Savietto et al., 2015). Initially, Theilgaard et al. (2007) proposed that the greater robustness of these animals was the consequence of their bigger and more durable soma. However, Savietto et al. (2015) reported that LP animals presented similar energy intake than other maternal females under normal conditions but higher during challenging conditions. Moreover, these animals produced more milk and were less 
dependent of body condition for production in the different environments. They concluded that the greater robustness of LP animals was the consequence of their particular strategy for the acquisition and allocation of resources. Contrary to other maternal animals, they do not prioritize a single function for production, they base production on energy intake while fat reserves are a safety factor (Savietto et al., 2013) having enough resources to afford a highly functional immune system (Ferrian et al., 2012, 2013).

A completely different genetic type is the $\mathrm{R}$ line, which is used as paternal line. Despite the major interest of this line is the feed conversion ratio of growing rabbits (Estany et al., 1992) and the semen quality of bucks (Viudes-de-Castro et al., 1998), there is a certain interest on the reproductive performance of females from this line. The main reasons are; (i) females of this line must raise enough male rabbits reaching to breed to produce the amount of semen required to inseminate the population of the crossbreed females of commercial farms. (ii) If the offspring of a generation is not numerous enough, the response to selection will be unsatisfactory because most of the animals will be selected (high, mean and even low genetic merit). Regarding to reproductive ability of R females, Gómez et al. (1999) showed that these females presented lower litter size than those from maternal lines. In this regard, Cifre et al. (1994) showed that the ovulation rate of animals from the $\mathrm{R}$ line was comparable to that reported from other maternal lines and Vicente et al. (2012) demonstrated that the lower litter size was the consequence of the higher losses during the whole gestation period. Moreover, Piles and Tusell (2012) reported a low to moderate negative genetic correlation between average daily gain and the fertility of the females, which would be in agreement with the long interval between parturitions of females reported for this paternal line (Baselga, 2002). High losses during gestation and lactation and poor fertility are serious reproductive disorders of this line, which could be partly related with the way animals acquire and use resources (Fortun-Lamothe et al., 1999; Cardinali et al., 2008). Therefore, having information related to the way $\mathrm{R}$ females acquire and allocate resources would help to develop suitable strategies for these females. However, the resource acquisition and allocation strategy of $\mathrm{R}$ animals remains almost unexplored.

\section{Statistical approach}

To estimate energy requirements of rabbit females, Xiccato and Trocino (2010) described three methods: long-term feeding experiments, calorimetric methods and the comparative slaughter technique. They also described non-destructive methods for body composition measurement which could be performed in long-term feeding experiments or calorimetric methods to provide information about the changes of body composition over time. As we have stated above, to carry out the described theoretical framework for resource allocation in reproductive rabbit females, we need to perform long-term feeding experiments. 
However, information in this regard is much scarce than information from short-term experiments. This situation is illustrated in Figure 0.5, where the number and the percentage of found references related with energy requirements in function of the number of cycles evaluated in experiments are represented. It can be observed that the percentage of references where one or less than one reproductive cycle were evaluated was more than $50 \%$. Regarding to mid- or long-term experiments, most of them recorded traits related with the energy requirements (or acquisition and allocation of energy) such as feed intake, body weight or litter size and litter weight. Some of them also recorded milk yield or traits related with body condition of females. In general, these traits were recorded several times per reproductive cycle during several reproductive cycles.

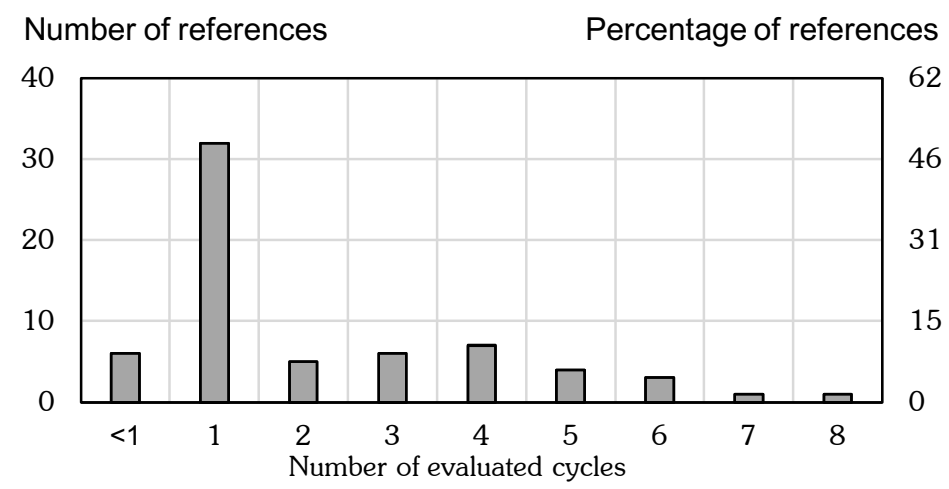

Figure 0.5 Number and percentage of found references ${ }^{1}$ related with energy requirements in function of the number of cycles evaluated in the experiment

When we record a trait several times from the same individual, we are talking about longitudinal studies. Consequently, the study of the dynamics of traits involved in acquisition and allocation of resources is a longitudinal study with longitudinal data. For these kind of data some statistical considerations have to be made related to correlations among data, homocedasticity of data or the distribution of the observations over time (Gibbons et al., 2010). There are two important aspects of the correlation. First, two measures on the same animal are correlated simply because they share common contributions from the animal. This is due to variation between animals. Second, measures on the same animal close in time are often more highly correlated than measures more distant in time. This is covariation within animal (Littell et al., 1998).

\footnotetext{
${ }^{1}$ References obtained making the following search in CAB Direct (www.cabdirect.org): (title:("ener*) OR ab:("ener*)) AND (ab:(diet*) OR ab:(nutrition) OR ab:(feed*)) AND (title:(rabbit* doe*) OR title:(rabbit* female*) OR title:(reprod* rabbit*) OR title:(breeding doe*) OR title:(lacta* rabbit))
} 
In animal science, the most used approaches to cope with longitudinal data were compared by Littell et al. (1998): (i) perform a different analysis at each time point, (ii) univariate ANOVA, (iii) univariate and multivariate analysis of time contrast variables, and (iv) mixed model methodology. They concluded that mixed model methodology was the most suitable approach for this kind of data as it can compute efficient estimates of fixed effects and valid standard errors of the estimates. Each effect on a mixed model analysis must be classified into fixed or random effect. Mixed models split and model (co)variance by modelling random effects. This approach for analysing data allow considering variation between animals, covariation within animal, heterocedasticity of data, differently spaced measures over time, etc. Random effects are modelled by variance components. These variance components define the (co)variance matrix of data.

After 2003, most of the found references for long-term experiments (more than four reproductive cycles) related with the energy requirements used mixed models (Mixed models: Fernández-Carmona et al., 2003; Quevedo et al., 2006a and 2006b; ANOVA: Gerencsér et al., 2011). Nonetheless, those using mixed models considered that observations recorded at different times of the reproductive cycle represented different physiological states and consequently they were studied as different traits that were analysed separately (e.g. female feed intake during lactation and out of lactation or litter weight at parturition and at weaning are considered as different traits). On the contrary, observations recorded from the same physiological state were considered repeated measures of the same trait and consequently they were analysed together in a single trait mixed model (e.g. data from female litter weight at parturition during several reproductive cycles). Although not statistically incorrect, this statistical approach is less efficient than considering together all the recorded information (Hedeker and Gibbons, 2006) (e.g. a single trait for female feed intake or litter weight). For example, as records within a subject are not perfectly correlated, the higher is the number of observations recorded from each subject, the higher is the amount of independent information and thus the higher is the statistical power of the analysis. Moreover, by considering together all the recorded information it is possible to evaluate properly the whole dynamics of the trait. In this sense, it is possible to evaluate the effect of a treatment (e.g. diet, genetics or its combination) over time within the reproductive cycle and over reproductive cycles.

On the other hand, another important advantage of considering together all the recorded information is that we can obtain useful information from modelling properly random effects. We can obtain information regarding to individual variation between animals and their individual trajectories over the reproductive cycle. In this sense, we have showed above that the homeorhetic control of nutrient partitioning defines genetically driven 
trajectories that could vary between individuals. Thus, information regarding to individual variation between animals and their individual trajectories over the reproductive cycle could be related with the homeorhetic control. Moreover, co-variation within an animal represents the way an animal responds to a deviation from its individual trajectory, which could be related with the homeostatic regulation. Thus, it seems that there could be a certain parallelism between variance components estimated with mixed models and the concepts described for nutrient partitioning. Making the parallelism between information provided by mixed models and the concepts involved in nutrient partitioning could be useful to understand how individual animals acquire and allocate resources and how these animals respond to environmental perturbations by adjusting acquisition and allocation of energy. This understanding could be used to explain the results obtained in nutritional studies. However, despite the described advantages of using mixed models in this way, this approach has never been used previously. None study has addressed how to model random effects from mixed models to take into account all the mentioned considerations related to longitudinal data of reproductive females nor the potential of information provided by these models to understand acquisition and allocation of energy of rabbit females. 


\section{Hypothesis and objectives}

If different genetic types, with different requirements, have different priorities for the life functions and if better diets imply ensuring good performance, but also preventing females from functional disorders, we hypothesized that nutritional strategies adapted to the genetic type could help to modulate acquisition and allocation of resources of females in the long term, and balancing functionality without impairing productivity. Therefore, our main objective is to fit nutrition to the genetic type in an overall sense. To reach this goal we planned a long-term experiment during a longish period of the lifetime of a large set of reproductive rabbit females. During the experiment, we monitored traits involved in acquisition and allocation of energy: i) feed intake to evaluate the acquisition capacity of females; ii) perirenal fat thickness to evaluate allocation to body reserves; iii) body weight to evaluate the costs of maintenance; iv) milk yield to evaluate maternal investment during lactation; v) litter weight to evaluate maternal investment during gestation and during lactation. Moreover, we monitored blood metabolites related with energy balance of females and also traits related with productivity (e.g. litter size, kits weaned per year, etc.), functionality and fitness (e.g. conception rate of females, survival rates of females and kits or individual weights of kits). Females belonged to three highly different genetic types, specialised in different goals, that were fed with two isoenergetic and isoprotein diets that differed in the main energy source to promote milk yield or body reserves accretion. For this experiment, we defined four specific objectives corresponding to each one of the works reported in the present thesis:

1. To find the most suitable mixed model for the study of the dynamics of the traits involved in the acquisition and use of energy over the reproductive life trajectory of the rabbit females.

2. To evaluate how individual rabbit females acquire and use energy in the long term. To reach this goal we aimed to find out the relation between information provided by mixed models (variation between animals, covariation within an animal and individual solution of random effects) and the concepts involved in nutrient partitioning (homeorhetic control and homeostatic regulation).

3. To evaluate how the three different genetic types acquired and used energy in the long term and how energy source of diet could modulate it.

4. To evaluate long term productivity and fitness of the three different genetic types and the effect of energy source of the diet on them. 


\section{References}

Baselga M 2002. Line R (Spain). In Rabbit genetic resources in Mediterranean countries (ed. Khalil MH, Baselga M), pp. 257-262. Zaragoza: Ciheam (Options Méditerranéennes: Série B. Etudes et Recherches; n. 38), Zaragoza, Spain.

Baselga M 2004. Genetic improvement of meat rabbits. Programmes and diffusion. Proceedings of the 8th World Rabbit Congress, September 2004, Puebla, Mexico, pp. $1-13$.

Bauman DE and Currie WB 1980. Partitioning of nutrients during pregnancy and lactation: a review of mechanisms Involving homeostasis and homeorhesis. Journal of Dairy Science 63, 1514-1529.

Beilharz RG 1998. Environmental limit to genetic change. An alternative theorem of natural selection. Journal of Animal Breeding and Genetics 115, 433-437.

Beilharz RG, Luxford BG and Wilkinson JL 1993. Quantitative genetics and evolution: Is our understanding of genetics sufficient to explain evolution? Journal of Animal Breeding and Genetics 110, 161-170.

Blasco A, Bidanel JP, Bolet G, Haley CS and Santacreu MA 1993. The genetics of prenatal survival of pigs and rabbits: a review. Livestock Production Science 37, 1-21.

Blasco A, Martínez-Álvaro M, García M-L, Ibáñez-Escriche N and Argente M-J 2017. Selection for environmental variance of litter size in rabbits. Genetics Selection Evolution 49, 48.

Braine A and Coutelet G 2012. Economie de la filière cunicole française: Situation à l'automne 2012. Cuniculture 39,67-74.

Cardinali R, Dal Bosco A, Bonanno A, Di Grigoli A, Rebollar PG, Lorenzo PL and Castellini C 2008. Connection between body condition score, chemical characteristics of body and reproductive traits of rabbit does. Livestock Science 116, 209-215.

Castellini C, Dal Bosco A, Arias-Álvarez M, Lorenzo PL, Cardinali R and Rebollar PG 2010. The main factors affecting the reproductive performance of rabbit does: a review. Animal Reproduction Science 122, 174-182.

Cifre J, Vicente JS, Baselga M and García-Ximénez F 1994. Ovulation rate in lines of rabbits selected on different criteria. In Rabbit production in hot climates (ed. Baselga M, Marai IFM), pp. 247-251. Zaragoza: Ciheam (Cahiers Options Méditerranéennes; n.8), Zaragoza, Spain.

Cifre J, Baselga M, García-Ximénez F and Vicente JS 1998. Performance of a hyperprolific rabbit line I. Litter size traits. Journal of Animal Breeding and Genetics 115, 131-138.

Council of Dairy Cattle Breeding (CDCB) 2016. Trend in milk BV for Holstein or Red \& white. Retrieved on 29 December 2017, from http://www.cdcb.us/eval/summary/trend.cfm

EL Nagar AG 2015. Genetic analysis of longevity in specialized lines of rabbits. PhD thesis, Universidad Politécnica de Valencia, Valencia, Spain.

Estany J, Camacho J, Baselga M and Blasco A 1992. Selection response of growth rate in rabbits for meat production. Genetics Selection Evolution 24, 527-537. 
Falconer DS and Mackay TFC 1996. Introduction to quantitative genetics, 4th edition. Longman, Essex, England.

Fernández-Carmona J, Alqedra I, Cervera C, Moya VJ and Pascual JJ 2003. Effect of lucerne-based diets on performance of reproductive rabbit does at two temperatures. Animal Science 76, 283-295.

Ferrian S, Guerrero I, Blas E, García-Diego FJ, Viana D, Pascual JJ and Corpa JM 2012. selection for reproduction or foundation for longevity could have affected blood lymphocyte populations of rabbit does under conventional and heat stress conditions. Veterinary Immunology and Immunopathology 150, 53-60.

Ferrian S, Blas E, Larsen T, Sánchez JP, Friggens NC, Corpa JM, Baselga M and Pascual JJ 2013. Comparison of immune response to lipopolysaccharide of rabbit does selected for litter size at weaning or founded for reproductive longevity. Research in Veterinary Science 94, 518-25.

Fix JS, Cassady JP, van Heugten E, Hanson DJ and See MT 2010. Differences in lean growth performance of pigs sampled from 1980 and 2005 commercial swine fed 1980 and 2005 representative feeding programs. Livestock Science 128, 108-114.

Forbes JM 2007. Voluntary food intake and diet selection in farm animals, 2nd edition. CABI Publishing, Wallingford, UK.

Fortun-Lamothe L 2006. Energy balance and reproductive performance in rabbit does. Animal Reproduction Science 93, 1-15.

Fortun-Lamothe L and Lebas F 1996. Effects of dietary energy level and source on foetal development and energy balance in concurrently pregnant and lactating primiparous rabbit does. Animal Science 62, 615-620.

Fortun-Lamothe L, Prunier A, Bolet G and Lebas F 1999. Physiological mechanisms involved in the effects of concurrent pregnancy and lactation on foetal growth and mortality in the rabbit. Livestock Production Science 60, 229-241.

Frayn KN 1998. Características metabólicas de los órganos y tejidos. In Regulación del metabolismo: Una perspectiva humana, pp. 53-92. Ediciones Omega, S.A., Barcelona, Spain.

Friggens NC 2003. Body lipid reserves and the reproductive cycle: towards a better understanding. Livestock Production Science 83, 219-236.

Friggens NC and Newbold JR 2007. Towards a biological basis for predicting nutrient partitioning: the dairy cow as an example. Animal 1, 87-97.

Friggens NC and Van der Waaij EH 2009. Modelling of Resources Allocation Patterns. In Resource allocation theory applied to farm animal production (ed. Rauw WM), pp. 302-320. CABI Publishing, Wallingford, UK.

Friggens NC, Brun-Lafleur L, Faverdin P, Sauvant D and Martin O 2013. Advances in predicting nutrient partitioning in the dairy cow: recognizing the central role of genotype and its expression through time. Animal 7, 89-101.

Gerencsér Zs, Matics Zs, Nagy I and Szendrö Zs 2011. Effect of feeding program before weaning on the production of rabbit does and their kits. World Rabbit Science 19, 217-223. 
Gibbons RD, Hedeker D and DuToit S 2010. Advances in analysis of longitudinal data. Annual Review of Clinical Psychology 6, 79-107.

Gómez EA, Baselga M and Rafel O 1999. Selection, diffusion and performances of six Spanish lines of meat rabbit. Cahiers Options Méditérranéennes 41, 147-152.

Havenstein GB, Ferket PR and Qureshi M a 2003. Growth, livability, and feed conversion of 1957 versus 2001 broilers when fed representative 1957 and 2001 broiler diets. Poultry Science 82, 1500-1508.

Hedeker D and Gibbons RD 2006. Introduction. In Longitudinal data analysis, pp. 1-12. John Willey \& Sons, Chicago, USA.

Henneberg W and Stohmann F 1859. Über das erhaltungsfutter volljährigen rindviehs. J. Landwirtsch 3, 485-551.

Hill WG 2008. Estimation, effectiveness and opportunities of long term genetic improvement in animals and maize. Lohmann Information 43, 3-20.

Hocking PM 2014. Unexpected consequences of genetic selection in broilers and turkeys: problems and solutions. British Poultry Science 55, 1-12.

Ibáñez N, Santacreu MA, Martinez M, Climent A and Blasco A 2006. Selection for ovulation rate in rabbits. Livestock Science 101, 126-133.

Ingvartsen KL 2006. Feeding-and management-related diseases in the transition cow Physiological adaptations around calving and strategies to reduce feeding-related diseases. Animal Feed Science and Technology 126, 175-213.

Jones DR, Anderson KE and Davis GS 2001. The effects of genetic selection on production parameters of single comb White Leghorn hens. Poultry Science 80, 1139-1143.

Kennedy GC 1953. The role of depot fat in the hypothalamic control of food intake in the rat. Proceedings of the Royal Society of London B: Biological Sciences 140, 578-592.

Khalil MH and Al-Saef AM 2008. Methods, criteria, techniques and genetic responses for rabbit selection: A review. Proceedings of the 9th World Rabbit Congress, 10 June 2008, Verona, Italy, pp. 1-22.

Knap PW and Su G 2008. Genotype by environment interaction for litter size in pigs as quantified by reaction norms analysis. Animal 2, 1742-1247.

Kolmodin R, Strandberg E, Jorjani H and Danell B 2003. Selection in the presence of a genotype by environment interaction: response in environmental sensitivity. Animal Science 76, 375-385.

Lebas F and Fortun-Lamothe L 1996. Effects of dietary energy level and origin (starch vs oil) on the performance of rabbits does and their litters: average situation after 4 weanings. Proceedings of the 6th World Rabbit Congress, 9 July 1996, Toulouse, France, pp. 217-221.

Littell RC, Henry PR and Ammerman CB 1998. Statistical analysis of repeated measures data using SAS procedures. Journal of Animal Science 76, 1216-31.

Lukefahr SD, Odi HB and Atakora JKA 1996. Mass selection for 70-day body weight in rabbits. Journal of Animal Science 74, 1481-1489.

Maertens L, Lebas F and Szendro Z 2006. Rabbit milk: A review of quantity, quality and non- 
dietary affecting factors. World Rabbit Science 14, 205-230.

Martin O and Sauvant D 2010. A teleonomic model describing performance (body, milk and intake) during growth and over repeated reproductive cycles throughout the lifespan of dairy cattle. 1. Trajectories of life function priorities and genetic scaling. Animal 4, 2030-2047.

McDonald P, Edwards RA, Greenhalgh JFD, Morgan CA, Sinclair LA and Wilkinson RG 2011. Animal nutrition, 7th edition. Pearson, Harlow, United Kingdom.

Merks JWM 2000. One century of genetic changes in pigs and the future needs. BSAS Occasional Publication 27, 8-19.

Mínguez C, Sanchez JP, EL Nagar AG, Ragab M and Baselga M 2015. Growth traits of four maternal lines of rabbits founded on different criteria: comparisons at foundation and at last periods after selection. Journal of Animal Breeding and Genetics, 1-13.

Neeteson-van Nieuwenhoven A-M, Knap P and Avendano S 2013. The role of sustainable commercial pig and poultry breeding for food security. Animal Frontiers 3, 52-57.

Pascual JJ 2010. The role of body condition on new feeding and breeding programmes for reproductive rabbit does. Proceedings of the 22nd Hungarian Conference on Rabbit Production, 1-21.

Pascual JJ, Cervera C, Blas E and Fernández Carmona J 1999. Effect of high fat diets on the performance, milk yield and milk composition of multiparous rabbit does. Animal Science 68, 151-162.

Pascual JJ, Motta W, Cervera C, Quevedo F, Blas E and Fernández-Carmona J 2002. Effect of dietary energy source on the performance and perirenal fat thickness evolution of primiparous rabbit does. Animal Science 75, 267-279.

Pascual JJ, Cervera C, Blas E and Fernández-Carmona J 2003. High-energy diets for reproductive rabbit does: effect of energy source. Nutrition Abstracts and Reviews 73, 27R-39R.

Pascual JJ, Savietto D, Cervera C and Baselga M 2013. Resources allocation in reproductive rabbit does: a review of feeding and genetic strategies for suitable performance. World Rabbit Science 21, 123-144.

Pavlidis HO, Balog JM, Stamps LK, Hughes Jr. JD, Huff WE and Anthony NB 2007. Divergent selection for ascites incidence in chickens. Poultry Science 86, 2517-2529.

Piles M and Tusell L 2012. Genetic correlation between growth and female and male contributions to fertility in rabbit. Journal of Animal Breeding and Genetics 129, 298305.

Piles M, Gomez EA, Rafel O, Ramon J and Blasco A 2004. Elliptical selection experiment for the estimation of genetic parameters of the growth rate and feed conversion ratio in rabbits. Journal of Animal Science 82, 654-660.

Poppi DP, Gill M and France J 1994. Integration of theories of intake regulation in growing ruminants. Journal of Theoretical Biology 167, 129-145.

Puillet L, Réale D and Friggens NC 2016. Disentangling the relative roles of resource acquisition and allocation on animal feed efficiency: insights from a dairy cow model. Genetics Selection Evolution 48, 72. 
Quevedo F, Cervera C, Blas E, Baselga M and Pascual JJ 2006. Long-term effect of selection for litter size and feeding programme on the performance of reproductive rabbit does 1. Pregnancy of multiparous does. Animal Science 82, 739-750.

Quevedo F, Cervera C, Blas E, Baselga M and Pascual JJ 2006. Long-term effect of selection for litter size and feeding programme on the performance of reproductive rabbit does 2. Lactation and growing period. Animal Science 82, 751-762.

Rauw WM (ed.) 2009. Resource allocation theory applied to farm animal production. CABI Publishing, Wallingford, UK.

Rauw WM, Kanis E, Noordhuizen-Stassen EN and Grommers F. 1998. Undesirable side effects of selection for high production efficiency in farm animals: a review. Livestock Production Science 56, 15-33.

Roche JR, Friggens NC, Kay JK, Fisher MW, Stafford KJ and Berry DP 2009. Invited review: Body condition score and its association with dairy cow productivity, health, and welfare. Journal of Dairy Science 92, 5769-5801.

Roff DA and Fairbairn DJ 2007. The evolution of trade-offs: Where are we? Journal of Evolutionary Biology 20, 433-447.

Rosell JM and de la Fuente LF 2009. Culling and mortality in breeding rabbits. Preventive Veterinary Medicine 88, 120-127.

Sánchez JP, Theilgaard P, Mínguez C and Baselga M 2008. Constitution and evaluation of a long-lived productive rabbit line. Journal of Animal Science 86, 515-525.

Sánchez JP, de la Fuente LF and Rosell JM 2012. Health and body condition of lactating females on rabbit farms. Journal of Animal Science 90, 2353-2361.

Santacreu MA, Mocé ML, Climent A and Blasco A 2005. Divergent selection for uterine capacity in rabbits. II . Correlated response in litter size and its components estimated with a cryopreserved control population. Journal of Animal Science 83, 2303-2307.

Savietto D 2014. Environmental and genetic factors driving robustness in reproductive rabbit does. PhD thesis, Universidad Politécnica de Valencia, Valencia, Spain.

Savietto D, Cervera C, Blas E, Baselga M, Larsen T, Friggens NC and Pascual JJ 2013. Environmental sensitivity differs between rabbit lines selected for reproductive intensity and longevity. Animal 7, 1969-1977.

Savietto D, Friggens NC and Pascual JJ 2015. Reproductive robustness differs between generalist and specialist maternal rabbit lines: the role of acquisition and allocation of resources. Genetics Selection Evolution 47, 2.

Stearns SC 1992. Trade-offs. In The evolution of life histories, pp. 72-90. Oxford University Press., Oxford.

Strandberg E, Groen AF and Sölkner J 1996. General introduction. Proceedings of the International workshop on genetic improvement of functional traits in cattle, January 1996, Gembloux, Belgium, pp. 5-10.

Theilgaard P, Sánchez JP, Pascual JJ, Friggens NC and Baselga M 2006. Effect of body fatness and selection for prolificacy on survival of rabbit does assessed using a cryopreserved control population. Livestock Science 103, 65-73.

Theilgaard P, Sánchez JP, Pascual JJ, Berg P, Friggens NC and Baselga M 2007. Late 
reproductive senescence in a rabbit line hyper selected for reproductive longevity, and its association with body reserves. Genetics Selection Evolution 39, 207-223.

Theilgaard P, Baselga M, Blas E, Friggens NC, Cervera C and Pascual JJ 2009. Differences in productive robustness in rabbits selected for reproductive longevity or litter size. Animal 3, 637-646.

Van Noordwijk AJ and De Jong G 1986. Acquisition and allocation of resources: Their influence on variation in life history tactics. The American Naturalist 128, 137-142.

Van Soest PJ, Robertson JB and Lewis BA 1991. Methods for dietary fiber, neutral detergent fiber, and nonstarch polysaccharides in relation to animal nutrition. Journal of Dairy Science 74, 3583-3597.

VanRaden PM and Cole JB 2014. Net merit as a measure of lifetime profit: 2014 revision. Retrieved on 29 December 2017, from http://aipl.arsusda.gov/reference/nmcalc2014.htm - VanRaden04

Veerkamp RF, Windig JJ, Claus MPL, Ouweltjes W, De Haas Y and Beerda B 2009. Selection for high production in dairy cattle. In Resource allocation theory applied to farm animal production (ed. Rauw WM), pp. 243-260. CABI Publishing, Wallingford, UK.

Vicente JS, Llobat L, Viudes-de-Castro MP, Lavara R, Baselga M and Marco-Jiménez F 2012. Gestational losses in a rabbit line selected for growth rate. Theriogenology 77, 81-88.

Viudes-de-Castro MP, Vicente JS, Lavara R and Lavara F 1998. Efficacité de l'insémination artificielle avec un faible nombre de spermatozoïdes dans des élevages commerciaux. Proceedings of the 7èmes Journées de la Recherche Cunicole, 1998, Lyon, France, pp. 241-243.

Wideman RF, Rhoads DD, Erf GF and Anthony NB 2013. Pulmonary arterial hypertension (ascites syndrome) in broilers: A review. Poultry Science 92, 64-83.

Xiccato G 1996. Nutrition of lactation does. Proceedings of the 6th World Rabbit Congress, 1996, Touluse, France, pp. 29-47.

Xiccato G and Trocino A 2010. Energy and protein metabolism and requirements. In Nutrition of the Rabbit, 2nd edition (ed. De Blas JC, Wiseman J), pp. 83-118. CABI Publishing, Wallingford, UK.

Xiccato G, Parigi-Bini R, Zotte DA, Carazzolo A and Cossu ME 1995. Effect of dietary energy level, addition of fat and physiological state on performance and energy balance of lactating and pregnant rabbit does. Animal Science 61, 387-398. 



\title{
PAPER I
}

\section{Accounting for (co)variance structure of longitudinal data from traits associated to productive performance in reproductive rabbit females: Model fitting and performance}

\author{
Arnau-Bonachera $\mathrm{A}^{1}$, Piles $\mathrm{M}^{2}$, Pascual $\mathrm{JJ}^{1}$ \\ ${ }^{1}$ Institute for Animal Science and Technology, Universitat Politècnica de València, Camino \\ de Vera, s/n. 46071 Valencia, Spain. \\ ${ }^{2}$ Institute for Food and Agriculture Research and Technology, Torre Marimon s/n, 08140 \\ Caldes de Montbui, Barcelona, Spain.
}

Submitted to World Rabbit Science

on December 2016 



\begin{abstract}
The study of the evolution of performance traits over time in reproductive rabbit females usually involves a few records per cycle during several reproductive cycles (such as feed intake, milk yield, body weight or body condition). The longitudinal study of this kind of data has to deal with some data features: (i) distribution of the observations over time; (ii) levels of correlation (i.e. the number of sources of variation); (iii) evolution of variance with time; (iv) time dependence of correlations. These features lead to specific (co)variance structures for each trait that must be taken into account in the analysis in order to have a suitable model fit to data as well as accurate predictions. This research aimed to compare the performance of several models in terms of goodness of fit for the analysis of longitudinal data of feed intake, female body weight, milk yield, perirenal fat thickness and litter weight. Akaike's information criterion was computed for each of three groups of models differing in the sources of variation included: i) residual variation only; ii) residual plus individual variation (permanent effect of the females); iii) residual, individual and variation associated with different reproductive cycles. In each group, several models were tested, which differed in the (co) variances structure for each factor of variation. For feed intake, milk yield and especially litter weight, phenotypic variance changed over time, especially within the reproductive cycle. The permanent effect of the female was relevant for all the traits. In general, phenotypic correlations tended to decrease as the lag between observations increased. However, much more complex patterns of correlations for feed intake and body weight were observed. None of the tested models was the best in terms of goodness of fit to the data for all traits, but it seems that models in which (co)variance structure was modelled in blocks of (co)variances for each reproductive cycle could be the most recommendable.
\end{abstract}

Key words: Random effect, mixed model, character process. 



\section{Introduction}

In rabbits, as in other domestic mammals, energy balance of females and its evolution over time are involved in many important traits related to reproduction, health or lifespan (Fortun-Lamothe, 2006; Castellini et al., 2010; Pascual et al., 2013). For this reason, in several studies from different fields of research (nutrition, management, reproduction or behaviour), traits reflecting energy balance of females are controlled at different points of their reproductive career (e.g. feed intake, body weight, body condition, milk yield, etc.). This kind of studies produces sets of longitudinal data, which have two key properties that distinguish them from other sorts of data: (i) groups of observations coming from the same source (e.g. the female or the cycle within female) are not independent; (ii) repeated measures are related to a continuous or to an ordered discrete variable (usually time) where consecutive measurements are usually more similar than more distant measures. Both characteristics lead to particular structures of (co)variances among the longitudinal data which must be taken into account in order to avoid biases in the estimated parameters and wrong conclusions.

There are several approaches to cope with the analysis of longitudinal data, but it seems that including all the recorded data from a trait into a single mixed model analysis provides some benefits (Hedeker and Gibbons, 2006a): (a) by improving the statistical power (as records within a subject are not perfectly correlated, repeated measures from a subject increase the amount of independent information); (b) by separating changes over time within individuals from differences between subjects and allowing their study; (c) by allowing the analysis of the effect of different treatments on a trait over the entire lifespan of the female.

In order to choose the most suitable model for the analysis of female longitudinal data, it is important to evaluate the following data features (Gibbons et al., 2010); (i) distribution of the observations: whether they are homogeneously or heterogeneously distributed over time; (ii) levels of correlation (i.e. the number of sources of variation): whether variation is due to differences between females, due to differences among cycles within a female or a combination of both; (iii) evolution of variance: whether it is constant or changes with time; (iv) evolution of covariance among records: whether they depend on the time lag or not.

The aim of this work was to evaluate different models for the analysis of several traits related to the energy balance of females that differ in the way they take into account the data structure of (co)variances. 


\section{Materials and methods}

The experimental procedure was approved by the animal welfare ethics committee of the Universitat Politècnica de València (UPV) and carried out following the Spanish Royal Decree 53/2013 on the protection of animals used for scientific purposes, as well as the European Group on Rabbit Nutrition (Fernández-Carmona et al., 2005).

\section{Animals and experimental procedure}

The experiment involved 203 rabbit females with a total of 758 lactations corresponding to their five first reproductive cycles. They came from three selection lines (genetic types, GT) of the Institute for Animal Science and Technology of Universitat Politècnica de València, which differed greatly in their breeding goals [R $(n=70), H(n=66)$, LP ( $\mathrm{n}$ = 67); see Estany et al. (1992), Cifre et al. (1998) and Sánchez et al. (2008) for details]. The experiment was performed at the farm of this Institute, which has an isolated roof and walls to avoid extreme temperatures in the farm (mean temperature ranged from 13 to 23 ${ }^{\circ} \mathrm{C}$ ), with a photoperiod of $16 \mathrm{~h}$ light/d. Females were individually housed in cages $(70 \times 50 \times 32 \mathrm{~cm})$ provided with a nest for litters from day $28^{\text {th }}$ of gestation.

Females were inseminated for the first time at 19 weeks of age and later followed a semi-intensive reproductive rhythm, being inseminated 11 days post-partum. When they did not get pregnant, they were re-inseminated every $21 \mathrm{~d}$ until a maximum of 3 consecutive negative attempts. Litters were standardised at birth to 8 kits in the first parturition and later on between 9 and 11 kits. Weaning was performed at day $30^{\text {th }}$ of lactation. At first parturition, females were randomly assigned to one of two feeding groups within line for the whole experimental period. Those groups differed in the kind of diet, formulated according to the recommendations of (De Blas and Mateos, 2010) for reproductive rabbit females. Diets were designed to be isoenergetic and isoproteic (11.3 MJ of digestible energy per kg of dry matter and $117 \mathrm{~g}$ of digestible protein per $\mathrm{kg}$ of dry matter; DM), but enhancing major differences in energy source. Diet CS was prepared promoting cereal starch [237 $\mathrm{g}$ of starch and $21 \mathrm{~g}$ of ether extract (EE) per kg DM], whereas in diet AF part of starch was replaced by animal fat (105 $\mathrm{g}$ of starch and $86 \mathrm{~g}$ of EE per kg DM).

\section{Traits and data}

Five traits were monitored during the experiment: Feed intake; Body weight; Perirenal fat thickness (PFT); Milk yield; Litter weight. For each female, each trait was recorded three times per cycle during five consecutive reproductive cycles. Consequently, for females reaching the end of the experiment, a maximum of fifteen observations were recorded. However, due to mortality of females (average survival rate at the end of the 
experiment $48 \%$ aprox), mortality of some litters and few missing data, many females presented less than 15 records for one or more traits. Cumulated feed intake (1974 records) was recorded during early lactation ( $\mathrm{EL}$, from parturition to day $18^{\text {th }}$ of lactation; $18 \mathrm{~d}$ ), late lactation (LL, from 18d to weaning) and weaning to parturition interval (WPI). At LL, feed intake corresponded to feed consumed also by the kits, which start to eat solid feed from around $21 \mathrm{~d}$ of age. Body weight (2079 records) and PFT (2071 records) were recorded at parturition, 18d and weaning. PFT was recorded according to Pascual et al. (2004). Milk yield (2068 records) was evaluated weekly during the first 3 weeks of lactation (until 18d) as the average of four measures per week. Daily milk yield was measured by weighing the female before and after suckling (Lebas, 1968). Litter weight (2082 records) was recorded at birth, $18 \mathrm{~d}$ and weaning. Means and number of records per state are presented in Table 1.1

Table 1.1 Means and number of records for traits conditioning acquisition and partition of energy at different states of the reproductive rabbit female cycle.

\begin{tabular}{|c|c|c|c|}
\hline & \multicolumn{3}{|c|}{ State $^{1}$} \\
\hline & State 1 & State 2 & State 3 \\
\hline \multicolumn{4}{|l|}{ Number of records } \\
\hline Feed intake (g DM/day) & 673 & 658 & 643 \\
\hline Body weight (kg) & 749 & 677 & 653 \\
\hline Perirenal fat thickness $(\mathrm{mm})$ & 745 & 676 & 650 \\
\hline Milk yield (g/day) & 705 & 689 & 674 \\
\hline Litter weight (kg) & 756 & 668 & 658 \\
\hline \multicolumn{4}{|l|}{ Means } \\
\hline Feed intake (g DM/day) & 298 & 400 & 176 \\
\hline Body weight (kg) & 4.28 & 4.45 & 4.67 \\
\hline Perirenal fat thickness $(\mathrm{mm})$ & 7.14 & 7.64 & 7.50 \\
\hline Milk yield (g/day) & 106 & 187 & 225 \\
\hline Litter weight (kg) & 0.52 & 2.23 & 4.29 \\
\hline \multicolumn{4}{|c|}{$\begin{array}{l}\text { DM: Dry Matter. }{ }^{1} \text { State of the reproductive cycle: [For feed intake: early lactation (State 1), } \\
\text { late lacation (female+litter) (State 2) and weaning to parturition interval (State 3)]; [For body } \\
\text { weight and perirenal fat thickness: parturition (State 1), day 18th of lactation (State 2) and } \\
\text { weaning (State 3)]; [For milk yield: first week of lactation (State 1), second week (State 2) and } \\
\text { third week (State 3)]; [For litter weight: total born (State 1), at day 18th of lactation (State 2) } \\
\text { and weaning (State 3)]. }\end{array}$} \\
\hline
\end{tabular}

\section{Statistical analysis}

Data coming from a single trait were analysed together in a unique longitudinal data analysis, but data from different traits were analysed separately. From the existing approaches to analyse longitudinal data, character process models (Jaffrézic and Pletcher, 2000; David et al., 2015), also named as covariance pattern models (Hedeker and Gibbons, 2006b), and random regression models have been widely used in animal science in recent 
years (Schaeffer, 2004; Speidel et al., 2010). Character process models attempt to model the distribution of data by estimating every component of the (co)variance structures at each time point, not assuming any trends for the trajectories of individuals. On the other hand, random regression models (RRM) estimate the parameters that define individual trajectories over time (with linear, polynomial or non-linear functions). RRM are used when there is interest in predicting the trait at any time point or in knowing individual values of the parameters of the curve defining the longitudinal trajectory over time and the effect of some factor on them. These models do not require the number of records per individual to be constant or the records from different individuals to be measured at the same time points. They have been widely used for modelling within cycle observations (lactation curve in dairy cattle, Schaeffer, 2004, or rabbit females, Bakr et al., 2015), generally using non-linear models (Blasco et al., 2003).

In the present study, time was considered as a discrete covariate because there were insufficient records in each reproductive cycle to perform RRM properly. Moreover, the objective of analysis was not the prediction of performance at some point of the longitudinal trajectory differing from the studied ones, or to consider changes in parameters of any curve. Therefore, only character process models were considered for all the analysed traits. The levels of time (as a discrete covariate) resulted from the combination of the state within the reproductive cycle ( 3 levels defined in a different way depending on the trait as described above) and order of reproductive cycle.

In matrix notation, the general equation of mixed models used in this work could be written as:

$$
\mathbf{y}=X \boldsymbol{\beta}+\mathbf{Z}_{1} \mathbf{p}+\mathbf{Z}_{2} \mathbf{c}+\varepsilon
$$

, where $\mathrm{y}$ is the vector of observations; $\beta$ is the unknown vector of effects at each level of the fixed factors and $\mathrm{X}$ is its known design matrix. All the models included as fixed effects the factors genetic type (3 levels; H, LP, R), diet (2 levels; AF, CS) and time of recording (15 levels: 3 records/cycle $x 5$ cycles) and their interactions. The linear regression of the trait value on the inner temperature of the farm was also considered as fixed effect. Moreover, as not all the females got pregnant at first attempt and there are differences in resource allocation of exclusively lactating females compared to females that concurrently are pregnant and lactating, we considered these phenomena in the models with dummy variables. This dummy variables considered that the female could be pregnant or not during lactation (2 levels; pregnant, non-pregnant) or lactating or not during gestation (2 levels; lactating, non-lactating). Finally, these variables were also included as fixed effects, allowing its effects being different for each state within RC. Regarding to random effects, $\mathrm{p}$ and $\mathrm{c}$ are the unknown vector of effects at each level of the permanent effects of female and 
reproductive cycle within female, respectively, with known incidence matrices $Z_{1}$ and $Z_{2}$, respectively; $\boldsymbol{\varepsilon}$ is the vector of random residuals. Mixed models assume that $\mathrm{p}, \mathrm{c}$ and $\boldsymbol{\varepsilon}$ are normally and independently distributed with:

$$
\mathrm{E}\left[\begin{array}{l}
\mathbf{p} \\
\mathbf{c} \\
\boldsymbol{\varepsilon}
\end{array}\right]=\left[\begin{array}{l}
\mathbf{0} \\
\mathbf{0} \\
\mathbf{0}
\end{array}\right] \quad \text { and } \quad \operatorname{Var}\left[\begin{array}{l}
\mathbf{p} \\
\mathbf{c} \\
\boldsymbol{\varepsilon}
\end{array}\right]=\left[\begin{array}{lll}
\mathbf{P} & \mathbf{0} & \mathbf{0} \\
\mathbf{0} & \mathbf{C} & \mathbf{0} \\
\mathbf{0} & \mathbf{0} & \mathbf{R}
\end{array}\right]
$$

, where $\mathrm{P}, \mathrm{C}$ and $\mathrm{R}$ are the (co)variance matrices of the random effects of female, reproductive cycle, and the random residuals, respectively. Consequently, the variance of $\mathrm{y}$ is $\mathrm{V}=\mathrm{Z}_{1} \mathrm{PZ} \mathrm{Z}_{1}{ }^{\prime}+\mathrm{Z}_{2} \mathrm{CZ}_{2}{ }^{\prime}+\mathrm{R}$, where $\mathrm{Z}_{1} \mathrm{PZ}_{1}{ }^{\prime}$ is the (co)variance matrix associated to the permanent effects of the female, $Z_{2} \mathrm{CZ}_{2}{ }^{\prime}$ is the (co)variance matrix associated to the permanent effects of the reproductive cycle within female, and $\mathrm{R}$ to the residuals. If there are $\mathrm{N}$ records of a given trait coming from $\mathrm{m}$ subjects with $\mathrm{n}$ observations per subject, $\mathrm{V}$ and its components $\mathrm{Z}_{1} \mathrm{PZ}_{1}$, $\mathrm{Z}_{2} \mathrm{CZ}_{2}{ }^{\prime}$ and $\mathrm{R}$ are matrices of dimension $\mathrm{N} \times \mathrm{N}$. As we used the character process approach for the study of longitudinal data with mixed models (Jaffrézic and Pletcher, 2000; David et al., 2015), we dealt with the modelling of $\mathrm{V}$ and its components $\mathrm{Z}_{1} \mathrm{PZ}_{1}, \mathrm{Z}_{2} \mathrm{CZ}_{2}$, and $\mathrm{R}$. However, if no relation is assumed among subjects, $\mathrm{V}$ and its component matrices can be split into $m$ identical blocks of $n \times n$ dimension ( $m$ being the number of females and $n$ the number of records per female), reducing the modelling problem to these individual blocks.

Three different groups of character process models were defined according to the sources of variation they account for: i) Group 1, models where there is only residual variation; ii) Group 2, models where, in addition to residual variation, there is also variation due to differences between females; iii) Group 3, models that also include the random effect of reproductive cycle within female as a source of variation. Within each of these groups, different models were defined according to the (co)variance structure among records at different time points for a given random effect. Table 1.2 shows the main characteristics of the models evaluated for each trait. Details about them and scripts for the analysis using SAS software can be found in Supplementary material of Paper I at the end of the document.

In the first group, the following models were tested which differ in the (co)variance structure of the $\mathrm{m}$ blocks of $\mathrm{n} \times \mathrm{n}$ dimension for model errors:

1. Unstructured model (UNST). This was the most parameterised structure, as it assumes no pattern over time for variances or correlations. Therefore, it depended on 120 parameters in our study.

2. Diagonal model (DIAG). It assumes that the error variance is constant at any time (i.e. homoscedastic) and no correlation exists between successive measurements of the trait. It depended on just one parameter. 


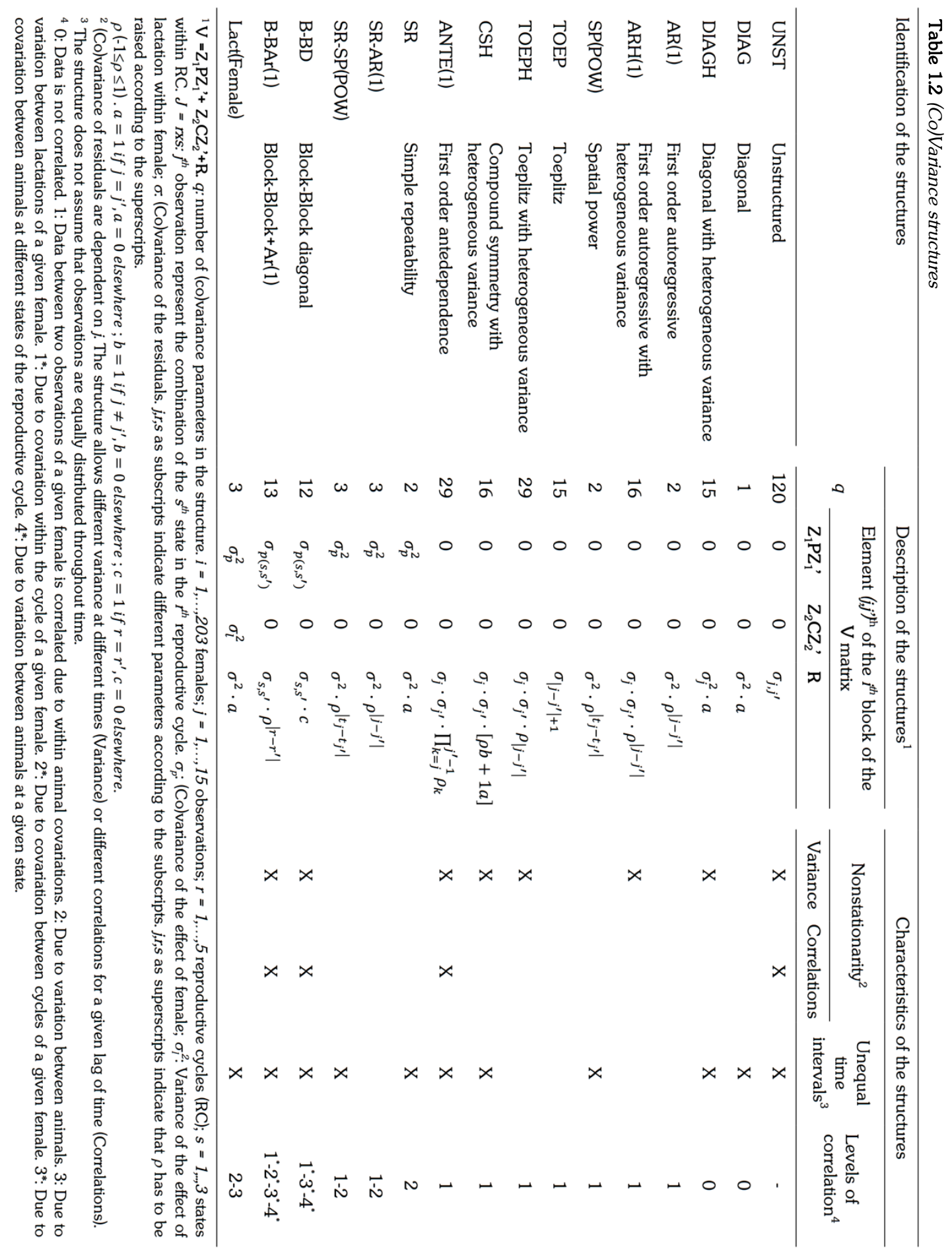


3. Diagonal with heteroscedastic variance (DIAGH). It assumes that error variance is different at different time points but, like DIAG, successive measurements of the trait are independent. Therefore, it required the estimation of 15 parameters.

4. First order autoregressive model [AR(1)]. It is assumed that error variance is homoscedastic and that the correlation between successive data decreases exponentially across the lags of the time points. Thus, the covariance between successive measurements $\left(j\right.$ and $\left.j^{\prime}\right)$ is defined as:

$$
\sigma_{j, j^{\prime}}=\sigma^{2} \cdot \rho^{\left|j-j^{\prime}\right|}
$$

, where $\sigma^{2}$ is the error variance and $\rho$ is the correlation of adjacent points. Therefore, this model depended on just 2 parameters.

5. First order autoregressive with heterogeneous variance model [ARH(1)]. This was defined like the $\mathrm{AR}(1)$ model, but here the error variance was assumed to be heteroscedastic (i.e. heterogeneous over time). Therefore, it depended on 16 parameters, from which the covariance between two measures was defined as:

$$
\sigma_{j, j^{\prime}}=\sigma_{j} \cdot \sigma_{j \prime} \cdot \rho^{\left|j-j^{\prime}\right|}
$$

6. Spatial power model (SP(POW)). Like AR(1), it assumed homoscedastic variances and decreasing correlations with increasing time lag. However, whereas AR(1) considered that observations within a subject are distributed homogeneously over time, SP(POW) allowed the use of differently spaced observations. It also depended on 2 parameters, from which the covariance between two measures was defined as:

$$
\sigma_{j, j^{\prime}}=\sigma^{2} \cdot \rho^{\left|t_{j}-t_{j \prime}\right|}
$$

, where $\mathrm{t}_{\mathrm{j}}$ is the time in days at the $\mathrm{j}^{\text {th }}$ observation.

7. Toeplitz model (TOEP). It considered homoscedastic error variances and different correlation for each time lag. Therefore, it depended on 15 parameters: the error variance and the 14 covariances corresponding to the 14 possible time lags.

8. Toeplitz with heteroscedastic variance model (TOEPH). It made the same assumptions as TOEP, but in this model error variance was considered to be heteroscedastic.

9. Compound symmetry with heteroscedastic variance ( $\mathrm{CSH}$ ). In this model, observations within a female were considered to be equally correlated among them and error variance was considered to be heteroscedastic.

10. First order antedependence [ANTE(1)]. It states that an observation at a particular time $t$ depends on the previous ones and it is independent of all observations before $t-r$, 
being $r$ the order of the model (in this case 1). The degree of dependence decays with time lag, considering that observations could not be equally distributed over time. This model depended on 29 parameters.

Models in the second group assume that part of the variation among data originate from differences between females. Thus, they include the random effect of female which has its own structure of (co)variances over time points. Therefore, all the models in this group have two covariance structures: one for the permanent effect of female and one for the model residuals. The following models were tested:

1. Simple repeatability model (SR). It states that the variance over time points of female effects was homoscedastic and that all observations within a female are equally and completely correlated, being their covariance equal to the variance of permanent effect.

The (co)variance structure for the random residuals was a diagonal matrix with homogeneous variances, as in DIAG model. Note that the residual (co)variance structure in the $\mathrm{CSH}$ model is equivalent to consider the variation between animals, assuming that residuals are not correlated. Consequently, $\mathrm{CSH}$ could be considered as the heteroscedastic version of SR model.

2. SR-AR(1) model. It states that the (co)variance structure of female permanent effects was the same as for SR model but the residual (co)variance structure was as in $\mathrm{AR}(1)$ model.

3. SR-SP(POW) model. Again, the (co)variance structure for female permanent effects was the same as for SR model but the residual (co)variance structure was as in SP(POW) model.

4. B-BD model. In this model, variances and covariances for the permanent effect to the female are allowed to change for different states of the reproductive cycle but this structure (sub matrix of dimension $3 \times 3$ ) is the same for all reproductive cycles. (i.e. there are $5 \times 5$ blocks of dimension $3 \times 3$ ). Similarly, variances and covariances for residuals are allowed to change for different states of the reproductive, but they were assumed to be uncorrelated between cycles.

5. B-BAr(1) model. In this model, the (co)variance structure for permanent effects was the same as in B-BD model, but residuals of different reproductive cycles were also allowed to be correlated among cycles with a decreased degree of dependence with cycle lag.

In the third group, we assumed that variation among data is also due to differences between reproductive cycles within a given female. Therefore, in addition to the residual matrix of (co)variances, there were two additional (co)variance matrices for random effects 
over time points within individual. Only one model was tested, which was named Lact(Female) model. In this model, the (co)variance structures for permanent effects of the female and model residual were the same as in SR model. However, there is a new source of correlation among data, which is the reproductive cycle, as records from the same lactation within a female could be more similar between them than they are with records from other lactations. For observations from a given female, the model states that one particular observation is more correlated with observations from the same reproductive cycle than with observations from different reproductive cycles.

The $q$ variance components of each structure were estimated using the restricted maximum likelihood method (Proc MIXED, SAS).

Model evaluation. The goodness of fit of each model was evaluated in terms of its deviance, which is -2 times the log-likelihood (i.e. -2 times the logarithm of the probability of the data given the estimated model parameters) and Akaike Information Criteria (AIC = deviance $+2 \times$ number of parameters) which includes a penalisation to more parametrised models. Differences in AIC between models do not depend on measurement units. This property allowed us to compare the relevance of introducing more complex (co)variance structures in the model for different traits.

All phenotypic variances (15) and phenotypic correlations (120) were estimated for each model of a given trait to show differences between them imposed by the models. Repeatability was also estimated for models including permanent effects of the female as the ratio between the variance associated to the permanent effect of the female and the phenotypic variance (for models $\mathrm{B}-\mathrm{BD}$ and $\mathrm{B}-\mathrm{BAR}(1)$ repeatability was estimated for each state as the ratio between the variance associated to the permanent effect at that state and the phenotypic variance at that state).

\section{Results and discussion}

In terms of deviance (i.e. -2 times the log-likelihood), DIAG had the worst performance for all traits: 20223.7 for feed intake, 2124.5 for weight, 5676.4 for PFT, 21084.0 for milk yield and 4553.8 for litter weight. On the contrary, UNST showed the lowest values: 19202.0 for feed intake, -390.1 for weight, 5107.3 for PFT, 19067.8 for milk yield and 1318.9 for litter weight. This outcome denotes that the most parameterised model (UNST) is the one which best fits the data for all the traits and implies that considering the structure of variances and covariances improves the fitting quality for all the traits. Fitting a more flexible model requires estimating a greater number of parameters. In addition, these complex models could overfit the data, which means they follow the errors, or noise, too closely, leading to a model that differs from the true one. Therefore, the goal is to find 
parsimonious structures. Thus, as UNST includes all the possible variances and correlations between individual records, the number of parameters estimated is considerably higher than for the rest of the structures. Consequently, due to the finite sample size we used in the experiment, UNST fitted best to this particular set of data but they could not properly represent the true (co)variance structure of the population.

A better approach for model selection was suggested by (Akaike, 1974) who proposed the use of Akaike Information Criteria (AIC) for this purpose. AIC penalise the parametrisation of models, adding a term to the deviance which depends on the number of parameter (i.e. AIC = Deviance $+2 \times$ number of parameters). The lower the value, the better the model fit. Table 1.3 shows the AIC values from each structure and trait. It can be observed that the minimum AIC was obtained from different structures depending on the trait, indicating that UNST is in general over-parameterised and simpler models could be used. Moreover, it suggests that each trait had its own idiosyncrasy in terms of variance covariance structure. In this sense, comparing AIC scores among structures could help us to understand the idiosyncrasy of a given trait.

\section{Structures considering residual variation exclusively: Group 1}

Comparing one structure with its heterogeneous version could be useful to understand the relevance of heterogeneity of variance for each trait (DIAG vs DIAGH; AR(1) vs $\mathrm{ARH}(1)$; TOEP vs TOEPH). Structures allowing heterogeneous variances presented on av. -451 of AIC score for feed intake, -11 for body weight, +5 for PFT, -387 for milk yield and 1951 for litter weight compared to their non-heterogeneous structures (Table 1.3). These results denote that, for the study of feed intake, milk yield and specially litter weight, considering heterogeneity of variance is relevant, whereas for body weight and PFT is not relevant. This idea can be observed in Figure 1.1, which represents the estimated phenotypic variances with different models for feed intake, body weight and milk yield. We can observe that variance changed with time in structures allowing heteroscedasticity [e.g. UNST, $\mathrm{TOEPH}, \mathrm{ANTE}, \mathrm{B}+\mathrm{BAr}(1)]$, whereas it remained constant through time for homoscedastic structures. Moreover, we can observe that the change in variance observed in heteroscedastic structures was especially relevant for the traits where AIC was greatly reduced (feed intake, milk yield and litter weight). For these traits, the main changes of phenotypic variance were within cycle, although some variances from the first cycle were higher than from subsequent cycles. On the contrary, body weight and PFT could be considered as homoscedastic for adult females. This is not the case of growing rabbits, as reported by Blasco et al. (2003). 
Table 1.3 Fitting information using Akaike information criteria (AIC).

\begin{tabular}{|c|c|c|c|c|c|c|c|}
\hline \multirow{3}{*}{ Structure $^{1}$} & \multicolumn{5}{|c|}{ Fitting per trait ${ }^{2}$} & \multirow{2}{*}{\multicolumn{2}{|c|}{$\begin{array}{c}\text { Global fitting }^{3} \\
\text { Within trait: } \\
\text { Distance to the } \\
\text { fittest structure }\end{array}$}} \\
\hline & \multirow{2}{*}{$\begin{array}{c}\begin{array}{c}\text { Feed intake } \\
\text { (g DM/day) }\end{array} \\
N=1974\end{array}$} & \multirow{2}{*}{$\begin{array}{c}\begin{array}{c}\text { Body } \\
\text { weight } \\
(\mathrm{kg})\end{array} \\
N=2079\end{array}$} & \multirow{2}{*}{$\begin{array}{c}\begin{array}{c}\text { PFT } \\
(\mathrm{mm})\end{array} \\
N=2071\end{array}$} & \multirow{2}{*}{$\begin{array}{c}\begin{array}{c}\text { Milk Yield } \\
\text { (g/day) }\end{array} \\
N=2068\end{array}$} & \multirow{2}{*}{$\begin{array}{c}\begin{array}{c}\text { Litter } \\
\text { weight } \\
(\mathrm{kg})\end{array} \\
N=2082\end{array}$} & & \\
\hline & & & & & & Min & Max \\
\hline \multicolumn{8}{|l|}{ Group 1} \\
\hline UNST & 19442.0 & -150.1 & 5347.3 & 19307.8 & 1558.9 & 0.0 & 65.5 \\
\hline DIAG & $20225.7^{+}$ & 2126.5 & 5678.4 & $21086.0^{+}$ & $4558.8^{+}$ & 396.6 & 3056.5 \\
\hline DIAGH & 19808.6 & $2137.4^{+}$ & $5685.5^{+}$ & 20818.5 & $\mathrm{NC}$ & 395.1 & 2309.9 \\
\hline $\mathrm{AR}(1)$ & 20016.4 & 256.1 & 5477.3 & 20099.1 & 4266.6 & 195.5 & 2764.3 \\
\hline $\mathrm{ARH}(1)$ & 19567.8 & 240.5 & 5482.9 & 19628.4 & $\mathrm{NC}$ & 154.2 & 413.0 \\
\hline $\mathrm{SP}(\mathrm{POW})$ & 20028.9 & 288.0 & 5480.8 & 19855.6 & 4296.1 & 199.0 & 2793.8 \\
\hline TOEP & 19902.0 & -46.4 & 5296.7 & 20028.7 & 4103.5 & 14.9 & 2601.2 \\
\hline TOEPH & $19413.5^{-}$ & -74.8 & 5299.2 & 19605.8 & 2152.9 & 0.0 & 650.6 \\
\hline $\mathrm{CSH}$ & 19558.4 & 242.0 & 5288.7 & 20220.3 & $\mathrm{NC}$ & 6.9 & 912.5 \\
\hline ANTE(1) & 19544.9 & 169.0 & 5490.8 & 19321.7 & 1608.7 & 13.9 & 341.5 \\
\hline \multicolumn{8}{|l|}{ Group 2} \\
\hline SR & 20020.2 & 256.7 & 5286.7 & 20561.5 & 4374.2 & 4.9 & 2871.9 \\
\hline SR-AR(1) & 19960.0 & 70.3 & 5284.0 & 20078.0 & 4243.8 & 2.2 & 2741.5 \\
\hline SR-SP(POW) & 19963.5 & 80.9 & 5281.8 & 19828.5 & 4261.4 & 0.0 & 2759.1 \\
\hline B-BD & 19443.3 & -153.6 & 5284.1 & 19359.6 & $\mathrm{NC}$ & 2.3 & 51.8 \\
\hline B-BAR(1) & 19425.2 & $-172.5^{-}$ & 5285.8 & 19341.2 & 1502.3 & 0.0 & 33.4 \\
\hline \multicolumn{8}{|l|}{ Group 3} \\
\hline Lact(Female) & 19967.3 & 96.1 & 5284.8 & 20020.2 & 4279.7 & 3.0 & 2777.4 \\
\hline
\end{tabular}

${ }^{1}$ Structures according to Table $1 .^{2} \mathrm{~N}$ is the total number of observations per trait. ${ }^{-}$Lowest value per trait. ${ }^{+}$Highest value per trait. PFT: Perirenal fat thickness. NC: The algorithm did not converge. ${ }^{3}$ How each structure fitted globally to the considered traits: Low values for min indicates that the considered structure fitted well at least to data from one trait (high values for wrong fit to data from all traits). High values for max indicates that the considered structure fit wrong at least to data from one trait (low values for good fit to data from all traits).

On the other hand, comparing structures differing on the correlation pattern, e.g. correlated with its uncorrelated version, could be useful to understand the relevance of correlations among successive records. In this sense, $\mathrm{AR}(1)$ and $\mathrm{ARH}(1)$ improved AIC on av. -225 for feed intake, -1884 for body weight, -202 for PFT, -1089 for milk yield and -292 for litter weight compared to DIAG and DIAGH (Table 1.3). These results indicate that, for all traits, data from the same animal are correlated to some degree, the correlations being especially relevant for body weight and milk yield. The above structures considered that the correlation between two observations depends exclusively on the time lag between them, assuming that correlation decreases exponentially as the lag between two observations increases (reaching zero for far observations). In addition, they assume that observations are equally distributed over time. These assumptions are not always met in many experiments, as happens in our data sets. Without increasing the number of parameters, the SP(POW) model takes into account that observations are not homogeneously distributed over time and therefore the correlation between consecutive records might be different if the time elapsed 
between them also differs. However, the goodness of fit of this model compared to $\mathrm{AR}(1)$ model only improved for milk yield (-243.5 units; Table 1.3). Milk yield was recorded at the beginning of each lactation and consequently, the lags between observations within a given cycle were much lower (7d) than between the last record of a given cycle and first record of the following one (min. 21d). For all other traits, observations were almost homogeneously distributed over time. Thus, this result seems to be a consequence of the experimental design.

Toeplitz structures (TOEP or TOEPH) also considered different correlations for different lags between two observations. However, unlike SP(POW) model, these correlations are additional parameters to be estimated instead of the result of raising to a different power (i.e. time lag) a unique parameter ( $\rho)$. Therefore, they do not assume that correlations necessarily decrease with time; however, they assumed that correlations between two consecutive observations were the same for each pairwise comparison, which implies a homogenous distribution of records over time. Because of its greater flexibility and despite the assumption that data distribution is not met, TOEP fitted better to data than SP(POW) for all traits but milk yield (-126.9 for feed intake, -334.4 for body weight, -184.1 for PFT and 192.6 for litter weight). This could be explained by the heterogeneous distribution of the observations for milk yield. Compared to AR(1) and ARH(1), TOEP and TOEPH improved AIC on average -134 units for feed intake, -309 units for body weight, -182 units for PFT, 47 units for milk yield and -163 units for litter weight (averages of TOEP vs AR(1) and TOEPH vs ARH(1) from Table 1.3). Therefore, unlike SP(POW) model, the goodness of fit of TOEP and TOEPH models improved with respect to first order autoregressive models for all traits. In Figure 1.2, we can observe that phenotypic correlations were different from zero even for remote data with the TOEPH structure. Moreover, correlations did not always decrease with time lag. For example, for feed intake and body weight, correlations between records at the same state of two different reproductive cycles were higher than between records at different states within cycle. 

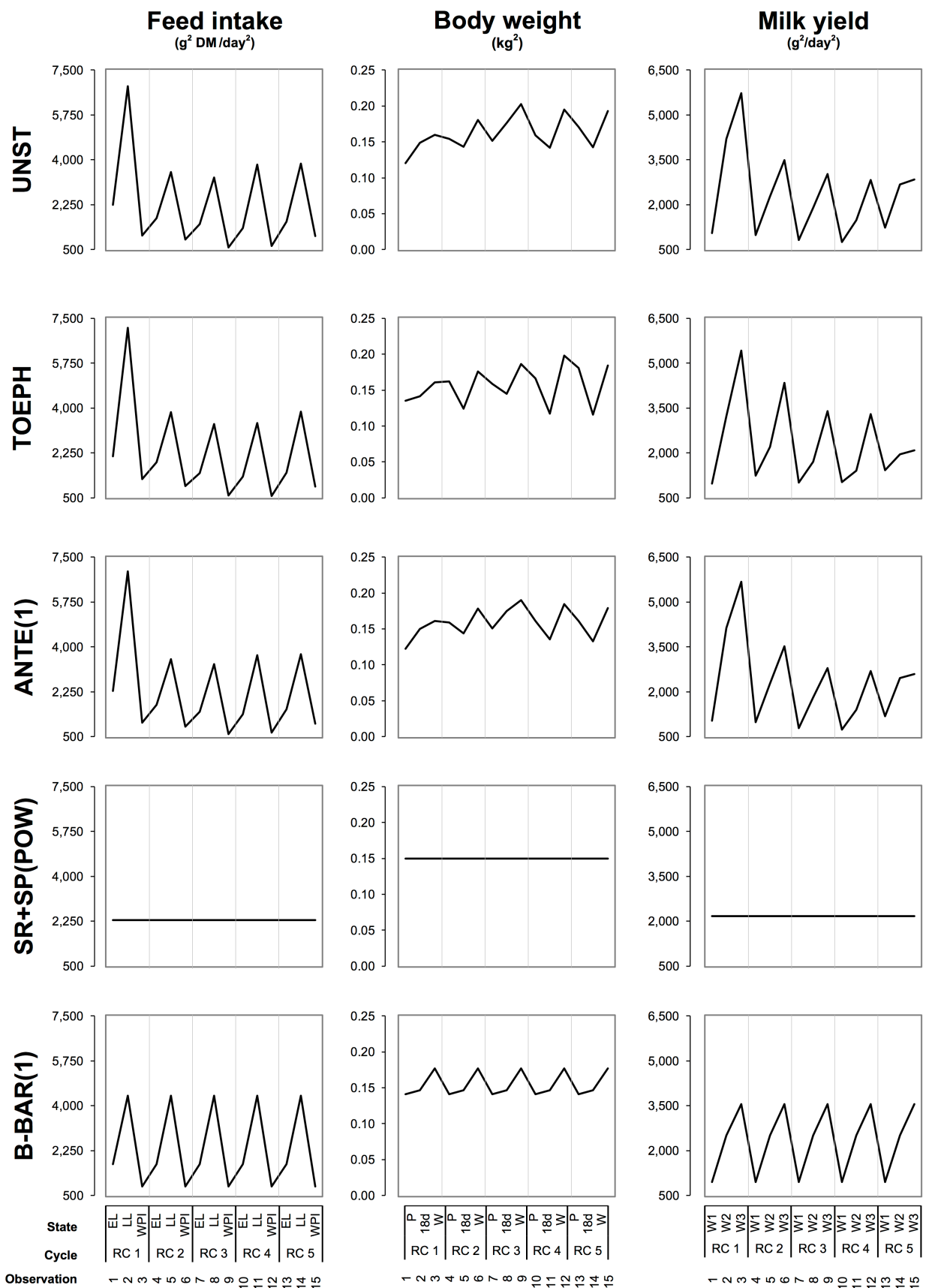

Figure 1.1 Estimated evolution of phenotypic variance over time with different structures for feed intake, body weight and milk yield. States: EL (Early lactation); LL (Late lactation); WPI (Weaning to parturition interval); P (Parturition); 18d (day 18 of lactation); W (Weaning); W1, W2, W3 (Week 1, 2 ,3 of lactation). $\mathrm{RC}$ : Reproductive cycle. 

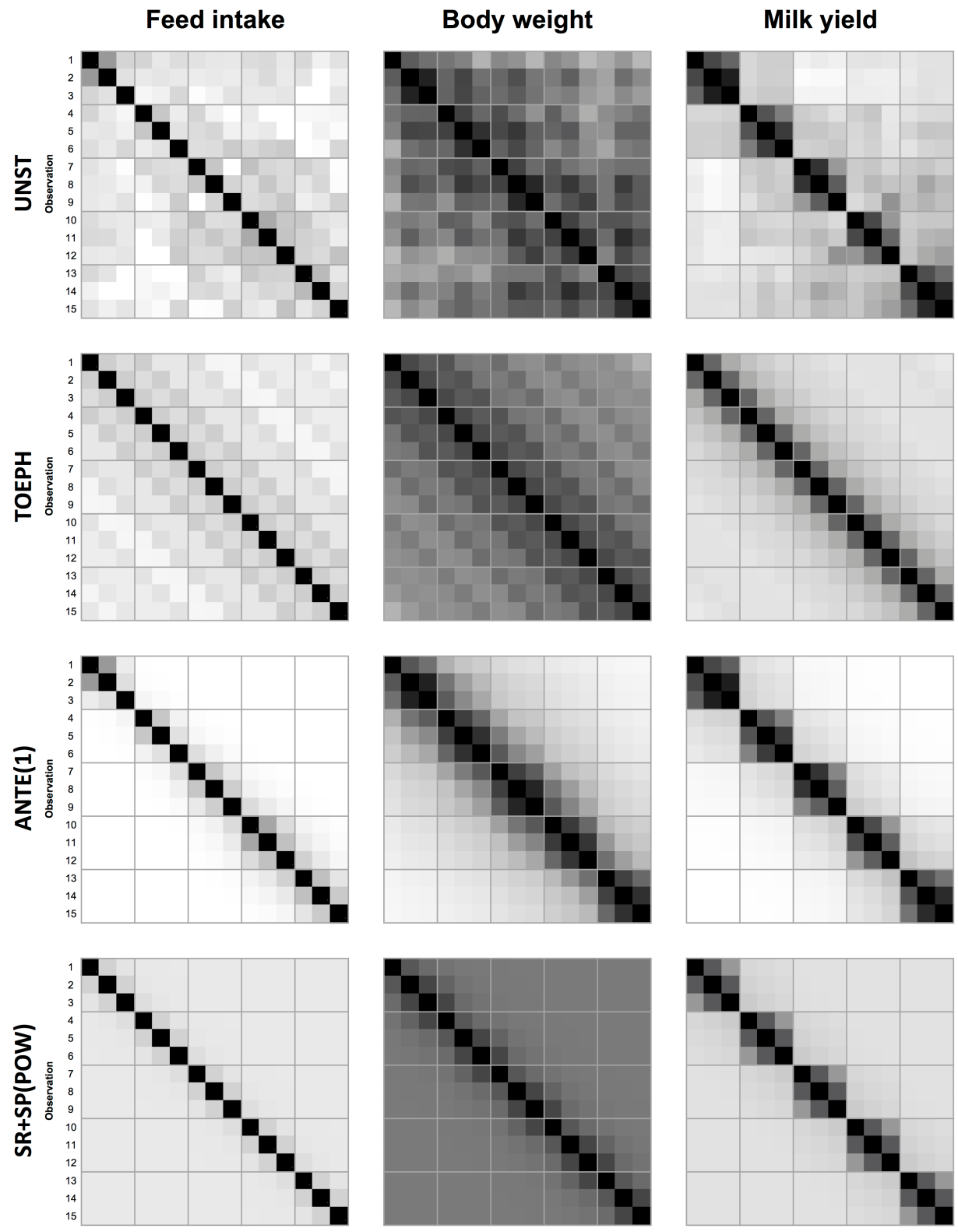

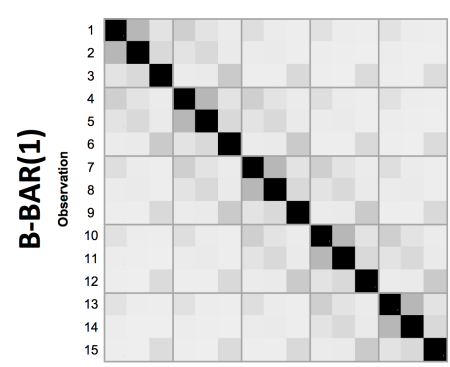

State EL ULWIEL UL WIEL LIWIEL UL WIEL ULWI

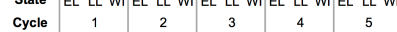
Observation $\begin{array}{lllllllllllllllll}1 & 2 & 3 & 4 & 5 & 6 & 7 & 8 & 9 & 10 & 11 & 12 & 13 & 14 & 15\end{array}$

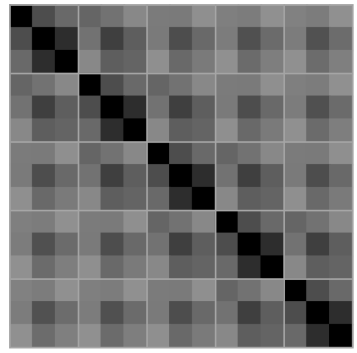

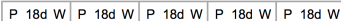
\begin{tabular}{|lllllllll|l} 
& 1 & & 2 & & 3 & 4 & & 5
\end{tabular} \mid

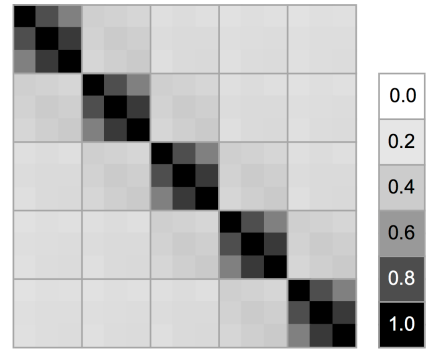

W1 W2 w3 $w_{1} W_{2} w_{3} W_{1} w_{2} w_{3} w_{1} w_{2} w_{3} w_{1} w_{2} w_{3}$

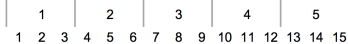

Figure 1.2 Estimated phenotypic correlations with different structures for feed intake, body weight and milk yield. State: EL (Early lactation); LL (Late lactation); WI (Weaning to parturition interval); P (Parturition); 18d (day 18 of lactation); W (Weaning); W1, W2, W3 (Week 1, 2 ,3 of lactation). 
As ARH(1), ANTE(1) considered that correlations decrease with time lag. However, ANTE(1) states that correlations for each pairwise of consecutive records are different and decrease proportionally to the distance between them. This pattern can be observed in Figure 1.2 for the analysed traits. Therefore, ANTE(1) is a proper model when observations are not homogeneously distributed over time or when correlations between consecutive observations do not depend exclusively on time. Compared to ARH(1), ANTE(1) produced a small improvement in the quality of fit for feed intake (change in AIC: -23) and body weight (72), but sizeable for milk yield (-307), as can be seen in Table 1.3. In Figure 1.2, it can be observed for milk yield that, for the same lag (in number not in time), records within the current cycle were more correlated than records from the previous or the next cycle, which could explain the better fit of this structure. On the contrary, correlations tended towards zero with increasing time lag, which could explain the worse performance of this model for feed intake, body weight and PFT compared to TOEPH.

\section{Structures including variation between animals: Group 2}

All the models included in Group 2 state that part of the observed variation is due to individual variation. Therefore, the phenotypic variation was split into variation associated to the permanent effect and variation associated to the residuals. Table 1.4 shows this decomposition of variances. It can be seen that the decomposition could be different depending on the way random effects are modelled. For example, compared to SR, including the autoregressive factors (SR-AR(1) and SR-SP(POW)) tended to decrease variance associated to the permanent effects and increase residual variance. Moreover, it can be observed that variance associated to the permanent effect was higher than zero for all the traits with all the structures. To evaluate the relevance of this effect it is possible to estimate the repeatability of the trait which is the ratio between the variance associated to the permanent effect and the phenotypic variance. For the models of this group, repeatability was high for female body weight ( $70 \%$ of the phenotypic variation) and low to moderate for all other traits, ranging from 14 to $29 \%$ for feed intake, 25 to $37 \%$ for PFT, 23 to $39 \%$ for Milk yield and 12 to $20 \%$ for litter weight. Therefore, for all traits female is an important source of variation.

The existence of individual variation in the data also means that observations from the same individual are more correlated than they are with data coming from different individuals. Consequently, correlations within an animal could not be zero even for very distant observations. The simplest structure in this group of models was SR, which only included the permanent effect of female. $\mathrm{CSH}$ could be considered the heterogeneous version of SR, although it does not include this factor. These structures improved AIC on average -228 units for feed intake, -1883 units for body weight, -394 units for PFT, -561 
units for milk yield and -185 units for litter weight compared to their uncorrelated versions (SR vs DIAG and CSH vs DIAGH from Table 1.3).

Table 1.4 Decomposition of variance (standard error) for the structures from group 2.

\begin{tabular}{cccccc}
\hline Structure $^{1}$ & $\begin{array}{c}\text { Feed intake } \\
(\mathrm{g} \text { DM/day })\end{array}$ & $\begin{array}{c}\text { Body weight } \\
(\mathrm{kg})\end{array}$ & $\begin{array}{c}\text { PFT } \\
(\mathrm{mm})\end{array}$ & $\begin{array}{c}\text { Milk Yield } \\
(\mathrm{g} / \text { day })\end{array}$ & $\begin{array}{c}\text { Litter weight } \\
(\mathrm{kg})\end{array}$ \\
\hline Permanent effect & & & & & \\
SR & $520(80.6)$ & $0.109(0.012)$ & $0.27(0.037)$ & $897(113.8)$ & $0.95(0.145)$ \\
SR-AR(1) & $423(80.6)$ & $0.102(0.012)$ & $0.27(0.037)$ & $504(116.2)$ & $0.58(0.143)$ \\
SR-SP(POW) & $416(77.5)$ & $0.102(0.012)$ & $0.27(0.037)$ & $502(109.2)$ & $0.60(0.132)$ \\
B-BD & & & & & \\
State1 & $506(94.5)$ & $0.100(0.012)$ & $0.34(0.052)$ & $294(54.1)$ & - \\
State2 & $930(223.7)$ & $0.120(0.014)$ & $0.24(0.046)$ & $816(146.4)$ & \\
State3 & $306(55.9)$ & $0.126(0.015)$ & $0.24(0.049)$ & $1188(213.6)$ & \\
B-BAr(1) & & & & & \\
State1 & $403(103.4)$ & $0.094(0.012)$ & $0.33(0.053)$ & $225(58.9)$ & $0.04(0.015)$ \\
State2 & $602(252.9)$ & $0.116(0.014)$ & $0.23(0.048)$ & $676(157.2)$ & $0.71(0.169)$ \\
State3 & $247(60.0)$ & $0.118(0.015)$ & $0.23(0.051)$ & $988(228.4)$ & $2.49(0.714)$ \\
& & & & & \\
Residual & & & & & \\
SR & $1843(63.3)$ & $0.048(0.002)$ & $0.62(0.021)$ & $1380(46.3)$ & $4.03(0.134)$ \\
SR-AR(1) & $1930(73.6)$ & $0.048(0.002)$ & $0.63(0.021)$ & $1737(101.4)$ & $4.35(0.172)$ \\
SR-SP(POW) & $1906(70.5)$ & $0.048(0.002)$ & $0.63(0.021)$ & $1678(94.9)$ & $4.20(0.154)$ \\
B-BD & & & & & \\
State1 & $1240(80.9)$ & $0.042(0.003)$ & $0.57(0.035)$ & $683(43.6)$ & - \\
State2 & $3435(230.8)$ & $0.028(0.002)$ & $0.60(0.039)$ & $1701(111.2)$ & \\
State3 & $581(39.1)$ & $0.052(0.004)$ & $0.70(0.046)$ & $2385(161.5)$ & \\
B-BAr(1) & & & & & \\
State1 & $1348(96.8)$ & $0.047(0.004)$ & $0.57(0.037)$ & $756(54.3)$ & $0.25(0.017)$ \\
State2 & $3785(281.2)$ & $0.031(0.002)$ & $0.60(0.041)$ & $1844(131.2)$ & $2.11(0.149)$ \\
State3 & $646(49.0)$ & $0.059(0.005)$ & $0.70(0.048)$ & $2567(187)$ & $10.16(0.724)$ \\
\hline
\end{tabular}

${ }^{1}$ Structures according to Table 1. - The algorithm did not converge.

The SR model states that records are repeated measurements of the same trait and are equally correlated within female. This assumption is relaxed in SR-AR(1) and SR$\mathrm{SP}(\mathrm{POW})$ models, which state that phenotypic correlations decrease exponentially with time until a constant value is reached (Littell et al., 1998). This constant value was defined by the repeatability of the trait. Unlike SR-AR(1), SR-SP(POW) also takes into account that records could be not homogeneously distributed over time. Compared to SR, SR-AR(1) improved AIC on -60 units for feed intake, -186 units for body weight, -3 units for PFT, -484 units for milk yield, -130 units for litter weight (Table 1.3). The difference in the quality of fit of SR$\mathrm{SP}(\mathrm{POW})$ vs SR-AR(1) was only sizeable for milk yield (-250 units of AIC). 
Except for PFT, this model did not fit the data better than any of the previous models. In fact, SR-SP(POW) provided the best fit for PFT. Consequently, compared to all other traits, it seems that the best fit for PFT was reached with a relatively simple structure. It could mean that mechanisms regulating body reserves act in agreement with SR-SP(POW), but such a simple structure seems abnormal if we consider the complexity of the trait and the complex relation with other functions (Friggens, 2003; Pascual, 2010). On the other hand, it could also be related to a higher uncertainty of measurements of this trait or to other factors affecting determination of PFT, such as the physiological state (Pascual et al., 2004).

Until now we have found that, depending on the trait, variance could change over time (especially within the reproductive cycle, Figure 1.1); there was great variation between animals (Table 1.4); there could be complex structures for the phenotypic correlations (Figure 1.2 ), and it is important to consider the distribution of data over time. However, none of the previous structures can take into account all of these data features simultaneously. For this purpose, $\mathrm{B}-\mathrm{BD}$ and $\mathrm{B}-\mathrm{BAR}(1)$ were designed. In both models, variance and covariance were allowed to change over states within a reproductive cycle, but this structure remains constant over cycles. $\mathrm{B}-\mathrm{BD}$ and $\mathrm{B}-\mathrm{BAR}(1)$ only differs in the residual covariance matrix, which was block diagonal for B-BD (i.e. residuals are only correlated within cycle) or followed the pattern of $\mathrm{AR}(1)$ model between cycles.

All the previous structures considered time as the only process involved. On the contrary, B-BD and B-BAR(1) split time into two processes (Galecki, 1994); changes within cycle and changes over cycles. Compared to SR-AR(1), B-BD improved AIC on -517 for feed intake, -224 for body weight, -718 for milk yield. It provided the same fit for PFT and it did not converge for litter weight (Table 1.3). Moreover, considering that residuals between reproductive cycles could also be correlated slightly improved AIC for feed intake (-18), body weight (-19) and milk yield (-18) compared to B-BD. In fact, B-BAR(1) provided the best fit for weight and litter weight. In terms of goodness of fit, the B-AR(1) model was the best model for all traits, or very close to it, the only differences being in AIC +12 units for feed intake, +4 units for PFT and +33 units for milk yield compared to the best fitted model (Table 1.3). In fact, the $\mathrm{B}-\mathrm{BAR}(1)$ correlation pattern was the most similar to the most flexible structure (UNST; Figure 1.3). Therefore, B-BAR(1) could be a good choice for the longitudinal study of this kind of data from female productive performance.

\section{Structures including variation between lactations from a given animal: Group 3}

Model Lact(Female) states that there is an additional source of variation which is the reproductive cycle within female. This means that observations from the same lactation of a given female could be more correlated than they are with observations from other lactations 
of the same female. The ratio of phenotypic variation due to this factor was estimated to be 0.17 for feed intake $(P<0.001), 0.11$ for weight $(P<0.001), 0.04$ for PFT $(P<0.05), 0.42$ for milk yield $(P<0.001)$ and 0.22 for litter weight $(P<0.001)$. Compared to SR, this structure improved AIC by -52.9 units for feed intake, -160.6 units for weight, -1.9 units for PFT, 541.3 units for milk yield and -94.5 units for litter weight. Note that the improvement was proportional to the proportion explained by the variation between lactations from a given female. However, as this structure did not consider either heterogeneity of variance and covariance within animal, it did not provide the best fit for any trait. In fact, this phenomenon of variation between lactations from a given female was gathered in a different way by the within-cycle residual correlations of the $\mathrm{B}-\mathrm{BD}$ and $\mathrm{B}-\mathrm{BAR}(1)$ structures.

\section{Conclusions}

It seems that data from each of the studied traits had its own idiosyncrasy in terms of phenotypic correlations within female and changes in phenotypic variance over time. For feed intake, milk yield and litter weight, phenotypic variance changed over time, especially within the reproductive cycle. The permanent effect of the female was relevant for all traits. In general, phenotypic correlations tended to decrease as the lag between observations increased. However, for feed intake and body weight much more complex patterns were observed. Moreover, observations for milk yield were highly heterogeneously distributed. To cope with the analysis of data from these traits, we have provided several structures starting from very simple ones and adding sophistications in several directions. Although none of the tested models was the best in terms of goodness of fit to the data for all traits, it seems that models in which (co)variance structure was modelled in blocks of (co)variances for each reproductive cycle could be the most recommendable (B-BD and $\mathrm{B}-\mathrm{BAR}(1)$ structures).

\section{Acknowledgments}

This study was supported by the Interministerial Commission for Science and Technology (CICYT) of the Spanish Government (AGL2014-53405-C2-1-P). Grant aid for Alberto Arnau from the Ministry of Economy and Finance (BES-2012-052345) is also gratefully acknowledged. 


\section{References}

Akaike $\mathrm{H}$ 1974. A new look at the statistical model identification. IEEE Transactions on Automatic Control 19, 716-723.

Bakr MH, Tusell L, Rafel O, Terré M, Sánchez JP and Piles M 2015. Lactating performance, water and feed consumption of rabbit does reared under a Mediterranean summer circadian cycle of temperature v. comfort temperature conditions. Animal 9, 12031209.

Blasco A, Piles M and Varona L 2003. A Bayesian analysis of the effect of selection for growth rate on growth curves in rabbits. Genetics Selection Evolution 35, 21-41.

Castellini C, Dal Bosco A, Arias-Álvarez M, Lorenzo PL, Cardinali R and Rebollar PG 2010. The main factors affecting the reproductive performance of rabbit does: a review. Animal Reproduction Science 122, 174-182.

Cifre J, Baselga M, García-Ximénez F and Vicente JS 1998. Performance of a hyperprolific rabbit line I. Litter size traits. Journal of Animal Breeding and Genetics 115, 131-138.

David I, Ruesche J, Drouilhet L, Garreau H and Gilbert H 2015. Genetic modeling of feed intake. Journal of Animal Science 93, 965-77.

De Blas JC and Mateos GG 2010. Feed formulation. In Nutrition of the rabbit, 2nd edition (ed. De Blas JC, Wiseman J), pp. 222-232. CABI Publishing, Wallingford, UK.

Estany J, Camacho J, Baselga M and Blasco A 1992. Selection response of growth rate in rabbits for meat production. Genetics Selection Evolution 24, 527-537.

Fernández-Carmona J, Blas E, Pascual JJ, Maertens L, Gidenne T and García J 2005. Recommendations and guidelines for applied nutrition experiments in rabbits. World Rabbit Science 13, 209-228.

Fortun-Lamothe L 2006. Energy balance and reproductive performance in rabbit does. Animal Reproduction Science 93, 1-15.

Friggens NC 2003. Body lipid reserves and the reproductive cycle: towards a better understanding. Livestock Production Science 83, 219-236.

Galecki A 1994. General class of covariances structures for two or more repeated factors in longitudinal data analysis. Communications in Statistics - Theory and Methods 23, 3105-3119.

Gibbons RD, Hedeker D and DuToit S 2010. Advances in analysis of longitudinal data. Annual Review of Clinical Psychology 6, 79-107.

Hedeker D and Gibbons RD 2006a. Introduction. In Longitudinal data analysis, pp. 1-12. John Willey \& Sons, Chicago, USA.

Hedeker D and Gibbons RD 2006b. Covariance pattern models. In Longitudinal data analysis, pp. 101-112. John Willey \& Sons, Chicago, USA.

Jaffrézic F and Pletcher SD 2000. Statistical models for estimating the genetic basis of repeated measures and other function-valued traits. Genetics 156, 913-922.

Lebas F 1968. Mesure quantitative de la production laitière chez la lapine. Annales de Zootechnie 17, 169-182. 
Littell RC, Henry PR and Ammerman CB 1998. Statistical analysis of repeated measures data using SAS procedures. Journal of Animal Science 76, 1216-31.

Pascual JJ 2010. The role of body condition on new feeding and breeding programs for reproductive rabbit does. Proc. 22nd Hungarian Conference on Rabbit Production, 121.

Pascual JJ, Blanco J, Piquer O, Quevedo F and Cervera C 2004. Ultrasound measurements of perirenal fat thickness to estimate the body condition of reproducing rabbit does in different physiological states. World Rabbit Science 12, 7-21.

Pascual JJ, Savietto D, Cervera C and Baselga M 2013. Resources allocation in reproductive rabbit does: a review of feeding and genetic strategies for suitable performance. World Rabbit Science 21, 123-144.

Sánchez JP, Theilgaard P, Mínguez C and Baselga M 2008. Constitution and evaluation of a long-lived productive rabbit line. Journal of Animal Science 86, 515-525.

Schaeffer LR 2004. Application of random regression models in animal breeding. Livestock Production Science 86, 35-45.

Speidel SE, Enns RM and Crews Jr DH 2010. Genetic analysis of longitudinal data in beef cattle: a review. Genetics and Molecular Research 9, 19-33. 


\title{
PAPER II
}

Homeorhetic control and homeostatic regulation from a mixed-model view: Reinterpreting nutrient partitioning using the rabbit female as a model

\begin{abstract}
Arnau-Bonachera $\mathrm{A}^{1}$, Pascual $\mathrm{JJ}^{1}$
${ }^{1}$ Institute for Animal Science and Technology, Universitat Politècnica de València, Camino de Vera, s/n. 46071 Valencia, Spain.
\end{abstract}





\begin{abstract}
Mixed models split phenotypic variance into variation between animals (due to differences between animals) and covariation within animal (due to environmental variation). On the other hand, animal's nutrient partitioning differs between the homeorhetic control and the homeostatic regulation. The aim of this work was to evaluate the relation between the processes involved in animal's nutrient partitioning and the information provided by mixed models. In 203 rabbit females, traits related to nutrient partitioning (feed intake, body weight, perirenal fat thickness, milk yield and litter weight) were controlled three times per cycle during 5 consecutive reproductive cycles. When mixed models were applied to the evolution of a given trait over time, they provided information on the individual trajectories of the females over the reproductive cycle. In this sense, we estimate repeatabilities between 0.15 and 0.78 for the different traits, without apparent changes over the reproductive cycle, and permanent correlations close to one for most of the traits, except for feed intake (from 0.53 to 0.83) and litter weigh (from 0.22 to 0.94). Residual correlations at different times within a given trait provide information on the ability to return to the targeted trajectory when the effective trajectory is deviated due to environmental effects. We estimated that these correlations decrease with time lag, but their effect could remain for even more than one reproductive cycle. When mixed models were applied to comparison among traits, they provided information on the strategies between animals for nutrient partitioning. We estimated correlations lower than one among all the traits (from 0.01 to 0.92), revealing a wide range of strategies between animals for nutrient partitioning. Residual correlations between traits (from -0.12 to 0.89 ) provided information on the way animals regulate acquisition of energy and its partition in order to maintain their targeted trajectory. Therefore, mixed models can provide useful information to improve our understanding about nutrient partitioning.
\end{abstract}

Key words: Resource allocation, trajectory, dynamics, long-term, individual variation 



\section{Introduction}

Acquisition of energy and its partition among life functions is associated with energy balance of reproductive females. Energy balance defines body condition profile of females over time and both are related with functionality of animals as it can impair reproduction, health or even lifetime performance (e.g. in rabbits, Fortun-Lamothe, 2006; in dairy cattle, Roche et al., 2009). In several studies, traits reflecting energy acquisition and partition of females are usually recorded within one reproductive cycle to evaluate their effects in the short term. Occasionally, these traits are recorded during several reproductive cycles to evaluate their effects in the long term. Nevertheless, the relation between nutrient partitioning and the evolution over time of traits reflecting energy balance remains unclear (Friggens and Newbold, 2007).

In recent years, a central role of the animal in nutrient partitioning has been acknowledged, distinguishing two different process: the homeorhetic control which defines genetically driven trajectories and the homeostatic regulation (Friggens et al., 2013). Homeorhesis has been defined as all the orchestrated changes in the animal necessary to support a physiological state (Bauman and Currie, 1980). For a given life function, such as lactation or body reserves storing, a genetically driven trajectory is the one that will be achieved by the animal under non-limiting conditions as a consequence of the homeorhetic control. Likewise, the homeostatic regulation of an animal is the ability to respond to environmental effects, adjusting nutrient partitioning to attempt to maintain the targeted trajectory (Friggens et al., 2013).

Long term trials, with several records per animal, would be a way to evaluate effective trajectories reflecting long term partitioning. As environment is not perfectly homogeneous throughout the farm and time, each female will be placed within a particular set of non-constant and non-controlled conditions that will affect to their observed effective trajectories. In this context, mixed model is a powerful tool to analyse this kind of data as it separates the fixed and random effects (Hedeker and Gibbons, 2006). Fixed effects provide information on the mean effect of a given treatment (e.g. diet, management, temperature...), whereas random effects on individual variation. Moreover, throughout random effects it is possible to split this variation into the effect of the animal and the effect of the environment.

We hypothesize that, variance components and the solution of random effects obtained from mixed models are meaningful, and could help us understand the processes involved in nutrient partitioning. For example, in the study of the dynamics of a given trait, understanding differences between animals over the reproductive cycle could be helpful to find out the variation in the genetically driven control (homeorhesis), whereas environmental 
effects could be used to evaluate how animals respond when they are deviated from their targeted trajectory (homeostatic regulation). Moreover, this strategy could also be applied to relations among traits, to find out variations in nutrient partitioning on animals and how each animal responds to environmental effects through homeostatic regulation.

Rabbit female model could be one of the best options to study this unexplored hypothesis because: (i) its breeding present certain zootechnical interest; (ii) they are easily handled, being possible to breed the large number of animals required to perform these experiments; (iii) they present a fast-reproductive rhythm, rabbit females can breed several litters per year. This fact reduces the time of experimentation that is required for the evaluation of a longish period of the lifetime of animals. Therefore, by studying variance components of mixed models and individual solutions of random effects, the aim of this work was to study variation between rabbit females across the reproductive cycle and among traits in a given production system (genetic type, diet, experimental farm...) and how each animal responds to environmental effects, to relate them with the homeorhetic control and homeostatic regulation.

\section{Materials and methods}

The experimental procedure was approved by the animal welfare ethics committee of the Universitat Politècnica de València (UPV) and carried out following the Spanish Royal Decree 53/2013 on the protection of animals used for scientific purposes, as well as the European Group on Rabbit Nutrition (Fernández-Carmona et al., 2005).

\section{Animals and experimental procedure}

The experiment involved 203 New Zealand $\mathrm{x}$ California rabbit does belonging to the Institute of Animal Science and Technology of the Universitat Politècnica de València. Females were randomly selected from three lines that differed greatly in their breeding goals [R ( $\mathrm{n}=70), \mathrm{H}(\mathrm{n}=66), \mathrm{LP}(\mathrm{n}=67)$; see Estany et al. (1992), Cifre et al. (1998) and Sánchez et al. (2008) for details]. Each female was individually housed in reproductive cages $(700 \mathrm{x}$ 500 × $320 \mathrm{~mm}$; provided with a nest for litters from 28 day of gestation), under commercial environmental conditions (on av. 13 to $26^{\circ} \mathrm{C}$ of daily temperature variation), with light alternating on a cycle of 16 light hours and 8 dark hours. They were first inseminated at 19 weeks of age and controlled between their first parturition to fifth weaning, producing a total of 758 lactations. From first parturition onward, they followed a semi-intensive reproductive rhythm, where inseminations took place 11 days after each parturition. When pregnancy failed to occur, the does were re-inseminated every 21 days until a maximum of 3 consecutive negative attempts. At parturition, litters were standardized to 8 kits in the first parturition and later on between 9 and 11 kits. This procedure was performed to equalize the 
energetic effort during lactation among females and to decrease the coefficient of variation of data which increases the statistical accuracy of the estimates (Fernández-Carmona et al., 2005). Litters were weaned at day 30 of lactation. Females were fed ad libitum during the whole experiment with one of two experimental diets. These diets were formulated according to the recommendations of De Blas and Mateos (2010) for reproductive rabbit females. Diets were designed to be isoenergetic and isoproteic (11.3 MJ of digestible energy per kg of dry matter and $117 \mathrm{~g}$ of digestible protein per $\mathrm{kg}$ of dry matter; DM), but enhancing major differences in energy source. Diet CS was prepared promoting cereal starch [237 $\mathrm{g}$ of starch and $21 \mathrm{~g}$ of ether extract (EE) per kg DM], whereas in diet AF part of starch was replaced by animal fat (105 $\mathrm{g}$ of starch and $86 \mathrm{~g}$ of EE per $\mathrm{kg} \mathrm{DM})$.

\section{Traits}

We monitored five traits related with the energy balance of females: feed intake, body weight, perirenal fat thickness (PFT), milk yield and litter weight. For each female, each of these traits was recorded three times per cycle during the five reproductive cycles (with a maximum of 15 observations per female for females that survive until trial end; approx. $48 \%$ of the females at the beginning of the trial). We considered that the different records within a reproductive cycle defined the different physiological states of the animal. Consequently, for feed intake (1974 records) we considered the states of intake during early lactation (from parturition to 18 days post-partum (dpp)), late lactation (as the joint intake of female plus litter from $18 \mathrm{dpp}$ to weaning) and weaning to parturition interval. For body weight (2079 records) and PFT (Pascual et al., 2000; 2071 records) we considered the states of parturition, $18 \mathrm{dpp}$ and weaning. For milk yield (2068 records) we considered the states of first, second and third week of lactation, which were calculated as the average of four daily measures per week. Daily milk yield was measured by weighing the female before and after suckling (Lebas, 1968). For litter weight (2082 records) we considered the states of weight at birth, 18 $\mathrm{dpp}$ and weaning. Available digestible energy (ADE; 1242 records) was individually calculated for the states of early lactation and weaning to parturition interval as the difference between the digestible energy intake and the energy that is theoretically required for maintenance (430 kJ/day per kg of metabolic live weight; Xiccato and Trocino, 2010). Table 2.1 shows the means and the number of records per state. 
Table 2.1 Means and number of records (in brackets) for the controlled traits at different states of the reproductive rabbit female cycle.

\begin{tabular}{lccc}
\hline & \multicolumn{3}{c}{ State $^{1}$} \\
\cline { 2 - 4 } & (i) & (ii) & (iii) \\
\hline Feed intake (g DM/day) & $298(673)$ & $400(658)$ & $176(643)$ \\
Available digestible energy (MJ/day) & $2.05(673)$ & - & $0.68(569)$ \\
Body weight (kg) & $4.28(749)$ & $4.45(677)$ & $4.67(653)$ \\
Perirenal fat thickness (mm) & $7.14(745)$ & $7.64(676)$ & $7.50(650)$ \\
Milk yield (g/day) & $106(705)$ & $187(689)$ & $225(674)$ \\
Litter weight (kg) & $0.52(756)$ & $2.23(668)$ & $4.29(658)$ \\
\hline
\end{tabular}

\footnotetext{
${ }^{1}$ State of the reproductive cycle: [For feed intake and available digestible energy: early lactation (i), late lactation (female+litter) (ii) and weaning to parturition interval (iii)]; [For body weight and perirenal fat thickness: parturition (i), day 18th of lactation (ii) and weaning (iii)]; [For milk yield: first week (i), second week (ii) and third week of lactation(iii)]; [For litter weight: total born (i), day 18th of lactation (ii) and weaning (iii)]. - Period not evaluated.
}

\section{Statistical analysis}

To understand differences between animals over the reproductive cycle in the study of the dynamics over time of a given trait (homeorhetic control) and the way animals respond to environmental effects from their trajectory (homeostatic regulation), each of the six traits was analysed according to the following model:

$$
\mathrm{y}_{\text {dgsrlgki }}=\mathrm{D}_{\mathrm{d}} \cdot \mathrm{GT}_{\mathrm{g}} \cdot \mathrm{S}_{\mathrm{s}} \cdot \mathrm{RC}_{\mathrm{r}}+S_{S} \cdot O L_{l}+S_{s} \cdot O G_{g}+\beta \mathrm{T}_{\mathrm{k}}+\mathrm{p}_{\mathrm{is}}+\mathrm{e}_{\mathrm{dgsrlgki}}
$$

, where $\mathrm{y}_{\mathrm{dgsrlgki}}$ represents one record of a given trait. As each trait was evaluated separately, traits were considered as if they were independent among them; $D_{d}$ was the diet effect as fixed effect (2 levels: AF, CS); $\mathrm{GT}_{\mathrm{g}}$ was the effect of genetic type (3 levels; H, LP, R); $\mathrm{S}_{\mathrm{s}}$ was the state fixed effect ( 3 levels for feed intake: early lactation, late lactation, weaning to parturition interval; body weight: parturition, 18d, weaning; PFT: parturition, 18d, weaning; milk yield: week 1, week 2, week 3; litter weight: total born, 18d, weaning; and 2 levels for ADEP: early lactation, weaning to parturition interval); $\mathrm{RC}_{\mathrm{r}}$ was the reproductive cycle fixed effect ( 5 levels; $\left.1^{\text {st }}, 2^{\text {nd }}, 3^{\text {rd }}, 4^{\text {th }}, 5^{\text {th }}\right) ; \mathrm{OL}_{1}$ was considered as fixed effect to take into account the effect of getting pregnant during lactation (2 levels: females getting or not pregnant during lactation). $\mathrm{OG}_{\mathrm{g}}$ was considered as fixed effect to take into account the effect of being lactating during gestation (2 levels: lactating or not lactating females at the beginning of gestation). We used the interactions $\mathrm{OL}_{1}$ and $\mathrm{OG}_{\mathrm{g}}$ with $\mathrm{S}_{\mathrm{s}}$ to consider that these effects could be different depending on the state. By using $\mathrm{OL}_{1}$ and $\mathrm{OG}_{\mathrm{g}}$ we aimed at taking into account the effects of simultaneously gestate and lactate in energy acquisition and allocation. $T_{k}$ was the average inner temperature of the farm during the reproductive cycle as covariate and $\beta$ its regression coefficient; As random effects we considered $p_{i s}$ and $e_{\text {dgsrlgki }}$, where $p_{i s}$ was the permanent effect of the $\mathrm{i}^{\text {th }}$ female at the $\mathrm{s}^{\text {th }}$ state and $e_{\mathrm{dgsr} g \mathrm{gii}}$ represented the random residuals of the records. This analysis was performed using the proc MIXED of SAS (2009), where variance 
components were estimated by the restricted maximum likelihood (REML) method according to the model B-BAR(1) described in Paper I.

The permanent effects of the female were modelled with identical blocks for all the females as:

$$
p_{i s} \sim \mathrm{N}\left(\mathbf{0}_{\boldsymbol{i}}, \mathbf{G}_{\boldsymbol{i}}\right) \text { with } \mathbf{G}_{\boldsymbol{i}}=\left(\begin{array}{ccc}
\sigma_{p\left(s_{1}\right)}^{2} & \sigma_{p\left(s_{1: 2}\right)} & \sigma_{p\left(s_{1: 3}\right)} \\
\sigma_{p\left(s_{1: 2}\right)} & \sigma_{p\left(s_{2}\right)}^{2} & \sigma_{p\left(s_{2: 3}\right)} \\
\sigma_{p\left(s_{1: 3}\right)} & \sigma_{p\left(s_{2: 3}\right)} & \sigma_{p\left(s_{3}\right)}^{2}
\end{array}\right)
$$

, assuming that permanent effects of the $\mathrm{i}^{\text {th }}$ female were normally distributed with mean zero and with a variance-covariance matrix $G_{i}$ where $\sigma_{p(s 1)}^{2}, \sigma_{p(s 2)}^{2}$ and $\sigma_{p(s 3)}^{2}$ were the variances of the permanent effect at state $s_{1}, s_{2}$ and $s_{3}$, respectively, and $\sigma_{p(s 1: 2)}, \sigma_{p(s 1: 3)}$ and $\sigma_{p(s 2: 3)}$ were the covariances of the permanent effects between the state $s_{1}$ and $s_{2}, s_{1}$ and $s_{3}, s_{2}$ and $s_{3}$, respectively. If we had considered these covariances equal to one, we would have assumed that all the animals are ranked always in the same position for each state of the reproductive cycle. In this situation, trajectory due to permanent effect of the female would have resulted in parallel trajectories for different females. Thus, as the permanent effect of a given female was not assumed to be constant over the reproductive cycle, we considered that different animals could follow different trajectories.

On the other hand, residuals were modelled with identical blocks for all the females, assuming that they were normally distributed with mean zero and with a variance-covariance matrix $\mathrm{R}_{\mathrm{i}}$ modelled for the $\mathrm{i}^{\text {th }}$ female as:

$$
\mathrm{e}_{i} \sim \mathrm{N}\left(\mathbf{0}_{\boldsymbol{i}}, \mathbf{R}_{\boldsymbol{i}}\right) \text { with } \mathbf{R}_{\boldsymbol{i}}=\left(\begin{array}{ccc}
\sigma_{e\left(s_{1}\right)}^{2} & \sigma_{e\left(s_{1: 2}\right)} & \sigma_{e\left(s_{1: 3}\right)} \\
\sigma_{e\left(s_{1: 2}\right)} & \sigma_{e\left(s_{2}\right)}^{2} & \sigma_{e\left(s_{2: 3}\right)} \\
\sigma_{e\left(s_{1: 3}\right)} & \sigma_{e\left(s_{2: 3}\right)} & \sigma_{e\left(s_{3}\right)}^{2}
\end{array}\right) \otimes\left(\begin{array}{ccccc}
1 & \rho & \rho^{2} & \rho^{3} & \rho^{4} \\
\rho & 1 & \rho & \rho^{2} & \rho^{3} \\
\rho^{2} & \rho & 1 & \rho & \rho^{2} \\
\rho^{3} & \rho^{2} & \rho & 1 & \rho \\
\rho^{4} & \rho^{3} & \rho^{2} & \rho & 1
\end{array}\right)
$$

, where $\sigma^{2}{ }_{e(\mathrm{~s} 1)}, \sigma^{2}{ }_{e(\mathrm{~s} 2)}$ and $\sigma^{2}{ }_{e(\mathrm{~s} 3)}$ were the variances of the random residuals at state $\mathrm{s}_{1}$, $\mathrm{s}_{2}$ and $\mathrm{s}_{3}$, respectively; $\sigma_{e(s 1: 2)}, \sigma_{e(s 1: 3)}$ and $\sigma_{e(s 2: 3)}$ were the covariances of the residuals between the state $s_{1}$ and $s_{2}, s_{1}$ and $s_{3}, s_{2}$ and $s_{3}$, respectively. $\rho$ was the proportion of the residual variance or covariance remaining after a lag of one reproductive cycle (autoregressive factor). Considering that residuals could be correlated allowed us to take into account that the effect of the environment at one point of a given animal could have an effect in other point of the effective trajectory of that animal. Thus, we considered that an environmental effect at a given time could affect other times differently depending on the state of the animal, but its effect could remain even in subsequent reproductive cycles. The effect on subsequent cycles was assumed to decrease with time. 
Repeatability, the proportion of variance that depends on the females' permanent effect, was estimated as $\sigma_{\mathrm{p}(\mathrm{s} 1)}^{2} /\left(\sigma_{\mathrm{p}(\mathrm{s} 1)}^{2}+\sigma_{\text {e(s } 1)}^{2}\right)$ for the state $\mathrm{s}_{1}$ and so on. Correlations between the permanent effects at state $s_{1}$ and state $s_{2}$ were estimate as $\sigma_{p(11: 2)} /\left(\sigma_{p(s 1)} \cdot \sigma_{p(s 2)}\right)$ and so on. Correlations between the residuals at state $s_{1}$ and state $s_{2}$ of a given reproductive cycle were estimated as $\sigma_{e(s 1: 2)} /\left(\sigma_{e(s 1)} \cdot \sigma_{e(s 2)}\right)$ and so on.

To determine the variation in energy acquisition and allocation between animals and how these animals respond to environmental effects through homeostatic regulation, we also assessed the relations among the six traits. We obtained one record per cycle and trait as the average of all the records from different states at that cycle of a given animal. Later on, we analysed this data with a six-trait mixed model using the proc MIXED of SAS (2009) and REML as the method for the estimation of variance components. In this multi-trait analysis, each of the six traits was evaluated according to the following model.

$$
\mathrm{y}_{\mathrm{dgtrki}}=\mathrm{D}_{\mathrm{d}} \cdot \mathrm{GT}_{\mathrm{g}} \cdot \mathrm{RC}_{\mathrm{tr}}+\beta \mathrm{T}_{\mathrm{tk}}+\mathrm{p}_{\mathrm{ti}}+\mathrm{e}_{\mathrm{dgtrki}}
$$

, where $y_{\text {trki }}$ represented one record of the $t^{\text {th }}$ trait; $D_{d}$ was the diet effect as fixed effect (2 levels: $\mathrm{AF}, \mathrm{CS}$ ); $\mathrm{GT}_{\mathrm{g}}$ was the effect of genetic type (3 levels; $\mathrm{H}, \mathrm{LP}, \mathrm{R}$ ); $\mathrm{RC}_{\mathrm{tr}}$ was the reproductive cycle fixed effect ( 5 levels; $1^{\text {st }}, 2^{\text {nd }}, 3^{\text {rd }}, 4^{\text {th }}, 5^{\text {th }}$ ); $T_{t k}$ was the average inner temperature of the farm during the reproductive cycle as covariate and $\beta$ its regression coefficient; $\mathrm{p}_{\mathrm{ti}}$ was the permanent effect of the $\mathrm{i}^{\text {th }}$ female and $e_{\text {trki }}$ represented the random residual effect of the model, assumed to be uncorrelated among reproductive cycles. Correlations between the permanent effects and between residuals were estimated as described in the previous section. We used LS means to estimate the global mean of each trait. Individual patterns of acquisition and allocation of females were obtained by adding each individual solution of the permanent random effect from a trait state to LS mean of that state.

\section{Results}

\section{Evolution of traits over the reproductive cycle}

The evolution of phenotypic variance and repeatability of each trait over the reproductive cycle is presented in Table 2.2. Phenotypic variance of feed intake and ADE during weaning to parturition interval was half of that estimated during early lactation. During late lactation, phenotypic variance of feed intake was 2.68 times higher than in early lactation. For body weight and PFT, no evidence of great changes in phenotypic variance was observed. For milk yield and litter weight, phenotypic variance increased as lactation progressed. Estimated repeatabilities were significant for all the traits at all the states, being high for body weight at the different states (on av. 0.71) and low-moderate for the other traits 
(from 0.15 to 0.36$)$. No evidence of great changes over the reproductive cycle in the repeatability of any trait was observed.

Table 2.2 Phenotypic variance and repeatability of traits conditioning acquisition and partition of energy at different states of the reproductive rabbit-female cycle. Standard error into brackets.

\begin{tabular}{lccc}
\hline & \multicolumn{3}{c}{ State $^{1}$} \\
\cline { 2 - 4 } & (i) & (ii) & (iii) \\
\hline Phenotypic variance & & & \\
Feed intake (g DM/day) & $1635(105.7)^{*}$ & $4384(268.0)^{*}$ & $892(61.0)^{*}$ \\
Available digestible energy (MJ/day) & $0.20(0.012)^{*}$ & - & $0.09(0.006)^{*}$ \\
Body weight (kg) & $0.14(0.011)^{*}$ & $0.15(0.014)^{*}$ & $0.17(0.015)^{*}$ \\
Perirenal fat thickness (mm) & $0.90(0.057)^{*}$ & $0.83(0.052)^{*}$ & $0.94(0.058)^{*}$ \\
Milk yield (g/day) & $977(61.4)^{*}$ & $2507(163.8)^{*}$ & $3545(237.9)^{*}$ \\
Litter weight (kg) & $0.03(0.002)^{*}$ & $0.28(0.018)^{*}$ & $1.27(0.078)^{*}$ \\
& & & \\
Repeatability & & & \\
Feed intake (g DM/day) & $0.27(0.051)^{*}$ & $0.16(0.054)^{*}$ & $0.29(0.055)^{*}$ \\
Available digestible energy (MJ/day) & $0.22(0.056)^{*}$ & - & $0.28(0.064)^{*}$ \\
Body weight (kg) & $0.65(0.038)^{*}$ & $0.78(0.027)^{*}$ & $0.70(0.035)^{*}$ \\
Perirenal fat thickness (mm) & $0.36(0.044)^{*}$ & $0.28(0.048)^{*}$ & $0.25(0.047)^{*}$ \\
Milk yield (g/day) & $0.24(0.053)^{*}$ & $0.27(0.052)^{*}$ & $0.28(0.054)^{*}$ \\
Litter weight (kg) & $0.15(0.048)^{*}$ & $0.26(0.052)^{*}$ & $0.20(0.052)^{*}$ \\
\hline
\end{tabular}

${ }^{1}$ State of the reproductive cycle: [For feed intake and available digestible energy: early lactation (i), late lacation (female+litter) (ii) and weaning to parturition interval (iii)]; [For body weight and perirenal fat thickness: parturition (i), day 18th of lactation (ii) and weaning (iii)]; [For milk yield: first week of lactation (i), second week (ii) and third week (iii)]; [For litter weight: total born (i), at day 18th of lactation (ii) and weaning (iii)]. - Period not evaluated. 'Significantly differed from zero $(P<0.05)$

Table 2.3 shows for each trait the correlations between the permanent effects at different states, between residuals at different states of a given reproductive cycle and between residuals of two consecutive reproductive cycles $(\rho)$. Regarding the permanent effects, correlations for feed intake varied from moderate $(0.56 \pm 0.14$ between early lactation and weaning to parturition interval) to high ( $0.83 \pm 0.13$ between early and late lactation). Estimated correlations for all the states of body weight, PFT and milk yield were very high (close to one), whereas for litter weight they were very high between day 18 of lactation and weaning and non-significant between parturition and the other two states. Regarding the residual effects, correlations between the residuals of two different states of a given reproductive cycle were lower than those between equivalent states for the permanent effects, varing all from low to moderate. Correlation between state i and iii $(0.10 \pm 0.050)$ was lower than between i and ii $(0.46 \pm 0.038)$ for feed intake. Likewise, for body weight and milk yield the correlation between state $\mathrm{i}$ and iii was lower than between $\mathrm{i}$ and ii and also lower than between ii and iii. For PFT, correlations were only significant between day 18 of lactation and weaning, but it was low. Regarding the correlations between the residuals of 
two consecutive reproductive cycles, they were low, but significant, for feed intake, ADE, milk yield and litter weight (from 0.13 to 0.20 ), whereas they were moderate for body weight $(0.32 \pm 0.05)$ and non-significant for PFT.

Table 2.3 Within-trait correlations for the traits conditioning acquisition and partition of energy of the reproductive rabbit female: between the permanent effects, between residuals from a given cycle and between residuals from two consecutive cycles ( $\rho)$. Standard error into brackets.

\begin{tabular}{|c|c|c|c|c|c|}
\hline & \multicolumn{2}{|c|}{ Permanent } & \multicolumn{3}{|c|}{ Residuals } \\
\hline & (ii) & (iii) & (ii) & (iii) & $\rho^{1}$ \\
\hline $\begin{array}{l}\text { Feed intake (g DM/day) } \\
\text { (i) Early lactation } \\
\text { (ii) Late lactation }{ }^{2} \\
\text { (iii )Weaning-Parturition }\end{array}$ & $0.83(0.128)^{*}$ & $\begin{array}{l}0.56(0.138)^{*} \\
0.68(0.160)^{*}\end{array}$ & $0.46(0.038)^{*}$ & $\begin{array}{l}0.10(0.050)^{*} \\
0.20(0.049)^{*}\end{array}$ & $0.17(0.045)^{*}$ \\
\hline $\begin{array}{l}\text { Available digestible energy (MJ/day } \\
\text { (i) Early lactation } \\
\text { (iii) Weaning-Parturition }\end{array}$ & & $0.53(0.165)^{*}$ & & $0.07(0.051)$ & $0.20(0.057)^{*}$ \\
\hline $\begin{array}{l}\text { Body weight (kg) } \\
\text { (i) Parturition } \\
\text { (ii) Day } 18 \text { of lactation } \\
\text { (iii) Weaning }\end{array}$ & $0.97(0.024)^{\circ}$ & $\begin{array}{l}1.00(0.030)^{*} \\
1.00(0.011)^{*}\end{array}$ & $0.41(0.044)^{\circ}$ & $\begin{array}{l}0.17(0.051)^{*} \\
0.58(0.033)^{*}\end{array}$ & $0.32(0.051)^{*}$ \\
\hline $\begin{array}{l}\text { Perirenal fat thickness (mm) } \\
\text { (i) Parturition } \\
\text { (ii) Day } 18 \text { of lactation } \\
\text { (iii) Weaning }\end{array}$ & $0.90(0.087)^{*}$ & $\begin{array}{l}0.96(0.089)^{*} \\
0.99(0.094)^{*}\end{array}$ & $0.03(0.047)$ & $\begin{array}{l}0.05(0.048) \\
0.10(0.047)^{*}\end{array}$ & $0.02(0.038)$ \\
\hline $\begin{array}{l}\text { Milk yield (g/day) } \\
\text { (i) Week } 1 \text { of lactation } \\
\text { (ii) Week } 2 \text { of lactation } \\
\text { (iii) Week } 3 \text { of lactation }\end{array}$ & $1.00(0.039)^{\circ}$ & $\begin{array}{l}0.96(0.066)^{*} \\
0.99(0.030)^{*}\end{array}$ & $0.72(0.022)^{\circ}$ & $\begin{array}{l}0.56(0.032)^{*} \\
0.80(0.017)^{*}\end{array}$ & $0.18(0.043)^{\circ}$ \\
\hline $\begin{array}{l}\text { Litter weight (kg) } \\
\text { (i) Parturition } \\
\text { (ii) Day } 18 \text { of lactation } \\
\text { (iii) Weaning }\end{array}$ & $0.22(0.177)$ & $\begin{array}{l}0.13(0.198) \\
0.94(0.026)^{*}\end{array}$ & $0.25(0.045)^{*}$ & $\begin{array}{l}0.18(0.047)^{*} \\
0.89(0.009)^{*}\end{array}$ & $0.13(0.040)^{*}$ \\
\hline
\end{tabular}

\section{Relations among traits}

Table 2.4 shows the estimated correlations between the permanent effects (above the main diagonal) and between residuals (under the main diagonal) of the six traits. Regarding correlations between the permanent effects, feed intake was positively correlated with all the other traits, these correlations being low for PFT, moderate for body weight and high for milk yield, litter weight and ADE. Similarly, ADE was highly correlated with milk yield and litter weight, but correlations with body weight and PFT were not significant. PFT was moderately correlated with body weight and litter weight was highly correlated with milk yield. Regarding the residual correlations, feed intake was highly correlated with ADE, milk yield and litter weight, but the correlations with body weight and PFT were not 
significant. Correlations of $\mathrm{ADE}$ with milk yield and with litter weight were positive and moderate, whereas the correlation was negative but low with body weight. The correlation between body weight and PFT was positive and moderate, between PFT and milk yield it was negative and low, and between milk yield and litter weight it was high and positive.

Table 2.4 Above the main diagonal, correlations between the permanent effects of the traits conditioning acquisition and partition of energy of the reproductive rabbit female. Under the main diagonal, residual correlations between traits. Standard error into brackets.

\begin{tabular}{|c|c|c|c|c|c|c|}
\hline & $\mathrm{FI}$ & ADE & BW & PFT & MY & LW \\
\hline Feed intake (FI; g DM/day) & & $0.90(0.027)^{\circ}$ & $0.46(0.086)^{\circ}$ & $0.26(0.105)^{\circ}$ & $0.72(0.058)^{\circ}$ & $0.83(0.044)$ \\
\hline Available digestible energy (ADE; MJ/day) & $0.80(0.018)^{*}$ & & $0.14(0.101)$ & $0.01(0.111)$ & $0.75(0.058)^{*}$ & $0.75(0.064)$ \\
\hline Body weight (BW; kg) & $0.05(0.050)$ & $-0.12(0.050)^{*}$ & & $0.52(0.067)^{*}$ & $-0.05(0.098)$ & $0.08(0.106)$ \\
\hline Perirenal fat thickness (PFT; mm) & $-0.04(0.049)$ & $-0.09(0.049)$ & $0.30(0.044)^{*}$ & & $0.12(0.108)$ & $0.18(0.116)$ \\
\hline Milk yield (MY; g/day) & $0.76(0.021)^{*}$ & $0.66(0.029)^{*}$ & $0.03(0.048)$ & $-0.10(0.048)^{*}$ & & $0.92(0.021)$ \\
\hline Litter weight (LW; kg) & $0.80(0.018)^{\circ}$ & $0.60(0.032)^{\circ}$ & $-0.01(0.048)$ & $-0.08(0.048)$ & $0.89(0.009)^{\circ}$ & \\
\hline
\end{tabular}

'Significantly differed from zero $(\mathrm{P}<0.05)$.

\section{Discussion}

The real trajectory that the animal aim at achieving (defined by homeorhesis) and regulations (homeostasis) are difficult to obtain, as they are always subjected to the given environment where the phenotypic records have been measured. Moreover, it is not possible to provide a perfect non-limiting environment to all the animals. However, Friggens et al., (2013) proposed that assuming that the curves obtained during the statistical evaluation of animals (such as genetic evaluations) reflect the potential within the current production system (diets, type of animals, management...) and would allow for the integration of animal factors into nutrient partitioning models. According to Roche et al. (2009), the part of the trajectory due to the effect of the animal could be individually estimated from the individual solutions of the permanent effect (random effect) plus the mean trajectory (fixed effects). In the present experiment, the part of the trajectory estimated by the permanent effect would reflect the trajectory that the animal aims at achieving (targeted trajectory) under the production system defined.

\section{(Co)Variation between animals and the homeorhetic control}

The permanent effects of the animal were integrated by the genetic and the permanent environmental effects. Repeatability is the ratio between the variance of the permanent effect and the sum of variances associated with the permanent and residual effects (values ranging from 0 to 1 ). Note that repeatability is positively related with heritability, because the permanent effect of an animal includes the genetic additive component of the animal. However, repeatability is always higher than heritability as also 
includes the effect of the permanent environment. Therefore, for an observed phenotype in a given state and production system, the higher the repeatability for a trait, the higher the proportion of the phenotype that depends on the animal and the lower that depending on non-constant environment. Estimates for repeatabilities of performance traits in reproductive rabbit females are scarce. Lukefahr and Hamilton (1997) reported a repeatability of 0.30 for feed intake during early lactation and 0.72 for body weight at parturition, in agreement with those reported in this study. However, they reported low repeatability for litter weight at different states of lactation (0.03 to 0.14 ), although they became higher when corrected by litter size (0.24 to 0.30). They proposed that standardizing litters at birth would increase repeatability. In this sense, the low-moderate repeatability we estimated for litter weight $(0.15$ to 0.26 ) would be the consequence of our standardization process at birth. Similarly, the higher estimates for repeatability of milk yield we have reported compared with those reported by Iraqi et al. (2010), ranging from 0.04 to 0.10 , would also be the consequence of litter standardization. Regarding the PFT of reproductive females, no information has been reported in reproductive rabbits females, but our estimates are comparable to those reported for back fat thickness in reproductive sows (Arango et al., 2005; Grandinson et al., 2005).

On the other hand, although we observed that phenotypic variance changed over the reproductive cycle for some traits, we could not elucidate properly whether repeatability of a given trait changed over the reproductive cycle, as has been reported in other species for heritability (Coffey et al., 2001; David et al., 2015). However, through correlations between the permanent effects, we were able to evaluate whether different animals follow different trajectories over the reproductive cycle. The high correlations we have reported denote that the permanent effect at a given state is highly related with the other states, indicating little change in the trajectory between animals (there was little change in the ranking of animals among states). In this sense, the correlations close to one between states and the moderate estimates for repeatability of most of the traits we found indicate that there was considerable variation between animals for all the traits, but animals tended to follow similar trajectories across the reproductive cycle. This phenomenon can be observed in Figure 2.1, where individual trajectories of rabbit females over the different states of the reproductive cycle are represented for all the traits. These results are in agreement with those reported in dairy cattle by Coffey et al. (2001) and with Taylor (1985), who stated that most of the differences between animals are the consequence of scale factors (such as animal size or maximum milk yield) rather than changes in shape of the trajectories. However, permanent correlations for feed intake of states within lactation with the state out of lactation were far from one (0.56 and 0.68). In fact, they were high enough to indicate that animals with a great feed intake tended to have this high intake during the whole reproductive cycle, but low enough to allow different strategies between females. 

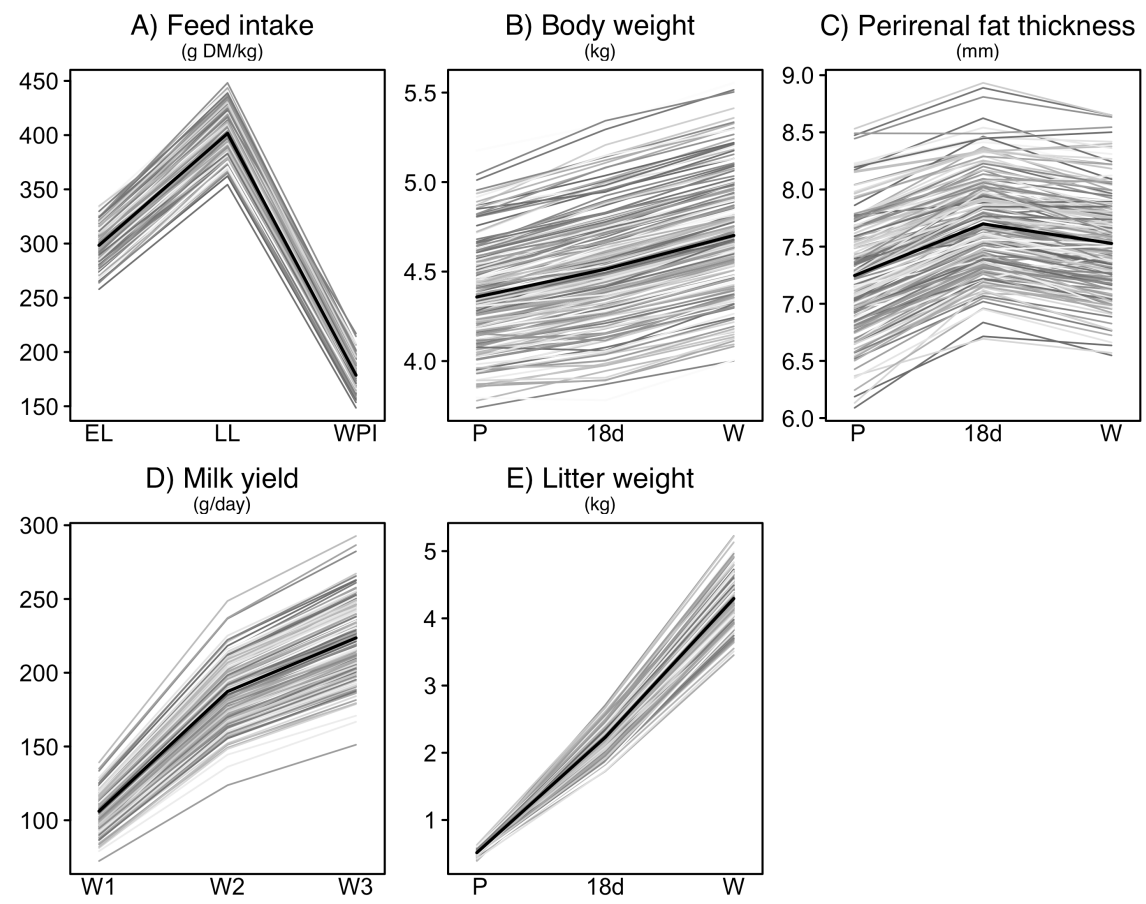

E) Litter weight

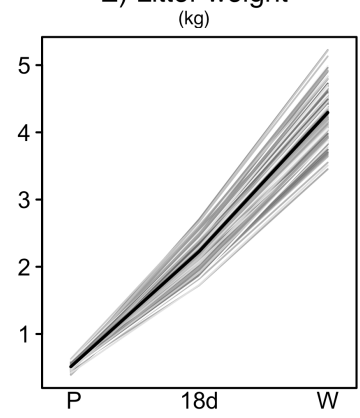

Figure 2.1 Individual trajectories of rabbit females across different states of their reproductive cycle represented for each one of the evaluated traits which condition acquisition and partition of energy. The black line represents the trajectory of the mean animal. EL: early lactation; LL: late lactation; WPI: weaning to parturition interval; P: parturition; 18d: day 18 of lactation; W: weaning; W1, W2, W3: week 1, 2, 3 of lactation.

Regarding correlations between the permanent effects of different traits, bigger animals tended to have greater intake, had more fat and produced more milk than the mean animal (and vice versa). However, after removing the energy for maintenance from the digestible energy ingested (ADE), the relation with milk yield remained, but the relation with body weight and body reserves disappeared. These results, jointly with the fact that most of the permanent correlations between traits were considerably lower than one, denote that there was a large number of different strategies between animals in the way they allocated energy. This idea can be observed in Figure 2.2, where each animal is represented by a hexagon whose vertices are its permanent effects for each trait. In this figure, it can be observed that there were heavy animals with moderate PFT and ADE or animals with high ADE and milk yield but low PFT. 


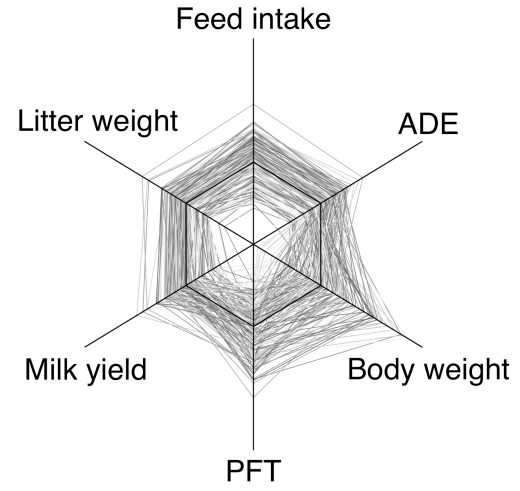

Figure 2.2 Estimated permanent value for each rabbit female and trait. Each hexagon represents one female with a particular combination of traits conditioning energy balance. The variability between females of these combinations represents the amount of strategies between animals for energy acquisition and allocation in a given nutritional environment. To show traits in a comparable scale, all the estimated values have been standardized dividing by their phenotypic standard deviation. The black hexagon represents the mean animal and the centre an animal placed two phenotypic standard deviations under the mean for all the traits. ADE: Available digestible energy. PFT: Perirenal fat thickness.

\section{Covariation within animals and homeostatic regulation}

All the previous discussion indicates that, for the traits considered on this work, the effect of the animal is relevant in the observed phenotypic variability. Nonetheless, the results showed that there was also an important impact of non-controlled environmental changes (low-moderate repeatabilities). These non-controlled environmental changes perturb trajectories involving the homeorhetic control, homeostatic regulation and its articulation (Sauvant and Martin, 2010). Figure 2.3 shows a schematic view of the relation between the process involved nutrient partitioning and information provided by the estimated residuals with mixed models. In Figure 2.3a, the grey line represents the effective trajectory of a given female, which is the response to the environmental factors, homeorhetic control and homeostatic regulation. The last acts to tend to achieve the targeted trajectory (black line) in a non-constant environment. In Figure $2.3 \mathrm{~b}$ is represented the effective (grey lines) and targeted trajectories (black lines) of two different females. The distance between the effective and targeted trajectories represents the environmental effect on the trajectories of each female (notice that the environmental effect is different for each female). This distance would also reflect the residual term included in the model of that record (notice that residuals only gather the environmental effects not considered as fixed effect). We can observe that residuals from points close in time (e.g. $\mathrm{t} 1-\mathrm{t} 2$ or $\mathrm{t} 3-\mathrm{t} 4)$ are more correlated than residuals far in time (e.g. t1-t4). Therefore, as proposed by Littell et al. (1998), observations close in time are correlated but correlation tends to decrease as increasing the lag of time between observations. From a biological point of view, it would indicate that environmental effects affecting at one record could persist in subsequent records, but their effects decrease with time. Consequently, residual correlation could be a way to evaluate the effect of environment on subsequent observations (states or reproductive cycles) in a non-controlled and nonpredictable environment. 
a)

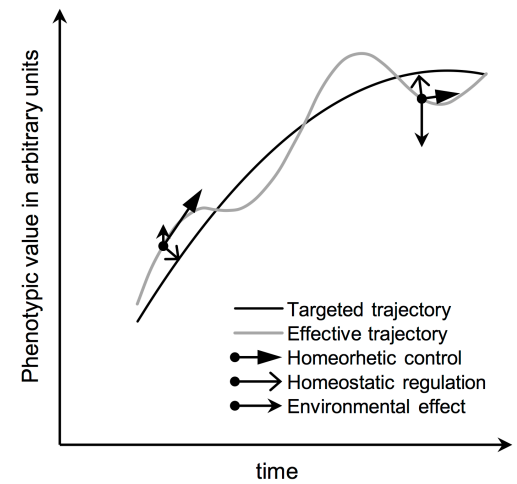

b)

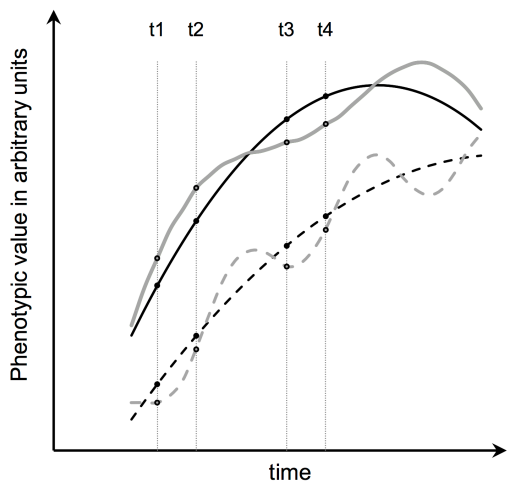

Figure 2.3 Schematic view of the relation between the process involving nutrient partitioning (a) and information provided by the estimated residuals with mixed models from two different animals (b). Grey lines represent effective trajectories, black lines represent targeted trajectory (a) or the trajectory defined by the permanent effects of the female (b). The distance between the trajectory defined by the permanent effects of the females and the effective trajectory is the residual term and represents the environmental effects.

In general, our results showed that correlations between two close states within a given reproductive cycle were higher than between non-consecutive states (Table 2.3), confirming that environmental effects on the trajectories persist but their effects decreased with time. Moreover, the fact that the estimated autoregressive factor between reproductive cycles $(\rho)$ was significantly higher than zero in most of the traits proved that perturbations persisted not exclusively in the short term. However, assuming that any change in the environmental conditions will be the same for all the traits of that animal (in duration and intensity), it seems that environmental effects perturbed the targeted trajectories differently depending on the trait. Thus, deviations from the targeted trajectory had a long-term effect $(\rho)$ for feed intake, ADE, milk yield, litter weight and especially for body weight, whereas effects were only in the short-term for PFT. These results could indicate that the time to return to the targeted trajectory of a given animal is different depending on the trait. Figure 2.4 represents the residuals for all the observations of two animals for a trait where residuals within an animal were moderately correlated not exclusively in the short term (feed intake; Figure 2.4A), and for another trait where correlations between residuals were low (PFT; Figure 2.4B). For feed intake, the moderate residual correlations can be reflected in the fact that the residuals from both animals were above or below zero for more than one complete reproductive cycle at least once during the experiment. Regarding PFT, the low correlations between residuals could mean that animals tend to return rapidly to the targeted trajectory defined by the animal. However, considering the accuracy of measurement and variability among physiological states (Pascual et al., 2004), these low correlations could also be the consequence of noise in the records. 
On the other hand, by comparing residual correlations between traits, we could establish relations between traits when there was a movement from their targeted trajectory caused by non-controlled environmental changes. Thus, when as a consequence of the environmental effects, animals were able to increase their intake in a reproductive cycle, they addressed this extra energy towards milk yield and litter weight, rather than towards body weight or body reserves (and vice versa). In fact, animals tended to acquire less ADE when they were heavier than normal (and vice versa). This latter result showed a certain regulation of body weight on energy acquisition, which would be in agreement with the lipostatic theory for the regulation of energy intake (Kennedy, 1953) and the homeostatic regulation of energy intake to achieve the targeted trajectory for body weight. Therefore, residual correlations between traits could be interpreted as the way animals regulate acquisition of energy and its partition in order to maintain homeostasis in a particular production system.

A) Feed intake

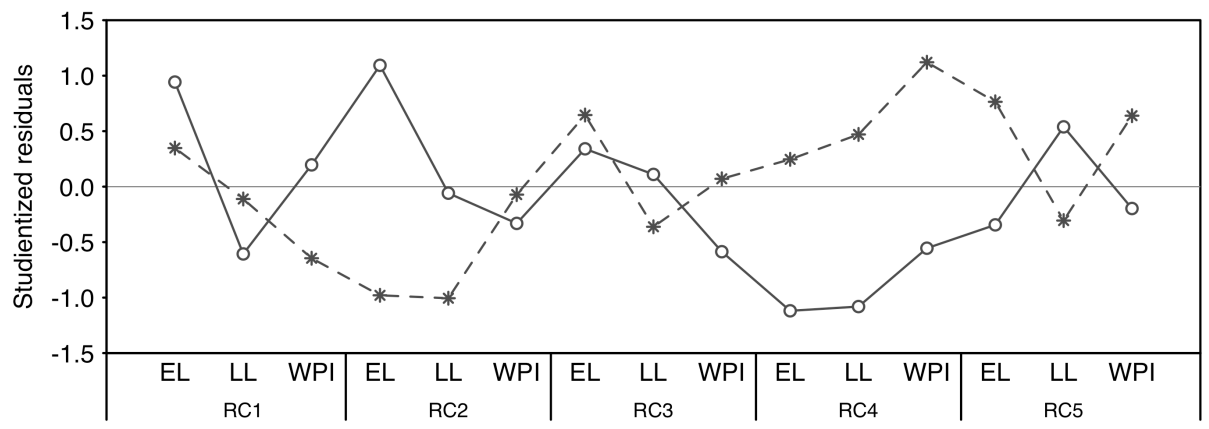

B) Perirenal fat thickness

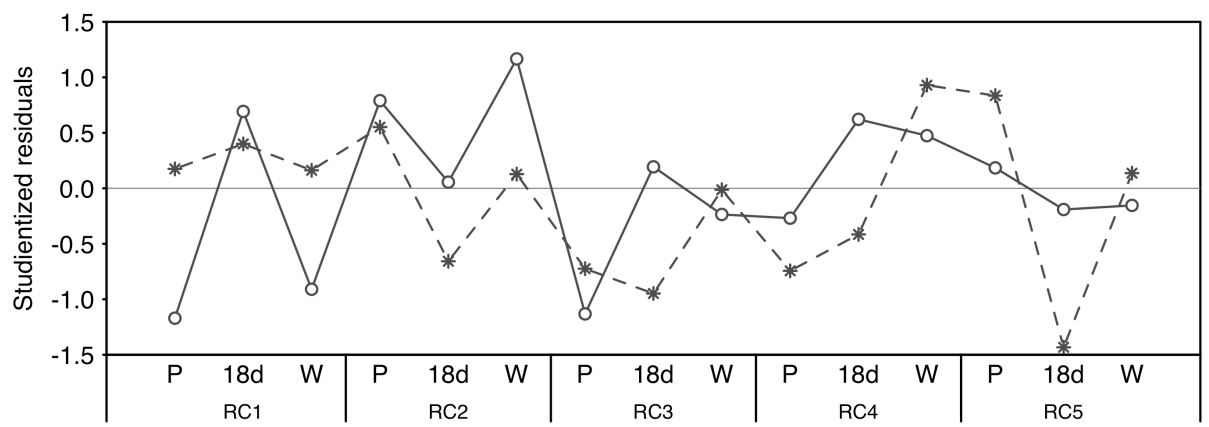

Figure 2.4 Studentized residuals for two different rabbit females (raw residuals divided by their estimated standard error). Feed intake (A) exemplifies a trait where residuals within a given animal were moderately correlated, whereas perirenal fat thickness $(B)$ exemplifies a trait where residuals within a given animal were little correlated. EL: early lactation; LL: late lactation; WPI: weaning to parturition interval; P: parturition; 18d: day 18 of lactation; W: weaning; RC: Reproductive cycle. 


\section{Body condition under this framework}

Information provided in this work could be used to interpret why nutritional strategies do not always work as expected. In this sense, several nutritional strategies (Pascual et al., 2003) have been designed to increase energy intake in order to lessen the negative effects of poor body condition on females' functionality (Cardinali et al., 2008; Sánchez et al., 2012). However, it was not always possible to improve considerable energy intake and many times, when it was reached, the extra energy intake was mainly addressed to milk yield rather than to body reserves (Lebas and Fortun-Lamothe, 1996; Pascual et al., 1998). On the contrary, with the presented results we would not expect that animals would increase their body reserves by increasing dietary energy content (residual correlation between ADE and PFT -0.09). We would expect that these animals would address the extra energy towards milk yield and the current litter (residual correlation between ADE and milk yield +0.66).

As nutritional strategies have not solve completely the negative effects of poor body condition on females' functionality, Xiccato et al. (1995) and Castellini et al. (2010) have proposed using strategies focused on searching for animals with a higher energy intake or with a higher amount of body reserves. However, considering results from the present study these animals also would tend to be heavier (permanent correlation 0.46 and 0.52 respectively, $P<0.05)$, which is not desirable. Therefore, considering that there was certain flexibility in the trajectories of feed intake over the reproductive cycle and considering also the number of strategies between animals in the way they acquire and partition energy, strategies should be addressed to searching for animals with proper acquisition and partition of energy over time (e.g. great intake during lactation mainly addressed to milk yield but without conditioning body reserves and low intake out of lactation).

\section{Conclusions}

We have shown that mixed models can provide information to interpret nutrient partitioning in a particular production system in terms of homeorhetic control and homeostatic regulation. If they are applied to the progress of a given trait over time, they can provide information on the individual trajectories of the females over the reproductive cycle and the ability to return to the targeted trajectory when the effective trajectory is deviated due to environmental effects. If they are applied to comparison among traits, they can provide information on the strategies among animals for nutrient partitioning and the way animals regulate acquisition of energy and its partition in order to maintain homeostasis. This information could be useful to develop sustainable strategies addressed to improving efficiency but balancing functionality of animals. 


\section{Acknowledgments}

The authors greatly thank Neil Macowan for checking English language of the manuscript. This study was supported by the Interministerial Commission for Science and Technology (CICYT) of the Spanish Government (AGL2014-53405-C2-1-P). Grant for Alberto Arnau from the Ministry of Economy and Finance (BES-2012-052345) is also gratefully acknowledged.

\section{References}

Arango J, Misztal I, Tsuruta S, Culbertson M and Herring W 2005. Threshold-linear estimation of genetic parameters for farrowing mortality, litter size, and test performance of Large White sows. Journal of Animal Science 83, 499-506.

Bauman DE and Currie WB 1980. Partitioning of nutrients during pregnancy and lactation: a review of mechanisms Involving homeostasis and homeorhesis. Journal of Dairy Science 63, 1514-1529.

Cardinali R, Dal Bosco A, Bonanno A, Di Grigoli A, Rebollar PG, Lorenzo PL and Castellini C 2008. Connection between body condition score, chemical characteristics of body and reproductive traits of rabbit does. Livestock Science 116, 209-215.

Castellini C, Dal Bosco A, Arias-Álvarez M, Lorenzo PL, Cardinali R and Rebollar PG 2010. The main factors affecting the reproductive performance of rabbit does: a review. Animal Reproduction Science 122, 174-182.

Cifre J, Baselga M, García-Ximénez F and Vicente JS 1998. Performance of a hyperprolific rabbit line I. Litter size traits. Journal of Animal Breeding and Genetics 115, 131-138.

Coffey MP, Emmans GC and Brotherstone S 2001. Genetic evaluation of rairy bulls for energy balance traits using random regression. Animal Science 73, 29-40.

David I, Ruesche J, Drouilhet L, Garreau H and Gilbert H 2015. Genetic modeling of feed intake. Journal of Animal Science 93, 965-77.

Estany J, Camacho J, Baselga M and Blasco A 1992. Selection response of growth rate in rabbits for meat production. Genetics Selection Evolution 24, 527-537.

Fernández-Carmona J, Blas E, Pascual JJ, Maertens L, Gidenne T and García J 2005. Recommendations and guidelines for applied nutrition experiments in rabbits. World Rabbit Science 13, 209-228.

Fortun-Lamothe L 2006. Energy balance and reproductive performance in rabbit does. Animal Reproduction Science 93, 1-15.

Friggens NC and Newbold JR 2007. Towards a biological basis for predicting nutrient partitioning: the dairy cow as an example. Animal 1, 87-97.

Friggens NC, Brun-Lafleur L, Faverdin P, Sauvant D and Martin O 2013. Advances in predicting nutrient partitioning in the dairy cow: recognizing the central role of genotype and its expression through time. Animal 7, 89-101.

Grandinson K, Rydhmer L, Strandberg E and Solanes FX 2005. Genetic analysis of body condition in the sow during lactation, and its relation to piglet survival and growth. Animal Science 80, 33-40. 
Hedeker D and Gibbons RD 2006. Longitudinal data analysis. John Willey \& Sons, Chicago, USA.

Iraqi MM, García ML, Khalil MH and Baselga M 2010. Evaluation of milk yield and some related maternal traits in a crossbreeding project of Egyptian Gabali breed with Spanish V-line in rabbits. Journal of Animal Breeding and Genetics 127, 242-248.

Kennedy GC 1953. The role of depot fat in the hypothalamic control of food intake in the rat. Proceedings of the Royal Society of London B: Biological Sciences 140, 578-592.

Lebas F 1968. Mesure quantitative de la production laitière chez la lapine. Annales de Zootechnie 17, 169-182.

Lebas F and Fortun-Lamothe L 1996. Effects of dietary energy level and origin (starch vs oil) on the performance of rabbits does and their litters: average situation after 4 weanings. Proceedings of the 6th World Rabbit Congress, 9 July 1996, Toulouse, France, pp. 217-221.

Littell RC, Henry PR and Ammerman CB 1998. Statistical analysis of repeated measures data using SAS procedures. Journal of Animal Science 76, 1216-31.

Lukefahr S and Hamilton $\mathrm{HH}$ 1997. Heritability and repeatability estimates of maternal performance traits in purebred and crossbred does. World Rabbit Science 5, 99-105.

Pascual JJ, Cervera C, Blas E and Fernández-Carmona J 1998. Effect of high fat diets on the performance and food intake of primiparous and multiparous rabbit does. Animal Science 66, 491-499.

Pascual JJ, Castella F, Cervera C, Blas E and Fernández-Carmona J 2000. The use of ultrasound measurement of perirenal fat thickness to estimate changes in body condition of young female rabbits. Animal Science 70, 435-442.

Pascual JJ, Cervera C, Blas E and Fernández-Carmona J 2003. High-energy diets for reproductive rabbit does: effect of energy source. Nutrition Abstracts and Reviews 73, 27R-39R.

Pascual JJ, Blanco J, Piquer O, Quevedo F and Cervera C 2004. Ultrasound measurements of perirenal fat thickness to estimate the body condition of reproducing rabbit does in different physiological states. World Rabbit Science 12, 7-21.

Roche JR, Friggens NC, Kay JK, Fisher MW, Stafford KJ and Berry DP 2009. Invited review: Body condition score and its association with dairy cow productivity, health, and welfare. Journal of Dairy Science 92, 5769-5801.

Sánchez JP, Theilgaard P, Mínguez C and Baselga M 2008. Constitution and evaluation of a long-lived productive rabbit line. Journal of Animal Science 86, 515-525.

Sánchez JP, de la Fuente LF and Rosell JM 2012. Health and body condition of lactating females on rabbit farms. Journal of Animal Science 90, 2353-2361.

Sauvant D and Martin O 2010. Robustesse, rusticité, flexibilité, plasticité... les nouveaux critères de qualité des animaux et des systèmes d'élevage: définitions systémique et biologique des différents concepts. INRA Productions Animales 23, 5-10.

Taylor CS 1985. Use of genetic size-scaling in evaluation of animal growth. Journal of Animal Science 61, 118-143. 
Xiccato G and Trocino A 2010. Energy and protein metabolism and requirements. In Nutrition of the Rabbit, 2ndedition (ed. De Blas JC, Wiseman J), pp. 83-118. CABI Publishing, Wallingford, UK.

Xiccato G, Parigi-Bini R, Dalle Zotte A, Carazzolo A and Cossu M 1995. Effect of dietary energy level, addition of fat and physiological state on performance and energy balance of lactating and pregnant rabbit does. Animal Science 61, 387-398. 


\title{
PAPER III
}

\section{Long-term implications of fitting feed energy source to the genetic type in reproductive rabbit females. I. Resource acquisition and allocation}

\author{
Arnau-Bonachera $\mathrm{A}^{1}$, Cervera $\mathrm{C}^{1}$, Blas $\mathrm{E}^{1}$, Larsen $\mathrm{T}^{2}$, \\ Martínez-Paredes $\mathrm{E}^{1}$, Ródenas $\mathrm{L}^{1}$ and J.J. Pascual ${ }^{1}$. \\ ${ }^{1}$ Institute for Animal Science and Technology, Universitat Politècnica de València, Camino \\ de Vera, s/n. 46071 Valencia, Spain. \\ ${ }^{2}$ Department of Animal Science, Integrative Physiology. Aarhus University. Blichers Allé 20. \\ 8830, Tjele, Denmark.
}

Submitted to Animal on May 2017 



\begin{abstract}
Genetic selection has improved considerably productivity of animals during the last 50 years, accompanied by a process of specialization of selected animals. However, sometimes this specialization has been linked to functional disorders, where the way animals acquire and allocate resources over time play a key role. To balance between productivity and functionality, we hypothesized that it is possible to modulate acquisition and allocation of animals from different genetic types by selecting properly the main energy source of the diet. To test this hypothesis, we used 203 rabbit belonging to 3 genetic types: $\mathrm{H}$, maternal line characterised by hyper-prolificacy; LP, maternal line characterised by functional hyperlongevity; R, paternal line characterised by growth rate. Females were fed during 5 consecutive reproductive cycles with 2 isoenergetic and isoprotein diets differing in energy source: animal fat (AF) enhancing milk yield; cereal starch (CS) promoting body reserves recovery. Performance and blood traits were controlled and numerous interactions were found in all traits. Results seem to indicate that $\mathrm{R}$ females were characterised by a high dependence on body reserves to cope with the reproductive requirements of the current reproductive cycle. $\mathrm{H}$ females were also highly dependent on body reserves, but storing body reserves during lactation to cope with future reproduction. LP females were characterised by an acquisition capacity better fitted to changing requirements, safeguarding body reserves. However, it seems that although trajectories of foundation or selection could have affected the acquisition and allocation strategies, they might also have affected the way females respond to diets across their life trajectories.
\end{abstract}

Keywords: Strategy, energy partitioning, life trajectory. 



\section{Introduction}

In the last 40 years, there has been a huge phenotypic improvement in most of productive traits of domestic animal species (Hill, 2008). This improvement was achieved thanks to the progress not only in genetics, but also on nutrition or management. However, long-term selection exclusively for productive criteria tend to generate specialised animals (Poggenpoel et al., 1996; Hansen, 2000) that prioritise functions related with the global context in which they have been selected (Savietto, 2014). As a result of this specialisation, depending on circumstances, selection exclusively for production criteria could be accompanied by undesired side effects (Rauw et al., 1998). In fact, Hocking (2014) recently argued that negative side effects of selection for productive criteria are inevitable. Therefore, one of the main challenges in the current animal science consists of developing strategies that provide productive but also balanced animals in their breeding context. In these circumstances, the importance of the way animals acquire and allocate resources among life functions is becoming highly relevant (Rauw, 2009). Acquisition and allocation of resources are affected by the animal's priorities throughout its life and could condition performance and health in the long term as they define the investment in each function at each moment of the life trajectory.

In this scenario, the rabbit represents a good zootechnical model to investigate these relationships in the long term, as they have a relatively short reproductive cycle and there are genetic lines founded and selected for a wide range of goals (Baselga, 2004) with different priorities among life functions. For instance, females coming from selection programmes aiming to improve daily gain during the growing period tend to be bigger and to gain more fat, but have lower maternal abilities (Gómez et al., 1999). Furthermore, females coming from selection programmes aiming to improve litter size tend to yield more milk, with some genetic types basing reproduction on body fat utilisation and others on feed intake ability (Savietto et al., 2013).

On the other hand, the energy source of the diet also plays an important role in the way rabbit females acquire and allocate resources. Although the effect can be different depending on whether the females are primiparous or multiparous, it has been reported that fat-enriched diets slightly increase energy intake and favour milk yield, whereas starchenriched diets favour body reserves gain (Pascual et al., 2003). Thus, if life functions are differently prioritised depending on the genetic type, and acquisition and allocation of resources are modulated by the diet, it could be hypothesised that nutritional strategies adapted to genetic type could allow a more suitable resource allocation throughout the female's life trajectory. This fitting could help to modulate performance and health of females in the long term, and consequently lifespan. In this sense, one could argue that females from 
maternal lines, with a great lactation effort, could not ensure body reserves properly and they could benefit from a diet that favoured body reserves. On the other hand, females from paternal lines could increase their maternal investment and avoid being overfat with a diet that favoured milk yield. In addition, studying the way nutrition and genetics interact could help us to better understand the way acquisition and allocation of resources are linked.

This is the first of three consecutive scientific papers that aim to evaluate the hypothesis that an adequate fitting of feed energy source to the genetic type may contribute to a sustainable production in the long term. The present thesis involves the first and third papers of this series, whereas the second one, which is related to the immunologic status of the animals used in this experiment, will be presented in Penades' thesis (2017). Specifically, in the present work we studied the dynamics of resource acquisition and allocation of three genetic types widely differing in genetic background, and how feed energy source could modulate them.

\section{Materials and methods}

The experimental procedure was approved by the Animal Welfare Ethics Committee of the Universitat Politècnica de València (UPV) and carried out following the recommendations of the European Group on Rabbit Nutrition (Fernández-Carmona et al., 2005) and the Spanish Royal Decree 53/2013 on the protection of animals used for scientific purposes.

\section{Animals}

A total of 203 female rabbits were used from their first artificial insemination (AI) until their sixth parturition (from December 2011 to April 2013). Rabbit females belonged to three genetic types developed at the Institute of Animal Science and Technology of the Universitat Politècnica de València (UPV), differing greatly in their genetic background. Line $\mathrm{H}(\mathrm{n}=66)$ was founded by hyper-prolific criteria at birth (more than 17 young born alive in any parity or cumulative number of young born alive in all recorded parities equal or higher to the threshold corresponding to the best 0.01 in a population with a mean of nine young born alive, a standard deviation of 2.65 and a repeatability of 0.2.; Cifre et al., 1998), and selected by litter size at weaning during 17 generations; line LP ( $n=67)$ was founded by functional hyper-longevity (females with at least 25 parturitions in commercial farms and an average live litter size of 8.8; more details in Sánchez et al., 2008), characterised by a high robustness (Theilgaard et al., 2009; Savietto et al., 2015), and selected for litter size at weaning during 7 generations; and line $\mathrm{R}(\mathrm{n}=70)$ was founded after 2 generations of randomly mating from a pool of animals of 3 commercial sire lines (Estany et al., 1992), and selected over 38 generations for average daily gain during the growing period. 
Two experimental diets were formulated and pelleted (Table 3.1), following the recommendations of De Blas and Mateos (2010) for reproductive rabbit females, enhancing major differences in energy source. The CS diet was prepared promoting cereal starch [237 $\mathrm{g}$ of starch and $21 \mathrm{~g}$ of ether extract (EE) per kg of DM], whereas in AF diet part of the starch was replaced by animal fat (105 g of starch and $86 \mathrm{~g}$ of EE per $\mathrm{kg}$ of DM). Nevertheless, both diets were designed to be isoenergetic and isoprotein [on av. 11.3 $\mathrm{MJ}$ of digestible energy (DE) and $126 \mathrm{~g}$ of digestible protein (DP) per kg of DM].

Chemical analyses of diets were performed according to the methods: 934.01 for DM, 942.05 for ash, 976.06 for CP, and 920.39 for EE with acid-hydrolysis of samples prior to extraction (Association of Official Analytical of Chemists (AOAC), 2000). Starch content was determined by means of a two-step enzymatic procedure (Batey, 1982) with solubilisation and hydrolysis to maltodextrins with thermostable $\alpha$-amylase followed by complete hydrolysis with amyloglucosidase (Sigma-Aldrich, Steinheim, Germany), and the resulting glucose being measured using the hexokinase/glucose- 6 phosphate dehydrogenase/NADP system (R-Biopharm, Darmstadt, Germany). NDF, ADF and ADL fractions were analysed sequentially (Van Soest et al., 1991) with a thermostable $\alpha$-amylase pre-treatment and expressed exclusive of residual ash, using a nylon filter bag system (Ankom, Macedon, NY, USA).

Table 3.1 Ingredients and chemical composition of experimental diets.

\begin{tabular}{|c|c|c|c|c|c|}
\hline \multirow{2}{*}{$\begin{array}{l}\text { Ingredients } \\
(\mathrm{g} / \mathrm{kg})\end{array}$} & \multicolumn{2}{|c|}{ Diets $^{1}$} & \multirow{2}{*}{$\begin{array}{l}\text { Chemical composition } \\
\text { (g/kg DM) }\end{array}$} & \multicolumn{2}{|c|}{ Diets $^{1}$} \\
\hline & $\mathrm{AF}$ & CS & & $\mathrm{AF}$ & CS \\
\hline Barley grain & 129 & 91.5 & $\mathrm{DM}(\mathrm{g} / \mathrm{kg})$ & 911 & 909 \\
\hline Maize starch & 0 & 180 & Organic matter & 901 & 911 \\
\hline Soybean meal & 142.5 & 180 & Ether extract & 86 & 21 \\
\hline Lard & 60 & 0 & Starch & 105 & 237 \\
\hline Wheat bran & 100 & 100 & $\mathrm{CP}$ & 173 & 172 \\
\hline Alfalfa hay & 400 & 350 & NDF & 364 & 286 \\
\hline Sugar beet pulp & 100 & 40 & $\mathrm{ADF}$ & 195 & 162 \\
\hline Defatted grape seed & 30 & 30 & $\mathrm{ADL}$ & 40 & 31 \\
\hline Sugarcane molasses & 10 & 0 & Gross energy (MJ/kg DM) & 18.1 & 17.2 \\
\hline DL-Methionine & 2.5 & 2.5 & Digestible energy (DE; MJ/kg DM) $)^{3}$ & 11.4 & 11.1 \\
\hline Dicalcium phosphate & 18 & 18 & Digestible protein $(\mathrm{DP})^{3}$ & 126 & 126 \\
\hline Sodium chloride & 3 & 3 & $\mathrm{DP} / \mathrm{DE}(\mathrm{g} / \mathrm{MJ})$ & 11.1 & 11.3 \\
\hline Vitamin/mineral mixture $e^{2}$ & 5 & 5 & & & \\
\hline Robenidine (ppm) & 66 & 66 & & & \\
\hline \multicolumn{6}{|c|}{$\begin{array}{l}{ }^{1} \mathrm{AF} \text { : diet enhancing animal fat inclusion as main energy source; } \mathrm{CS} \text { : diet enhancing cereal starch as main energy } \\
\text { source. } \\
{ }^{2} \mathrm{Contains}(\mathrm{g} / \mathrm{kg}) \text { : thiamine, } 0.25 \text {; riboflavin, } 1.5 \text {; calcium pantothenate, } 5 \text {; pyridoxine, } 0.1 \text {; nicotinic acid, } 12.5 \text {; } \\
\text { retinol, } 2 ; \mathrm{cholecalciferol,} 0.1 ; \alpha \text {-tocopherol, } 15 ; \text { phytylmenaquinone, } 0.5 ; \text { cyanobalamin } 0.0006 \text {; choline chloride, } \\
100 ; \mathrm{MgSO}_{4} \mathrm{H}_{2} \mathrm{O}, 7.5 ; \mathrm{ZnO}, 30 ; \mathrm{FeSO}_{4} 7 \mathrm{H}_{2} \mathrm{O}, 20 ; \mathrm{CuSO}_{4} 5 \mathrm{H}_{2} \mathrm{O}, 3 ; \mathrm{KI}, 0.5 ; \mathrm{CoCl}_{2} 6 \mathrm{H}_{2} \mathrm{O}, 0.2 ; \mathrm{Na}_{2} \mathrm{SeO}_{3}, 0.03 \text {. } \\
{ }^{3} \text { Experimentally determined according to Perez et al. }(1995) \text {. Using } 24 \text { healthy growing rabbits of } 42 \text { days of live } \\
\text { per diet weaned at } 30 \text { days. Faces were collected during } 4 \text { days after a period of } 7 \text { days of adaptation to diets. }\end{array}$} \\
\hline
\end{tabular}




\section{Experimental procedure}

Females were housed under conventional environmental conditions (average daily temperatures varying from 13.3 to $26.1^{\circ} \mathrm{C}$ ), with an alternating cycle of $16 \mathrm{~h}$ of light and $8 \mathrm{~h}$ of darkness. Despite not all the females began the experiment at the same time, the entry of animals from each one of the three genetic type was distributed over time similarly. They were housed in individual cages $(700 \times 500 \times 320 \mathrm{~mm})$ at 12 weeks of age, inseminated at 19 weeks of age (with pooled semen of their respective lines) and provided with a nest for litters from day $28^{\text {th }}$ of gestation. After the first parturition, the females from the three genetic types were randomly assigned to one of the experimental diets. Until this moment, all the females received the same commercial diet for reproductive rabbit females (11.3 $\mathrm{MJ}$ of $\mathrm{DE}$, $141 \mathrm{~g}$ of DP, $170 \mathrm{~g}$ of starch and $34 \mathrm{~g}$ of EE per $\mathrm{kg}$ of DM). Experimental diets were provided ad libitum and the females from each group (within genetic type and experimental diet) were homogeneously distributed across the experimental farm. Litters were standardised to 8-9 kits at first parturition and 9-11 onwards within genetic type. This procedure was performed to equalize the energetic effort during lactation among females and to decrease the coefficient of variation of data (Fernández-Carmona et al., 2005) to increase the statistical accuracy of the estimates. Females were inseminated at 11 days postpartum and weaned at day 30 of lactation. Non-pregnant females were re-inseminated 21 days after until a maximum of three chances. Females and litters were controlled until $6^{\text {th }}$ parturition.

Traits

To study the dynamics of the acquisition and use of resources, all the traits were recorded several times within and throughout reproductive cycles $(\mathrm{RC})$.

Performance traits. Within RC, milk yield was recorded four days a week during the three first weeks of lactation. To record it, nests were closed, except for weekend, and once a day were opened to let the females suckle their kits. Milk yield was measured by weighing the females before and after suckling. From day 18 of lactation (18d) nests were kept permanently opened to allow kits leaving the nest and start solid intake. As kits could suckle freely and they had free access to the females' feeder, this situation prevented us from evaluating milk yield and feed intake of females during late lactation (from $18 \mathrm{~d}$ to weaning). Within RC feed intake was recorded during early lactation (EL, from parturition to $18 \mathrm{~d}$ ) and weaning to parturition interval (WPI). Body weight (BW) and perirenal fat thickness (PFT) was recorded at parturition, $18 \mathrm{~d}$ and weaning according to Pascual et al. (2000). Litter weight was recorded at birth, $18 \mathrm{~d}$ and weaning. 
Blood plasma traits. Blood samples were collected at parturition of the $1^{\text {st }}, 2^{\text {nd }}$ and $5^{\text {th }} \mathrm{RC}$, and at $18 \mathrm{~d}$ and weaning of the $1^{\text {st }}$ and $5^{\text {th }} \mathrm{RC}$, from the central artery of the ear using tubes with EDTA, always at 11:00 a.m. after a fasting period of $3 \mathrm{~h}$. Samples were immediately centrifuged ( $3000 \mathrm{x} \mathrm{g}$ during $10 \mathrm{~min}$ at $4^{\circ} \mathrm{C}$ ), and plasma was separated and frozen at $-40^{\circ} \mathrm{C}$ until further analysis. Plasma samples from 11 females per group [3 genetic types $(\mathrm{H}, \mathrm{LP}$ and $\mathrm{R}) \times 2$ diets $(\mathrm{AF}, \mathrm{CS})$ ] with complete records (from $1^{\text {st }}$ artificial insemination to $5^{\text {th }}$ weaning) were analysed for glucose, $\beta$-OH-butyrate, non-esterified fatty acids (NEFA) and leptin. Glucose was determined according to standard procedures (Siemens Diagnostics ${ }^{\circledR}$ Clinical Methods for ADVIA 1650). $\beta$-OH-butyrate was determined as an increase in absorbance at $340 \mathrm{~nm}$ due to the production of $\mathrm{NADH}$, at slightly alkaline $\mathrm{pH}$ in the presence of $\beta$-OH-butyrate dehydrogenase; sample blanks were included and the method involved oxamic acid in the media to inhibit lactate dehydrogenase as proposed by Harano et al. (1985). NEFA were determined using the NEFA C ACS-ACOD assay method (Wako Chemicals $\mathrm{GmbH}$, Neuss, Germany). Analyses of glucose, $\beta$-OH-butyrate, and NEFA were performed using an auto-analyser, ADVIA $1650 \circledR$ Chemistry 53 System (Siemens Medical Solutions, Tarrytown, NY 10591, USA); in all instances the intra- and inter-assay coefficients of variation were below 2.0 and $4.0 \%$, respectively. Leptin was analysed by Multi-Species Leptin assays (RIA, XL-85K) (Millipore Corporation, Billerica, MA, USA), according to the manufacturer's guidelines. Intra- and inter-assay coefficients of variation were 9.1 and $9.3 \%$, respectively.

\section{Statistical analysis}

Available $\mathrm{DE}$ for production (ADEP) in rabbit females was estimated individually by subtracting the energy for maintenance ( $430 \mathrm{kJday}^{-1} \mathrm{~kg}^{-1} \mathrm{LW}^{0.75}$; Xiccato and Trocino, 2010) to the DE intake.

For daily feed intake, ADEP, BW, PFT, milk yield and litter weight, all data from each trait was studied using only one statistic analysis. To perform it, we considered that records within an $\mathrm{RC}$ represented different states of the $\mathrm{RC}$. Consequently, variance was allowed to vary within an $\mathrm{RC}$, remaining constant throughout $\mathrm{RCs}$ for a given state. We included the permanent effect of the animal, which could be different depending on the state within an RC. These different permanent effects were assumed to be differently correlated among them. Regarding to the residuals, it was also considered that they could be different at different states within an $\mathrm{RC}$, being differently correlated among them and correlated in a decreasing way among reproductive cycles (the more distant two measures were, the lower was their correlation). In some respects, this way of modelling variance could be considered as that performed in multi-trait mixed models where states within an $\mathrm{RC}$ would be different traits, but correlated, and records among $\mathrm{RCs}$ would be repeated measures of these traits. 
Arnau-Bonachera et al. (2017a, 2017b) described it, for this kind of data, as a parsimonious model which, considering females and its sources of variation, allows a proper statistical fitting and a biological interpretation of its (co)variance components. This modelling was performed using the MIXED procedure from SAS (2009). Genetic type (H, LP, R), diet (AF, $\mathrm{CS}$ ), state within an RC (Feed intake: EL, WPI; ADEP: EL, WPI; BW: parturition, 18d, weaning; PFT: parturition, 18d, weaning; Milk yield: week 1, week 2, week 3; Litter weight: total born, standardisation, $18 \mathrm{~d}$, weaning) and $\mathrm{RC}\left(1^{\text {st }}, 2^{\text {nd }}, 3^{\text {rd }}-5^{\text {th }}\right)$ were included as main effects. We also included their interactions as fixed effects and the average inner temperature of farm during the $\mathrm{RC}$ as covariate for each state within an $\mathrm{RC}$. As not all the females got pregnant at first attempt and there are differences in resource allocation of exclusively lactating females compared to females that concurrently are pregnant and lactating, we considered these phenomena in the models with a dummy variable. This dummy variable considered that the female could be pregnant or not during lactation. Finally, this variable was also included as fixed effect, allowing its effect being different for each state within RC.

For blood plasma parameters the model described above did not fit appropriately, as it is not a proper repeated measures experiment and no defined parameterised structure fit well, although correlations among measures were still present, therefore no permanent effects were included and variance-covariance data was modelled without assuming any defined structure (unstructured matrix; SAS, 2009). Genetic type (H, LP, R), diet (AF, CS), time control (parturition, $18 \mathrm{~d}$ and weaning for the $1^{\text {st }} \mathrm{RC}$; parturition for the $2^{\text {nd }} \mathrm{RC}$; and parturition, 18d and weaning for the $5^{\text {th }} \mathrm{RC}$ ) and their interactions were included as fixed effects, whereas inner temperature of farm was included as covariate.

\section{Results}

A proper understanding of mechanisms governing the links between resources acquisition and allocation requires the control of a large number of traits, and it could make results presentation complex. Consequently, only relevant interactions have been presented to promote understanding. In any case, $P$-values for all the effects of all the traits are reported in the supplementary material of Paper III at the end of the document (Supplementary Tables S3.1 and S3.2).

\section{Acquisition and allocation of resources}

Table 3.2 presents the main effects on acquisition and allocation traits. $\mathrm{R}$ females had the greatest average feed intake than females from the maternal lines ( $\mathrm{H}$ and LP females; on av. $+10.9 \%$; $P<0.05$ ). Moreover, this greater acquisition was used differently. $\mathrm{R}$ females presented the highest values for BW $(+36.0 \%$; $P<0.05)$ and PFT $(+27.5 \%$; $P<0.05)$, but their milk yield and litter weight were similar to those of $\mathrm{H}$ females. On the other hand, LP females 
presented higher intake than $\mathrm{H}$ females $(+6.3 \% ; P<0.05)$, but the lowest PFT $(-0.19$ and -1.79 mm compared to $\mathrm{H}$ and $\mathrm{R}$ females, respectively; $P<0.05)$, the highest milk yield $(+18 \%$; $P<0.05)$ and litter weight $(+10 \% ; P<0.05)$. Average feed intake was also affected by diet, as females fed with $\mathrm{AF}$ had an intake $5.1 \%$ greater than those fed with $\mathrm{CS}(P<0.05)$. Nevertheless, it was also differently used, whereas females fed with CS presented higher PFT $(+0.2 \mathrm{~mm}, P<0.05)$, those fed AF had higher milk yield $(+11.7 \%, P<0.05)$ and litter weight $(+7.6 \%, P<0.05)$, no differences being found in BW.

Table 3.2 LSmeans and standard errors of the main effects on feed intake, perirenal fat thickness, milk yield and litter weight.

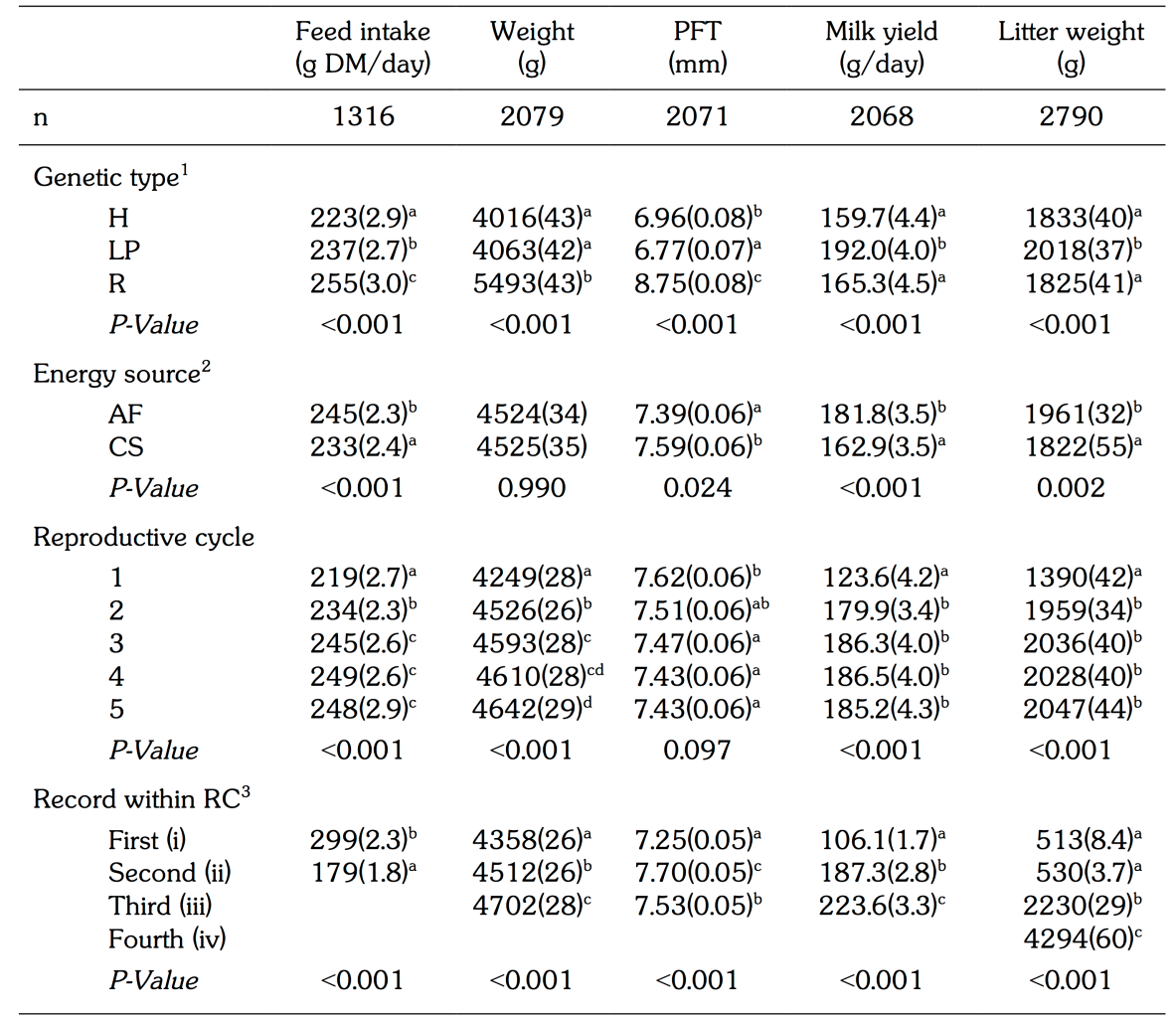

$\mathrm{n}$ : Number of records per trait. PFT: Perirenal Fat Thickness. RC: Reproductive cycle. ${ }^{1}$ Genetic Type: $\mathrm{H}$ characterized by hyper-prolificacy; LP characterized by functional hyper-longevity; R characterized by high average daily gain. ${ }^{2}$ Energy source: $\mathrm{AF}$ animal fat; $\mathrm{CS}$ cereal starch (Table 1 for details). ${ }^{3}$ Record within $\mathrm{RC}$ according to the trait were: [For feed intake: early lactation (i) and weaning to parturition interval (ii)]; [For weight and PFT: parturition (i), day 18th of lactation (ii) and weaning (iii)]; [For milk yield: first week of lactation (i), second week (ii) and third week (iii)]; [For litter weight: total born (i), at standardization (ii), at day 18th of lactation (iii) and weaning (iv)]. ${ }^{a, b, c, d}$ Means at the same effect and column not sharing superscripts significantly differ at $P<0.05$. 
As expected, feed intake and BW increased with age, reaching the maximum between third and fourth reproductive cycle $(+21.1$ and $+8.8 \%$ compared to primiparous females, respectively; $P<0.05)$. On the other hand, primiparous females presented higher PFT and lower milk yield and litter weight than multiparous $(+2.1,-33.0$ and $-31.1 \%$, respectively; $P<0.05)$. As expected, feed intake was higher in lactation, milk yield increased throughout the first three weeks of lactation and litter weight increased as lactation progressed. BW of females increased from parturition to weaning whereas PFT was the lowest at parturition and the highest at mid lactation. These results were the general pattern observed in the experiment. However, numerous interactions were also observed (Supplementary Table S3.1). They are presented for each trait.

Feed intake. Females from the maternal lines increased their intake during early lactation with age, reaching a maximum around third lactation (on av. 257, 288 and $303 \mathrm{~g}$ $\mathrm{DM} /$ day for primiparous, secundiparous and multiparous, respectively; $P<0.05$ ), whereas for $\mathrm{R}$ females, feed intake did not increase with age. $\mathrm{R}$ primiparous females fed with $\mathrm{AF}$ ate $8.0 \%$ more than those fed with $\mathrm{CS}(P<0.05)$, whereas primiparous females from the maternal lines did not differ in feed intake when fed with both. In multiparous, LP females had a feed intake during early lactation as high as $\mathrm{R}$ females (on av. $+6.9 \%$ compared to $\mathrm{H} ; P<0.05$ ). On the other hand, the greatest intake of $\mathrm{R}$ females was expressed especially out of lactation $(+16.3 \%$ compared to $\mathrm{H}$ and LP; $P<0.05$; Figure 3.1B). Moreover, out of lactation, greater feed intake with $\mathrm{AF}$ was observed in $\mathrm{R}$ females $(+7.1 \% ; P<0.05)$ and $\mathrm{H}$ multiparous females $(+11.8 \% ; P<0.05)$. 
A) Early lactation $\quad \mathrm{H}$

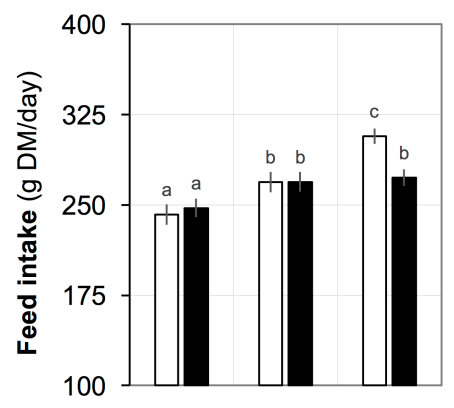

B) Weaning to parturition

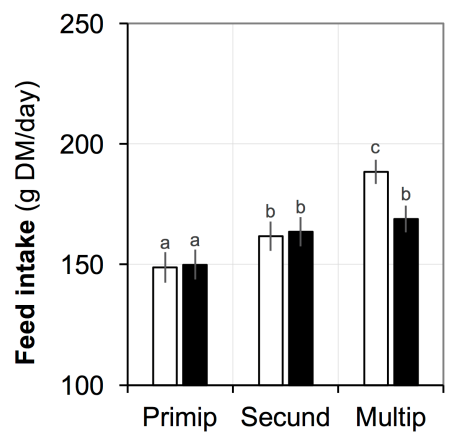

LP

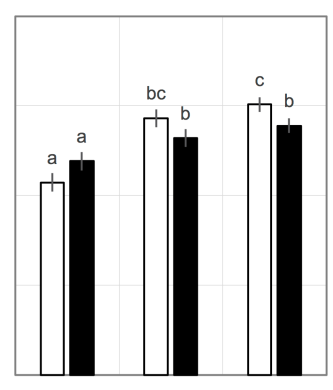

$\mathrm{R}$

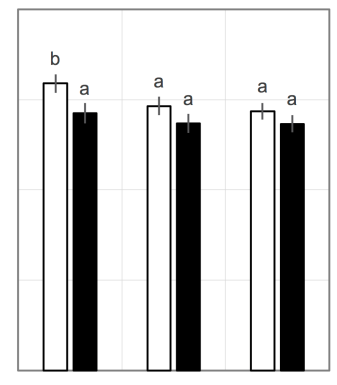

Figure 3.1 Evolution of feed intake among reproductive cycles [RC, primiparous, secundiparous and multiparous (av. of $3^{\text {rd }}, 4^{\text {th }}$ and $5^{\text {th }}$ cycles)] for the different states within the RC (Early lactation, Weaning to parturition) depending on genetic type $(\mathrm{H}$, characterised by hyperprolificacy; LP, characterised by functional hyper-longevity; R, characterised by daily gain) and the energy source [AF ( $\square)$; CS ( $\square)$ ]. LS means and standard errors. ${ }^{\text {a,b,c,d }}$ Means for a genetic type within a state not sharing superscripts significantly differ at $P<0.05$.

Perirenal fat thickness. As mentioned above, $\mathrm{R}$ females always presented a considerable larger body condition compared to the maternal lines, but PFT pattern was different according to genetic type. Figure 3.2 shows that the PFT decrease of $\mathrm{R}$ females at late lactation $(-4.3 \%$; $P<0.05)$ was significantly higher to than that observed for $\mathrm{H}$ and LP lines (on av. $-0.1 \%$; $P>0.05$ ), particularly for those fed with AF. Moreover, LP females fed with AF progressively increase PFT across the $\mathrm{RC}$, whereas those fed with CS increase PFT during early lactation $(+7.3 \%$; $P<0.05)$, but partially mobilised it during late lactation $(-2.8 \%$; $P<0.05)$. H females fed with both diets followed a similar trajectory throughout the RC. 
$\mathrm{H}$

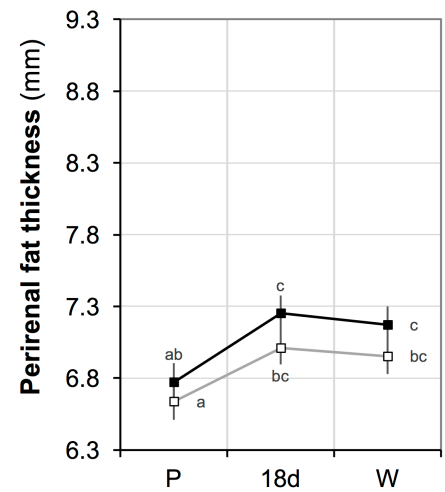

LP

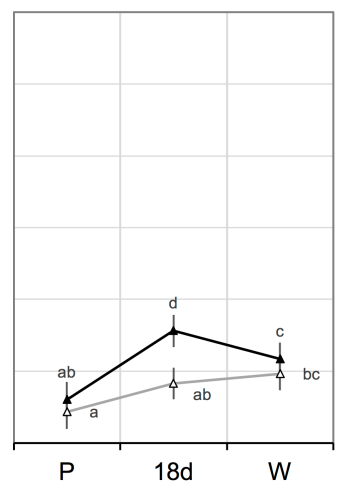

$\mathrm{R}$

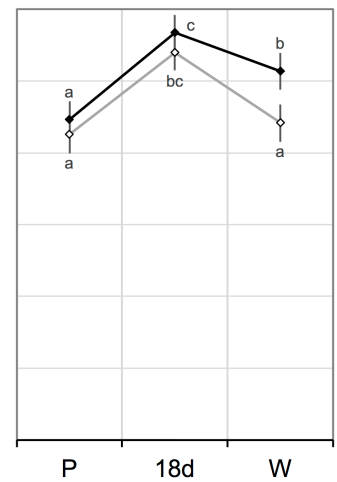

Figure 3.2 Evolution within a reproductive cycle of perirenal fat thickness depending on genetic type $[\mathrm{H}(-\mathbf{\square}-)$, characterised by hyper-prolificacy; LP $(-\mathbf{\Delta} \longrightarrow)$, characterised by functional hyper-longevity; R $(-)$, characterised by daily gain] and energy source [AF $(\square \triangle \diamond)$, animal fat; CS $(\mathbf{\square} \wedge)$, cereal starch]. P: Parturition; 18d: day $18^{\text {th }}$ of lactation; W: Weaning. LS means and standard errors. ${ }^{a, b, c, d}$ Means within a genetic type not sharing superscripts significantly differ at $P<0.05$.
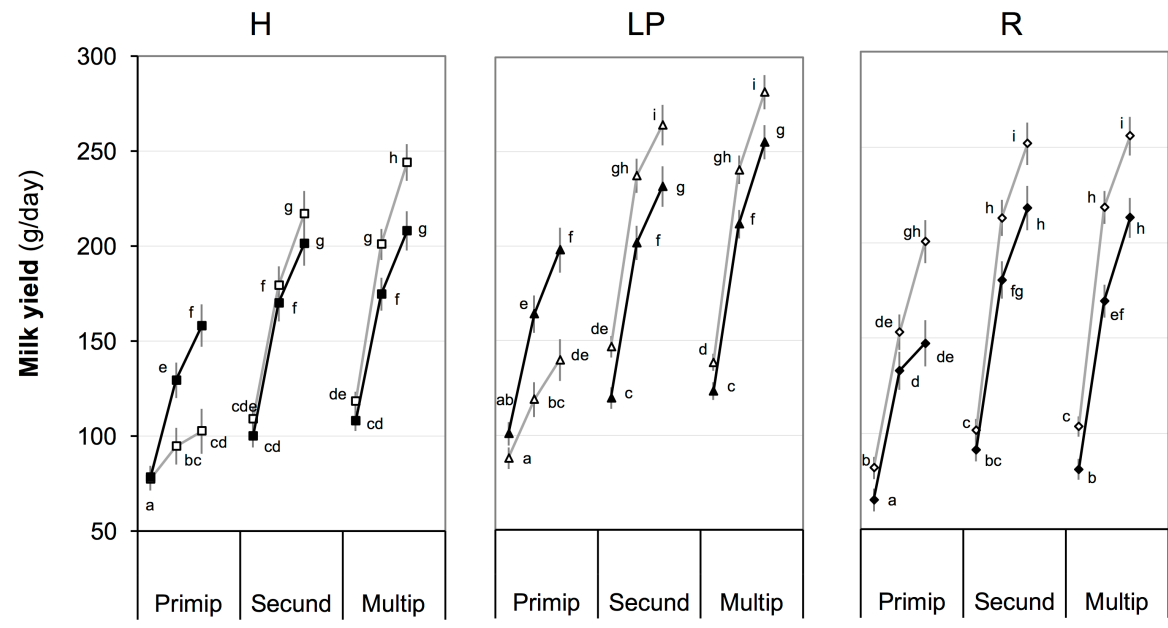

Figure 3.3 Evolution of the lactation curve throughout the reproductive cycles [primiparous, secundiparous and multiparous (av. of $3^{\text {rd }}, 4^{\text {th }}$ and $5^{\text {th }}$ cycles)] depending on genetic type: [ $\mathrm{H}$ $(--)$, characterised by hyper-prolificacy; LP (- - ), characterised by functional hyperlongevity; R $(-)$, characterised by daily gain] and energy source [AF $(\square \triangle \diamond)$, animal fat; CS $(\boldsymbol{\Delta} \bullet)$, cereal starch]. LS means and standard error. "Means for diets in a time control, genetic type and cycle significantly differ at $P<0.05$.

Milk yield. Figure 3.3 shows the evolution of milk yield throughout the $\mathrm{RC}$ depending on genetic type or diet. In general, females fed with AF diet had higher milk yield compared to CS from second parturition independently of genetic type. This occurred particularly in the 2 nd and 3 rd week of lactation, although differences were not significant in 
the second $\mathrm{RC}$ of $\mathrm{H}$ females. However, although primiparous $\mathrm{R}$ females yielded more milk with AF diet $(+26.2 \% ; P<0.05)$, primiparous $\mathrm{H}$ and LP females yielded more with $\mathrm{CS}$ $(+34.1 \% ; P<0.05)$, especially from second week of lactation. On the other hand, $\mathrm{R}$ females yielded less milk at first week of lactation than $\mathrm{H}$, and especially LP females (on av. 87.5, 98.5 and $119.5 \mathrm{~g} /$ day, respectively; $P<0.05)$.

\section{Blood plasma parameters}

Average glucose plasma concentration was always higher for $\mathrm{LP}$ and $\mathrm{R}$ than for $\mathrm{H}$ females (on av. +4.6\%; $P<0.05$; Table 3.3), but differences were mainly due to the higher glucose concentration of LP females at $18 \mathrm{~d}$ of first $\mathrm{RC}$ and at second parturition, and of $\mathrm{R}$ females at fifth weaning (Figure 3.4A). There were no significant differences in average NEFA plasma concentration between genetic types. However, $\mathrm{R}$ females presented lower NEFA values at $18 \mathrm{~d}$ and weaning of the first $\mathrm{RC}$ than LP and H, whereas LP females had lower values at second and fifth parturitions compared to $\mathrm{R}$ and $\mathrm{H}$. Average $\mathrm{BOHB}$ concentration was significantly lower in the plasma of LP compared to $\mathrm{H}$ females $(-27.6 \%$; $P<0.05$; Table 3.3). However, although BOHB plasma concentration decreased as the first lactation progressed independently of genetic type and diet (on av. $-81.8 \%$ from parturition to weaning; $P<0.05$ ), BOHB evolution during the fifth $\mathrm{RC}$ depended on genetic type and diet (Figure 3.5). In contrast to that observed during the first $\mathrm{RC}$, females fed with $\mathrm{AF}$ and LP females fed with CS had no relevant
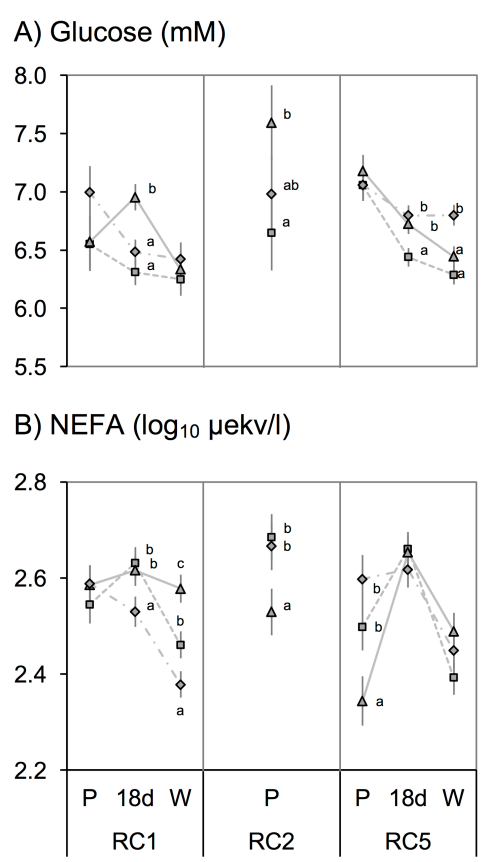

Figure 3.4 Plasma glucose [a)] and nonesterified-fatty-acids [b), NEFA] concentration through time depending on genetic type. Least squared means and standard error for $\mathrm{H}$ (- - - - ), characterised by hyper-prolificacy; LP $(-\boldsymbol{\Delta}-)$, characterised by functional hyperlongevity; R (-.---.-), characterised by daily gain. P: Parturition; W: Weaning. LS means and standard errors. ${ }^{\mathrm{a}, \mathrm{b}}$ Means in a time control and cycle not sharing superscripts significantly differ at $P<0.05$. variations in $\mathrm{BOBH}$ plasma concen-tration throughout the fifth lactation. However, $\mathrm{BOHB}$ concentration of $\mathrm{R}$ and $\mathrm{H}$ females fed with $\mathrm{CS}$ decreased significantly throughout the fifth lactation (on av. $-79.8 \%$ from parturition to weaning; $P<0.05$ ) as in the first $\mathrm{RC}$. 
Table 3.3 Effect of genetic type, energy source and time control on plasma concentration of glucose, 6-OH-butyrate (BOHB), non-esterified fatty acids (NEFA) and leptin

\begin{tabular}{lcccc}
\hline & $\begin{array}{c}\text { Glucose } \\
(\mathrm{mM})\end{array}$ & $\begin{array}{c}\mathrm{BOHB} \\
\left(\log _{10} \mathrm{mM}\right)\end{array}$ & $\begin{array}{c}\text { NEFA } \\
\left(\log _{10} \mu \mathrm{kv} / \mathrm{l}\right)\end{array}$ & $\begin{array}{c}\text { Leptin } \\
\left(\log _{10} \mathrm{ng} / \mathrm{ml}\right)\end{array}$ \\
\hline $\mathrm{n}$ & 462 & 462 & 462 & 462 \\
\hline Genetic type $^{1}$ & & & & \\
$\mathrm{H}$ & $6.51(0.07)^{\mathrm{a}}$ & $-1.09(0.04)^{\mathrm{b}}$ & $2.55(0.02)$ & $-0.40(0.03)$ \\
$\mathrm{LP}$ & $6.82(0.07)^{\mathrm{b}}$ & $-1.23(0.04)^{\mathrm{a}}$ & $2.54(0.02)$ & $-0.40(0.03)$ \\
$\mathrm{R}$ & $6.79(0.07)^{\mathrm{b}}$ & $-1.16(0.04)^{\mathrm{ab}}$ & $2.55(0.02)$ & $-0.32(0.03)$ \\
P-Value & 0.003 & 0.037 & 0.923 & 0.093 \\
Energy source & & & & \\
AF & $6.67(0.06)$ & $-0.96(0.03)^{\mathrm{b}}$ & $2.56(0.02)$ & $-0.39(0.02)$ \\
CS & $6.75(0.06)$ & $-1.36(0.03)^{\mathrm{a}}$ & $2.53(0.02)$ & $-0.35(0.02)$ \\
P-Value & 0.312 & $<0.001$ & 0.187 & 0.178 \\
Time control & & & & \\
RC1:Parturition & $6.70(0.13)^{\mathrm{cd}}$ & $-0.73(0.04)^{\mathrm{d}}$ & $2.57(0.02)^{\mathrm{b}}$ & $-0.50(0.04)^{\mathrm{a}}$ \\
RC1:18d & $6.58(0.07)^{\mathrm{bc}}$ & $-1.17(0.04)^{\mathrm{b}}$ & $2.59(0.02)^{\mathrm{bc}}$ & $-0.42(0.04)^{\mathrm{b}}$ \\
RC1:Weaning & $6.33(0.08)^{\mathrm{b}}$ & $-1.51(0.03)^{\mathrm{b}}$ & $2.47(0.02)^{\mathrm{a}}$ & $-0.39(0.04)^{\mathrm{bc}}$ \\
RC2:Parturition & $7.07(0.19)^{\mathrm{de}}$ & $-0.95(0.07)^{\mathrm{c}}$ & $2.63(0.02)^{\mathrm{bc}}$ & $-0.42(0.04)^{\mathrm{ab}}$ \\
RC5:Parturition & $7.10(0.08)^{\mathrm{b}}$ & $-1.13(0.06)^{\mathrm{b}}$ & $2.48(0.02)^{\mathrm{a}}$ & $-0.19(0.02)^{\mathrm{d}}$ \\
RC5:18d & $6.65(0.05)^{\mathrm{c}}$ & $-1.18(0.04)^{\mathrm{b}}$ & $2.64(0.02)^{\mathrm{c}}$ & $-0.32(0.03)^{\mathrm{c}}$ \\
RC5: Weaning & $6.51(0.05)^{\mathrm{b}}$ & $-1.46(0.03)^{\mathrm{a}}$ & $2.44(0.02)^{\mathrm{a}}$ & $-0.39(0.04)^{\mathrm{bc}}$ \\
P-Value & $<0.001$ & $<0.001$ & $<0.001$ & $<0.001$ \\
\hline
\end{tabular}

n: Number of records per trait. ${ }^{1}$ Genetic Type: $\mathrm{H}$ characterised by hyper-prolificacy; LP characterised by functional hyper-longevity; $\mathrm{R}$ characterised by daily gain. ${ }^{2}$ Energy source: AF animal fat; CS cereal starch (Table 1 for details). RC: Reproductive cycle. ab.c.de Means at the same effect and column not sharing superscripts significantly differ at $P<0.05$.

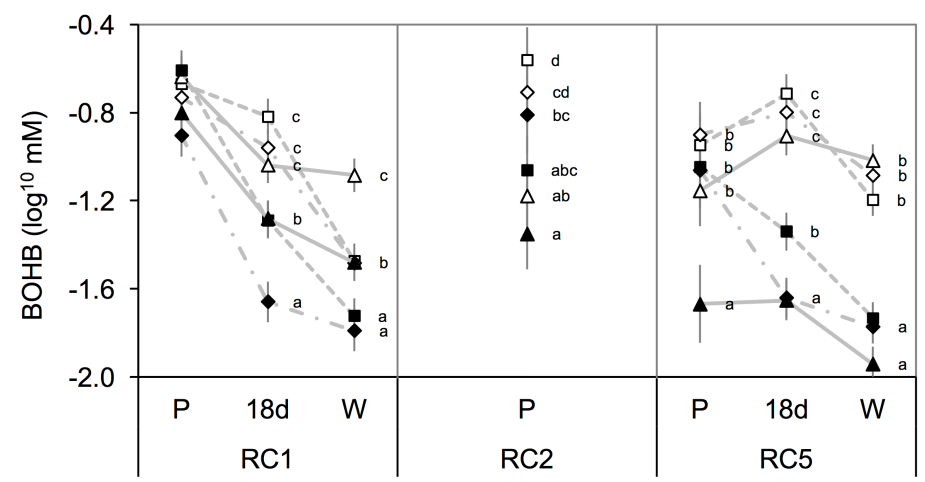

Figure 3.5 Plasma $\beta$-OH-butyrate (BOHB) concentration through time depending on genetic type [H (- - - - ), characterised by hyper-prolificacy; LP $(-\mathbf{\Delta}-)$, characterised by functional hyper-longevity; $\mathrm{R}(-.---.-)$, characterised by daily gain] and energy source

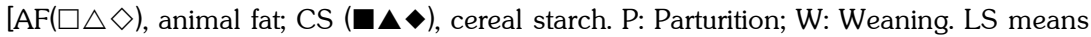
and standard errors. ${ }^{a, b, c, d}$ Means in a time control and cycle not sharing superscripts significantly differ at $P<0.05$. 


\section{Discussion}

The aim of the present work was to study the way different genetic types acquire and allocate resources and how energy source could modulate it. The traits, states and cycles controlled in this study were selected because we considered them relevant for this purpose; nevertheless, nature is so complex that many other traits and states could have been considered. In this setting, results showed that the pattern of resource acquisition and allocation of primiparous does was clearly different compared to the general pattern, so the results from primiparous females are discussed separately for a better understanding.

\section{General pattern of acquisition and allocation of resources}

The acquisition capacity of the females increased with age (Xiccato, 1996), reaching a plateau around the third cycle. In this regard, it is commonly accepted that, once females reach their maximum capacity of intake, they regulate it by a chemostatic mechanism during lactation (with diets above $11 \mathrm{MJ} / \mathrm{kg}$ DM; Xiccato and Trocino, 2010). If the chemostatic mechanism is the only one regulating feed intake, we would expect similar energy intake from isoenergetic diets with different energy sources. However, this was not the case. Energy source affected feed intake as previously observed by Lebas and Fortun-Lamothe (1996) for similar diets and multiparous females. In fact, it was higher for those fed AF, which was slightly more energetic than CS (Table 3.1).

On the other hand, Friggens and Newbold (2007) stated that to a great extent of body reserves change is genetically driven and feed intake responds to these driving forces. In this sense, Pascual et al. $(2002 ; 2003)$ observed an effect of body condition on further feed intake, females eating during weaning to parturition interval proportionally to mobilisation at late lactation. In agreement, we observed a negative environmental correlation between feed intake out of lactation and previous PFT at weaning $(-0.19 \pm 0.05 ; P<0.05)$. This result indicates that females tend to increase their intake after lactation to recover from low body condition at weaning. Therefore, it is not likely that a mechanism based on a single factor is regulating feed intake (Forbes, 2007). It also suggests that acquisition and allocation are deeply connected (Martin and Sauvant, 2010) and highlights the need to develop a theoretic framework taking into account this multifactorial approach (Forbes, 2007).

Regarding the energy source effect, in general, diets worked as expected. Females fed with CS diet presented higher PFT whereas females fed with AF yielded more milk and had heavier litters (Pascual et al., 2003). Moreover, females fed AF presented higher feed intake, suggesting that females fed with AF increased their intake to cope with the higher lactation requirements, but not enough to allow females store as many reserves as those fed 
with CS. Consequently, by selecting the energy source of the diet we could impose a shift of energy partitioning between milk and body reserves of females.

\section{Acquisition and allocation patterns of genetic types}

$\mathrm{R}$ females were heavier and fatter than those from the maternal lines (Table 3.2), in agreement with the results recently reported by Naturil-Alfonso et al. (2016). Consequently, their requirements for maintenance were much higher (+26\%). The requirements for milk production were not low (similar to $\mathrm{H}$ females), but smaller than those expected for their metabolic weight (Maertens et al., 2006). This fact suggests a lower priority of $\mathrm{R}$ females for milk than females from the maternal lines. To cover all of these requirements, $\mathrm{R}$ females presented the highest energy acquisition (Table 3.2). Apart from the particular average allocation, energy was differently allocated across time compared to females from the maternal lines; the lactation effort was low at the beginning but it increased as lactation progressed (Figure 3.3), while females recovered a great amount of body reserves during early lactation $(+0.2 \mathrm{~mm}$ than females from maternal lines; $P<0.05)$, which was used afterwards during late lactation (Figure 3.2). Both facts suggest that, at the onset of lactation, $\mathrm{R}$ females prioritised their body recovery more than current litter interests, whereas as lactation progressed these priorities would have been inverted. In fact, this pattern is opposite to that proposed for maternal lines (Savietto et al., 2015) and could consequently it could be a side effect of the selection process. However, it also could be a consequence of the experimental design ( $\mathrm{R}$ females could have taken longer to adapt milk yield to the standardised litter because the difference between standardised and total born litter weight was $+120 \mathrm{~g}$, whereas for females from the maternal lines was $-22 \mathrm{~g} ; P<0.05$ ).

On the other hand, when comparing the shift imposed by energy source, milk yield was higher during the whole controlled lactation for $\mathrm{R}$ females fed with $\mathrm{AF}$ (Figure 3.3), but the effects on body condition (Figure 3.2) and feed intake (figure 3.1) were more evident from mid lactation onward. $\mathrm{R}$ females fed with $\mathrm{AF}$ presented higher mobilisation during late lactation (Figure 3.2) and, in response to this higher mobilisation, they had higher feed intake between weaning and the next parturition (Figure 3.1B). As we could not record feed intake or milk yield during late lactation, it was not possible to find out whether observed differences were the consequence of milk yield, feed intake or a combination of both. Nevertheless, it seems that females fed with AF made a greater effort in the current litter at the end of lactation than those fed with $\mathrm{CS}$, which is in agreement with the inversion of priorities between current litter and body reserves recovery as lactation progressed. Therefore, it seems that females from the paternal line had a great acquisition capacity, mainly addressed to maintaining their larger body size. Moreover, they were highly 
dependent on body reserves to cope with the reproductive requirements of the current reproductive cycle, especially at the end of lactation.

LP females were characterised by the lowest amount of body reserves, and the highest milk yield (Table 3.2). In agreement with previous knowledge (Theilgaard et al, 2009; Savietto et al., 2013), to meet their lactation requirements, multiparous LP females presented a high acquisition capacity during lactation (Figure 3.1). In fact, the acquisition capacity of LP females during lactation was much higher than that expected for their size. For example, if we discount the energy that is required for maintenance, we observed that LP females presented the highest ADEP during early lactation (2.22 \pm 0.04 vs. $1.91 \pm 0.04$ and $1.99 \pm 0.04 \mathrm{MJ}$ DM per day for $\mathrm{H}$ and $\mathrm{R}$, respectively; $P<0.05)$ but similar values during weaning to parturition interval $(0.71 \pm 0.03,0.69 \pm 0.03$ and $0.66 \pm 0.03 \mathrm{MJ} \mathrm{DM}$ per day, respectively; $P>0.05$ ). Moreover, the use of body reserves as a safety factor is a described characteristic of this line (Savietto et al., 2015). In this sense, LP females fed with AF tried to gain body reserves during the whole lactation, whereas those fed with a diet promoting body reserves gain (CS) accumulated a large amount of reserves during early lactation, but they mobilised later (Figure 3.2). In addition to the greater acquisition capacity when requirements were high, it seems that LP females were able to adapt their allocation across time (Theilgaard et al., 2009; Savietto et al., 2013), allowing them to reach parturition in suitable metabolic conditions (higher glucose, lower NEFAs and lower BOHB levels compared to females from the other genetic lines). This metabolic status was particularly evident at second parturition, which is considered the most critical point in the life trajectory of the rabbit females (Rosell and de la Fuente, 2009). Consequently, LP females were characterised by an acquisition capacity and an allocation pattern adapted to changing requirements (imposed by physiological state or diet) that allow them to confront high reproductive efforts, but safeguarding body reserves (Savietto et al., 2015).

Finally, the pattern of $\mathrm{H}$ females pattern was located between $\mathrm{R}$ and LP. As previously reported for females specialised in prolificacy (Rauw et al., 1999), lower values of average feed intake and glucose but higher values of BOHB and PFT (Tables 2 and 3) would indicate that $\mathrm{H}$ females were more dependent on body reserves than LP females. However, $\mathrm{H}$ females tried to accumulate reserves in early lactation and maintain them during late lactation (Figure 3.2). As $\mathrm{H}$ females accumulated reserves during early lactation that were not used during late lactation and this pattern was observed for females fed with both diets, these results suggest that $\mathrm{H}$ females tend to store body reserves for the next reproductive cycle. Consequently, $\mathrm{CS}$ diet could be enhancing $\mathrm{H}$ females to maximise their storing skills at the end of lactation. The higher values of PFT, and lower values of BOHB and milk yield than when fed with AF, support this statement. However, similarly to R females fed with CS, 
this strategy would lead $\mathrm{H}$ females fed with $\mathrm{CS}$ to high mobilisation at parturition (high values of $\mathrm{BOHB}$ ) and high $\mathrm{BOHB}$ changes during the reproductive cycle compared to $\mathrm{LP}$ females (Figure 3.5). Therefore, $\mathrm{H}$ females were dependent on body reserves but, in contrast to $\mathrm{R}$ females, it seems that they accumulated them to cope with future reproduction.

\section{Primiparous females}

Information regarding to the effect of dietary energy source on dry matter intake in primiparous females is highly controversial, although it is widely accepted that feed intake is physically limited (reviewed by Pascual et al., 2003). Compared to a control diet, energyenriched diets tend to increase the energy intake of females but address it differently depending on energy source. Similarly to multiparous females, for primiparous females fed with starch-enriched diets the increase of energy intake is mainly addressed to body reserves, whereas for those fed with fat-enriched diets this increase is mainly addressed to milk yield (Xiccato et al., 1995; Fortun-Lamothe and Lebas, 1996; Pascual et al., 2002). In this sense, the results for $\mathrm{R}$ females totally agree with previous knowledge, whereas results from maternal lines disagree at a great extent (especially those related with milk yield). However, a low-temperature challenge could be the underlying cause of these results, as most of the females were reared and had their first parturition during winter (Figure 3.6).

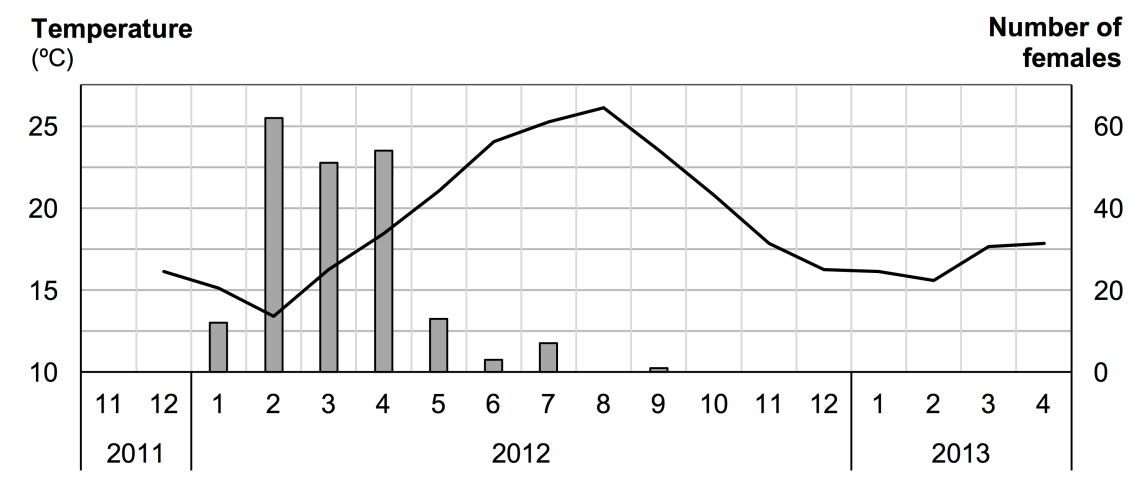

Figure 3.6 Inner-average temperature per month of the farm (black line) and number of females (grey bars) that had their first parturition in the corresponding month.

Thus, as young females were fed with commercial diet for reproductive rabbit females until first parturition, it is highly likely that they would have reached their first insemination overfat. Martínez-Paredes et al. (2012) reported that in such circumstances females mobilise extra body reserves around parturition. In fact, females presented the lowest leptin and the highest BOHB plasma concentration at first parturition (Table 3.3), supporting this statement. This situation could have been perceived by females as a risk to ensuring 
body condition. Moreover, in a low-temperature challenge, the individual physical limitation when primiparous could have affected food availability, conditioning the response to the challenge for each genetic type. Comparing to females of the maternal lines, it seems that the acquisition capacity of $\mathrm{R}$ females during early lactation was completely developed when primiparous, as there was no difference in feed intake between primiparous and multiparous does (Figure 3.1A). Consequently, independently of diet, $\mathrm{R}$ females could have enough intake to ensure an adequate thermogenesis, body condition and milk yield, the allocation of resources being modulated by diet as expected. In fact, $\mathrm{R}$ females fed with $\mathrm{AF}$ were able to increase their intake during early lactation to confront that situation (Figure 3.1A). On the contrary, females from the maternal lines fed with a diet that did not ensure body condition $(\mathrm{AF})$ were not able to increase feed intake (Figure 3.1A) and gave priority to thermogenesis and to safeguarding body condition at the expense of milk yield. It has been proposed that under challenging conditions mammals could accelerate the weaning process (Martin and Sauvant, 2010), as staying alive prevails over reproduction (Wade and Schneider, 1992). In this sense, several studies have reported that the effect of low temperatures on reproduction depends on food availability (Marsteller and Lynch, 1987; Manning and Bronson, 1990) and the moment it happens (Bronson and Marsteller, 1985) but can be attenuated or exaggerated by body reserves (Schneider and Wade, 1991). Consequently, the weaning process in primiparous maternal females could have been greatly accelerated to safeguard body condition in this challenging situation (progressive lower milk yield as lactation progressed in females from maternal lines fed with AF compared to those fed with CS, Figure 3.3).

\section{Conclusions}

Resource acquisition capacity and allocation pattern of rabbit females is different for each genetic type, and would be modulated differently by energy source according to the females' priorities, given by their genetic background. $\mathrm{R}$ females were characterised by a high dependence on the body reserves to cope with the reproductive requirements of the current reproductive cycle. Selection for post-weaning weight gain would have modified the $\mathrm{R}$ females' pattern, enhancing their effort at late lactation to obtain heavy weaned kits, being more evident when females were fed with diets promoting milk yield (AF). Similarly, $\mathrm{H}$ females were also highly dependent on body reserves, but with a different goal. Foundation for hyper-prolificacy would have promoted a pattern based on body reserves accretion during lactation to cope with future reproduction, magnified when fed with diets promoting body condition (CS), and higher depletion at parturition imposed by a supposed larger offspring. Finally, LP females were characterised by an acquisition capacity better fitted to changing requirements. Foundation for functional longevity would have promoted body 
reserves safeguards to ensure both reproduction and lifespan, independently of the energy source available.

In our opinion, although acquisition and allocation of all the genetic types are regulated by the same mechanisms, it seems that trajectories of foundation or selection could have affected not only the acquisition and allocation strategies but also to the way females respond to diets in normal and challenging situations.

\section{Acknowledgments}

This study was supported by the Interministerial Commission for Science and Technology (CICYT) of the Spanish Government (AGL2014-53405-C2-1-P). The authors thank Juan Carlos Moreno for his technical support. The grant for Alberto Arnau from the Ministry of Economy and Finance (BES-2012-052345) is also gratefully acknowledged.

\section{References}

Arnau-Bonachera A, Piles M and Pascual JJ 2017a. Accounting for (co)variance structure of longitudinal data from traits associated to productive performance in reproductive rabbit females: Model fitting and performance. World Rabbit Science (submitted).

Arnau-Bonachera A and Pascual JJ 2017b. Homeorhetic control and homeostatic regulation from a mixed-model view: Reinterpreting nutrient partitioning using the rabbit female as a model. Animal (submitted).

Association of Official Analytical Chemists (AOAC) 2000. Official methods of analysis of the AOAC International, 17th edition. AOAC, Gaithersburg, MD, USA.

Baselga M 2004. Genetic improvement of meat rabbits. Programmes and diffusion. In Proceedings of the 8th World Rabbit Congress, 7-10 September 2004, Puebla, Mexico, pp. 1-13.

Batey IL 1982. Starch analysis using thermostable alpha-amylases. Starch - Stärke 34, 125128.

Bronson FH and Marsteller FA 1985. Effect of short-term food deprivation on reproduction in female mice. Biology of Reproduction 33, 660-667.

De Blas JC and Mateos GG 2010. Feed formulation. In Nutrition of the rabbit, 2nd Edition (ed. C de Blas and J Wiseman), pp. 222-232. CABI Publishing, Wallingford, UK.

Cifre J, Baselga M, García-Ximénez F and Vicente JS 1998. Performance of a hyperprolific rabbit line I. Litter size traits. Journal of Animal Breeding and Genetics 115, 131-138.

Estany J, Camacho J, Baselga M and Blasco A 1992. Selection response of growth rate in rabbits for meat production. Genetics Selection Evolution 24, 527-537.

Fernández-Carmona J, Blas E, Pascual JJ, Maertens L, Gidenne T and García J 2005. Recommendations and guidelines for applied nutrition experiments in rabbits. World Rabbit Science 13, 209-228.

Forbes JM 2007. Voluntary food intake and diet selection in farm animals, 2nd edition. CABI Publishing, Wallingford, UK. 
Fortun-Lamothe L and Lebas F 1996. Effects of dietary energy level and source on foetal development and energy balance in concurrently pregnant and lactating primiparous rabbit does. Animal Science 62, 615-620.

Friggens NC and Newbold JR 2007. Towards a biological basis for predicting nutrient partitioning: the dairy cow as an example. Animal 1, 87-97.

Gómez EA, Baselga M and Rafel O 1999. Selection, diffusion and performances of six Spanish lines of meat rabbit. Cahiers Options Méditérranéennes 41, 147-152.

Hansen LB 2000. Consequences of selection for milk yield from a geneticist's viewpoint. Journal of Dairy Dcience 83, 1145-1150.

Harano Y, Ohtsuki M, Ida M, Kojima H, Harada M, Okanishi T, Kashiwagi A, Ochi Y, Uno S and Shigeta Y 1985. Direct automated assay method for serum or urine levels of ketone bodies. Clinica Chimica Acta 151, 177-183.

Hill WG 2008. Estimation, effectiveness and opportunities of long term genetic improvement in animals and maize. Lohmann Information 43, 3-20.

Hocking PM 2014. Unexpected consequences of genetic selection in broilers and turkeys: problems and solutions. British Poultry Science 55, 1-12.

Lebas F and Fortun-Lamothe L 1996. Effects of dietary energy level and origin (starch vs oil) on the performance of rabbits does and their litters: average situation after 4 weanings. In Proceedings of the 6th World Rabbit Congress, 9-12 July 1996, Toulouse, France, pp. 217-221.

Maertens L, Lebas F and Szendro Z 2006. Rabbit milk: A review of quantity, quality and nondietary affecting factors. World Rabbit Science 14, 205-230.

Manning JM and Bronson FH 1990. The Effects of Low Temperature and Food Intake on Ovulation in Domestic Mice. Physiological Zoology 63, 938-948.

Marsteller FA and Lynch CB 1987. Reproductive responses to variation in temperature and food supply by house mice. II. Lactation. Biology of Reproduction 37, 844-850.

Martin O and Sauvant D 2010. A teleonomic model describing performance (body, milk and intake) during growth and over repeated reproductive cycles throughout the lifespan of dairy cattle. 1. Trajectories of life function priorities and genetic scaling. Animal 4, 2030-2047.

Martínez-Paredes E, Ródenas L, Martínez-Vallespín B, Cervera C, Blas E, Brecchia G, Boiti C and Pascual JJ 2012. Effects of feeding programme on the performance and energy balance of nulliparous rabbit does. Animal 6, 1086-1095.

Naturil-Alfonso C, Lavara R, Millán P, Rebollar PG, Vicente JS and Marco-Jiménez F 2016. Study of failures in a rabbit line selected for growth rate. World Rabbit Science 24, 4753.

Pascual JJ, Castella F, Cervera C, Blas E and Fernández-Carmona J 2000. The use of ultrasound measurement of perirenal fat thickness to estimate changes in body condition of young female rabbits. Animal Science 70, 435-442.

Pascual JJ, Motta W, Cervera C, Quevedo F, Blas E and Fernández-Carmona J 2002. Effect of dietary energy source on the performance and perirenal fat thickness evolution of primiparous rabbit does. Animal Science 75, 267-279. 
Pascual JJ, Cervera C, Blas E and Fernández-Carmona J 2003. High-energy diets for reproductive rabbit does: effect of energy source. Nutrition Abstracts and Reviews 73, 27R-39R.

Penadés M 2017. Staphylococcus aureus infections in rabbits from different genetic lines: study of the host, the bacterium and the bacterial-host interaction. $\mathrm{PhD}$ thesis, Universidad CEU Cardenal Herrera, Valencia, Spain.

Poggenpoel DG, Ferreira GF, Hayes JP and du Preez JJ 1996. Response to long-term selection for egg production in laying hens. British Poultry Science 37, 743-756.

Rauw WM 2009. Resource allocation theory applied to farm animal production. CABI Publishing, Wallingford, UK.

Rauw WM, Kanis E, Noordhuizen-Stassen EN and Grommers F 1998. Undesirable side effects of selection for high production efficiency in farm animals: a review. Livestock Production Science 56, 15-33.

Rauw WM, Luiting P, Beilharz RG, Verstegen MWA and Vangen O 1999. Selection for litter size and its consequences for the allocation of feed resources: a concept and its implications illustrated by mice selection experiments. Livestock Production Science 60, 329-342.

Rosell JM and de la Fuente LF 2009. Culling and mortality in breeding rabbits. Preventive Veterinary Medicine 88, 120-127.

Sánchez JP, Theilgaard P, Mínguez C and Baselga M 2008. Constitution and evaluation of a long-lived productive rabbit line. Journal of Animal Science 86, 515-525.

SAS Institute Inc. 2009. SAS/STAT ${ }^{\circledR} 9.2$ user's Guide, 2nd edition. SAS Institute Inc., Cary, NC.

Savietto D 2014. Environmental and genetic factors driving robustness in reproductive rabbit does. $\mathrm{PhD}$ thesis, Universitat Politècnica de València, Valencia, Spain.

Savietto D, Cervera C, Blas E, Baselga M, Larsen T, Friggens NC and Pascual JJ 2013. Environmental sensitivity differs between rabbit lines selected for reproductive intensity and longevity. Animal 7, 1969-1977.

Savietto D, Friggens NC and Pascual JJ 2015. Reproductive robustness differs between generalist and specialist maternal rabbit lines: the role of acquisition and allocation of resources. Genetics Selection Evolution 47, 2. doi: 10.1186/s12711-014-0073-5.

Schneider JE and Wade GN 1991. Effects of ambient temperature and body fat content on maternal litter reduction in Syrian hamsters. Physiology \& Behaviour 49, 135-139.

Theilgaard P, Baselga M, Blas E, Friggens NC, Cervera C and Pascual JJ 2009. Differences in productive robustness in rabbits selected for reproductive longevity or litter size. Animal 3, 637-646.

Van Soest PJ, Robertson JB and Lewis BA 1991. Methods for dietary fiber, neutral detergent fiber, and nonstarch polysaccharides in relation to animal nutrition. Journal of Dairy Science 74, 3583-3597.

Wade GN and Schneider JE 1992. Metabolic fuels and reproduction in female mammals. Neuroscience and Biobehavioural Reviews 16, 235-272. 
Xiccato G 1996. Nutrition of lactation does. In Proceedings of the 6th World Rabbit Congress, 9-12 July 1996, Toulouse, France, pp. 29-47.

Xiccato $G$ and Trocino A 2010. Energy and protein metabolism and requirements. In Nutrition of the rabbit, 2nd Edition (ed. C de Blas and J Wiseman), pp. 83-118. CABI Publishing, Wallingford, UK.

Xiccato G, Parigi-Bini R, Dalle Zotte A, Carazzolo A and Cossu M 1995. Effect of dietary energy level, addition of fat and physiological state on performance and energy balance of lactating and pregnant rabbit does. Animal Science 61, 387-398. 



\title{
PAPER IV
}

\section{Long-term implications of fitting feed energy source to the genetic type in reproductive rabbit females. III. Fitness and productivity}

\author{
A. Arnau-Bonachera ${ }^{1}$, Savietto $\mathrm{D}^{2}$ and J.J. Pascual ${ }^{1}$ \\ ${ }^{1}$ Institute for Animal Science and Technology, Universitat Politècnica de València, Camino \\ de Vera, s/n. 46071 Valencia, Spain. \\ ${ }^{2}$ INRA UMR 1388 Génétique, Physiologie et Système d'Élevage, F-32326, Castanet- \\ Tolosan, France.
}

Submitted to Animal

on May 2017 



\begin{abstract}
To find out whether specific nutritional strategies adapted to specialized animals would result in balanced productivity and reproductive success ('fitness'), we used 203 animals belonging to three genetic types that vary greatly on their genetic background. We fed each genetic type with two diets specifically designed to promote milk yield or body reserves recovery and we controlled them between their first and fifth reproductive cycles. We found that genetic types prioritized different fitness components. Females from the paternal line ( $\mathrm{R}$ females) were characterized by greater adult weight and little but heavier kits, although it seems they could be more immature. When $\mathrm{R}$ females were fed with a diet promoting milk yield, they invested more on the current litter, whereas when fed with a diet promoting body reserves recovery, it seems that they invested more in recovering for future reproduction. On the contrary, females from the maternal lines were smaller and had numerous but lighter kits, but each genetic type used different strategies. The strategy used by $\mathrm{H}$ females makes them more sensible to the energy source of the diet, triggering problems to ensure future reproduction when fed with a diet promoting body reserves recovery (low conception rate or higher mortality of females). However, the strategy used by LP females seems to be more generalist, allowing them to ensure high performance of the current litter without neglecting future reproduction and with less sensibility to the diet. Therefore, diets affected to fitness components. Moreover, the response to diet varied with genetic types. It seems that more specialized genetic types, that base reproduction on body reserves, were more sensible to diets than the more generalist and robust type, that base reproduction on energy intake.
\end{abstract}

Key words: Functionality, productivity, priority, trade-off 



\section{Introduction}

To better estimate the response per generation to artificial selection, animals within selection programs are usually raised in highly stable environments. However, focusing on one environment could underestimate the factors that occur over the whole range of environments (Lewontin, 1974), triggering a situation where specialized animals could be favored (Kolmodin et al., 2003). The net result would be a specialization process that could alter the way selected animals acquire and allocate resources (Savietto et al., 2015). In this sense, it has been proposed that selection exclusively for productive criteria could reduce their ability to cope with physiological demands and/or environmental constrains when coping with 'new environments' (Rauw, 2009; Friggens et al., 2013), and could be accompanied by undesirable negative side effects in behavioral, physiological or immunological traits (Rauw et al., 1998).

This is the last of three consecutive scientific papers that aim to evaluate the hypothesis that an adequate fitting of feed energy source of the diet to the genetic type of the females may contribute to a sustainable production in the long term. In the first paper we investigated the way three genetic types differing greatly in their genetic background acquire and allocate resources when fed with diets specially designed to influence either the milk production or body reserves (I, Paper III of the present thesis). Despite not presented in this thesis, in the second paper we investigated parameters related to the immune system of these genetic types across time and how previous diets affected them (II; Penadés (2017)). Here we explored how these genetic types allocate the acquired resources to optimize traits related to productivity and fitness. The underlying hypothesis of this last work is that if energy source of the diet is affecting the way different genetic types acquire and allocate resources, specific nutritional strategies adapted to specialized animals could be useful to optimize the allocation of acquired resources between reproduction and maintenance, resulting in a better immune status and reproductive success ('fitness').

\section{Materials and methods}

The experimental procedure was approved by the animal welfare ethics committee of the Universitat Politècnica de València (UPV) and carried out following the Spanish Royal Decree 53/2013 on the protection of animals used for scientific purposes and the recommendations of the European Group on Rabbit Nutrition (Fernández-Carmona et al., 2005). 


\section{Animals}

A total of 203 female rabbits were used from their first artificial insemination (AI; 19 weeks old) until their sixth parturition (from December 2011 to April 2013). Rabbit females belonged to three genetic types developed at the Institute for Animal Science and Technology of the Universitat Politècnica de València (UPV), differing greatly on their breeding goals. Line $\mathrm{H}(\mathrm{n}=66)$, founded by hyper-prolific criteria at birth and selected by litter size at weaning; line LP ( $\mathrm{n}=67)$, founded by functional hyper-longevity characterized by a high robustness; line $\mathrm{R}(\mathrm{n}=70)$, selected for average daily gain during the growing period. For a further description of the lines see (I, Paper III of the present thesis).

Diets

Two experimental diets were formulated and pelleted, according to the recommendations of De Blas and Mateos (2010) for reproductive rabbit does, enhancing major differences on energy source. Diet CS was prepared promoting cereal starch [237 g of starch and $21 \mathrm{~g}$ of ether extract (EE) per $\mathrm{kg} \mathrm{DM}$ ], whereas in diet AF part of starch was replaced by animal fat (105 g of starch and $86 \mathrm{~g}$ of EE per kg DM). Nevertheless, both diets were design to be isoenergetic and isoproteic [on av. 11.3 $\mathrm{MJ}$ of digestible energy (DE) and $126 \mathrm{~g}$ of digestible protein per $\mathrm{kg} \mathrm{DM}$. For a further description of the diets see (I, Paper III of the present thesis).

\section{Experimental procedure}

Animals were housed under conventional environmental conditions (average daily temperatures varying from 12.5 to $26.5^{\circ} \mathrm{C}$ ), with an alternating cycle of $16 \mathrm{~h}$ of light and $8 \mathrm{~h}$ of darkness. At 19 weeks of age, all the female rabbits were inseminated (with pooled semen of their respective lines), and housed in individual cages (700 × $500 \times 320 \mathrm{~mm}$ ) provided with a nest for litters from gestation day 30. After the first parturition, the animals from the three genetic types were randomly assigned to one of the reproductive diets. Until this moment, all the animals had received the same commercial diet for reproductive rabbit does. Both experimental diets were provided ad libitum and the animals from each group (within genetic type and reproduction diet) were homogeneously distributed across the experimental farm. Litters were standardized to 8-9 kits at first parturition and 9-11 onwards. Females were inseminated at 11 days postpartum and weaned at day 30 of lactation. Status at palpation at eleven days after insemination was recorded to evaluate whether the female had conceived or not. Non-pregnant females were re-inseminated ten days after palpation, until a maximum of three chances. 
Individual adult life weight (AW) was considered for females reaching the sixth parturition as the average weight at effective insemination of fourth, fifth and sixth reproductive cycles. Maturity of females at effective insemination was calculated for females reaching the sixth parturition as the weight at that insemination divided by its AW. Interval between parturitions was determined as the days between two consecutive parturitions. Conception rate was the percentage of females getting pregnant at first attempt. Productivity of females was calculated as the cumulated number of weaned kits divided by the time (in years) the female stayed in the experiment (from first parturition to death or the end of the experiment at sixth parturition). Survival rate of females evaluated as the percentage of females at parturition of each reproductive cycle respect to the initial number of females. Litter size traits were total born, born alive, stillborn, standardized at birth and weaned. Individual weight of the kits was calculated as the litter weight divided by the litter size for total born, born alive, stillborn, standardized at birth and weaned. Maturity of the offspring was calculated as the individual weight of the kits divided by adult weight of their mother for total born, born alive, stillborn), standardized at birth and weaned. Survival rate of the offspring was recorded at parturition and during lactation. The cumulated number of kits per female was evaluated for born alive and weaned.

\section{Statistical analysis}

Interval between parturitions, litter size traits, individual weight and maturity of the offspring traits were analysed using a linear mixed model that included the effects of genetic type, energy source of the diet, reproductive cycle and their interactions as fixed effects (Proc Mixed of SAS). The error and the permanent effect of the female were included as random effects, considering that the residuals could be correlated among reproductive cycles in a decreasing way (assuming that the higher was the lag between parturitions, the lower was the correlation between residuals; Littell et al., 1998). Maturity of females at effective insemination was analysed using also a linear mixed model with the same fixed effects but considering that variance could change across reproductive cycles and residuals were correlated assuming that the higher was the lag between parturitions, the lower was the correlation between residuals (Proc Mixed of SAS). Adult live weight, productivity of females, cumulated kits born alive and cumulated kits weaned were analysed using a linear model that included the effects of genetic type, energy source of the diet and its interaction as fixed effects (Proc GLM of SAS). Conception rate of females, survival rate of the offspring at parturition and during lactation were evaluated using a generalized mixed model, with a binomial probability distribution for the response and a logit transformation $[\ln (\mu /(1-\mu))]$ as a link function (Proc Glimmix of SAS). The model included the genetic type, energy source of 
the diet, the reproductive cycle and their interactions as fixed effects and the permanent effect of the female and the error as random effects. Cumulated survival rate of the females was analysed twice also using generalized mixed models. Firstly, to find out differences at the end of the experiment, it was evaluated exclusively using data at sixth parturition, including in the model the effects of genetic type, energy source and its interaction. Secondly, to find out the trends across time, the whole data was considered, including the interactions of the genetic type, energy source and genetic type $\mathrm{x}$ energy source with the reproductive cycle as fixed effects.

\section{Results}

P-Values for all the effects tested in the models are presented in Tables S4.1 and S4.2 of the supplementary material. Here we present means of the main effects and the most relevant interactions. Traits related to females according to the genetic type $(H, L P, R)$ or diet (AF, CS) are presented in Table 4.1. $\mathrm{R}$ females surviving until sixth parturition presented an adult weight $37.6 \%$ heavier than $\mathrm{H}$ and LP females $(P<0.05)$. Conception rate at first attempt was not different between LP and R females, but it was 15 percentage units lower in $\mathrm{H}$ females $(P<0.05)$. Interval between parturitions was 6 days shorter for LP females compared to $\mathrm{H}$ and $\mathrm{R}$ females $(P<0.05)$. Productivity and survival rate up to sixth parturition was higher for LP females (on av. +12 weaned per year and +37 percentage units of survival rate respect to $\mathrm{H}$ and $\mathrm{R}$ females; $P<0.05$ ). Regarding to the energy source of the diet, no significant differences were observed for these traits. However, some interactions of genetic type with the reproductive cycle and the diet are presented below

Table 4.1 Effect of genetic type and energy source on female traits.

\begin{tabular}{|c|c|c|c|c|c|c|c|c|c|}
\hline & \multicolumn{5}{|c|}{ Genetic type $^{1}$} & \multicolumn{4}{|c|}{ Energy source ${ }^{2}$} \\
\hline & $\mathrm{H}$ & LP & $\mathrm{R}$ & $\mathrm{SEM}^{3}$ & $P$ & AF & CS & $\mathrm{SEM}^{3}$ & $P$ \\
\hline Weight at first $\mathrm{AI}(\mathrm{kg})$ & $3.62^{\mathrm{a}}$ & $3.65^{\mathrm{a}}$ & $4.61^{\mathrm{b}}$ & 0.040 & $<0.001$ & 3.97 & 3.94 & 0.033 & 0.469 \\
\hline Adult live weight (AW; kg) & $4.10^{\mathrm{a}}$ & $4.19^{\mathrm{a}}$ & $5.71^{\mathrm{b}}$ & 0.077 & $<0.001$ & 4.69 & 4.64 & 0.070 & 0.287 \\
\hline Conception rate pregnant at $1^{\text {st }}$ attempt; \%) & $63^{\mathrm{a}}$ & $79^{b}$ & $78^{\mathrm{b}}$ & - & 0.004 & 74 & 73 & - & 0.866 \\
\hline Interval between parturitions (days) & $56^{b}$ & $49^{a}$ & $55^{\mathrm{b}}$ & 1.3 & $<0.001$ & 52 & 55 & 1.1 & 0.098 \\
\hline Productivity (weaned per year) & $33^{\mathrm{a}}$ & $43^{b}$ & $29^{\mathrm{a}}$ & 1.9 & $<0.001$ & 35 & 35 & 1.5 & 0.750 \\
\hline Survival rate up to $6^{\text {th }}$ parturition $(\%)$ & $42^{\mathrm{a}}$ & $72^{\mathrm{b}}$ & $28^{\mathrm{a}}$ & - & $<0.001$ & 47 & 48 & - & 0.861 \\
\hline
\end{tabular}

${ }^{1}$ Line H: maternal line characterized by prolificacy. Line LP: maternal line characterized by functional longevity. Line R: Paternal line characterized by daily gain during the growing period. ${ }^{2} \mathrm{AF}$ : diet enhancing animal fat inclusion as main energy source; CS: diet enhancing cereal starch as main energy source. ${ }^{3} \mathrm{SEM}$ : Pooled standard error of the means for traits analysed with linear mixed models. ${ }^{a, b}$ Means in a row within an effect not sharing superscript differ significantly $(P<0.05)$.

Figure 4.1 shows the evolution of females' maturity (as proportion of weight respect to the AW at the effective insemination) depending on the genetic type. At first insemination, each genetic type presented different proportion of their adult weight; Considering females ending the experiment, LP females reached first insemination with the highest proportion 
(+2.9 and +9.1 percentage units respect to $\mathrm{H}$ and $\mathrm{R}$ females; $P<0.05)$, whereas $\mathrm{H}$ females presented higher proportion respect $\mathrm{R}$ females (+6.2 percentage units; $P<0.05$ ). Moreover, $\mathrm{LP}$ females reached the $95 \%$ of adult weight at second reproductive cycle, whereas $\mathrm{H}$ and $\mathrm{R}$ females did at third. In Figure 4.2 is showed the evolution of cumulated survival rate of females at parturition throughout the reproductive cycles depending on the genetic type. At second parturition LP animals presented a significant higher survival rate compared to $\mathrm{H}$ and $\mathrm{R}$ animals (94 vs. 77 and 77\%, respectively; $P<0.05$ ), this difference was maintained or even increased from this point on (72 vs. 42 and $29 \%$ at sixth parturition, respectively; $P<0.05)$.

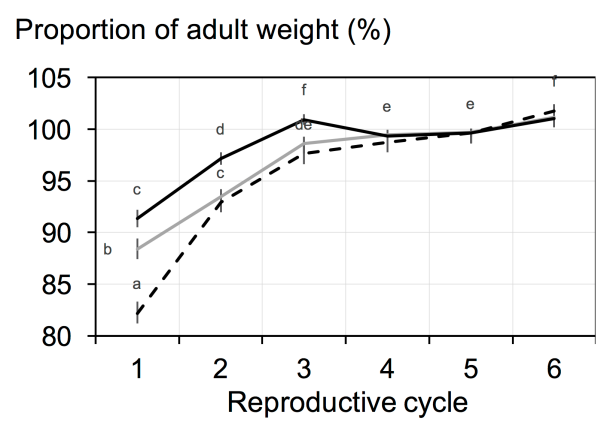

Figure 4.1 For females reaching the $5^{\text {th }}$ reproductive cycle: Percentage of adult weight (AW) at insemination for the subsequent RC depending on the genetic type [H in dark grey, LP in black, $\mathrm{R}$ in black dashed line]. AW calculated as the average weight at fourth, fifth and sixth insemination for females reaching sixth parturition. ${ }^{a, b, c, d, e, f}$ Means not sharing letter differs significantly $(P<0.05)$.

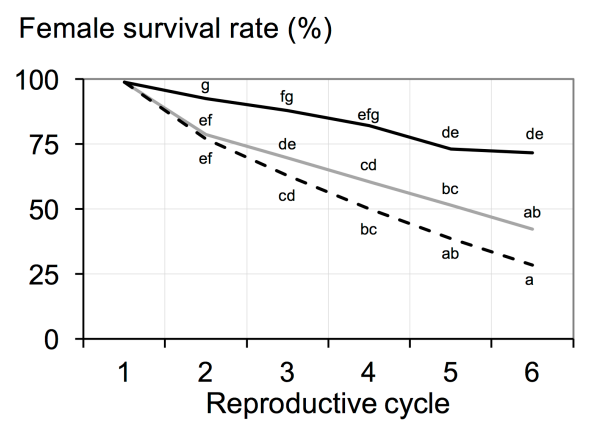

Figure 4.2 Cumulated survival rate (\%) at parturition in each reproductive cycle depending on genetic type $[\mathrm{H}$ in dark grey, LP in black, $\mathrm{R}$ in black dashed line]. a,b,c,d,e,f,g Means not sharing letter differs significantly $(P<0.05)$.

Conception rate at first attempt varied depending on genetic type, energy source and reproductive cycle (Figure 4.3). When nulliparous, no evidence for any difference among groups was found, but different patterns were observed from this point onward. $\mathrm{R}$ females decreased conception rate with age (27 percentage points less of multiparous compared to nulliparous, $P<0.05)$ independently of the diet. Decrease of conception rate with age was less evident for LP females, except for primiparous fed with CS (-24 percentage points respect to nulliparous, $P<0.05)$. H females showed a great conception rate decrease when primiparous (on av. -41 percentage points respect to nulliparous, $P<0.05$ ). However, only those $\mathrm{H}$ females fed with AF were able to increase again conception rate when multiparous $(+27$ percentage points, $P<0.05$ ). 


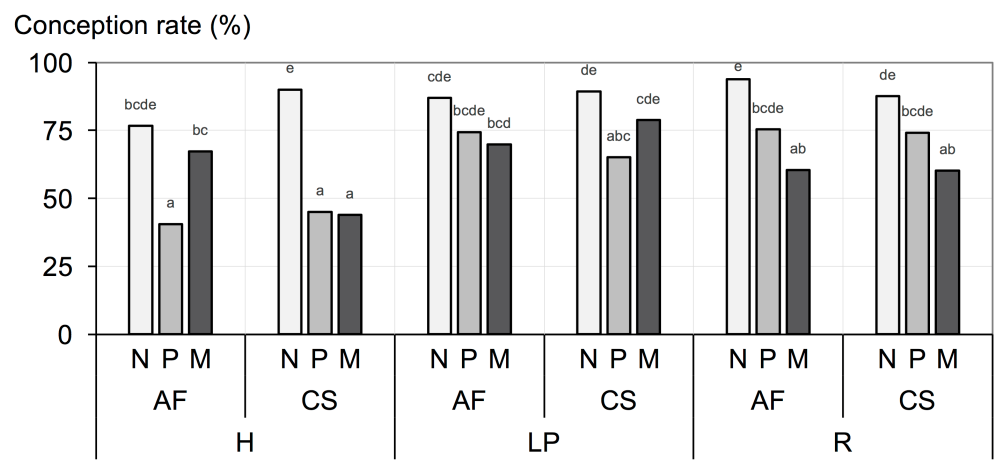

Figure 4.3 Conception rate (Pregnant at first attempt; \%) for nulliparous ( $\mathrm{N}$, light grey) primiparous $(\mathrm{P}$, medium grey) and multiparous $(\mathrm{M}$, dark grey) depending on genetic type (H,LP,R) and energy source of the diet (AF, CS). a,b,c,d,e Means not sharing lower case letter differ significantly $(P<0.05)$.

Traits related to litters according to the genetic type or diet are presented in Table 4.2. For litter size traits and compared to $\mathrm{R}$ females, females from maternal lines ( $\mathrm{H}$ and $\mathrm{LP}$ ) presented higher number of born alive (on av. 3.8 kits more; $P<0.05$ ) and lower number of stillborn (on av. 0.8 kits less; $P<0.05)$. Moreover, for the same standardized litter size at birth (on av. 9.7 kits), litters from the maternal lines presented also higher number of weaned (on av. 0.55 kits more; $P<0.05$ ). Regarding to diet, litters from females fed with CS had 0.9 total born more to those fed with $\mathrm{AF}(P<0.05)$. Survival rate of the offspring was higher for the maternal lines than for $\mathrm{R}$ animals (on av. +16 percentage points at birth and +8 percentage points during suckling; $P<0.05$ ). At the end of the experiment, $\mathrm{H}$ females had 17 kits born alive more than $\mathrm{R}$ females $(P<0.05)$. Nevertheless, LP females presented the highest number of cumulated born alive $1+12$ and +29 to $\mathrm{H}$ and $\mathrm{R}$ females, respectively; $P<0.05)$ and weaned (on av. +9; $P<0.05$ ). An interaction of genetic type, energy source and reproductive cycle for offspring survival rate during lactation was observed (Figure 4.4). In the first lactation, offspring survival rate in maternal lines with $\mathrm{AF}$ was 20

\section{Offspring survival rate (\%)}

$A(G T: H)$
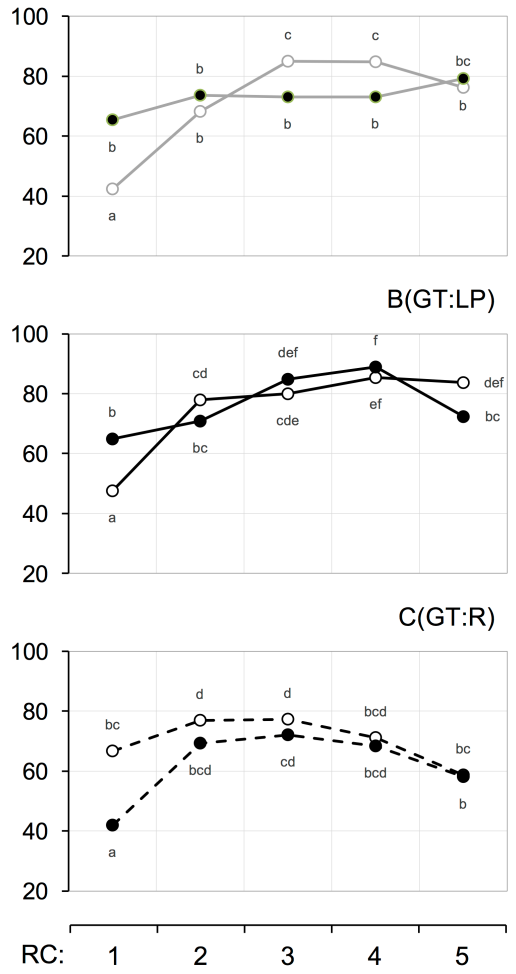

Figure 4.4 Offspring survival rate during lactation in each reproductive cycle $(\mathrm{RC})$ according to the energy source of the diet $[\mathrm{AF}(\mathrm{O})$;CS (O)]. Panel A: Line $\mathrm{H}$, Panel B: Line LP, Panel C: Line R. ${ }^{a, b, c, d, e, f}$ Means not sharing letter differ significantly $(P<0.05)$. 
percentage units lower to those with $\mathrm{CS}(P<0.05)$. On the contrary, survival of $\mathrm{R}$ offspring fed with $\mathrm{AF}$ was 25 percentage units higher to those with $\mathrm{CS}(P<0.05)$. From the second lactation on, survival of offspring with $\mathrm{AF}$ was higher or similar to those with $\mathrm{CS}$, independently of genetic type. In general, offspring survival rate increased from the first and the second lactation, but it decreased progressively from this point on in $\mathrm{R}$ offspring.

Table 4.2 Effect of genetic type and energy source on litter traits.

\begin{tabular}{|c|c|c|c|c|c|c|c|c|c|}
\hline & \multicolumn{5}{|c|}{ Genetic type $e^{1}$} & \multicolumn{4}{|c|}{ Energy source $e^{2}$} \\
\hline & $\mathrm{H}$ & LP & $\mathrm{R}$ & SEM $^{3}$ & $P$ & $\mathrm{AF}$ & CS & $\mathrm{SEM}^{3}$ & $P$ \\
\hline \multicolumn{10}{|l|}{ Litter size } \\
\hline Total born & $10.8^{\mathrm{b}}$ & $10.6^{\mathrm{b}}$ & $7.7^{\mathrm{a}}$ & 0.32 & $<0.001$ & $9.2^{\mathrm{a}}$ & $10.1^{\mathrm{b}}$ & 0.26 & 0.016 \\
\hline Born alive & $9.3^{b}$ & $9.5^{\mathrm{b}}$ & $5.6^{\mathrm{a}}$ & 0.35 & $<0.001$ & 7.8 & 8.5 & 0.29 & 0.061 \\
\hline Stillborn & $1.4^{\mathrm{a}}$ & $1.0^{\mathrm{a}}$ & $2.0^{\mathrm{b}}$ & 0.18 & $<0.001$ & 1.4 & 1.6 & 0.15 & 0.553 \\
\hline Standardized & 9.7 & 9.7 & 9.6 & 0.03 & 0.056 & 9.7 & 9.7 & 0.03 & 0.947 \\
\hline Weaned & $7.7^{b}$ & $7.8^{\mathrm{b}}$ & $7.2^{\mathrm{a}}$ & 0.15 & 0.013 & 7.6 & 7.5 & 0.12 & 0.577 \\
\hline \multicolumn{10}{|l|}{ Survival rate (\%) } \\
\hline At parturition & $87^{b}$ & $89^{b}$ & $72^{\mathrm{a}}$ & - & $<0.001$ & 84 & 84 & - & 0.920 \\
\hline During suckling & $73^{\mathrm{b}}$ & $77^{\mathrm{b}}$ & $67^{\mathrm{a}}$ & - & 0.002 & 74 & 72 & - & 0.393 \\
\hline \multicolumn{10}{|c|}{ Cumulated number at $5^{\text {th }}$ weaning } \\
\hline Born alive & $37^{\mathrm{b}}$ & $49^{c}$ & $20^{\mathrm{a}}$ & 1.7 & $<0.001$ & 34 & 36 & 2.1 & 0.473 \\
\hline Weaned & $23^{\mathrm{a}}$ & $30^{\mathrm{b}}$ & $19^{\mathrm{a}}$ & 1.7 & $<0.001$ & 24 & 25 & 1.4 & 0.753 \\
\hline \multicolumn{10}{|l|}{ Individual weight (g) } \\
\hline Total born & $55.9^{\mathrm{b}}$ & $52.8^{\mathrm{a}}$ & $62.3^{\mathrm{c}}$ & 0.95 & $<0.001$ & $58.6^{\mathrm{b}}$ & $55.4^{\mathrm{a}}$ & 0.78 & 0.003 \\
\hline Born alive & $56.6^{\mathrm{b}}$ & $53.7^{\mathrm{a}}$ & $65.5^{\mathrm{c}}$ & 0.94 & $<0.001$ & $60.6^{b}$ & $56.6^{\mathrm{a}}$ & 0.76 & $<0.001$ \\
\hline Stillborn & $39.7^{\mathrm{a}}$ & $41.1^{\mathrm{a}}$ & $49.0^{\mathrm{b}}$ & 2.5 & 0.017 & $46.6^{\mathrm{b}}$ & $39.9^{\mathrm{a}}$ & 2.0 & 0.022 \\
\hline Standardized & $54.2^{\mathrm{b}}$ & $51.8^{\mathrm{a}}$ & $59.6^{c}$ & 0.63 & $<0.001$ & $55.9^{\mathrm{b}}$ & $54.5^{\mathrm{a}}$ & 0.52 & 0.049 \\
\hline Weaned & $542^{\mathrm{a}}$ & $600^{\mathrm{b}}$ & $586^{\mathrm{b}}$ & 8.2 & $<0.001$ & $596^{\mathrm{b}}$ & $556^{\mathrm{a}}$ & 6.5 & $<0.001$ \\
\hline \multicolumn{10}{|c|}{ Individual maturity ${ }^{4}(\%$ of female $\mathrm{AW}$ ) } \\
\hline Total born & $1.44^{\mathrm{c}}$ & $1.34^{\mathrm{b}}$ & $1.01^{\mathrm{a}}$ & 0.022 & $<0.001$ & 1.26 & 1.27 & 0.018 & 0.827 \\
\hline Born alive & $1.47^{\mathrm{c}}$ & $1.36^{\mathrm{b}}$ & $1.04^{\mathrm{a}}$ & 0.019 & $<0.001$ & 1.29 & 1.29 & 0.015 & 0.880 \\
\hline Stillborn & 0.97 & 1.06 & 0.84 & 0.078 & 0.124 & $1.05^{\mathrm{b}}$ & $0.87^{\mathrm{a}}$ & 0.061 & 0.042 \\
\hline Standardized & $1.38^{\mathrm{c}}$ & $1.29^{\mathrm{b}}$ & $1.06^{\mathrm{a}}$ & 0.021 & $<0.001$ & 1.25 & 1.24 & 0.017 & 0.820 \\
\hline Weaned & $13.8^{\mathrm{b}}$ & $15.0^{c}$ & $10.6^{\mathrm{a}}$ & 0.26 & $<0.001$ & $13.6^{\mathrm{b}}$ & $12.8^{\mathrm{a}}$ & 0.21 & 0.009 \\
\hline
\end{tabular}

${ }^{1}$ Line H: maternal line characterized by prolificacy. Line LP: maternal line characterized by functional longevity. Line R: Paternal line characterized by high daily gain during the growing period. ${ }^{2} \mathrm{AF}$ : diet enhancing animal fat inclusion as main energy source; CS: diet enhancing cereal starch as main energy source. ${ }^{3} \mathrm{SEM}$ : Pooled standard error of the means. ${ }^{4}$ Estimated exclusively with litters from females reaching the sixth parturition. ${ }^{a, b, c}$ Means in a row within an effect not sharing superscript differ significantly $(\mathrm{P}<0.05)$. 
For traits related to the individual weight of the offspring, $\mathrm{R}$ females had heavier offspring during the whole cycle than $\mathrm{H}$ females. On the contrary, LP females had the lightest offspring at birth $(P<0.05)$, but they were as heavy as $\mathrm{R}$ at weaning. Regarding to diet, the offspring of females fed with AF was always heavier than that of females fed with CS ( $8 \%$ heavier; $P<0.05)$. For individual maturity, $\mathrm{R}$ offspring always represented the lowest maturity rates throughout lactation $(P<0.05)$. Compared to $\mathrm{LP}, \mathrm{H}$ offspring represented a higher maturity rates at birth, but lower at weaning $(P<0.05)$.

Finally, Figure 4.5 summarises the live history traits for each genetic type in function of dietary energy source received. LP females were the least affected by diet, only differing in the higher maturity at weaning of their kits when fed with $\mathrm{AF}(P<0.05)$. The survival rate of $\mathrm{H}$ females fed with $A F$ until $6^{\text {th }}$ parturition was 24 percentage units higher than those fed with $\mathrm{AF}(P<0.05)$. In addition, kits from $\mathrm{H}$ females fed with $\mathrm{AF}$ had always higher maturity than with CS $(P<0.05)$. $\mathrm{R}$ females fed with CS had higher litter size, but less mature, at parturition $(P<0.05)$.
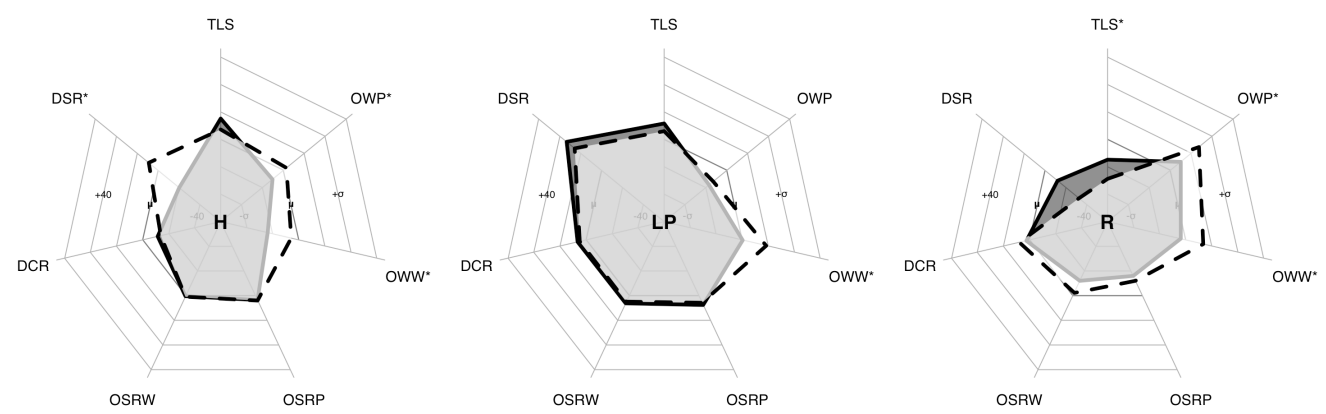

Figure 4.5 Live history traits for each genetic type (H, LP, R) depending on the energy source of the diet (AF: dashed line and white background, CS: solid line and grey background). Total litter size (TLS), Individual offspring weight at parturition (OWP) and individual offspring weight at weaning (OWW) expressed in standard deviation $(\sigma)$ respect to the global mean $(\mu)$. Offspring survival rate at parturition (OSRP), offspring survival rate at weaning (OSRW), doe conception rate (DCR) and doe survival rate (DSR) expressed as rate (\%) respect to the mean $(\mu) .{ }^{*}$ Means for diets within a genetic type of the corresponding trait differ significantly $(P<0.05)$.

\section{Discussion}

\section{Energy source}

As it was observed in the first paper of this series (Paper III of the thesis), and in agreement with the general knowledge (Pascual et al., 2003), when animal-fat is the main dietary energy source, lactating females produce more milk, increasing the amount available for their offspring. In the present study, we have observed that our animal-fat enriched diet (AF) resulted in heavier and more mature kits at weaning, but also affected the number and 
size of kits at birth differently to our cereal-starch diet (CS). Likewise, females fed with diet CS had more kits of small sizes, females fed with diet AF delivered less but heavier kits. In spite of the effect of energy source on litter size at birth is not properly elucidated (Pascual et al., 2003), Fortun-Lamothe et al. (1999) observed that when lactation and pregnancy overlaps, rabbit females are unable to increase their energy intake to cover both functions and a competition between the gravid uterus and the mammary gland is then stablished. In this scenario, energy source also would have shifted energy partitioning at this point; when females were fed with a diet rich in an energy source that is primarily used by the mammary gland (diet AF), less energy would have been available for the initial gestation process (e.g. higher energy deficit; Fortun-Lamothe and Prunier, 1999). Fewer kits of bigger sizes were produced (Vicente et al., 1995). Therefore, animal fat did not just increase milk yield or cereal starch improved body condition (Paper III); energy source of the diet seems also to alter the way concurrent lactating-gestating animals allocate resources when homeorhetic process are involved, affecting fitness traits.

\section{Genetic type}

Selection for post-weaning average daily gain is accompanied by an increasing of AW (Blasco et al., 2003). Consequently, females from paternal lines are bigger than females from the maternal lines (Pascual et al., 2015). Apart from a bigger body weight, $\mathrm{R}$ females were also characterized in the present study by few kits of big size (Vicente et al., 1995), by higher gestational losses (Vicente et al., 2012) and by large interval between parturitions. Baselga (2002a) reported 7.7 kits born, 57 days between parturitions, $4300 \mathrm{~g}$ of live weight at first $\mathrm{AI}$ and $600 \mathrm{~g}$ of the kits at weaning as mean values for this line. These results are in agreement with those showed in the present study. However, that work reported lower proportion of stillbirths (11 vs 28\%) and lower litter size at weaning (6.1 vs 7.2) respect to the present study, which could be related to the standardization of litters at birth we performed.

On the contrary, maternal lines were characterized by lower AW with larger litters but lighter kits at birth, although it varied between genetic types. Kits from LP females were lighter than those from $\mathrm{H}$ females at birth but heavier at weaning due to the higher milk yield of LP females (Paper III; Savietto et al., 2015). Moreover, LP females were characterized by great survival rate at the end of the experiment, which is in agreement with the results reported by Sánchez et al. (2008) and EL Nagar (2015). On the other hand, (Baselga, 2002b) reported 10.5 kits born, 46 days between parturitions, $3279 \mathrm{~g}$ at first insemination, $7.9 \%$ of stillbirths and $530 \mathrm{~g}$ of the kits at weaning as mean values for $\mathrm{H}$ line. Except for the interval between parturitions, which varied with reproductive cycle and diet (Figure 4.3), all results are in agreement with those showed in the present study. Therefore, we have showed that 
different genetic types had different features for fertility, number and size of the offspring and survival of females, suggesting that they prioritize different components of fitness.

\section{Genetic type $x$ energy source and the genetic background}

We have observed that different genetic types prioritized different components of fitness, which has been proposed to be shaped by their genetic background (conditions and criteria at foundation and during selection; Savietto et al., 2015). These priorities may arise because the environment limits the amount of resources an animal can acquire and subsequently they have to split them among fitness components (Beilharz and Nitter, 1998). As energy source can alter the way animals allocate energy, it could affect fitness components differently depending on the genetic type.

Paternal line. Line $\mathrm{R}$ was founded crossing a pool of animals from three paternal lines and has been selected exclusively for average daily gain during the growing period since 1984, increasing their AW (Blasco et al., 2003). However, as maternal abilities have never been considered as breeding goals, energy acquisition capacity during lactation and milk yield have not evolved proportionally to their size, as females from the maternal lines did (Paper III). Moreover, as R females were characterized by few offspring of big size, when litters were standardized to 9.7 kits (aiming equalizes lactational effort among genetic types), we force females to nurse many kits of big size with non-adapted energy intake and milk output. In other words, we set the reproductive effort to be much greater than the initially set by $\mathrm{R}$ females' genetic potential. All these facts highlight the difficulty of comparing so different genetic types, especially if we consider that the consequences of an increased reproductive effort depend also on genetic type (Theilgaard et al., 2009). Consequently, this increased reproductive effort could be related with the low survival rate of the offspring observed for this line during lactation. Moreover, it could have altered energy balance while females were concurrently pregnant and lactating (Fortun-Lamothe et al., 1999), increasing the risk of death of unborn kits and accelerating senescence of females (decreasing of conception rate of females and survival rate of the kits during lactation with age). Females reached at first insemination with a lower maturity (interpreted as proportion of their AW; Figure 4.3). Both facts, increased reproductive effort and lower maturity at first insemination could be related to the low survival rate of $\mathrm{R}$ females (Rosell and de la Fuente, 2009).

Regarding to the effect of energy source, when $\mathrm{R}$ females were fed with a diet promoting milk yield, initially improved survival rate of the kits during lactation (Figure 4.4) and their individual weight at weaning (Figure 4.5). However, due to the increasing lactational effort as lactation progress (Paper III), the competition between mammary gland and gravid uterus would be higher for $\mathrm{R}$ females fed with AF than for maternal lines fed with 
the same diet, producing less but heavier kits (Figure 4.5). Moreover, as the reproductive effort was set even further than they naturally would have done when they were fed with AF, it increased the negative effects of the excessive reproductive effort with age (Figure 4.4 and 4.5).

Maternal lines. Breeding goals for maternal lines are different from those for the paternal ones (Baselga, 2004). However, as the proportion at first reproductive cycle respect to subsequent cycles of voluntary feed intake in maternal lines is much lower than in a paternal line (Paper III), it seems that maternal breeding goals do not favour early development of acquisition capacity. Moreover, we reported that, under cold challenging conditions (Paper III), primiparous $\mathrm{H}$ and LP females, with limited acquisition capacity, could not increase their energy intake in response to cold temperatures and they would have accelerated weaning to safeguard body condition when they were fed with a diet not favouring body condition restore (AF). The consequence was the lower survival rate of their offspring at first reproductive cycle (Figure 4.4). Although it seems contradictory, it could be a strategy to improve fitness. For example, in poor or uncertain environments, animals that continue investing on the current litter are seriously penalized if doing it reduces their chances of survival. On the contrary, those animals reducing the investment on the current litter would live longer to explore more reproductive events awaiting for better conditions (Hrdy, 1979; Stearns, 1992). It seems that this strategy could have been a proper bet of maternal lines to cope with that situation: females fed with AF did not live less than those fed with CS and they pay the lower survival rate during the first reproductive cycle with a higher one in subsequent cycles.

Criteria at foundation and for selection of $\mathrm{H}$ females were focus on prolificacy. Rauw et al. (1999) showed that selection for prolificacy increased the amount of reserves of selected animals. In agreement, we proposed in the first work of this series (Paper III) that $\mathrm{H}$ females tend to store body reserves during lactation to cope with future reproduction. In a selection context where large litters in a short interval are demanded by farmers and breeders, females have little time for recovering fat between weaning and next parturition. In such context, this pattern of body reserves accretion could be an adaptive strategy of $\mathrm{H}$ females preventing them from poor body condition risks (Theilgaard et al., 2006; Sánchez et al., 2012). In this sense, despite females fed with CS stored more fat, we observed that they followed the same trajectory for body condition across lactation when fed with both diets (Paper III). However, as they tend to store as much reserves as they can, when fed with a diet promoting the restore of body reserves (CS), they could become overfat, increasing the risk of not getting pregnant (Figure 4.3) or death (Figure 4.5) due to metabolic or immunologic imbalances (Paper III; Penadés, 2017). Moreover, this situation could be especially risky if we 
consider that $\mathrm{H}$ females presented some symptoms of aging of their immune system at second parturition that increased with age (Penadés, 2017). Therefore, despite the results from the first reproductive cycle, fitness traits of $\mathrm{H}$ females were globally more favoured when fed with AF compared to CS (Figure 4.3), not affecting mean productivity at sixth parturition.

LP females have been selected for litter size at weaning during 7 generations. However, due to the criteria used at the foundation of the line, there are two important goals for these animals, productivity and survival in commercial farms. Commercial farms are characterized by a great variability of their environmental control, size, management or reproductive rhythm (Rosell and de la Fuente, 2009), leading to highly variable environments between and within farms. It has been proposed (Philippi and Seger, 1989; Olofsson et al., 2009) that, in highly variable and unpredictable environments, strategies addressed to reduce risks could be better strategies than adaptive ones (generalist instead of specialist). For example, amongst other reasons, mammals accumulate reserves to cope with the uncertainty of food in the future. However, the probability for a female of not finding food in a farm is close to zero so, the accumulation of too much body reserves for their later utilization, could not pay the risk of being too fat or too thin in the long term (Theilgaard et al., 2006). In other words, the uncertainty is not on food availability.

By using a particular pattern for acquisition and allocation of resources (Paper III), LP animals could have adopted this generalist safety way to be productive and to cope with uncertainty of farms conditions (Savietto et al., 2015). We reported that LP females had a great acquisition capacity but they were able to adapt their energy intake and allocation of resources to their temporary requirements. In this way, they could safeguard body condition and reach critic points of their life trajectory in good metabolic or immunological status (Paper III; Penadés, 2017). For example, at second parturition, females are still growing, their acquisition capacity is not fully developed, but they are under highly productive conditions. Consequently, this point has been described as the moment with the highest risk for females to be removed from farms (Rosell and de la Fuente, 2009). However, at this point, LP females presented high values of blood glucose, low levels of NEFA and BOHB (Paper III) and higher counts of lymphocytes $\mathrm{T}$ and $\mathrm{B}$ (Penadés, 2017). Therefore, the main consequence of this low risk strategy would be the highest survival rate at second parturition of LP females (Figure 4.2). Moreover, this higher survival remained until the end of the experiment independently of the diet (Figure 4.5). The higher proportion of weight respect to AW (used as indicator of degree of maturity) and the lower incidence of diet or reproductive cycle on fertility would also have reduced the risk of death or culling under farm conditions (Rosell and de la Fuente, 2009). Therefore, from all the possible strategies allowing animals being 
productive, LP animals seem to use the one minimizing risks, which allowed them to survive and being highly productive in the long term with little influence of energy source of the diet.

\section{Conclusions}

Genetic types differing greatly in their genetic background seem to prioritize different fitness components. Females from the paternal line ( $\mathrm{R}$ females) were characterized by greater adult weight and little but heavier kits, although it seems they could be more immature. When $\mathrm{R}$ females were fed with a diet with animal fat as main energy source, they invested more on the current litter, whereas when fed with a diet with cereal starch as main energy source, it seems that they invested more in recovering for future reproduction. On the contrary, females from the maternal lines were smaller and had numerous but lighter kits, but each genetic type used different strategies. The strategy used by $\mathrm{H}$ females makes them more sensible to the energy source of the diet, triggering problems to ensure future reproduction when fed with cereal starch (low conception rate or higher mortality of females). However, the strategy used by LP females seems to be more generalist, allowing them to ensure high performance of the current litter without neglecting future reproduction and with less sensibility to the energy source than for the other genetic types. Therefore, energy source of the diet, which affected to energy acquisition and allocation, also affected to fitness components. Moreover, the response to energy source varied with genetic types. It seems that more specialized genetic types, that base reproduction on body reserves, were more sensible to energy source than the more generalist and robust type, that base reproduction on energy intake.

\section{Acknowledgments}

This study was supported by the Interministerial Commission for Science and Technology (CICYT) of the Spanish Government (AGL2014-53405-C2-1-P). The authors thank Juan Carlos Moreno for his technical support. Grants for Alberto Arnau from the Ministry of Economy and Finance (BES-2012-052345) are also gratefully acknowledged.

\section{References}

Baselga M 2002a. Line R (Spain). In Rabbit genetic resources in Mediterranean countries (ed. Khalil MH and Baselga M), pp. 257-262. Zaragoza: Ciheam (Options Méditerranéennes : Série B. Etudes et Recherches; n. 38), Zaragoza, Spain.

Baselga M 2002b. Line H (Spain). In Rabbit genetic resources in Mediterranean countries (ed. Khalil MH and Baselga M), pp. 247-251. Zaragoza: Ciheam (Options Méditerranéennes : Série B. Etudes et Recherches; n. 38), Zaragoza, Spain.

Baselga M 2004. Genetic improvement of meat rabbits. Programmes and diffusion. In Proceedings of the 8th World Rabbit Congress, September 2004, Puebla, Mexico, pp. $1-13$. 
Beilharz RG and Nitter G 1998. The missing E: the role of the environment in evolution and animal breeding. Journal of Animal Breeding and Genetics 115, 439-453.

Blasco A, Piles M and Varona L 2003. A Bayesian analysis of the effect of selection for growth rate on growth curves in rabbits. Genetics Selection Evolution 35, 21-41.

De Blas JC and Mateos GG 2010. Feed formulation. In Nutrition of the rabbit, 2nd edition (ed. De Blas JC and Wiseman J), pp. 222-232. CABI Publishing, Wallingford, UK.

EL Nagar AG 2015. Genetic analysis of longevity in specialized lines of rabbits. $\mathrm{PhD}$ thesis, Universidad Politécnica de Valencia, Valencia, Spain.

Fernández-Carmona J, Blas E, Pascual JJ, Maertens L, Gidenne T and García J 2005. Recommendations and guidelines for applied nutrition experiments in rabbits. World Rabbit Science 13, 209-228.

Fortun-Lamothe L and Prunier A 1999. Effects of lactation, energetic deficit and remating interval on reproductive performance of primiparous rabbit does. Animal Reproduction Science 55, 289-298.

Fortun-Lamothe L, Prunier A, Bolet G and Lebas F 1999. Physiological mechanisms involved in the effects of concurrent pregnancy and lactation on foetal growth and mortality in the rabbit. Livestock Production Science 60, 229-241.

Friggens NC, Brun-Lafleur L, Faverdin P, Sauvant D and Martin O 2013. Advances in predicting nutrient partitioning in the dairy cow: recognizing the central role of genotype and its expression through time. Animal 7, 89-101.

Hrdy SB 1979. Infanticide among animals: A review, classification, and examination of the implications for the reproductive strategies of females. Ethology and Sociobiology 1, 13-40.

Kolmodin R, Strandberg E, Jorjani H and Danell B 2003. Selection in the presence of a genotype by environment interaction: response in environmental sensitivity. Animal Science 76, 375-385.

Lewontin RC 1974. Annotation: the analysis of variance and the analysis of causes. American Journal of Human Genetics 26, 400-411.

Littell RC, Henry PR and Ammerman CB 1998. Statistical analysis of repeated measures data using SAS procedures. Journal of Animal Science 76, 1216-31.

Olofsson H, Ripa J and Jonzén N 2009. Bet-hedging as an evolutionary game: the trade-off between egg size and number. Proceedings of the Royal Society B-Biological Sciences 276, 2963-2969.

Pascual JJ, Cervera C, Blas E and Fernández-Carmona J 2003. High-energy diets for reproductive rabbit does: effect of energy source. Nutrition Abstracts and Reviews 73, 27R-39R.

Pascual M, Calle EW and Blasco A 2015. Comparison of degrees of maturity of rabbit lines selected for different traits. World Rabbit Science 23, 155-161.

Penadés M 2017. Staphylococcus aureus infections in rabbits from different genetic lines: study of the host, the bacterium and the bacterial-host interaction. $\mathrm{PhD}$ thesis, Universidad CEU Cardenal Herrera, Valencia, Spain. 
Philippi T and Seger J 1989. Hedging one's evolutionary bets, revisited. Trends in Ecology and Evolution 4, 41-44.

Rauw WM 2009. Introduction. In Resource allocation theory applied to farm animal production (ed. Rauw WM), pp. 1-21. CABI Publishing, Wallingford, UK.

Rauw WM, Kanis E, Noordhuizen-Stassen EN and Grommers F 1998. Undesirable side effects of selection for high production efficiency in farm animals: a review. Livestock Production Science 56, 15-33.

Rauw WM, Luiting P, Beilharz RG, Verstegen MWA and Vangen O 1999. Selection for litter size and its consequences for the allocation of feed resources: a concept and its implications illustrated by mice selection experiments. Livestock Production Science 60, 329-342.

Rosell JM and de la Fuente LF 2009. Culling and mortality in breeding rabbits. Preventive Veterinary Medicine 88, 120-127.

Sánchez JP, Theilgaard P, Mínguez C and Baselga M 2008. Constitution and evaluation of a long-lived productive rabbit line. Journal of Animal Science 86, 515-525.

Sánchez JP, de la Fuente LF and Rosell JM 2012. Health and body condition of lactating females on rabbit farms. Journal of Animal Science 90, 2353-2361.

Savietto D, Friggens NC and Pascual JJ 2015. Reproductive robustness differs between generalist and specialist maternal rabbit lines: the role of acquisition and allocation of resources. Genetics Selection Evolution 47, 2. doi: 10.1186/s12711-014-0073-5.

Stearns SC 1992. Number and size of offspring. In The evolution of life histories, pp. 150179. Oxford University Press, Oxford.

Theilgaard P, Sánchez JP, Pascual JJ, Friggens NC and Baselga M 2006. Effect of body fatness and selection for prolificacy on survival of rabbit does assessed using a cryopreserved control population. Livestock Science 103, 65-73.

Theilgaard P, Baselga M, Blas E, Friggens NC, Cervera C and Pascual JJ 2009. Differences in productive robustness in rabbits selected for reproductive longevity or litter size. Animal 3, 637-646.

Vicente JS, García-Ximénez F and Viudes-de-Castro MP 1995. Neonatal performances in 3 lines of rabbit (litter sizes, litter and individual weights). Annales de Zootechnie 44, 255-261.

Vicente JS, Llobat L, Viudes-de-Castro MP, Lavara R, Baselga M and Marco-Jiménez F 2012. Gestational losses in a rabbit line selected for growth rate. Theriogenology 77, 81-88. 



\section{GENERAL DiscusSION}



The main objective of this thesis was to fit nutrition to the genetic type in an overall sense. To do it, a long-term experiment with three highly different genetic types fed with two iso-energetic diets that differed in the main energy source was performed. To understand properly the results of the experiment it was necessary to use concepts and ideas from resource allocation and nutrient partitioning frameworks. However, these concepts and ideas implied considering the effect of time and the individual variation of animals. Both effects produced databases with particular structures that had to be considered adequately.

\section{Statistical approach}

Gibbons et al. (2010) reported some statistical problems inherit to longitudinal data. These problems were related to subjects clustered in centers (generating different sources of variation), heterogeneity of variance over time, correlations between errors or irregular distributions of measurements over time. From all the reviewed references for long-term experiments using reproductive rabbit females, many of them avoid some problems by considering observations within the reproductive cycle as different physiological states (defining different traits) and observations from the same physiological state as the same trait. However, analysing all the data coming from a trait together into a single longitudinal analysis presents some statistical and interpretation profits (Hedeker and Gibbons, 2006). As far as I know, this is the first time that all of these problems have been addressed directly with mixed models using data from long-term experiments with rabbit females. In this regard, we have proposed several structures of the (co)variance matrix to cope with the different aspects of data. Despite none of the proposed structures fitted best to data from all the traits, it seems that models in which (co)variance structure was modelled in blocks of (co)variances for each reproductive cycle [such as $\mathrm{B}-\mathrm{BD}$ or $\mathrm{B}-\mathrm{BAR}(1)$ ], presented an overall suitable statistic performance (in terms of parsimony and fitting; Paper I) and biological interpretation (Paper II). Moreover, considering all the information coming to a single trait into an unique analysis has allowed the study of the complex interactions on acquisition and allocation traits observed in Paper III. Therefore, despite the higher complexity of the models, these models are useful to improve the efficiency of the statistical analysis, to provide information about individual variation of animals and to evaluate the effect of treatments (such as diet or genetics) over time.

\section{The role of the animal and the effect of energy source}

The structure where data was modelled in blocks of (co)variances for each reproductive cycle allowed us to consider individual variation in the trajectories over the reproductive cycle of the different traits involved in acquisition and allocation of energy. Moreover, one them could consider residual correlations at two levels [within the

reproductive cycle and over reproductive cycles; B-BAR(1]. Variance components and 
individual solution of random effects obtained from this structure and from a multi-trait mixed model which included all the traits, allowed us to find a parallelism between information provided by the random effects of mixed models and concepts involved in nutrient partitioning. In fact, results from Paper II revealed relevant variation between animals for all the traits (repeatability ranging from 0.15 to 0.78), a wide range of strategies between animals for acquisition and allocation of energy (permanent correlations between traits ranging from -0.05 to 0.92 ), but little variation in the individual trajectories of the traits over the reproductive cycle (permanent correlations over the reproductive cycle close to one). Despite little variation in the individual trajectories is in agreement with the ideas of Taylor (1985), there are evidences in rabbits that selection can modify the shape of the lactation trajectory of females (Savietto et al., 2014). In addition, in Paper III we have reported different trajectories over the reproductive cycle of milk yield, body reserves or feed intake for the different genetic types. However, it is important to point out that, given the uncertainty shown by the standard errors, permanent correlations could be lower than what we have estimated (we did not proof that correlations were equal to one). Moreover, correlations could be population dependent. We did not estimate genetic correlations, we estimated permanent correlations. All of these factors would explain the observed trajectories over the reproductive cycle for so different genetic types.

On the other hand, residual correlations (Table 2.3) showed high environmental relation between feed intake and milk yield $(0.76 \pm 0.021)$ but non-significant between feed intake and body weight or PFT. Moreover, a negative environmental correlation but low was observed between milk yield and PFT $(-0.10 \pm 0.048)$. These results indicated that the main response to environmentally milk-yield variations were produced through proportional variations in feed intake, although with some antagonistic effects on body reserves. These residual correlations agree with the results previously reported for the effect of energy source (Pascual et al., 2003) and with those reported in Paper III. Diet AF (enriched with animal fat) promoted milk yield of females. Females fed with AF responded by increasing their energy intake, but not enough to avoid a reduction of body reserves. On the contrary, when females were fed with a diet enriched with cereal starch (Diet CS), they tend to accrete body reserves, but decreasing their milk yield.

The large variation between animals in the strategies for acquisition and allocation of energy and the way animals responded to energy source and to environmental perturbations revealed a complex role of the animal, in which animals adjust acquisition and allocation of energy to meet their targeted trajectories, maintain homeostasis and safeguard body reserves (Friggens and Newbold, 2007; Friggens et al., 2013). This situation was illustrated in Paper III by the response during the first lactation of females from the maternal 
lines (H and LP) fed with Diet AF (Figure 3.3). At this point, it is important recall that most of the females gave birth their first litter under winter conditions. In such environmental conditions, rather than increasing milk yield, Diet AF reduced the yield of those females. We suggested that females were not able to increase their energy intake enough to cope with all of the requirements in that moment and we argued that in that situation they gave priority to thermogenesis and to safeguard body condition. However, this situation was not observed in females from the paternal line. Consequently, it seems that varying the main energy source of the diet we can modulate allocation of females, but altering their normal homeostasis. To properly understand the way females acquire and allocate resources we had to consider the amount of acquired energy, how much of this energy was addressed to each function and also the way different animals responded to environmental perturbations (such as different diets). All of these factors allowed us to understand the priorities of different animals over their life trajectory and their allocation strategies according to their genetic background (Savietto et al., 2015). Moreover, in Paper IV we could observe the relation between acquisition and allocation of energy and productivity and fitness of the different genetic types.

\section{Optimizing resource allocation to the genetic type}

Several reproductive disorders have been reported for females of the paternal line $\mathrm{R}$, such as lower ovulation frequency or higher implantation, foetal, gestational and perinatal losses (Vicente et al., 2012). Consequently, the number of born alive, weaned and finally the number of animals reaching to adulthood could be too low to perform an effective selection. Females from this line are bigger and fatter than females from maternal lines (Pascual et al., 2015; Naturil-Alfonso et al., 2016). Cardinali et al. (2008) showed that extreme body condition (both very low and very high) was related with poor sexual receptivity and fertility. To improve the reproductive performance of $\mathrm{R}$ females, we hypothesized that they could be over-fat and animal-fat enriched diets, which do not promote body reserves accretion, could be beneficial to improve their fertility (Naturil-Alfonso et al., 2016). Moreover, as animal-fat enriched diets promote milk yield, we expected that Diet AF would improve survival of the offspring during lactation. However, in Paper III and Paper IV we have observed that the real situation was much more complex due to the particular priorities of $\mathrm{R}$ females. It seems that at the beginning of lactation these females tended to prioritize body reserves accretion rather than milk yield, which had a negative impact on survival of current litter. Moreover, this situation was inverted at the end of lactation. Savietto et al. (2015) related the evolution of energy addressed to milk yield and to body reserves accretion with the trade-off current vs future reproduction. In this sense, compared to females from the maternal lines, it seems that the priority for current reproduction of $\mathrm{R}$ females decrease more rapidly at the beginning of 
lactation, but would persist more at the end of lactation. Consequently, when we fed $\mathrm{R}$ females with Diet AF, we force females to yield more milk which increased the priority for current reproduction. However, as the priority for current litter was especially increased at the end of lactation, it decreased considerably the priorities for future reproduction and maintenance, affecting negatively to future litter and accelerating senescence. This idea is schematized in Figure 5.1, where the priorities between current and future reproduction of $R$ females compared to a non-selected female and a highly selected female for litter sized at weaning are presented. Unfortunately, we could not elucidate whether these priorities were the consequence of the experimental design or due to the genetic background of $\mathrm{R}$ females.

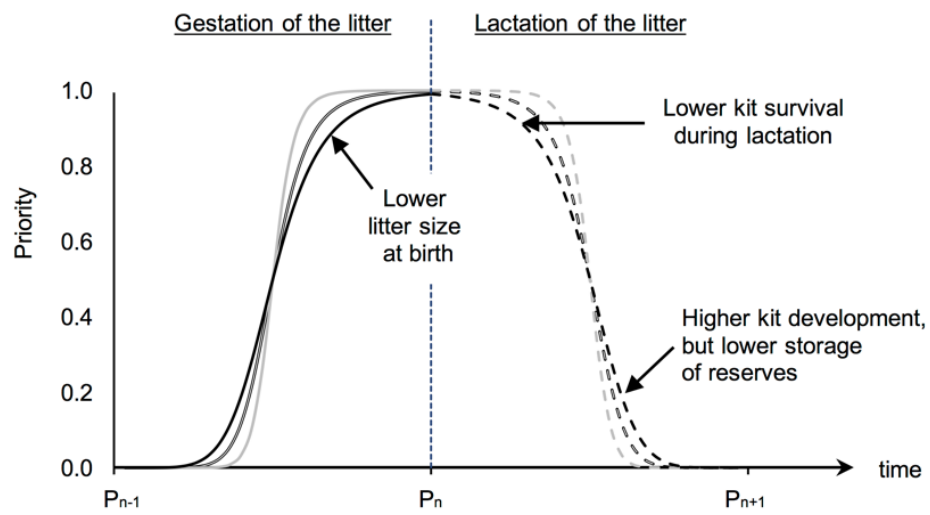

Figure 5.1 Relative priorities between current and future litter. litter being nurse (dotted line) litter being gestate (solid line) of $\mathrm{R}$ females (black line), females highly selected for litter size at weaning (gray line) and non-selected female (parallel lines). To simplify the figure I have suppressed priority for current litter of $P_{n-1}$ and priority for future litter of $P_{n+1}$.

$\mathrm{H}$ line was founded selecting hyper-prolific females. High productive performance has been associated with poor body condition (Xiccato, 1996). Poor body condition has been related to reproductive or health disorders (Cardinali et al., 2008; Sánchez et al., 2012), increasing the risk of culling of females (Theilgaard et al., 2006; Rosell and de la Fuente, 2009). As the fast turnover between current and future reproduction let females with high reproductive effort little time to recover body reserves under current production systems, we hypothesized that Diet $\mathrm{CS}$, which should promote body reserves accretion, could be beneficial for $\mathrm{H}$ females. However, recent studies have described none problem of longevity for this genetic type. In fact, it seems that selection for litter size at weaning is improving its longevity (EL Nagar, 2015). Similarly to highly selected mice (Rauw et al., 1999), our data suggests that $\mathrm{H}$ females could overcome high productive performances and cope with future reproduction by accreting body reserves whenever possible. Consequently, when we fed 
with Diet CS, excessive promotion of body reserves accretion altered this equilibrium triggering reproductive disorders and increasing their risk of death.

On the other hand, some authors have claimed for selecting females for feed intake to cope with problems related with negative energy balance (Xiccato et al., 1995; Castellini et al., 2010). In this sense, we have observed that animals with higher feed intake tend to have more PFT, to yield more milk and to have heavier litters (Table 2.3). Moreover, the moderate variation between animals (phenotypic variance and repeatability) suggests that theoretically it would be possible to select by appetite but likely associated with an increase on live weight of the animals and feed intake in non-productive periods. However, to avoid these or other non-expected side effects and, we have argued that the goal should not be to get animals with higher appetite. Considering the wide range of strategies for acquisition and allocation of resources (Figure 2.2), we have argued that the goal should be to obtain animals with a great acquisition capacity, but able to adapt their energy intake to their transitory requirements (e.g. great intake during lactation which allows increasing milk yield without conditioning body reserves and low intake out of lactation). Several studies have reported that LP females follow this strategy (Theilgaard et al., 2009; Savietto et al., 2015). Data reported in the present thesis also support this statement. In fact, it seems that LP females use body reserves as a safety factor rather than as a reproduction fuel (Savietto et al., 2015). We have argued that it is a low risk strategy, which let LP females being highly productive and functional when fed with both diets and over a wide range of environmental conditions existing in commercial farms (Theilgaard et al., 2007; Ferrian et al., 2013; Savietto et al., 2013). In fact, independently of the energy source of the diet, these females presented the highest fitness at the end of the experiment (highest number of cumulated born alive and weaned). In this sense, the criterion of functional hyper-longevity could be considered as a criterion to search for females with high fitness merit under farm conditions. Moreover, making the parallelism between fitness and functionality LP females could be considered as highly functional females (high survival rate of females and their offspring, high conception rate, etc.).

Despite I cannot prove it with the data from the present experiment, reported genetic correlations in previous experiments suggest that the cost of selection for productivity traits is very small in rabbits. For example, genetic correlations between growing traits and litter size are positive but low (García and Baselga, 2002; Mínguez et al., 2015). Moreover, litter size and interval between parturitions has been reported to be profitably correlated (Ragab and Baselga, 2011), but growth rate and fertility are moderately negatively correlated (Piles and Tusell, 2012). Respect to longevity of females, it has been reported low relation with litter size (Piles et al., 2006; Sánchez et al., 2006) or even a generalized positive 
response in lines selected by different productive criteria (EL Nagar, 2015). In this sense, it seems that productivity do not trade-off very much with functionality in rabbits. However, the way that the different genetic types responded to energy sources used in the present study suggests a cost of specialization of females highly selected for productivity $(H$ and $R$ females). We should consider this situation and the priorities of each genetic type when formulating diets for reproductive rabbit females.

\section{References}

Cardinali R, Dal Bosco A, Bonanno A, Di Grigoli A, Rebollar PG, Lorenzo PL and Castellini C 2008. Connection between body condition score, chemical characteristics of body and reproductive traits of rabbit does. Livestock Science 116, 209-215.

Castellini C, Dal Bosco A, Arias-Álvarez M, Lorenzo PL, Cardinali R and Rebollar PG 2010. The main factors affecting the reproductive performance of rabbit does: a review. Animal Reproduction Science 122, 174-182.

Ferrian S, Blas E, Larsen T, Sánchez JP, Friggens NC, Corpa JM, Baselga M and Pascual JJ 2013. Comparison of immune response to lipopolysaccharide of rabbit does selected for litter size at weaning or founded for reproductive longevity. Research in Veterinary Science 94, 518-25.

Friggens NC and Newbold JR 2007. Towards a biological basis for predicting nutrient partitioning: the dairy cow as an example. Animal 1, 87-97.

Friggens NC, Brun-Lafleur L, Faverdin P, Sauvant D and Martin O 2013. Advances in predicting nutrient partitioning in the dairy cow: recognizing the central role of genotype and its expression through time. Animal 7, 89-101.

García ML and Baselga M 2002. Estimation of correlated response on growth traits to selection in litter size of rabbits using a cryopreserved control population and genetic trends. Livestock Production Science 78, 91-98.

Gibbons RD, Hedeker D and DuToit S 2010. Advances in analysis of longitudinal data. Annual Review of Clinical Psychology 6, 79-107.

Hedeker D and Gibbons RD 2006. Introduction. In Longitudinal data analysis, pp. 1-12. John Willey \& Sons, Chicago, USA.

Mínguez C, Sanchez JP, EL Nagar AG, Ragab M and Baselga M 2015. Growth traits of four maternal lines of rabbits founded on different criteria: comparisons at foundation and at last periods after selection. Journal of Animal Breeding and Genetics, 1-13.

EL Nagar AG 2015. Genetic analysis of longevity in specialized lines of rabbits.PhD thesis, Universidad Politécnica de Valencia, Valencia, Spain.

Naturil-Alfonso C, Lavara R, Millán P, Rebollar PG, Vicente JS and Marco-Jiménez F 2016. Study of failures in a rabbit line selected for growth rate. World Rabbit Science 24, 47.

Pascual JJ, Cervera C, Blas E and Fernández-Carmona J 2003. High-energy diets for reproductive rabbit does: effect of energy source. Nutrition Abstracts and Reviews 73, 
27R-39R.

Pascual M, Calle EW and Blasco A 2015. Comparison of degrees of maturity of rabbit lines selected for different traits. World Rabbit Science 23, 155-161.

Piles M and Tusell L 2012. Genetic correlation between growth and female and male contributions to fertility in rabbit. Journal of Animal Breeding and Genetics 129, 298305.

Piles M, Garreau H, Rafel O, Larzul C, Ramon J and Ducrocq V 2006. Survival analysis in two lines of rabbits selected for reproductive traits. Journal of Animal Science 84, 1658-1665.

Ragab M and Baselga M 2011. A comparison of reproductive traits of four maternal lines of rabbits selected for litter size at weaning and founded on different criteria. Livestock Science 136, 201-206.

Rauw WM, Luiting P, Beilharz RG, Verstegen MWA and Vangen O 1999. Selection for litter size and its consequences for the allocation of feed resources: a concept and its implications illustrated by mice selection experiments. Livestock Production Science 60, 329-342.

Rosell JM and de la Fuente LF 2009. Culling and mortality in breeding rabbits. Preventive Veterinary Medicine 88, 120-127.

Sánchez JP, Baselga M and Ducrocq V 2006. Genetic and environmental correlations between longevity and litter size in rabbits. Journal of Animal Breeding and Genetics 123, 180-185.

Sánchez JP, de la Fuente LF and Rosell JM 2012. Health and body condition of lactating females on rabbit farms. Journal of Animal Science 90, 2353-2361.

Savietto D, Cervera C, Blas E, Baselga M, Larsen T, Friggens NC and Pascual JJ 2013. Environmental sensitivity differs between rabbit lines selected for reproductive intensity and longevity. Animal 7, 1969-1977.

Savietto D, Cervera C, Ródenas L, Martínez-Paredes E, Baselga M, García-Diego FJ, Larsen T, Friggens NC and Pascual JJ 2014. Different resource allocation strategies result from selection for litter size at weaning in rabbit does. Animal 8, 618-28.

Savietto D, Friggens NC and Pascual JJ 2015. Reproductive robustness differs between generalist and specialist maternal rabbit lines: the role of acquisition and allocation of resources. Genetics Selection Evolution 47, 2.

Taylor CS 1985. Use of genetic size-scaling in evaluation of animal growth. Journal of Animal Science 61, 118-143.

Theilgaard P, Sánchez JP, Pascual JJ, Friggens NC and Baselga M 2006. Effect of body fatness and selection for prolificacy on survival of rabbit does assessed using a cryopreserved control population. Livestock Science 103, 65-73.

Theilgaard P, Sánchez JP, Pascual JJ, Berg P, Friggens NC and Baselga M 2007. Late reproductive senescence in a rabbit line hyper selected for reproductive longevity, and its association with body reserves. Genetics Selection Evolution 39, 207-223. 
Theilgaard P, Baselga M, Blas E, Friggens NC, Cervera C and Pascual JJ 2009. Differences in productive robustness in rabbits selected for reproductive longevity or litter size. Animal 3, 637-646.

Vicente JS, Llobat L, Viudes-de-Castro MP, Lavara R, Baselga M and Marco-Jiménez F 2012. Gestational losses in a rabbit line selected for growth rate. Theriogenology 77, 81-88.

Xiccato G 1996. Nutrition of lactation does. Proceedings of the in proc: 6th World Rabbit Congress, 1996, Touluse, France, pp. 29-47.

Xiccato G, Parigi-Bini R, Dalle Zotte A, Carazzolo A and Cossu M 1995. Effect of dietary energy level, addition of fat and physiological state on performance and energy balance of lactating and pregnant rabbit does. Animal Science 61, 387-398. 
CONCLUSIONS 

There was a parallelism between information provided by the random effects of mixed models and the concepts involved in nutrient partitioning. In this sense, it seems that there is variability between rabbit females in the way they acquire and allocate resources, but low variation in the individual trajectories over the reproductive cycle. These facts, jointly with the different ways females responded to diets and to environmental perturbations, suggest that the female (and its genetics) plays a key role in homeorhetic control and the homeostatic regulation.

By changing the main energy source of the diet, it is possible to modulate acquisition and allocation of energy towards different functions. The diet enriched with animal fat promoted milk yield, increasing energy intake of females but not enough to avoid or even promoting a reduction of their body reserves. On the contrary, the diet enriched with cereal starch promoted body reserves accretion, but reducing milk yield. However, it seems that this modulation could alter the normal homeostasis status of females. The response to each diet on allocation and the consequences on productivity and fitness depended on the priorities and the acquisition capacity of each animal at each moment.

It seems that hyper-prolific females tended to accrete body reserves whenever possible. However, when they were fed with cereal-starch enriched diets, this equilibrium was altered by an excessive promotion of body reserves accretion, triggering reproductive disorders and increasing their risk of death. $\mathrm{R}$ females prioritize accreting body reserves during early lactation. However, compared to females from the maternal lines, it seems that the priority for current reproduction of $\mathrm{R}$ females decrease more rapidly at the beginning of lactation, but would persist more at the end of lactation. In this sense, when $\mathrm{R}$ females were fed with $\mathrm{AF}$, the priority for current reproduction was increased, especially at the end of lactation. It decreased considerably the priorities for future reproduction and maintenance, affecting negatively to future litter and accelerating senescence. On the other hand, LP females have a great acquisition capacity, but they are able to adapt acquisition and allocation of energy to their transitory requirements (e.g. great intake during lactation which allows increasing milk yield without conditioning body reserves and low intake out of lactation), using body reserves as a safety factor. This strategy could be considered as a low risk strategy, which let LP females being highly productive and functional when fed with both diets. In fact, they reached at the end of the experiment with the highest fitness. Therefore, the way three completely different genetic types responded to energy source of the diet suggests that rabbit females highly selected for productivity ( $\mathrm{H}$ and $\mathrm{R}$ females) were more sensitive to energy source modulations. This situation and the priorities of each genetic type should be considered when formulating diets for reproductive rabbit females. 



\section{PERSPECTIVES}



The results of the present thesis show that it was possible to modulate resource allocation of females. However, by changing main energy source of the diet, normal homeostasis was also altered and females responded in an unpredictable way according to their genetic background. Thus, it would be interesting to find out additional alternatives to optimize resource allocation to the genetic type. In this sense, digestive disorders of growing rabbits are one of the main handicaps of current rabbit meat production. It has been reported that milk plays a protective role in kits. Extended lactation would act reducing the risk of digestive disorders of current litters, but it could affect negatively to the recovery of females' body reserves. Considering that there is genetic variation in the risk of digestive disorders and the ability to safeguard body reserves, the length of lactation could be another way to explore the change of priorities between current and future reproduction on different genetic types.

The unpredictable response of different genetic types to different energy sources of the diet highlight our poor understanding of the mechanisms regulating energy balance (acquisition and allocation of energy) in rabbit females. Using existing information, mechanistic models of systems aim to model the mechanisms regulating a given system such energy balance of reproductive females. These models could be helpful to understand and to quantify the way individual animals acquire and allocate energy. Moreover, they could be used in a predictive way to find the gaps in current knowledge and to plan future experiments. 



\section{Short curriculum vitae}

Degree in agricultural engineering on 2009. My research career started immediately afterwards. I worked for three years as $R \& D$ engineer in a fertilizer company implementing NIRs technology for the quality control of raw materials and final products (2008-2011). I have been PhD candidate in Animal Science and Technology program of UPV since 2012. During this period, I got the degree of MSc in animal science on 2013 and I took some courses about statistics, quantitative genetics, biological consequences of selection, systemic modelling and rabbit production. I also performed two short stays of three months out of UPV to deep inside the links between nutrition, genetics and the global status of animals. The first stay was on the Swedish University of Agricultural Sciences (Dept. Animal Breeding and Genetics, Uppsala, Sweden). The second stay on the French Institute for Agricultural Science (INRA - MoSAR, Paris, France). Currently, I am professor of animal nutrition in the veterinary school of Universidad Cardenal Herrera CEU (Valencia, Spain).

\section{List of publications}

\section{Research articles}

Arnau-Bonachera A, Cervera C, Blas E and Pascual JJ 2015. Milk yield prediction at late lactation in reproductive rabbit does. World Rabbit Science 23, 91-102.

Arnau-Bonachera A, Cervera C, Martínez-Paredes E, Ródenas L, Pascual JJ and Blas E 2017. Milk intake in kits: Not only the total amount matters. World Rabbit Science (Accepted).

García-Quirós A, Arnau-Bonachera A, Penadés M, Cervera C, Martínez-Paredes E, Ródenas L, Selva L, Viana D, Corpa JM and Pascual JJ 2014. A robust rabbit line increases leucocyte counts at weaning and reduces mortality by digestive disorder during fattening. Veterinary Immunology and Immunopathology 161, 123-131.

\section{Conference contributions}

Arnau-Bonachera A and Savietto D 2014. Consecuencias de la robustez y de los criterios de eliminación sobre la productividad de una granja. Proceedings of the XXXIX Symposium de Cunicultura, 29 May 2014, Tudela, Spain, pp. 59-62.

Arnau-Bonachera A, Cervera C, Martínez-Paredes E, Ródenas L and Pascual JJ 2013. Efecto del origen genético, fuente de energía en lactación y uso de antibióticos en conejo de engorde. Proceedings of the XXXVIII Symposium de Cunicultura, 30 May 2013, Zamora, Spain, pp. 6771.

Arnau-Bonachera A, Blas E, Cervera C, Martínez-Paredes E, Ródenas L and Pascual JJ 2015. Variabilité des profils d'ingestion de lait des lapereaux et conséquences sur leurs performances. Proceedings of the 16émes Journées de la Recherche Cunicole, 24 November 2015, Le Mans, France, pp. 157-160. 
Arnau-Bonachera A, Cervera C, Blas E, Martínez-Paredes E, Ródenas L and Pascual JJ 2015. Fitting nutrition to genetic selection: dietary energy source and fitness response in rabbit does. Proceedings of the 66th Annual Meeting of the European Federation of Animal Science, August 2015, Varsaw, Poland, pp. 501.

Arnau-Bonachera A, Pascual JJ and Baselga M 2016. Feed intake in reproductive rabbit does: Animal's view. Proceedings of the 11th World Rabbit Congress, 15 June 2016, Quingdao, China, pp. 361-364.

Arnau-Bonachera A, Pascual JJ and Savietto D 2016. Towards mixed models focusing on the animal nature of body condition: Reproductive rabbit does. Proceedings of the 67th Annual Meeting of the European Federation of Animal Science, 29 August 2016, Belfast, United Kingdom, pp. Accepted.

García-Quirós A, Penadés M, Arnau-Bonachera A, Blas E, Corpa JM, Viana D and Selva L 2013. Estudio de poblaciones linfocitarias sanguíneas en gazapos de diferentes tipos genéticos cunícolas. Proceedings of the XXXVIII Symposium de Cunicultura, 30 May 2013, Zamora, Spain, pp. 72-75.

Penadés M, Arnau-Bonachera A, García-Quirós A, Martínez-Paredes E, Ródenas L, Selva L, Viana D, Cervera C, Pascual JJ and Corpa JM 2015. ¿Existen diferencias tempranas entre las conejas que alcanzan el quinto ciclo reproductivo y las que no? Proceedings of the 40 Symposium de Cunicultura de ASESCU, May 2015, Santiago de Compostela, Spain, pp. 136-139. 
SUPPLEMENTARY MATERIAL 



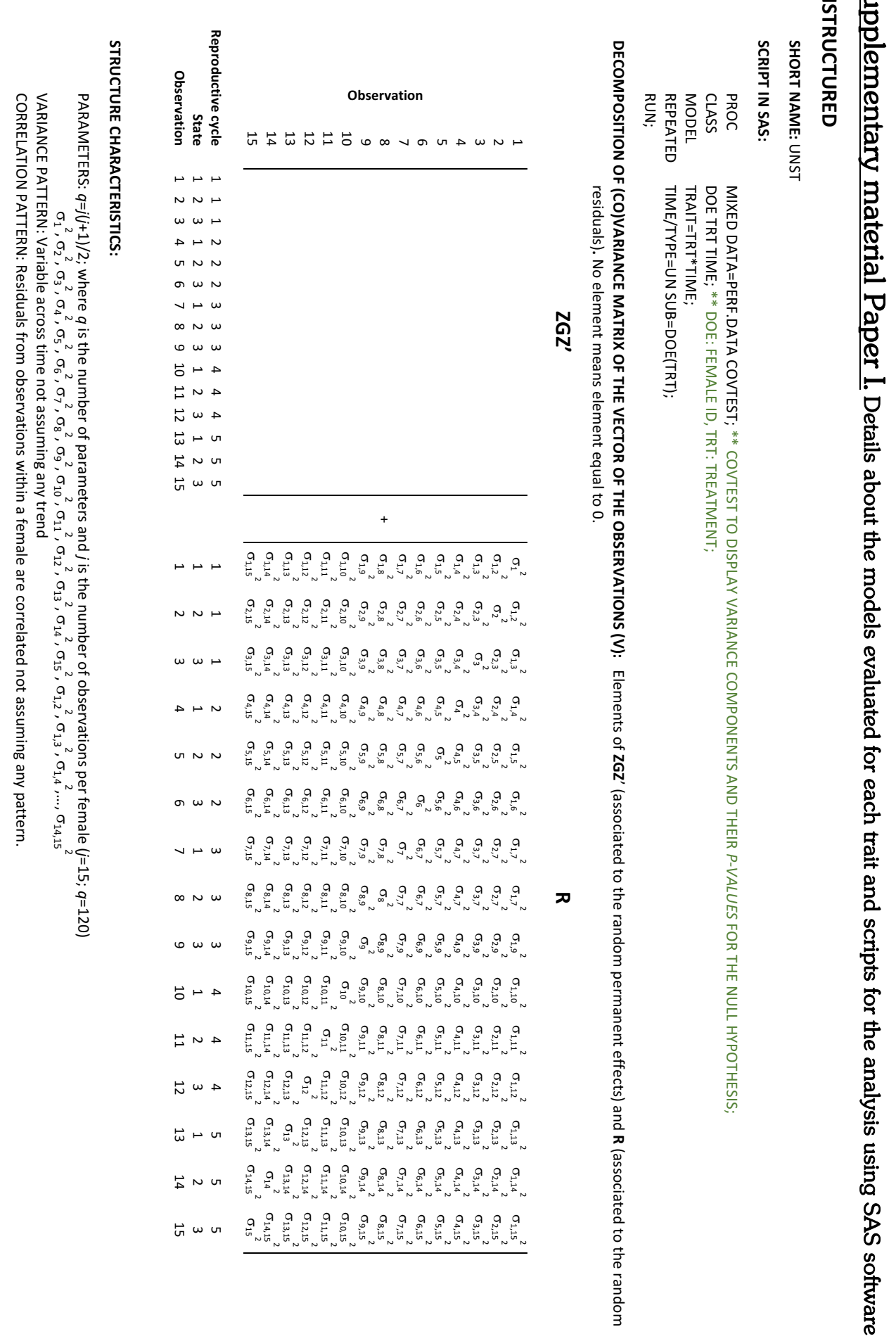




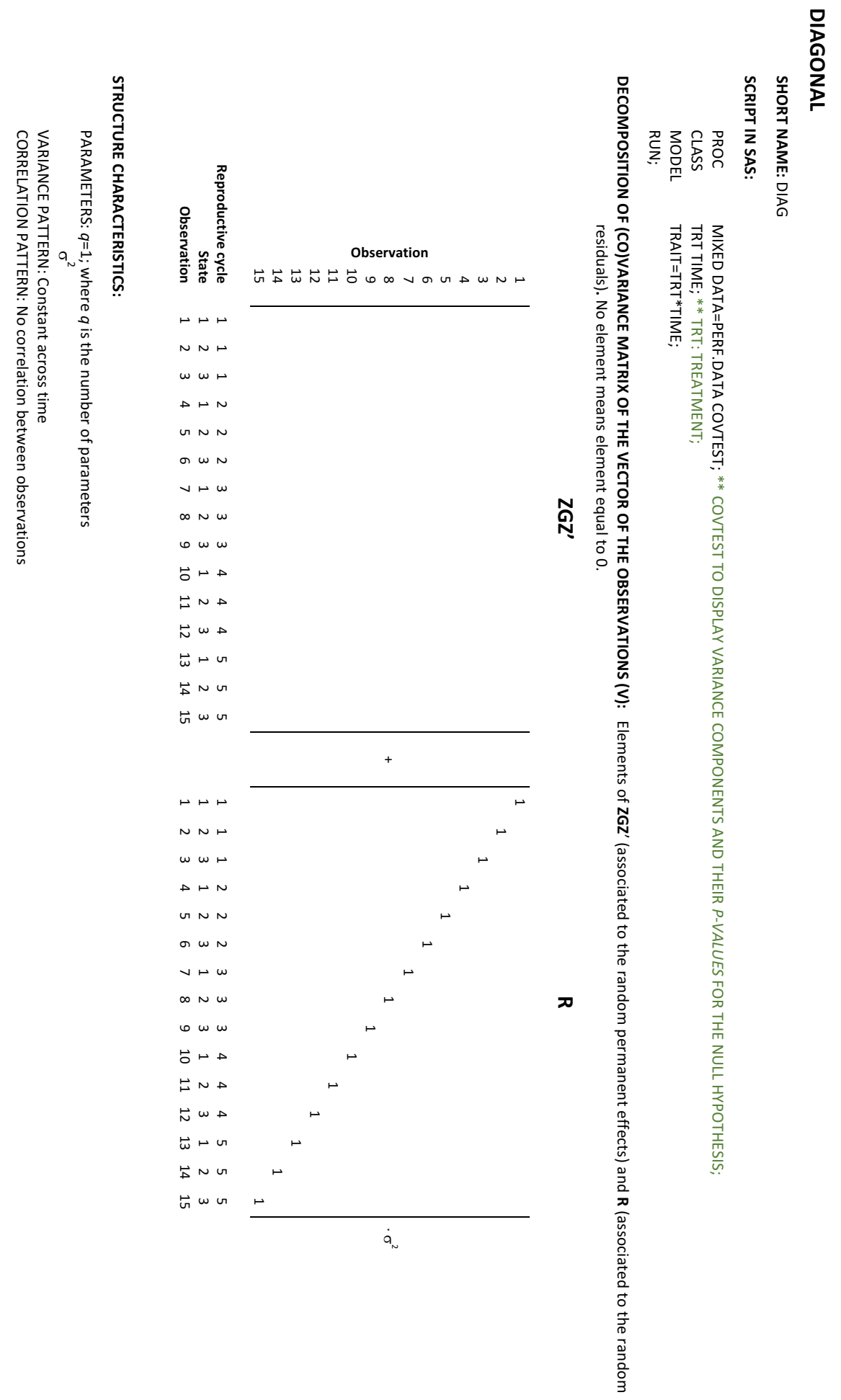




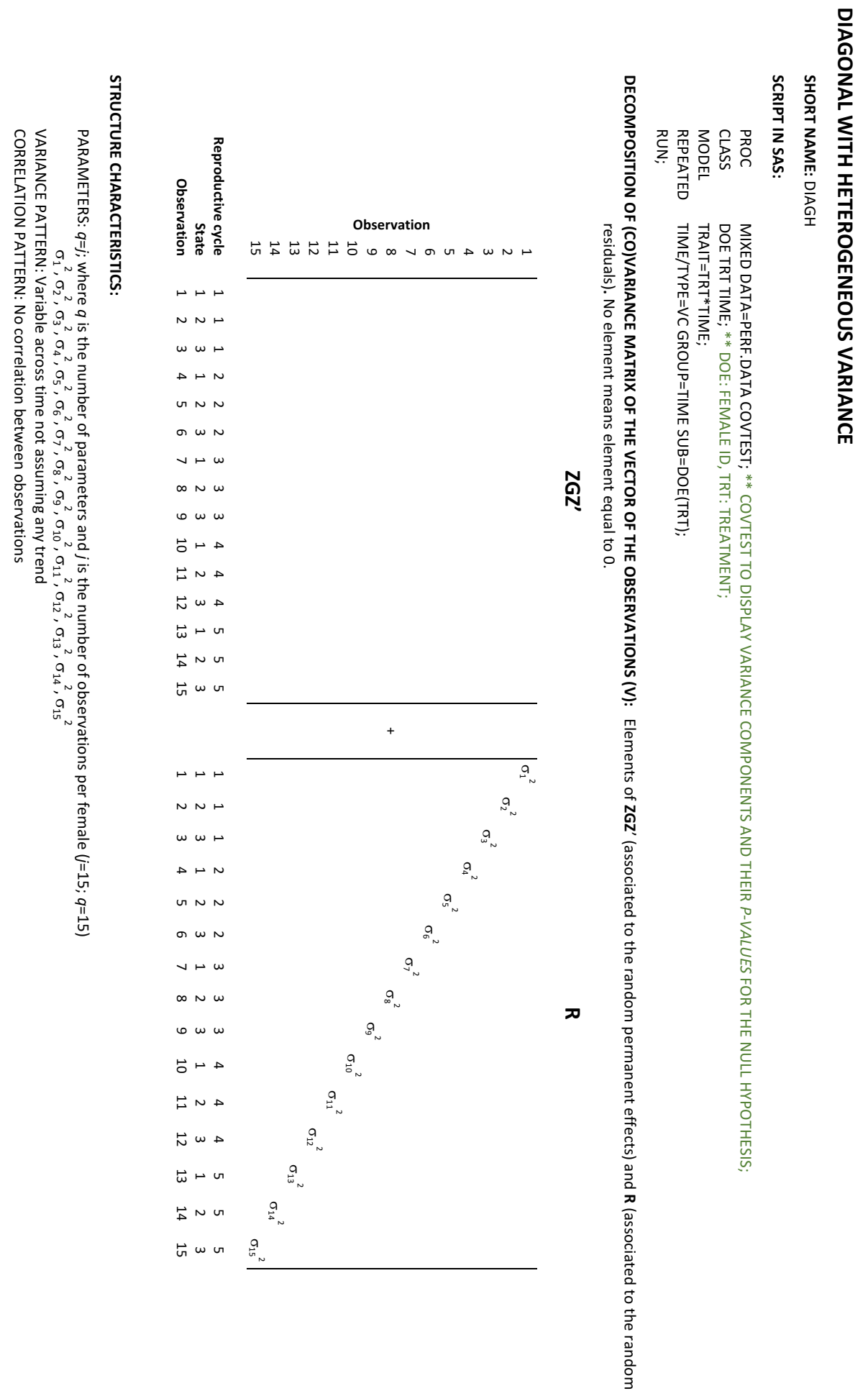




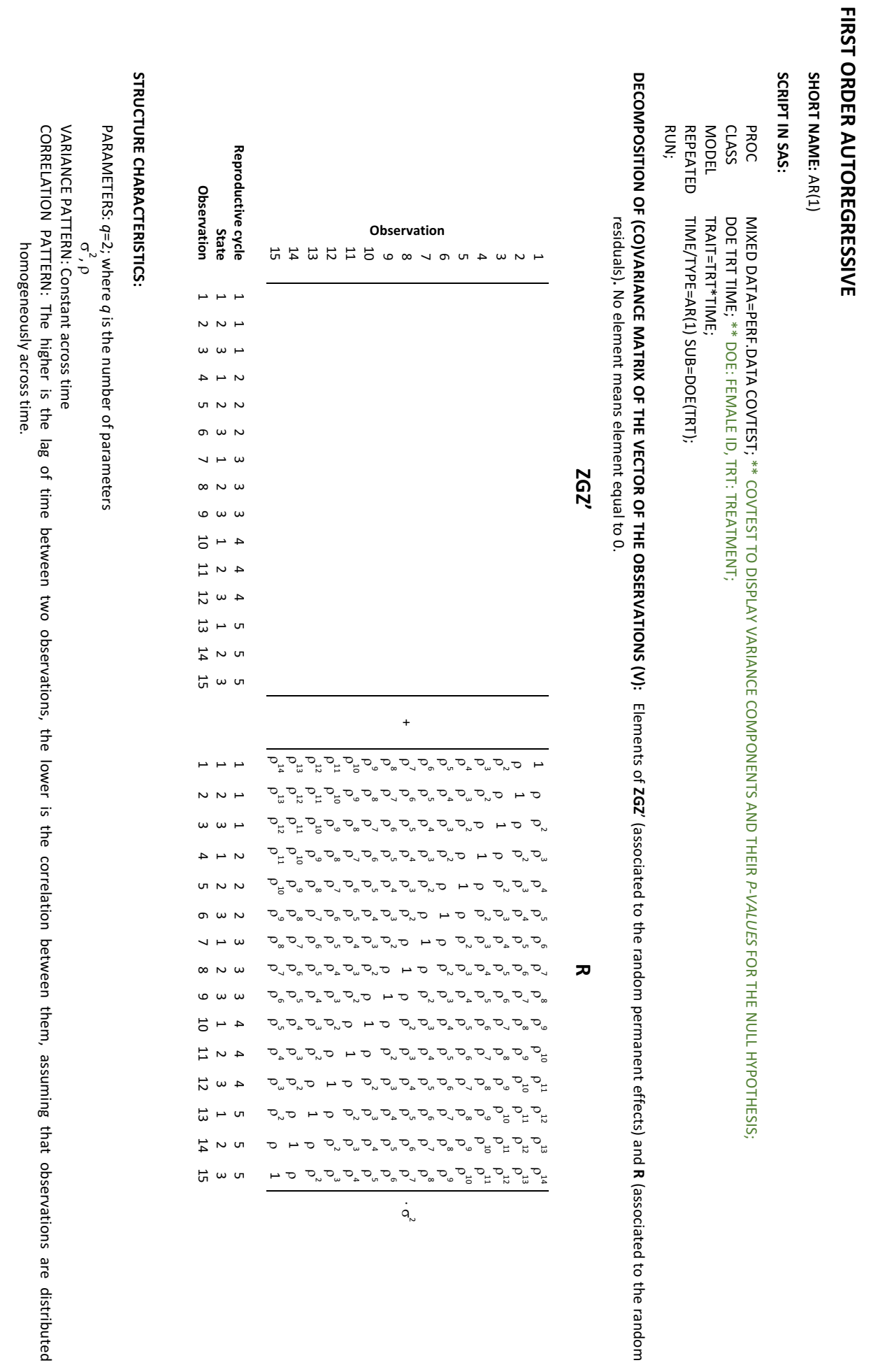



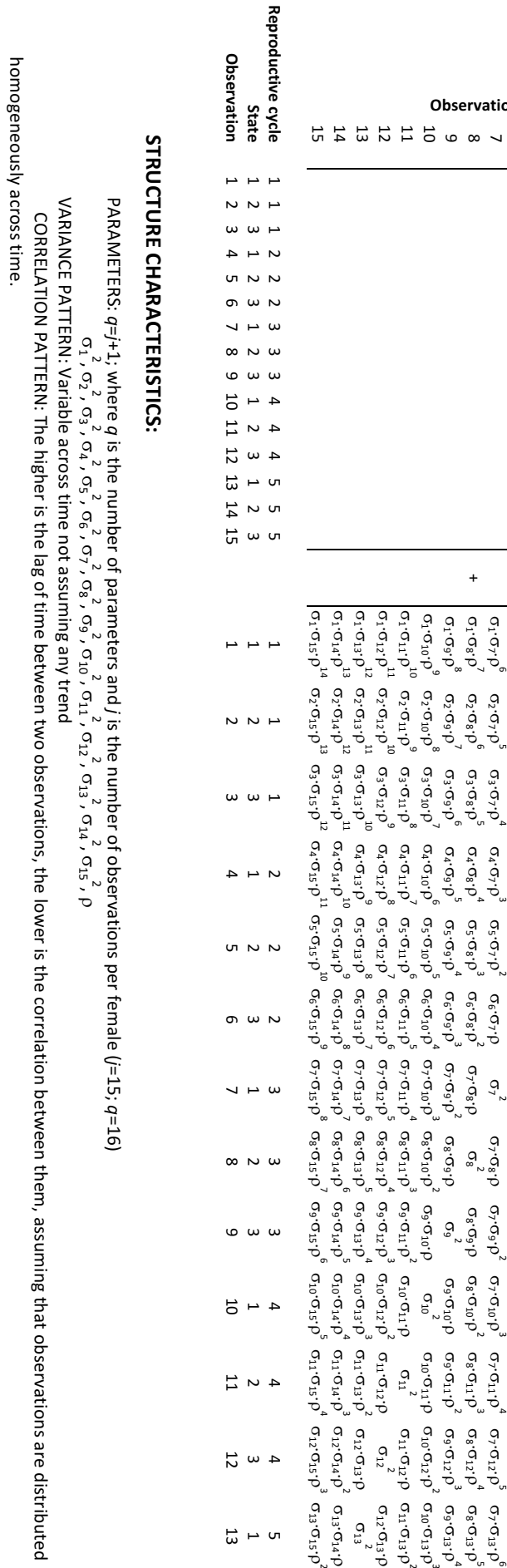

棺占仵占

$\stackrel{\sim}{\sim}$

$\omega \omega$

$\triangle \mapsto N$

G $N$

a $\omega N$

$\checkmark \mapsto \omega$

$\infty \sim \omega$

$6 \omega$

品

$\mapsto N \triangleright$

完 $\omega \rightarrow$

மே

$\stackrel{5}{\perp}$ v

जै $w$ v

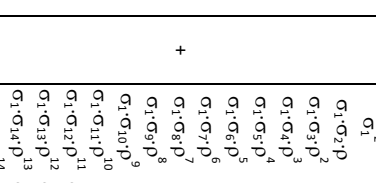

ว

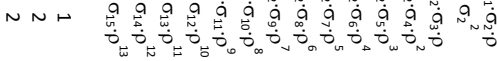

a $a a^{a}$ a $a a^{a}$ a a a a a a a $a$

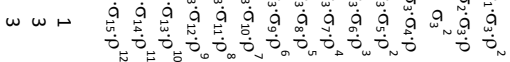

a a a a a a a a a a a a a

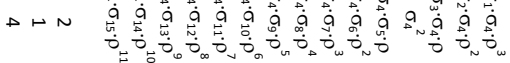

जी $a$ a $a$ a $a$ a $a$ a a a a $a$

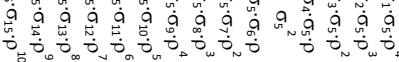

a a a a a a a a a a a a a a

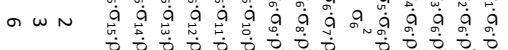

a a a a a a a a a a a a a a

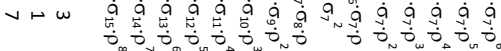

a $a$ a $a$ a $a$ a $a$ a $a$ a $a$

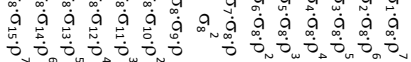

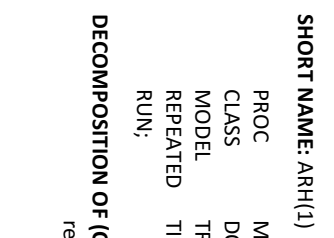

กิ

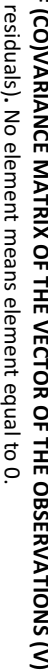

商

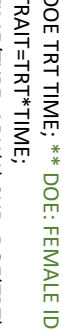

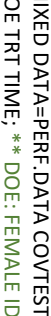

考

永

惫

妾

$\infty N \omega$

a a a a a a a a a a a a

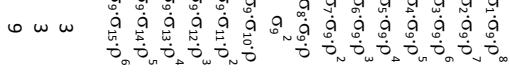

a a a a a a a a a a a a

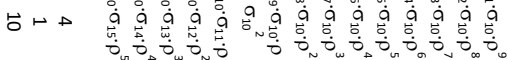

a a a a a a a a a a a $a$

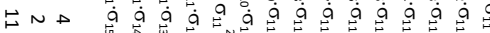

\%

a a a a a a a a a a a a o a

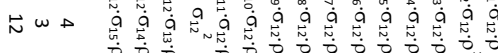

a a a a a a a a a a a a

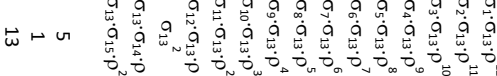

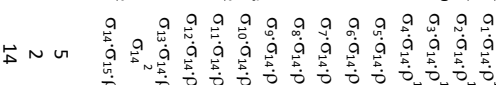

a a a a a a a a a a a a a

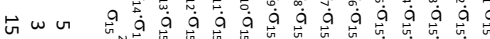

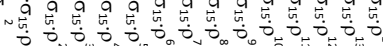




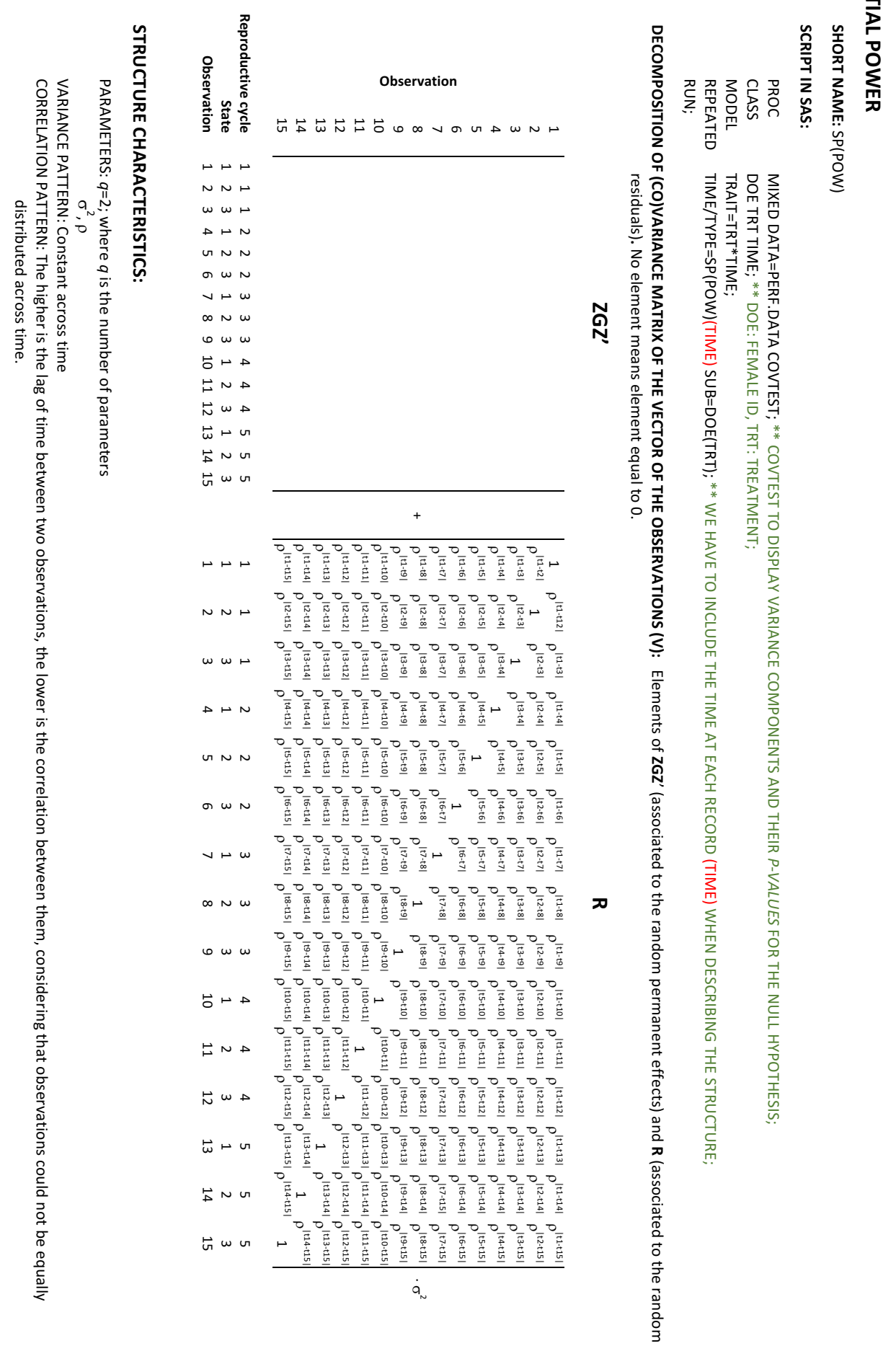




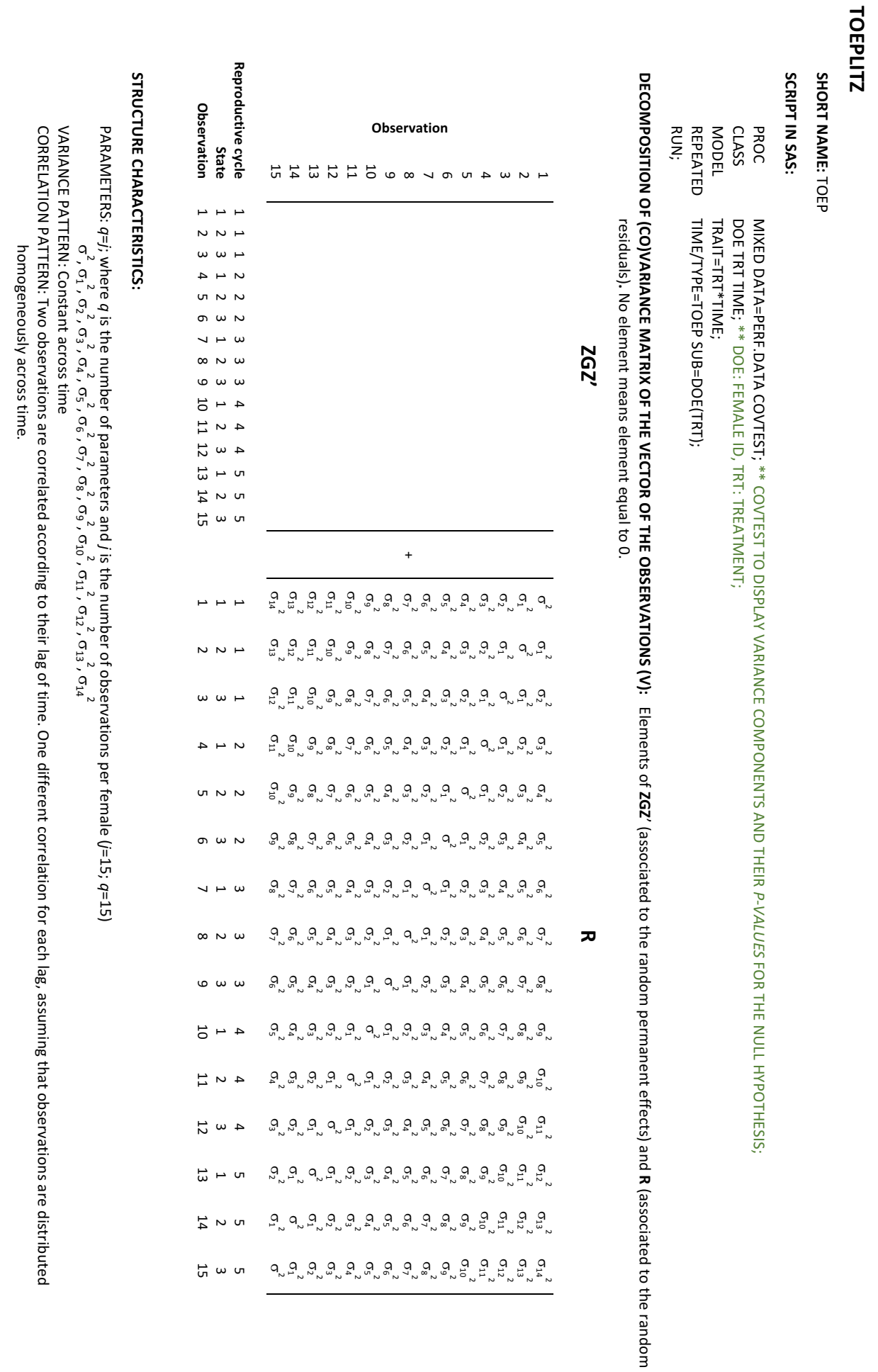




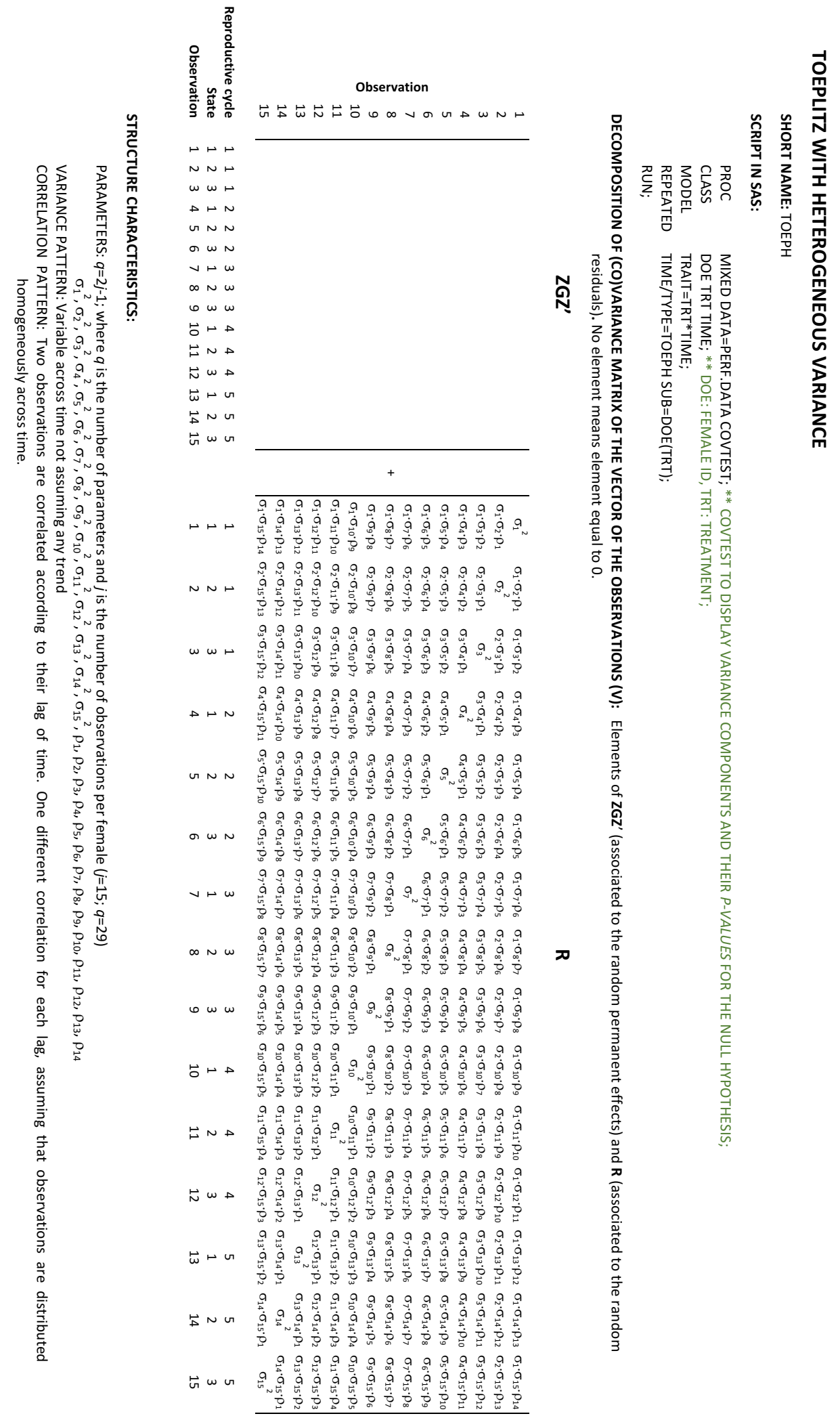




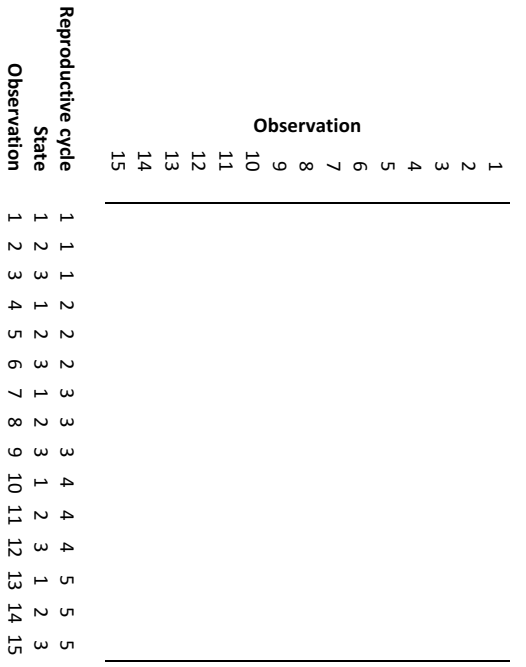

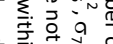

\%

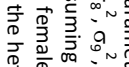

a a a a a a a a a a a

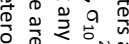

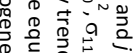

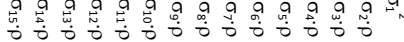

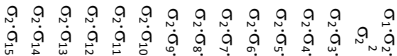

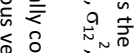

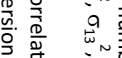

용 a

$a^{2}$ o

जे o

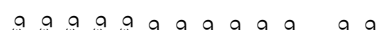

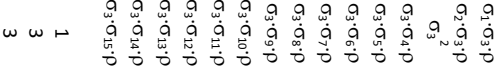

a a a a a a a a a a a a a a

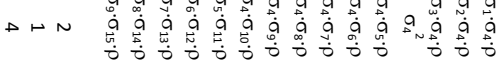

กิ

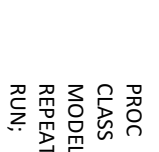

겇겅ㅁㅀ

a a a a a a a a a a a

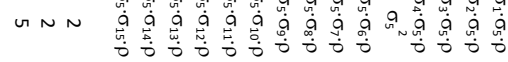

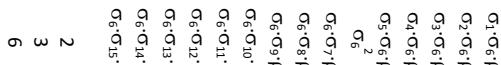

- a a a a a a a a a a

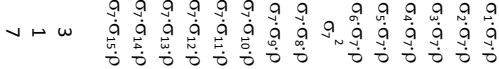

a $a$ a $a$ a $a$

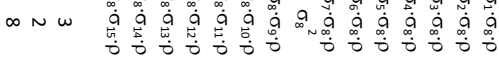

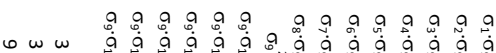

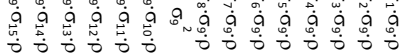

a a a a a a a a a a a a

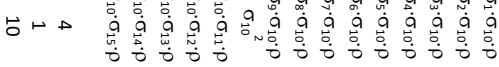

a a a a a a a a a a a a

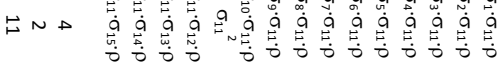

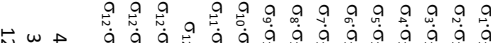

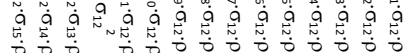

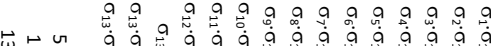

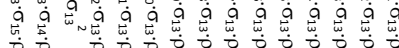

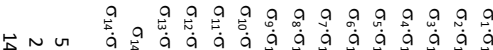

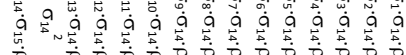




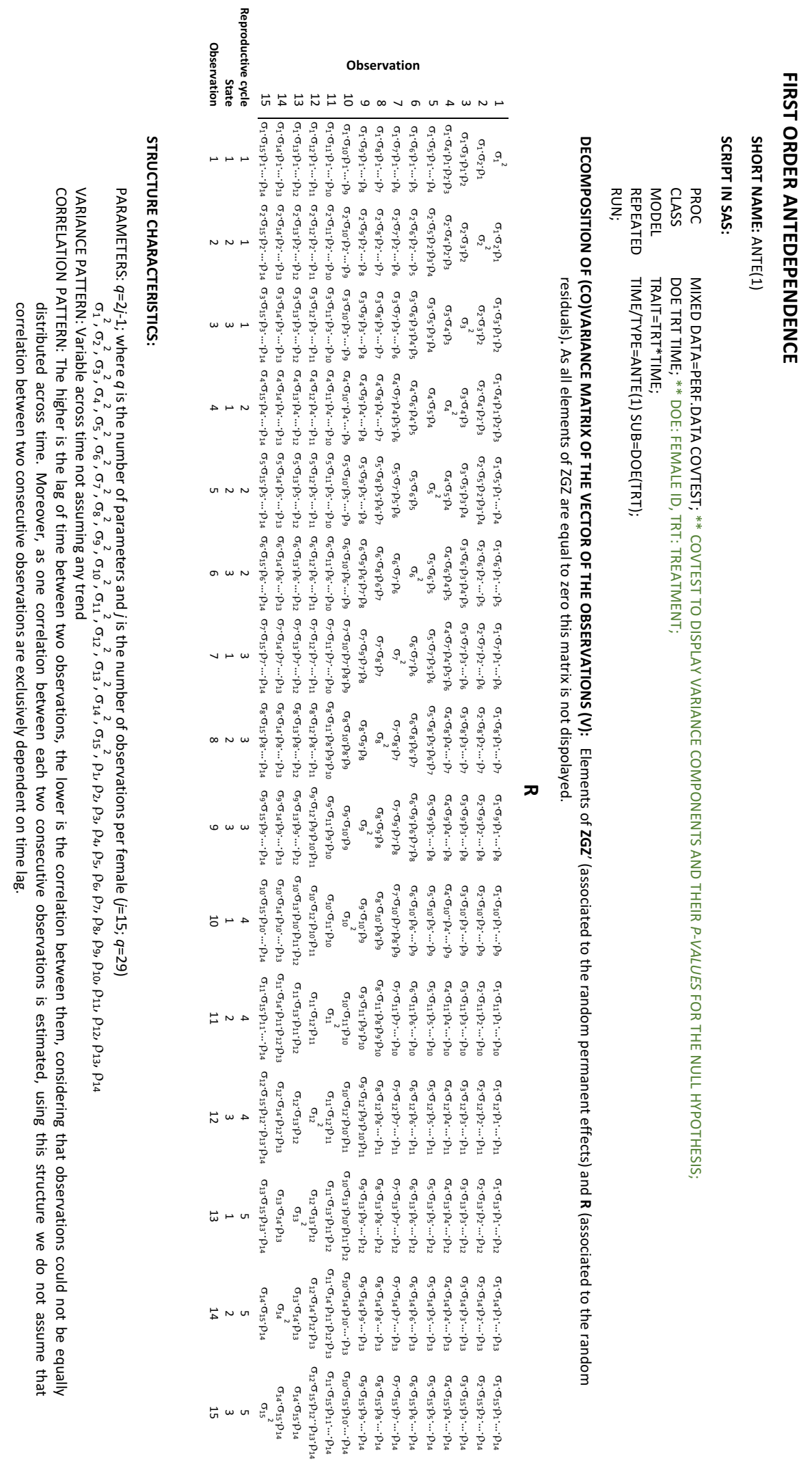



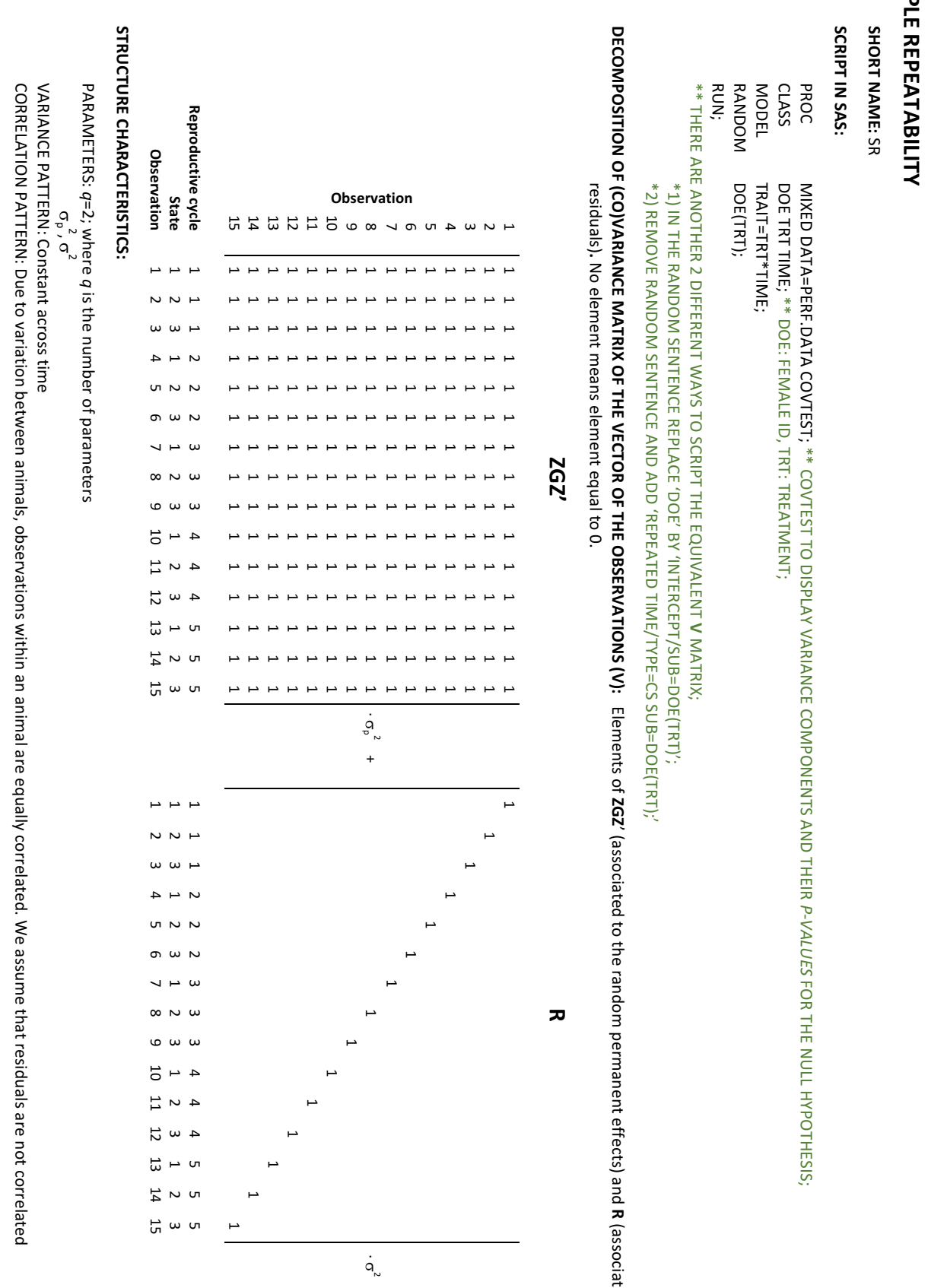

응걲응

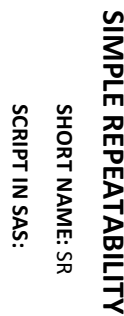




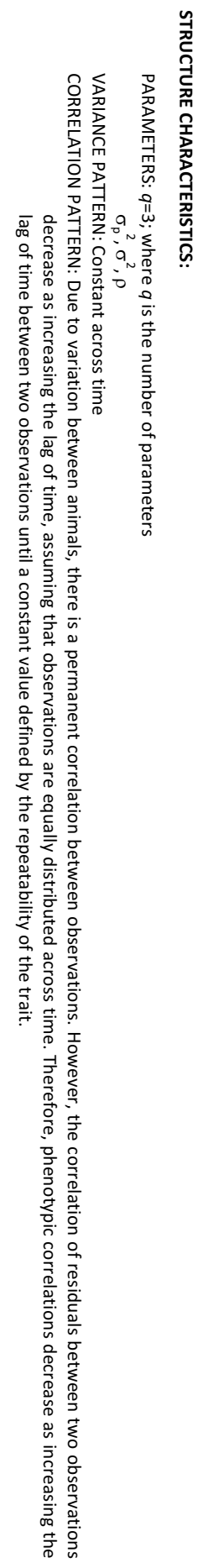

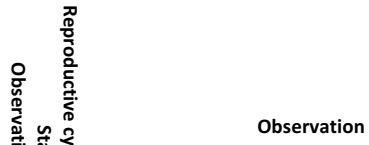

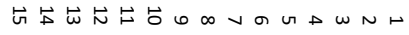
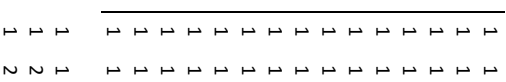

$\omega \omega \mapsto \quad \mapsto \mapsto \mapsto \mapsto \mapsto \mapsto \mapsto \mapsto \mapsto \mapsto \mapsto \mapsto \mapsto \mapsto \mapsto$

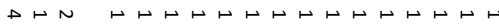

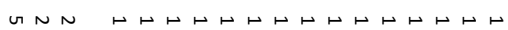

a $\omega$

$\checkmark \mapsto \omega$

$\infty \sim \omega$

$6 \omega \omega$

$\hookleftarrow \vdash \triangleright$

$\mapsto N \mapsto$

$\stackrel{\sim}{\sim} \omega$

ம $\mapsto v$

$\stackrel{\mapsto}{\triangleright} \sim$ V

ต $\omega$

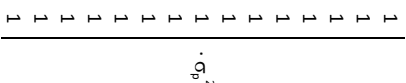

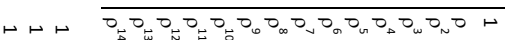

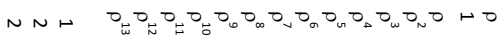

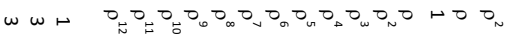

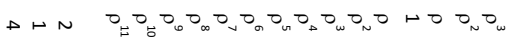

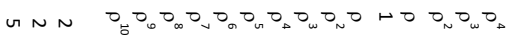

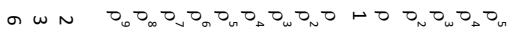

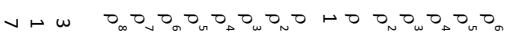

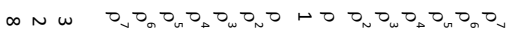

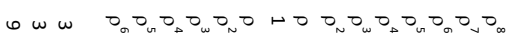

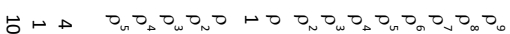

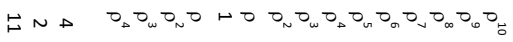

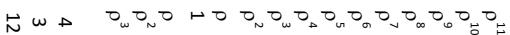

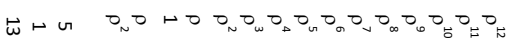

台N G

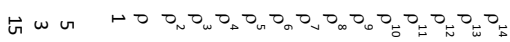

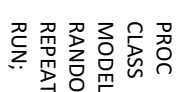

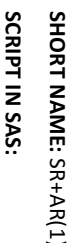
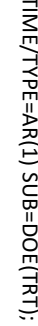

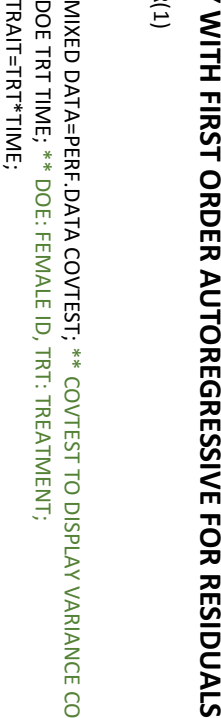



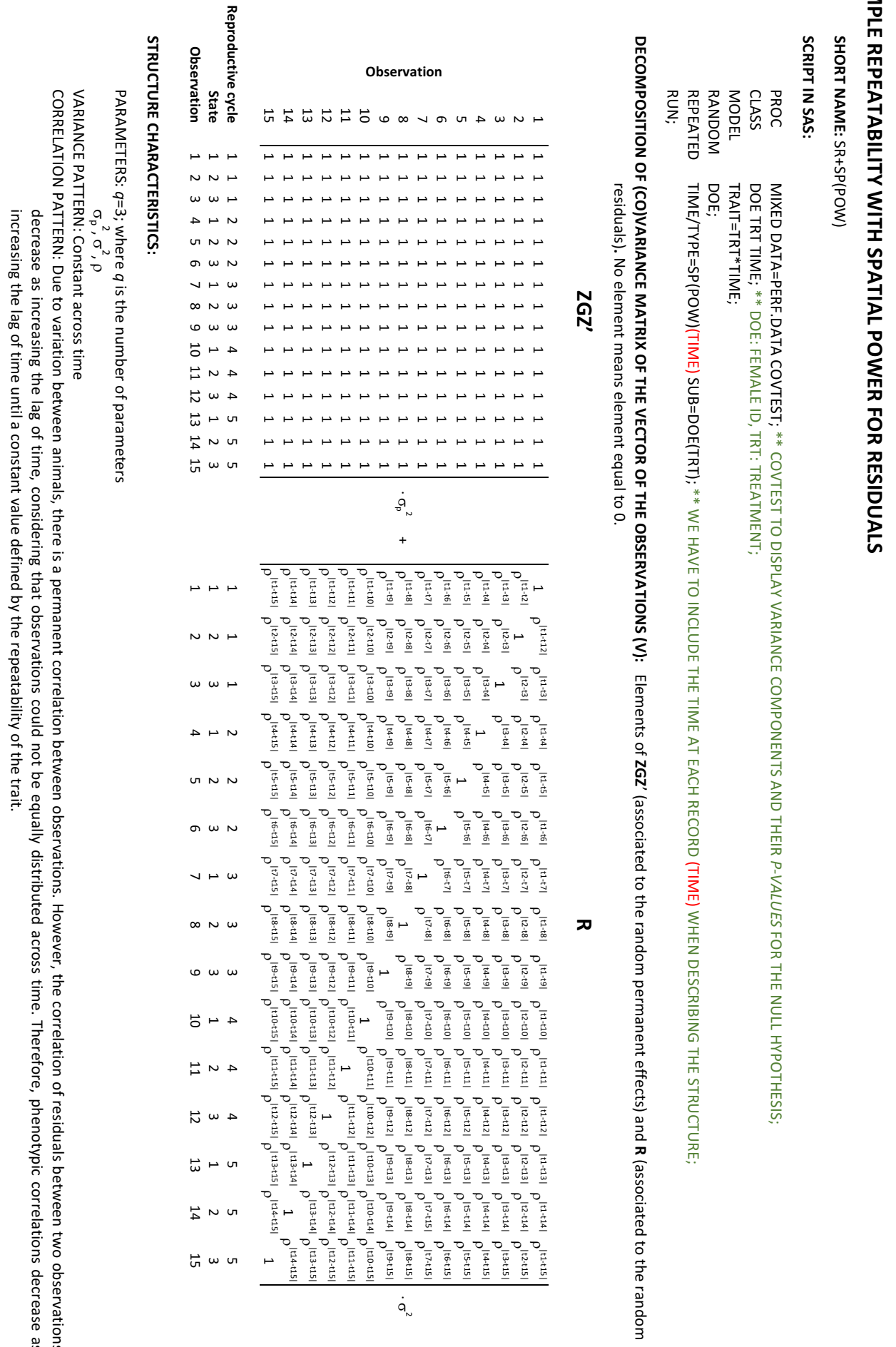


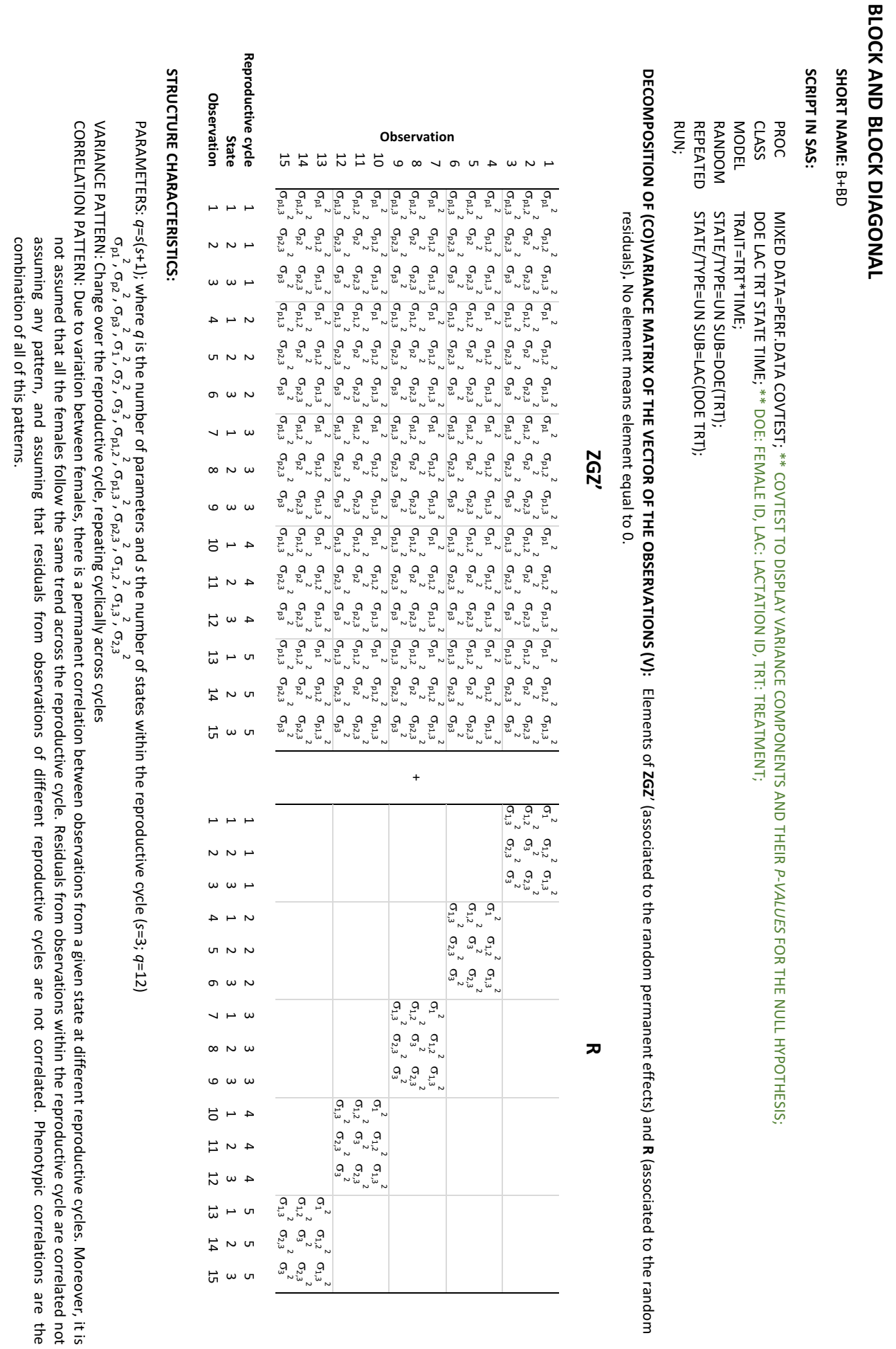




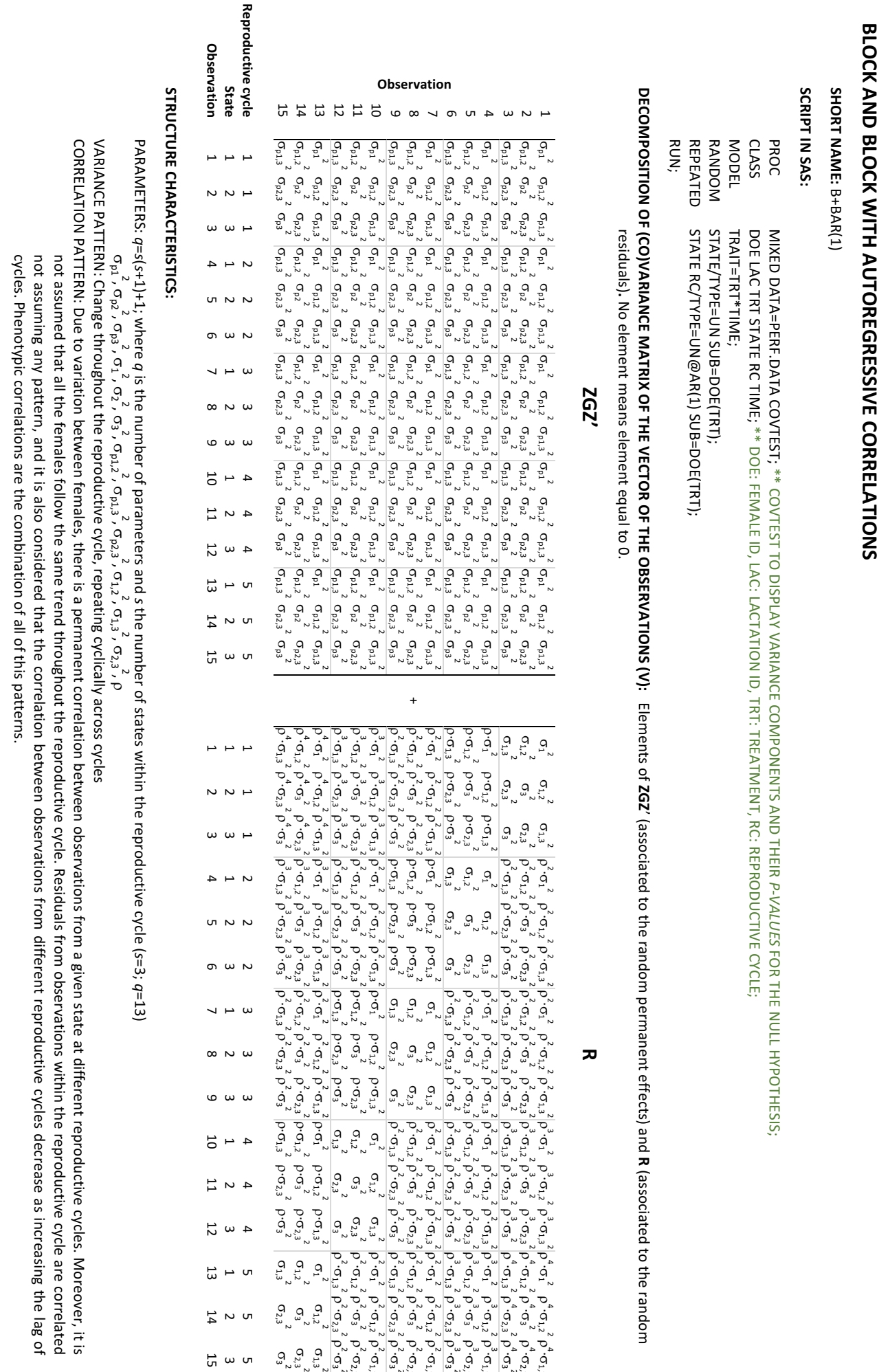




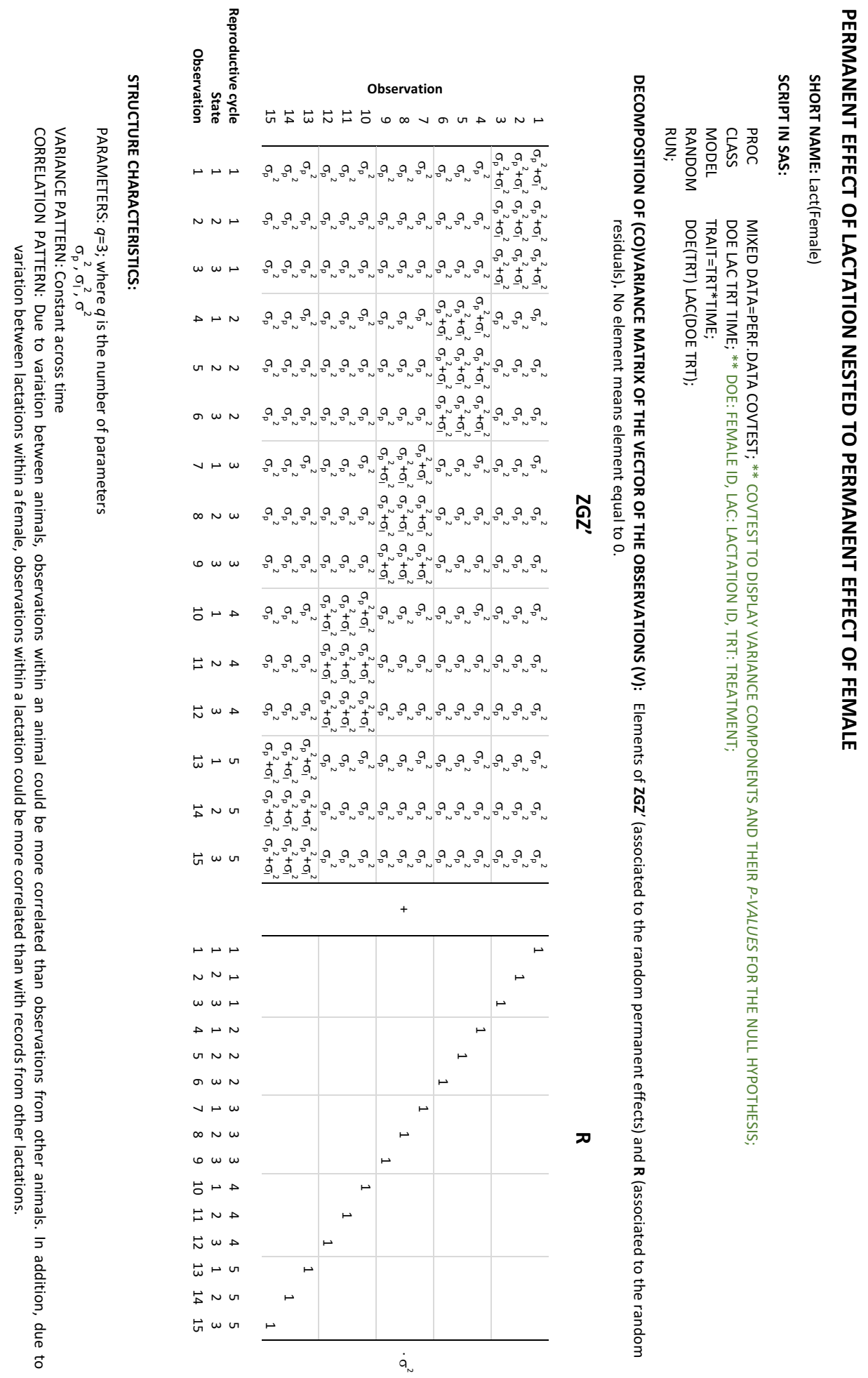




\section{Supplementary material Paper III}

Table S3.1 P-Values for all the effects considered in the models used to analyse acquisition and allocation traits

\begin{tabular}{lcccccc}
\hline & & \multicolumn{5}{c}{ P-Value } \\
\cline { 2 - 6 } Effect & Order $^{1}$ & $\begin{array}{c}\text { Feed } \\
\text { intake }\end{array}$ & Weight & PFT & Milk & $\begin{array}{c}\text { Litter } \\
\text { weight }\end{array}$ \\
\hline Genetic Type (GT) & 1 & $<.0001$ & $<.0001$ & $<.0001$ & $<.0001$ & 0.0003 \\
Energy source (ES) & 1 & 0.0007 & 0.9904 & 0.0235 & 0.0001 & 0.0023 \\
Reproductive cycle (RC) & 1 & $<.0001$ & $<.0001$ & 0.0972 & $<.0001$ & $<.0001$ \\
State within RC (SWRC) & 1 & $<.0001$ & $<.0001$ & $<.0001$ & $<.0001$ & $<.0001$ \\
OG & 1 & $<.0001$ & $<.0001$ & 0.1614 & 0.0149 & 0.1486 \\
OL & 1 & 0.0227 & $<.0001$ & 0.3969 & 0.5118 & 0.7056 \\
GTxES & 2 & 0.3084 & 0.6862 & 0.9964 & 0.0896 & 0.1844 \\
GTxRC & 2 & $<.0001$ & 0.0835 & 0.3493 & 0.0479 & 0.0605 \\
ESxRC & 2 & 0.0348 & 0.1216 & 0.6842 & $<.0001$ & 0.0153 \\
GTxSWRC & 2 & $<.0001$ & $<.0001$ & 0.0087 & $<.0001$ & $<.0001$ \\
ESxSWRC & 2 & 0.1870 & 0.9156 & 0.2949 & 0.0237 & $<.0001$ \\
RCxSWRC & 2 & 0.2445 & $<.0001$ & $<.0001$ & $<.0001$ & $<.0001$ \\
SWRCXOG & 2 & $<.0001$ & 0.0004 & 0.1651 & 0.7937 & 0.0034 \\
SWRCxOL & 2 & 0.6298 & $<.0001$ & 0.1638 & 0.2698 & 0.6771 \\
TemperaturexSWRC & 2 & $<.0001$ & $<.0001$ & $<.0001$ & 0.0002 & $<.0001$ \\
GTxESxRC & 3 & 0.0108 & 0.9075 & 0.6368 & 0.0035 & 0.0037 \\
GTxESxSWRC & 3 & 0.4367 & 0.1899 & 0.1594 & 0.1083 & 0.3627 \\
GTxRCxSWRC & 3 & $<.0001$ & 0.0018 & 0.2304 & 0.2486 & 0.0326 \\
ESxRCxSWRC & 3 & 0.4175 & 0.7731 & 0.0749 & $<.0001$ & $<.0001$ \\
GTxESxRCxSWRC & 4 & 0.1229 & 0.0245 & 0.2818 & 0.0079 & 0.0251 \\
\hline 1 Order 1 for the main effects and higher values for the corresponding order of interactions among \\
effects. & & & & & & \\
& & & & & &
\end{tabular}

Table S3.2 P-Values for all the effects considered in the models used to analyse blood plasma traits

\begin{tabular}{lccccc}
\hline \multirow{2}{*}{ Effect } & Order $^{1}$ & \multicolumn{5}{c}{$\boldsymbol{P}$-Value } \\
\cline { 3 - 6 } & & Glucose & BOHB & NEFA's & Leptin \\
\hline Genetic Type (GT) & 1 & 0.0029 & 0.0371 & 0.9234 & 0.0934 \\
Energy source (ES) & 1 & 0.3118 & $<.0001$ & 0.1871 & 0.1778 \\
Time control (R) & 1 & $<.0001$ & $<.0001$ & $<.0001$ & $<.0001$ \\
Temperature & 1 & 0.0028 & 0.9517 & 0.9433 & 0.0363 \\
GTxES & 2 & 0.7243 & 0.5934 & 0.3868 & 0.9236 \\
GTxR & 2 & 0.0153 & $<.0001$ & $<.0001$ & 0.1174 \\
ESxR & 2 & 0.2451 & $<.0001$ & 0.6879 & 0.8061 \\
GTxESxR & 3 & 0.4500 & 0.0073 & 0.7065 & 0.9684
\end{tabular}

${ }^{1}$ Order 1 for the main effects and higher values for the corresponding order of interactions among effects. 
Table S3.3 Effect of simultaneous gestation and lactation on main trait of resource acquisition and allocation (estimates and, between brackets, SE).

\begin{tabular}{|c|c|c|c|c|c|}
\hline & $\begin{array}{l}\text { Feed intake } \\
\text { (gDM/day) }\end{array}$ & $\begin{array}{l}\text { Weight } \\
(\mathrm{g})\end{array}$ & $\begin{array}{l}\text { PFT } \\
(\mathrm{mm})\end{array}$ & $\begin{array}{l}\text { Milk yield } \\
\text { (g/day) }\end{array}$ & $\begin{array}{l}\text { Litter weight } \\
\quad(\mathrm{g})\end{array}$ \\
\hline \multirow{2}{*}{\multicolumn{6}{|c|}{$\begin{array}{l}\text { Previous lactation situation during current gestation: Contrast (Lactating - Non lactating) } \\
\text { Average effect }\end{array}$}} \\
\hline & & & & & \\
\hline & $14.3(2.3)^{\star}$ & $-100(15)^{*}$ & $-0.08(0.05)$ & $8.7(3.4)^{*}$ & $53(37)$ \\
\hline \multicolumn{6}{|c|}{ Depending on record within $\mathrm{RC}$} \\
\hline First (i) & $27.1(3.4)^{*}$ & $-144(19)^{*}$ & $-0.05(0.07)$ & $7.6(2.6)^{*}$ & $0(15)$ \\
\hline Second (ii) & $1.5(2.6)$ & $-58(20)^{*}$ & $-0.17(0.08)$ & $9.5(4.2)^{*}$ & $19(6.7)^{*}$ \\
\hline Third (iii) & & $-98(22)^{*}$ & $0.01(0.08)$ & $9.2(4.9)^{*}$ & $108(46)^{*}$ \\
\hline Fourth (iv) & & & & & $88(99)$ \\
\hline \multirow{2}{*}{\multicolumn{6}{|c|}{$\begin{array}{l}\text { Next gestation situation during current lactation: Contrast (Pregnant - Non Pregnant) } \\
\text { Average effect }\end{array}$}} \\
\hline & & & & & \\
\hline & $4.7(2.6)^{*}$ & $76(14)^{*}$ & $-0.04(0.08)$ & $-2.1(3.2)$ & $-13(3.3)$ \\
\hline \multicolumn{6}{|c|}{ Depending on record within $\mathrm{RC}^{1}$} \\
\hline First (i) & $5.6(3.1)$ & 13(17) & $-0.14(0.07)$ & $0.2(2.4)$ & $-8(13)$ \\
\hline Second (ii) & $3.8(2.3)$ & $44(17)^{*}$ & $0.01(0.07)$ & $-3.7(3.7)$ & $4(6)$ \\
\hline Third (iii) & & $171(20)^{*}$ & $0.00(0.07)$ & $-2.9(4.5)$ & $-23(41)$ \\
\hline Fourth (iv) & & & & & $-24(89)$ \\
\hline
\end{tabular}

RC: Reproductive cycle. PFT: Perirenal Fat Thickness. ${ }^{1}$ Record within RC according to the trait were: [For feed intake: early lactation (i) and weaning to parturition interval (ii)]; [For weight and PFT: parturition (i), day 18th of lactation (ii) and weaning (iii)]; [For milk yield: first week of lactation (i), second week (ii) and third week (iii)]; [For litter weight: total born (i), at standardization (ii), at day 18 th of lactation (iii) and weaning (iv)]. ${ }^{*} \mathrm{P}<0.05$. 

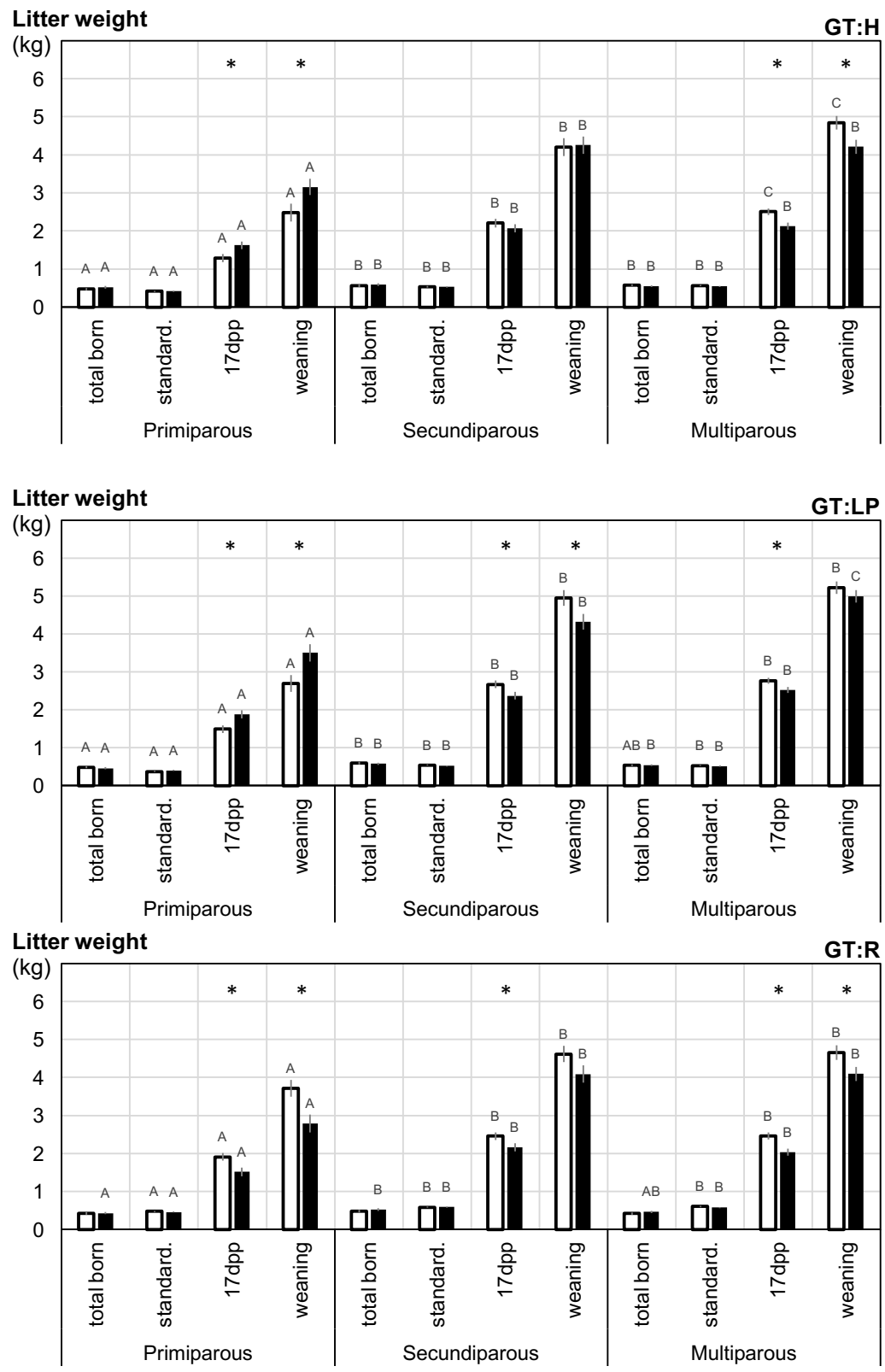

Figure S3.1 Evolution of litter weight within and among reproductive cycles (RC) depending on genetic type $[G T(H, L P, R)]$ and energy source [ES: Animal Fat (AF, white bar); Cereal Starch (CS, black bar)]. * Means for different $E S$ in a time control within a RC and GT differ significantly at $P<0.05$. ${ }^{A}, B, C$ Means within $G T$, ES and record for different $R C$ not sharing letter differ significantly at $\mathrm{P}<0.05$. 


\section{Supplementary material Paper IV}

Table S4.1 P-Values for all the effects considered in the models used to analyse female traits

\begin{tabular}{|c|c|c|c|c|c|c|c|}
\hline & $\begin{array}{c}\text { Genetic } \\
\text { type } \\
\text { (GT) }\end{array}$ & $\begin{array}{c}\text { Energy } \\
\text { source } \\
\text { (ES) }\end{array}$ & $\begin{array}{c}\text { Reproductive } \\
\text { cycle } \\
\text { (RC) }\end{array}$ & GTxES & GTxRC & ESxRC & GTxESxRC \\
\hline Weight at first Al & $<.0001$ & 0.5449 & - & 0.8787 & - & - & - \\
\hline $\begin{array}{l}\text { Adult live } \\
\text { weight }^{1}\end{array}$ & $<.0001$ & 0.2869 & - & 0.9433 & - & - & - \\
\hline $\begin{array}{l}\text { Conception rate } \\
\mathrm{IBP}^{3}\end{array}$ & 0.0039 & 0.8660 & $<.0001$ & 0.7524 & 0.1031 & 0.8135 & 0.0414 \\
\hline Productivity $^{4}$ & $<.0001$ & 0.7504 & - & 0.1320 & - & - & - \\
\hline Survival rate ${ }^{5}$ & $<.0001$ & 0.8608 & - & 0.0375 & - & - & - \\
\hline
\end{tabular}

Table S4.2 P-Values for all the effects considered in the models used to analyse litter traits

\begin{tabular}{|c|c|c|c|c|c|c|c|}
\hline & $\begin{array}{c}\text { Genetic } \\
\text { type } \\
\text { (GT) }\end{array}$ & $\begin{array}{c}\text { Energy } \\
\text { source } \\
\text { (ES) }\end{array}$ & $\begin{array}{c}\text { Reproductive } \\
\text { cycle } \\
\text { (RC) }\end{array}$ & GTxES & GTxRC & ESxRC & GTxESxRC \\
\hline \multicolumn{8}{|l|}{ Litter size } \\
\hline Total born & $<.0001$ & 0.0162 & $<.0001$ & 0.6519 & 0.5778 & 0.0691 & 0.6050 \\
\hline Born alive & $<.0001$ & 0.0606 & 0.0009 & 0.9902 & 0.1661 & 0.4707 & 0.3034 \\
\hline Stillborn & 0.0008 & 0.5536 & 0.0772 & 0.2230 & 0.5903 & 0.3155 & 0.7402 \\
\hline Standardized & 0.0239 & 0.9472 & $<.0001$ & 0.8936 & 0.0404 & 0.8776 & 0.9568 \\
\hline Weaned & 0.0133 & 0.5766 & $<.0001$ & 0.0481 & 0.0197 & 0.2386 & 0.0259 \\
\hline \multicolumn{8}{|l|}{ Survival rate } \\
\hline At parturition & $<.0001$ & 0.9197 & 0.0023 & 0.7657 & 0.0002 & 0.0073 & 0.0006 \\
\hline During suckling & 0.0024 & 0.3933 & $<.0001$ & 0.3320 & $<.0001$ & 0.0591 & $<.0001$ \\
\hline \multicolumn{8}{|c|}{ Cumulated number at $5^{\text {th }}$ weaning } \\
\hline Born alive & $<.0001$ & 0.4776 & - & 0.4618 & - & - & - \\
\hline Weaned & $<.0001$ & 0.7530 & - & 0.1776 & - & - & - \\
\hline \multicolumn{8}{|l|}{ Individual weight } \\
\hline Total born & $<.0001$ & 0.0036 & 0.1606 & 0.3171 & 0.0299 & 0.0751 & 0.1454 \\
\hline Born alive & $<.0001$ & 0.0003 & 0.0340 & 0.2036 & 0.0768 & 0.0340 & 0.3419 \\
\hline Stillborn & 0.0166 & 0.0215 & 0.9558 & 0.0408 & 0.0612 & 0.0150 & 0.1976 \\
\hline Standardized & $<.0001$ & 0.0525 & $<.0001$ & 0.5289 & 0.3522 & 0.3737 & 0.1475 \\
\hline Weaned & $<.0001$ & $<.0001$ & 0.0255 & 0.9973 & 0.4515 & 0.8540 & 0.8752 \\
\hline \multicolumn{8}{|l|}{ Individual maturity ${ }^{1}$} \\
\hline Total born & $<.0001$ & 0.8272 & $<.0001$ & 0.6799 & 0.0059 & 0.3656 & 0.0376 \\
\hline Born alive & $<.0001$ & 0.8797 & 0.1950 & 0.9027 & $<.0001$ & 0.8139 & 0.3034 \\
\hline Stillborn & 0.1244 & 0.0423 & 0.5185 & 0.0380 & 0.0359 & 0.1105 & 0.2711 \\
\hline Standardized & $<.0001$ & 0.8195 & $<.0001$ & 0.9548 & 0.4348 & 0.6065 & 0.0097 \\
\hline Weaned & $<.0001$ & 0.0094 & 0.2041 & 0.9565 & 0.7034 & 0.5802 & 0.6903 \\
\hline
\end{tabular}

\footnotetext{
${ }^{3}$ Estimated exclusively with litters from females reaching the sixth parturition as the ratio
} 